\title{
Impact of Toxoplasma gondii on STAT1 activity and epigenetic regulation during IFN- $\gamma$ signaling of its host cell
}



Dissertation

in partial fulfilment of the requirements for the degree “Doctor rerum naturalium (Dr. rer. nat.)"
of the Georg-August-Universität Göttingen

within the doctoral program "Biology" of the Georg-August University School of Science (GAUSS)

submitted by

Roswitha Nast

born in Halle (Saale)

Göttingen, 2018 
for my family 


\section{Members of the Thesis Committee:}

Prof. Dr. rer. nat. Carsten G. K. Lüder (supervisor)

(Institute for Medical Microbiology, Department of Medical Microbiology, University Medical Center Göttingen)

Prof. Dr. med. Uwe Groß

(Institute for Medical Microbiology, Department of Medical Microbiology, University Medical Center Göttingen)

Prof. Dr. rer. nat. Jörg Stülke

(Institute for Microbiology and Genetics, Department of General Microbiology, University Göttingen)

\section{Members of the Examination Board:}

Prof. Dr. med. Uwe Groß (1 $1^{\text {st }}$ Reviewer)

(Institute for Medical Microbiology, Department of Medical Microbiology, University Medical Center Göttingen)

Prof. Dr. rer. nat. Jörg Stülke ( $2^{\text {nd }}$ Reviewer)

(Institute for Microbiology and Genetics, Department of General Microbiology, University Göttingen)

\section{Further Members of the Examination Board:}

Prof. Dr. rer. nat. Carsten G. K. Lüder

(Institute for Medical Microbiology, Department of Medical Microbiology, University Medical Center Göttingen)

Prof. Dr. mult. Thomas Meyer

(Institute for Psychosomatic Medicine and Psychotherapy, Department of Psychosomatic Cardiology, University Medical Center Göttingen)

Prof. Dr. rer. nat. Rolf Daniel

(Institute for Microbiology and Genetics, Department of Genomic and Applied Microbiology, University Göttingen)

Prof. Dr. rer. nat. Stefan Pöhlmann

(German Primate Center, Infection Biology Unit, University Göttingen) 


\section{Table of contents}

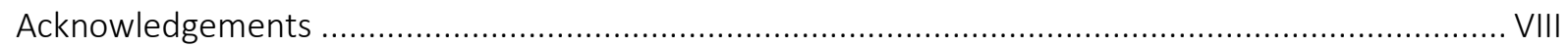

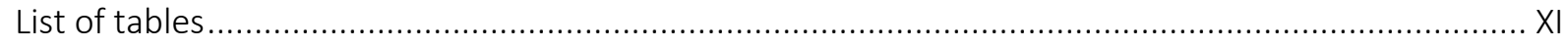

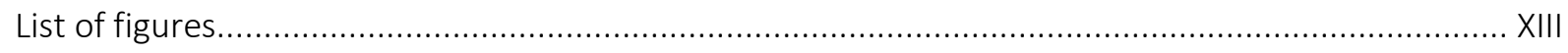



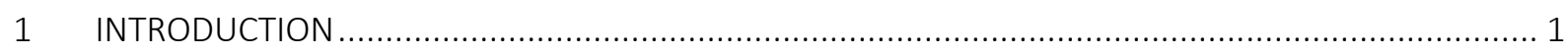



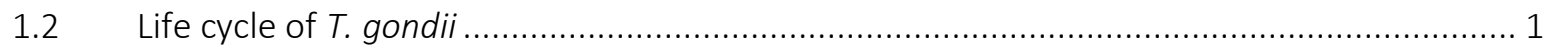

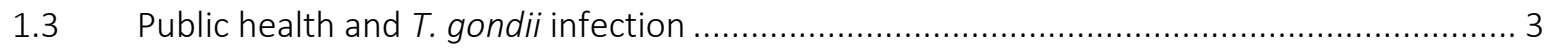

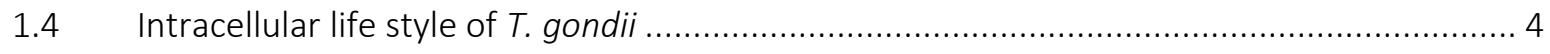

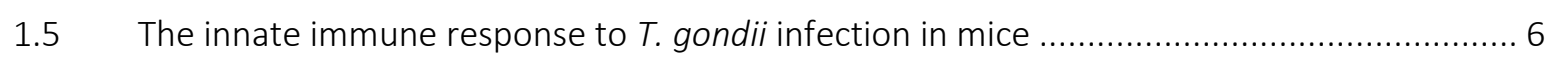

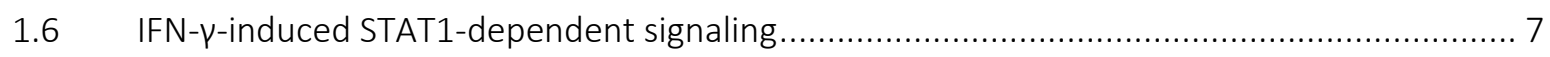

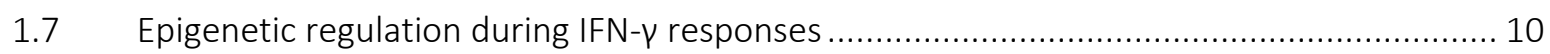

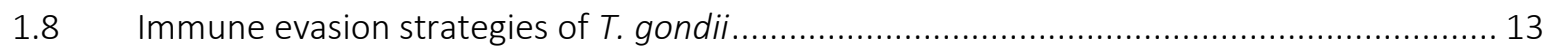

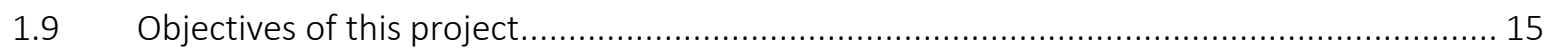



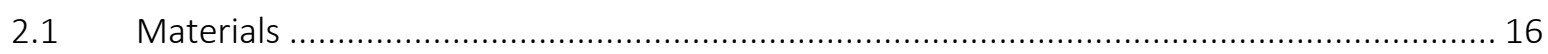

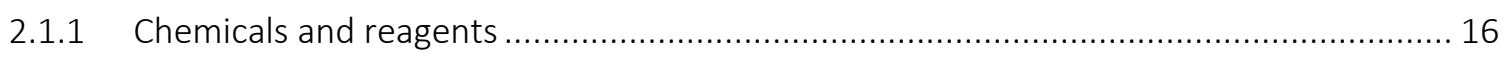

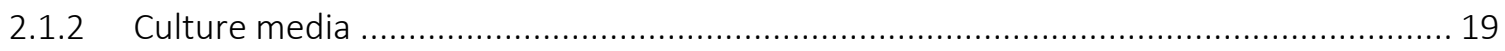

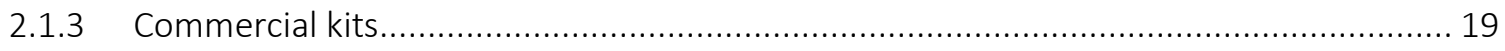

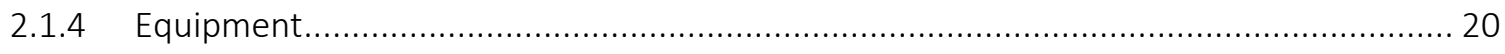

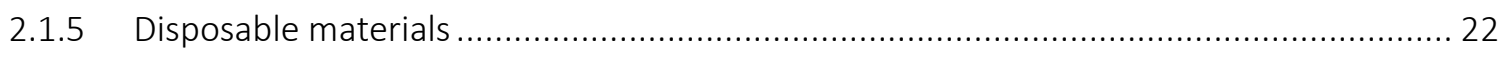

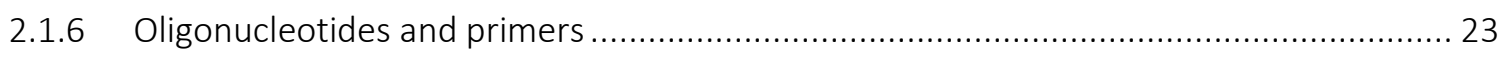

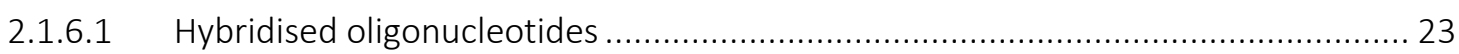



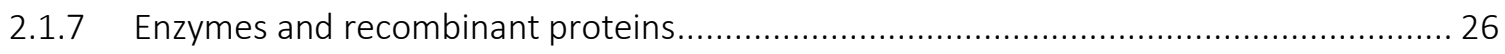

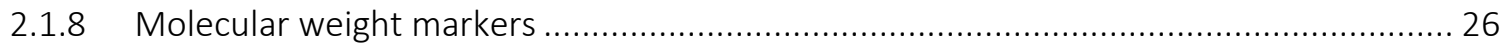

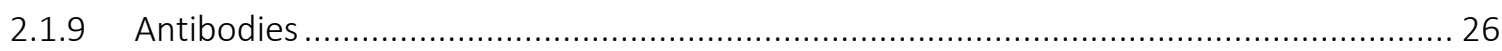




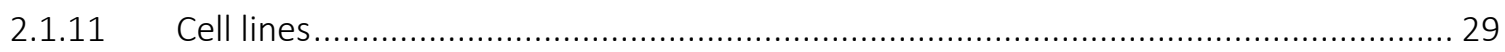

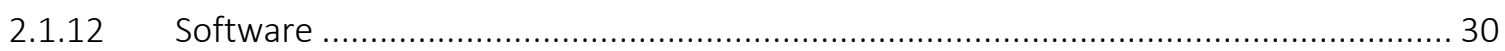

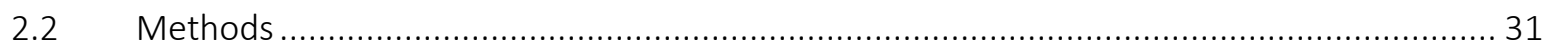

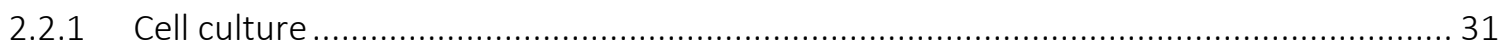

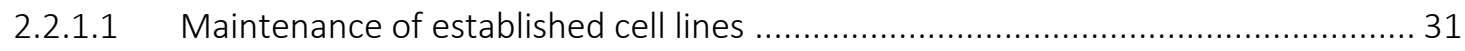

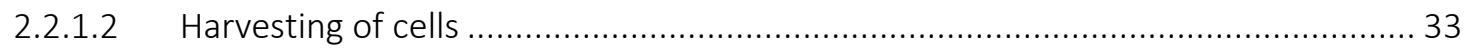



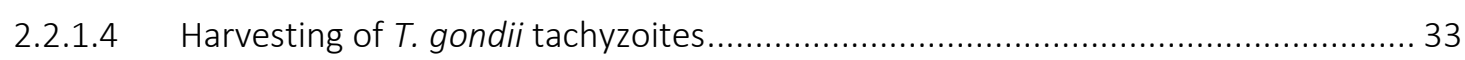

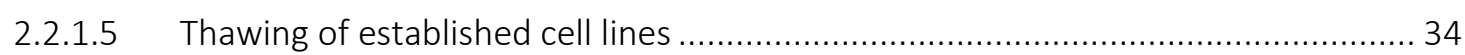

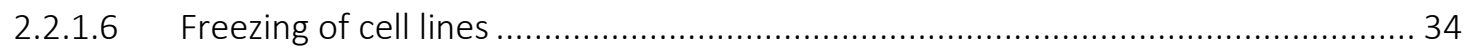

2.2.1.7 Transient transfection of cultured cells with plasmid DNA .......................................... 34

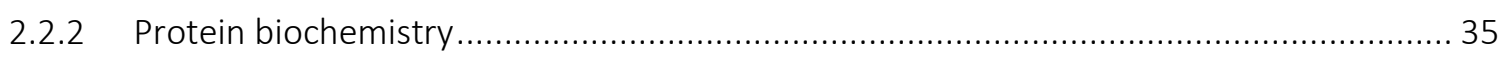

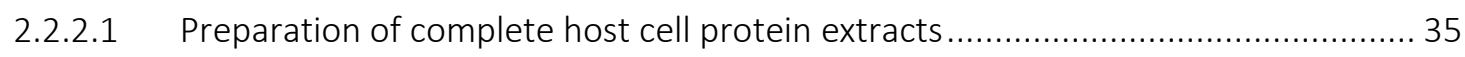

2.2.2.2 Preparation of cytosolic and nuclear protein fractions .......................................... 35

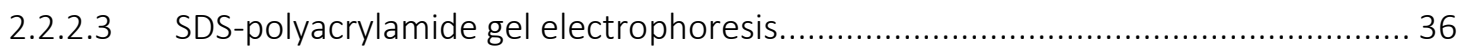

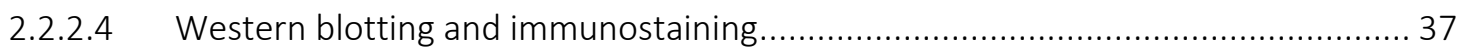

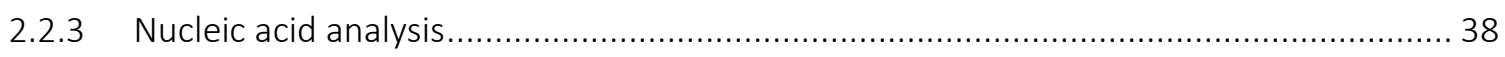

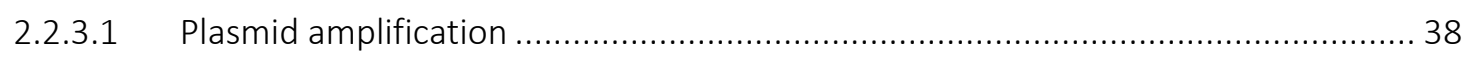

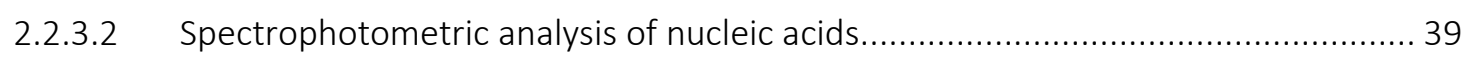



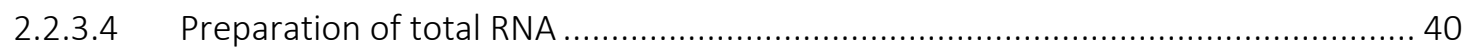





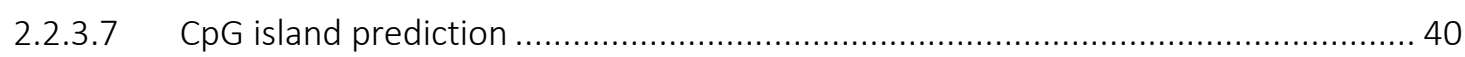

2.2.4 Generation of the reporter construct pGL3-mCIITApIV-luc ......................................... 41

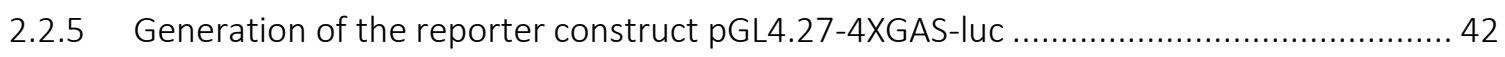

2.2.6 Generation of stably transfected RAW264.7-4XGAS-luc cells ......................................... 42



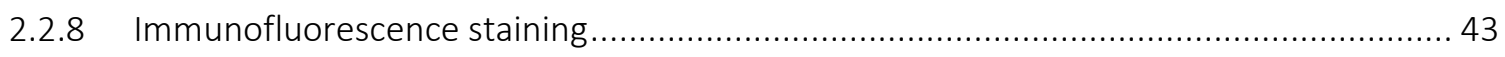

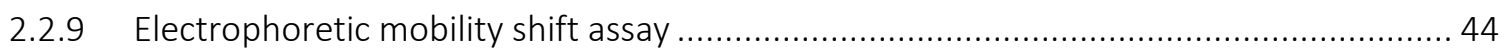

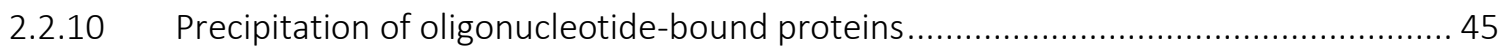








3.1 Epigenetic plasticity at IFN- $\gamma$-responsive promoters in Toxoplasma gondii-infected macrophages

3.1.1 The T. gondii-mediated inhibition of IFN- $\gamma$-regulated genes largely depends on a native chromatin structure

3.1.2 Strong inhibition of IFN- $\gamma$-induced genes by $T$. gondii correlates with absence of CpG islands 54

3.1.3 Toxoplasma gondii interferes with distinct histone modifications at IFN- $\gamma$ primary and secondary response promoters 56

3.2 Modulation of STAT1 activity by Toxoplasma gondii..... 65

3.2.1 Toxoplasma gondii modulates Y701- and S727-phosphorylation of STAT1 66

3.2.2 Representative T. gondii clonal strains all modulate STAT1 phosphorylation 67

3.2.3 Toxoplasma gondii increases nuclear localisation of activated STAT1 69

3.2.3.1 Toxoplasma gondii modulates subcellular distribution of STAT1 69

3.2.3.2 Toxoplasma gondii increases DNA association of activated STAT1 ..................... 72

3.2.3.3 Toxoplasma gondii prolongs nuclear accumulation of STAT1 .......................... 75

3.2.3.4 Toxoplasma gondii inhibits nuclear export of STAT1 ...................................... 78

3.3 Modulation of GAF and STAT1 DNA binding activity by Toxoplasma gondii..................... 80

3.3.1 Toxoplasma gondii differentially modulates GAF complexes depending on STAT1 conformation 80

3.3.2 Toxoplasma gondii modulates activity and specificity of STAT1 DNA binding 83

3.3.2.1 Toxoplasma gondii infection promotes STAT1 binding activity to DNA in the absence of IFN- $\gamma$

3.3.2.2 Toxoplasma gondii infection promotes binding of STAT1 tetramers to DNA without a GAS motif

3.3.2.3 Toxoplasma gondii enhances DNA-binding activities of STAT1 tetramers to DNA with GAS and non-GAS motifs

3.3.2.4 Toxoplasma gondii differentially modulates GAF dissociation depending on STAT1 conformation.....

3.3.3 The STAT1-N-terminal domain is critical for T. gondii-induced modulation of GAF

3.3.3.1 The STAT1-N-terminus is essential for formation of non-canonical GAF complexes... 
3.3.3.2 Cooperative binding of STAT1 is critical for its parasite-mediated modification..... 94

3.3.3.3 STAT1 cooperative binding is not essential for T. gondii to modulate the

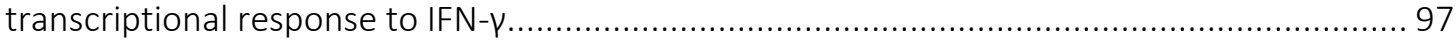

4.1 Toxoplasma gondii modifies GAF and 2xGAF complexes in a STAT1 N-terminus-dependent manner

4.2 Toxoplasma gondii inhibits the residual IFN- $\gamma$ responses in the absence of cooperative DNA binding of STAT1 103

4.3 Toxoplasma gondii increases the binding affinity of STAT1 to GAS and facilitates promiscuous DNA binding to nonGAS sequences. 104

4.4 Toxoplasma gondii promotes increased and sustained nuclear accumulation of activated STAT1 108

4.5 Toxoplasma gondii infection induces nuclear accumulation of STAT1 in parasite-negative bystander cells. 109

4.6 Toxoplasma gondii induces DNA binding activity of STAT1 in the absence of IFN- $\gamma$ 110

4.7 Toxoplasma gondii mediated inhibition of IFN- - -regulated gene expression depend on host native chromatin 112

4.8 Promoters of IFN- - -response genes which are strongly inhibited by $T$. gondii often lack CpG islands

4.9 Toxoplasma gondii remodels the epigenetic landscape at IFN- $\gamma$-responsive promoters by abolishing transcription-activating histone modifications 


\section{Affidavit}

Here I declare that my doctoral thesis entitled

"Impact of Toxoplasma gondii on STAT1 activity and epigenetic regulation during IFN- $\gamma$ signaling of its host cell"

has been written independently and with no other sources and aids than quoted.

Roswitha Nast

Göttingen, May 2018 


\section{Acknowledgements}

As the time of my doctorate studies comes to an end, there are a number of people I sincerely would like to thank for their help and support. Without these people, this work would not have been possible to complete.

I hold the deepest gratitude towards my supervisor Prof. Dr. Carsten G. K. Lüder. During the past four years in his laboratory, he always provided me with generous and patient support and shared with me his experience and expertise. Even in times, when I was thrown back by disappointing results, he encouraged me and helped me through these difficult and frustrating moments. I benefited a lot from his professional insights, his creative ideas of experimental design and his skills in scientific writing and presentation. He lastingly shaped my view on what it means to be a scientist. This work would not have been possible without his advisory.

Moreover, I would like to thank Prof. Dr. Uwe Groß for giving me the opportunity to study and work in the Department of Medical Microbiology of the University Medical Centre of the Georg-AugustUniversity in Göttingen.

I especially would like to thank the members of my thesis committee, Prof. Dr. Uwe Groß and Prof. Dr. Jörg Stülke who provided me support for this work and helped me with valuable contributions during thesis committee meeting presentations.

I also would like to express my gratitude towards our collaborator Prof. Dr. Thomas Meyer who significantly contributed to this work by performing valuable experiments and by extensive and enlightening discussions. I truly admire his dedication to science and his contagious enthusiasm. I would also like to thank his lab group members Dr. Julia Staab and Anke Gregus for their experimental support, fruitful suggestions and for providing such pleasant working atmosphere.

During my doctorate I have experienced and received lots of support from people from insight and outsight of the Georg-August-University. I want to thank everybody who helped me at some point by providing a protocol, a reagent, a cell line, a discussion or the opportunity to use laboratory equipment. To name only a few: I want to thank Dr. Mario Köster, Braunschweig for providing the NIH/3T3 cell line expressing the STAT1-GFP fusion protein and Dr. Joel Ernst, New York for providing the RAW264.7 cell line stably transfected with the ciita promoter IV driving luciferase and a plasmid carrying a corresponding construct. Furthermore, I want to thank Prof. Dr. Volker Ellenrieder, Göttingen for giving me the opportunity to perform some experimental steps in his laboratory.

I also want to acknowledge the Deutsche Forschungsgesellschaft for their financial support. 
I would like to express my gratitude towards my co-workers at the laboratories of the Medical Microbiology in Göttingen for being supportive and helpful and of course for making the work fun. There are a few colleagues I want to mention especially: Emilia Gomes, Sabrina Minatelli, Julian Schwanbeck, Taibur Rahman, Pia Sternisek, Vincent Buschatzky, Matthias Ehmele, Kristina Sumpf, Oliver Bader, Wolfgang Bohne, Raimond Lugert, Renate Althaus, Ruth Rosenhagen, Maik Tomm, Marco Köhler and Frank Zickenrott. It was a pleasure to work with them and I wish them all the best for their future.

Finally, I would like to thank my parents Ilona and Burkhard, my grandparents Gislinde, Siegfried, Elsa and Horst and my partner Felix for their love, help and care. These wonderful people supported me in every thinkable way. I also want to mention my closest friends Lea Maciolek, Fränze Seidel and MarieKristin Meir who always bolstered me up and were so patient and understanding when I made myself scarce. 


\section{List of Publications}

Original Publications:

Lüder, C. G. K., Sumpf, K. and Nast, R. (2015) "Releasing the brake on IFN- $ү$ Signaling on Infection". Trends in Parasitology 31(10): 456-459.

Sumpf, K., Nast, R., Downie, B., Salinas, G., Lüder, C. G. K. (2017) "Histone deacetylase inhibitor MS-275 augments expression of a subset of IFN- $\gamma$-regulated genes in Toxoplasma gondii-infected macrophages but does not improve parasite control". Experimental Parasitology 180: 45-54.

Nast, R., Staab, J., Meier T., Lüder. C. G. K. "Toxoplasma gondii stabilizes tetrameric complexes of tyrosine-phosphorylated STAT1 and leads to its sustained and promiscuous DNA binding". Submitted to Cellular Microbiology. In revision.

Abstracts:

Nast, R., Staab, J., Meier T., Lüder. C. G. K.. "Aberrant DNA-binding of STAT1 in Toxoplasma gondiiinfected macrophages". $67^{\text {th }}$ Annual Meeting of the German Association for Hygiene and Microbiology (DGHM), Münster, Germany, 27-30. September 2015.

Nast, R., Staab, J., Meier T., Lüder. C. G. K.. "Toxoplasma gondii modifies DNA binding of STAT1". Status workshop of the DGHM - Eukaryotic Pathogens, Aachen, Germany, 28-29 January 2016.

Nast, R., Staab, J., Meier T., Lüder. C. G. K.. "Inhibition of the interferon- $\gamma$ response in Toxoplasma gondiiinfected macrophages - adding more pieces to the puzzle." $27^{\text {th }}$ Annual Meeting of the German Association for Parasitology (DGP), Göttingen, Germany, 9-12 March 2016.

Nast, R., Staab, J., Meier T., Lüder. C. G. K.. "Toxoplasma gondii induces promiscuous DNA binding and impaired nucleocytoplasmic recycling of STAT1 during IFN- $\gamma$ stimulation".68 ${ }^{\text {th }}$ National Congress of the German Association for Hygiene and Microbiology (DGHM), Ulm, Germany, 11-14. September 2016. 


\section{List of tables}

Table 1: List of chemicals and reagents

Table 2: List of culture media

Table 3: List of kits

Table 4: List of equipment

Table 5: List of disposable materials

Table 6: List of oligonucleotides for electromobility shift assay

Table 7: List of oligonucleotides for oligonucleotide precipitation assay

Table 8: List of oligonucleotide primers for ChIP analysis

Table 9: List of oligonucleotide primers for analysis of transcriptional regulation in myocardial fibroblasts

Table 10: List of oligonucleotide primers for sequence verification 25

Table 11: List of enzymes 26

Table 12: List of recombinant proteins..... 26

Table 13: List of molecular weight marker...... 26

Table 14: List of primary antibodies for immunofluorescence staining 26

Table 15: List of primary antibodies for ChIP analysis

Table 16: List of primary antibodies for Western blot analysis.

Table 17: List of primary antibodies for electrophoretic mobility shift assays

Table 18: List of secondary antibodies for immunofluorescence staining 28

Table 19: List of secondary antibodies for Western blot analysis 28

Table 20: List of plasmids and constructs 28 








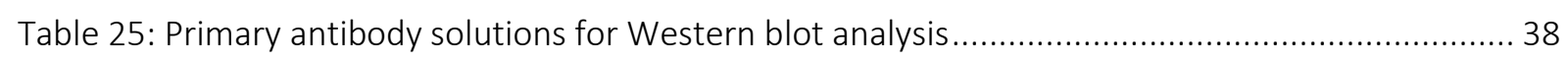



Table 27: Dilution concentration of secondary antibodies for immunofluorescence staining ............. 44

Table 28: Amounts of antibodies used per immunoprecipitation ............................................... 48

Table 29: Representative experimental real-time qPCR program.................................................... 49

Table 30: Primer and target specific PCR program parameters for ChIP analysis ............................... 50

Table 31: Primer and target specific PCR program parameters for analysis of transcriptional regulation

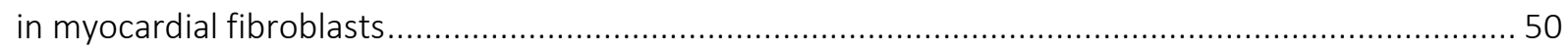




\section{List of figures}

Figure 1: The complex life cycle and transmission ways of Toxoplasma gondii (Hunter and Sibley, 2012).

Figure 2: Toxoplasma invasion and protein secretion into the host cell (Rosowski, 2013)

Figure 3: IFN- $\gamma /$ STAT1 signaling (Adapted from Lüder et al. (2015)). 9

Figure 4: Chromatin remodeling and post-translational modification of histones.

Figure 5: Toxoplasma gondii differentially interferes with luciferase reporter activity, depending on whether reporter constructs are integrated or not into the host's genome.

Figure 6: Toxoplasma gondii-mediated inhibition pattern of IFN- $\gamma$-regulated genes partly correlate with absence of $\mathrm{CpG}$ islands in their promoters.

Figure 7: The impact of $T$. gondii infection on the regulation of histone modifications during IFN- $Y$ stimulation was determined at distal and proximal promoter sequences

Figure 8: Toxoplasma gondii infection counter-regulates the increased histone $\mathrm{H} 4$ acetylation in response to IFN- - .

Figure 9: Toxoplasma gondii infection counter-regulates the increased acetylation of histone H3 at Lys ${ }^{9}$ in response to IFN- $\gamma$.

Figure 10: Toxoplasma gondii infection counter-regulates the increased tri-methylation of histone $\mathrm{H} 3$ at $\mathrm{Lys}^{4}$ in response to IFN- $\gamma$.

Figure 11: Toxoplasma gondii infection partially counter-regulates the reduced phosphorylation of histone $\mathrm{H} 3$ at $\mathrm{Ser}^{10}$ in response to IFN- $\gamma$.

Figure 12: Toxoplasma gondii differentially affects STAT1 phosphorylations.

Figure 13: Toxoplasma gondii clonal lineages I, II and III similarly modulate STAT1 phosphorylations. 68

Figure 14: Toxoplasma gondii elevates IFN- - -induced nuclear localisation of STAT1 and its phosphorylated isoforms. 70

Figure 15: Toxoplasma gondii increases total Y701- and S727-STAT1 phosphorylations. 73 
Figure 17: Toxoplasma gondii -infection promotes nuclear STAT1 $\alpha$-GFP accumulation after prolonged IFN- $\gamma$ stimulation 75

Figure 18: Toxoplasma gondii decelerates overall nuclear export of STAT1 $\alpha-$ GFP 79

Figure 19: Toxoplasma gondii modulates GAS binding of tyrosine-phosphorylated STAT1 dimers and tetramers in the monocyte/macrophage cell line RAW264.7 81

Figure 20: Toxoplasma gondii promotes DNA binding of non-canonical GAF and 2xGAF complexes in the absence of IFN- $\gamma$.

Figure 21: Toxoplasma gondii -induced non-canonical 2xGAF complexes can bind to DNA without a classical GAS site.

Figure 22: Toxoplasma gondii increases DNA binding of STAT1-tetramer molecules to GAS and non-GAS sites.

Figure 23: Toxoplasma gondii -induced non-canonical GAF complexes have different DNA dissociation characteristics.

Figure 24: Toxoplasma gondii infects and replicates within mutant U3A cells. 92

Figure 25: The STAT1 N-terminus, but not the C-terminus is required for formation of the T. gondiiinduced non-canonical GAF-complexes.

Figure 26: Toxoplasma gondii infects and replicates within STAT1-WT and mutant -F77A cells to similar extents. 95

Figure 27: Toxoplasma gondii -induced non-canonical GAF complex formation is largely abolished in STAT1-F77A cells 96

Figure 28: Toxoplasma gondii inhibits residual IFN- - -induced transcription in STAT1-F77A cells. 98

Figure 29: Toxoplasma gondii -mediated modulation of STAT1 DNA binding activity 105

Figure 30: Interference of T. gondii with STAT1-dependent gene transcription. 107

Figure 31: Interference of T. gondii with the epigenetic landscape at IFN- $\gamma$-responsive promoters... 119 


\section{Abbreviations}

AIDS

APC

APS

ATP

BAF

BRCT

BRG1

BSA

CBP

CDNA

ChIP

CIITA

$\mathrm{CP}$

$\mathrm{CpG}$

CtBP

C-terminus

DC

$\mathrm{ddH}_{2} \mathrm{O}$

DMEM

DMSO

DNA

DNTM

DNase

dNTP

dsDNA

DTT

ECL

EDTA

e.g.

EMSA

et al.

EZH2

FCS
Acquired Immune Deficiency Syndrome

Antigen-presenting cell

Ammonium persulfate

Adenosine triphosphate

BRG1/BRM-associated factor

BRCA1 C terminus

Brahma-related gene 1

Bovine serum albumin

CREB-binding protein

Complementary deoxyribonucleic acid

Chromatin immunoprecipitation

Class II transactivator

Crossing point

5'-C(ytosine)-phosphate-G(uanine)-3'

C-terminal binding protein

Carboxy-terminus

Dendritic cell

Double distilled water

Dublecco's modified Eagle's medium

Dimethyl sulphoxide

Deoxyribonucleic acid

DNA methyltransferases

Deoxyribonuclease

Deoxynucleotide triphosphate

Double-stranded deoxyribonucleic acid

Dithiothreitol

Enhanced chemiluminiescence

Ethylenediaminetetraacetic acid

exempli gratia

Electrophoretic mobility shift assay

et alia

Enhancer of zeste homolog 2

Foetal calf serum 
GAF

GAPDH

GAS

GBP

GFP

GRA

GTP

$\mathrm{H}$

HAT

HDAC

$\mathrm{HDACl}$

HDM

HEPES

HMT

HPLC

HRP

IDO

i.e.

IFN-

IFNGR

IgG

IL

IRF

IRG

JAK

LB

LPS

Mф

MBP

MHC

MJ

mRNA

NC

NEAA

NF-KB
Gamma interferon-activated factor

Glyceraldehyde 3-phosphate dehydrogenase

Gamma interferon-activated sequence/site

Guanylate binding protein

Green fluorescent protein

Granule protein

Guanosin triphosphate

Histone

Histone acetyltransferase

Histone deacetylase

Histone deacetylase inhibitor

Histone demethylase

4-(2-hydroxyethyl)-1-piperazineethanesulphonic acid

Histone methyltransferase

High-performance liquid chromatography

Horse raddish peroxidase

Indolamine 2,3-dioxygenase

id est

Interferon $\gamma$

Interferon receptor

Immunoglobolin class $\mathrm{G}$

Interleukin

Interferon regulatory factor

Immunity-related p47 GTPase

Janus kinase

Lysogeny broth

Lipopolysaccharide

Macrophage

Methyl-CpG-binding protein

Major histonecompatibility complex

Moving junction

Messenger ribonucleic acid

Nitrocellulose

Non-essential amino acid

Nuclear factor kappa-light-chain-enhancer of activated B cells 


\begin{tabular}{|c|c|}
\hline n.i. & Non-infected \\
\hline NK & Natural killer cells \\
\hline NO & Nitric oxide \\
\hline n.s. & Non-stimulated \\
\hline N-terminus & Amino-terminus \\
\hline NuRD & Nucleosomal remodelling and deacetylase \\
\hline PAGE & Polyacrylamide gel electrophoresis \\
\hline PAMP & Pathogen-associated molecular patterns \\
\hline PBS & Phosphate-buffered saline \\
\hline PCR & Polymerase chain reaction \\
\hline pDNA & Plasmid deoxyribonucleic acid \\
\hline p.i. & Post infection \\
\hline PIAS & Protein inhibitor of activated STAT1 \\
\hline PMSF & Phenylmethylsulfonylfluorid \\
\hline PRC & Polycomb repressive complex \\
\hline PRG & Primary response gene \\
\hline p-STAT & Phosphorylated STAT protein \\
\hline PTM & Post-translationale modificaton \\
\hline PV & parasitophorous vacuole \\
\hline PVM & parasitophorous vacuole membrane \\
\hline RNA & Ribonucleic acid \\
\hline RNA pol & RNA polymerase \\
\hline RNase & Ribonuclease \\
\hline RON & Rhoptry neck protin \\
\hline ROP & Rhoptry bulb protein \\
\hline RPMI & Roswell Park Memorial Institute medium \\
\hline SDS & Sodium dodecyl sulphate \\
\hline SOCS & Suppressors of cytokine signaling \\
\hline SRG & Secondary response gene \\
\hline STAT & Signal transducer and activator of transcription \\
\hline SWI/SNF & Switch/Sucrose Non-Fermentable \\
\hline TAE & Tris, acetic acid, EDTA \\
\hline $\mathrm{TBS}(\mathrm{T})$ & Tris-buffered saline (supplemented with Tween-20) \\
\hline Tc-45 & T-cell protein tyrosine phosphatase 45 \\
\hline TEMED & Tetraethylenediamine \\
\hline
\end{tabular}


TgIST

TGF- $\beta$

TLR

TNF

Tris

TSS

USF-1

WT

Units

x g

$\%$

${ }^{\circ} \mathrm{C}$

A

bp

g

h

I

min

M

mol

$\mathrm{nm}$

rpm

sec

U

V
T. gondii inhibitor of STAT1-dependent transcription

Transforming growth factor- $\beta$

Toll-like receptor

Tumor necrosis factor

Tris(hydroxymethyl)-aminomethan

Transcription start site

Upstream stimulatory factor 1

Wild type

Times gravity

Percent

Degree Celsius

Ampere

Base pair(s)

Gram

Hour

Liter

Minute

$\mathrm{mol} / \mathrm{l}$

Mole

Wave length

Rounds per minute

Second

Unit

Volt 


\section{Prefixes}

$\begin{array}{ll}k & \text { Kilo, factor } 10^{3} \\ m & \text { Milli, factor } 10^{-3} \\ \mu & \text { Micro, factor } 10^{-6} \\ \mathrm{n} & \text { Nano, factor } 10^{-9} \\ \mathrm{p} & \text { Pico, factor } 10^{-12}\end{array}$

\section{Amino acids}

When referred to amino acids, either the three letter code or the one letter code is used.

$\begin{array}{llr}\text { Amino acid } & \text { three letter code } & \text { One } \\ \text { Alanine } & \text { Ala } & \text { A } \\ \text { Phenylalanine } & \text { Phe } & \text { F } \\ \text { Serine } & \text { Ser } & \text { S } \\ \text { Tyrosine } & \text { Tyr } & \text { T } \\ \text { Lysine } & \text { Lys } & \text { K }\end{array}$

\section{Post-translational modifications of histones}

ac

$\mathrm{me} / \mathrm{me} 2 / \mathrm{me} 3$

p

u one letter code
A
F $S$ T
K 


\section{Abstract}

Toxoplasma gondii is an obligate intracellular parasite which infects up to $30 \%$ of humans world-wide. To control T. gondii, the host mounts a strong IFN- $\gamma$-driven immune response via the signal transducer and activator of transcription (STAT)-1 pathway. The parasite, on the other side, largely silences STAT1mediated gene transcription and thereby counteracts multiple host resistance functions. The mechanism of this immune evasion strategy is only incompletely understood. In this study, the native chromatin within the host cell was shown to play a decisive role in the T. gondii-mediated inhibition of IFN- $\gamma$-regulated gene transcription. Luciferase reporter assays revealed that the parasite inhibits the cytokine-induced transcription of reporter constructs which were stably transfected into the host's genome but does not significantly diminish transcription of constructs which are transcribed from transiently transfected plasmids. In addition, T. gondii abrogates the IFN- - -induced transcriptional activity of both, the CIITA promoter IV and a minimal GAS-containing promoter in a chromatindependent manner. This suggests a common molecular mechanism of the parasite to inhibit both, primary and secondary IFN- $\gamma$ response genes. Consistently, the parasite profoundly impairs the epigenetic landscape around several IFN- $\gamma$-responsive promoters, as determined by chromatin immunoprecipitation assays. Kinetical analyses revealed that T. gondii abolishes IFN- - -triggered enrichment of multiple histone modifications which were here identified to be indicative for active IFNp-stimulated transcription, i.e. H4ac, H3K9ac and H3K4me3. In contrast, H3S1Op and under distinct conditions also some of the other chromatin marks are also induced by the parasite. The data nevertheless suggests that $T$. gondii specifically inhibits IFN- $\gamma$-dependent epigenetic regulation in infected macrophages. Consistently, in silico analyses revealed a correlation between a strong repression of IFN- $\gamma$-induced transcription by $T$. gondii and the absence of $\mathrm{CpG}$ islands. Thus, the majority of genes whose expression is heavily counteracted by $T$. gondii appear to have a more closed promoter state under resting conditions. DNA binding studies by electrophoretic mobility shift assays (EMSA) showed that T.gondii diminishes the formation of IFN- $\gamma$-induced canonical STAT1-DNA binding complexes and instead induces modified complexes with lower electrophoretic mobility. The data suggests that the parasite effector T.gondii inhibitor of STAT1-dependent transcription (TgIST) previously identified to bind to STAT1 dimers, i.e. the gamma interferon-activated factor (GAF), also targets and even preferentially binds to the transcriptionally more relevant 2xGAF complex, thereby inducing a non-canonical parasite-modified 2xGAF complex. 2xGAF complexes are stabilised by reciprocal $\mathrm{N}$-terminal STAT1 interactions and the cooperative DNA binding is critical for efficient IFN- $\gamma$ induced gene transcription. Interestingly, TgIST binding to STAT1 is largely abolished when cooperative DNA binding is prevented by a phenylalanine to alanine substitution in the N-terminal domain of STAT1. However, analysis of the mRNA level of several IFN- $\gamma$-responsive genes indicated that the T. gondiiinduced transcriptional inhibition does not solely depend on STAT1 cooperativity. Binding of TgIST 
requires the amino-terminus, but not the C-terminal domain of STAT1, as determined by cell free in vitro co-incubation studies of extracts from infected cells and deletion mutants of STAT1. Remarkably, binding of TgIST to STAT1 profoundly modulates the DNA binding activity of the transcription factor. Oligonucleotide precipitation as well as EMSA competition experiments showed that the parasiteinduced non-canonical 2xGAF complex exhibits strongly increased DNA binding activity towards DNA with high affinity GAS motifs. Furthermore, binding of TgIST also facilitates strong promiscuous STAT1 binding to imperfect nonGAS sequences as determined by EMSA and pulldown assays. This suggests that $T$. gondii infection dramatically diminishes the demands of the transcription factor for sequence specificity of its DNA recognition site. Although the pool of total STAT1 is reduced in parasite-infected cells after IFN- $\gamma$ stimulation as compared to non-infected cells, Western blot analyses and immunofluorescence microscopy revealed that T.gondii increases and prolongs the nuclear accumulation of the transcription factor. Nuclear STAT1 from parasite-infected cells appears to be fully activated as revealed by the phosphorylation of the signature residues $\mathrm{Tyr}^{701}$ and $\mathrm{Ser}^{727}$. Moreover, nuclear STAT1 from T. gondii-infected cells is to a significant extent strongly bound to DNA as determined by protein extraction combined with an additional DNase treatment or cell extraction with harsh detergent containing lysis buffer and subsequent Western blotting. Disruption of IFN- $\gamma$ signal transduction with the kinase inhibitor staurosporine further unravelled that STAT1 remains significantly longer in the nuclei of infected cells, suggesting that the nuclear export is decelerated. In conclusion, T. gondii interferes with the epigenetic regulation of promoter activity in response to IFN- $\gamma$. In addition, parasite infection impairs the IFN- $\gamma$ signal transduction by altering the binding activities of STAT1 to DNA and consequently reducing the pool of activation-competent STAT1. These mechanisms may contribute to the $T$. gondii-mediated inhibition of IFN- $\gamma$ responsiveness, thus facilitating intracellular survival and the establishment of persistent infection. 


\section{INTRODUCTION}

\subsection{Toxoplasma gondii}

The organism was discovered simultaneously in tissue of a North-African rodent by Nicolle and Manceaux (1908) and in a rabbit in Brazil by Splendor (1908, translated into english in 2009). The name Toxoplasma gondii was proposed by Nicolle and Manceaux (1909) by reason of the crescent shape of the tachyzoite stage (greek "toxon" = arch, "plasma" = form) and the hosting rodent Ctenodactylus gundi (Ferguson, 2009). T. gondii belongs to the phylum Apicomplexa Levine, 1970, a diverse group of primarily obligate intracellular protozoan parasites that also includes for example the etiological agent of malaria, i.e. Plasmodium spec.. Apicomplexans are named for a unique form of organelle at their apical pole, i.e. the apical complex, an adaption that is required during penetration of a host cell. There is only one Toxoplasma species, $T$. gondii. Despite its world-wide occurrence, $T$. gondii maintains a rather clonal population structure, where the majority of isolates from Europe and North America belong to one of three lineages, referred to as type I, II and III (Howe and Sibley, 1995).

\subsection{Life cycle of $T$. gondii}

Infections by T. gondii are prevalent world-wide in nearly all warm-blooded animals (Kniel et al., 2002; reviewed in Dubey, 2009). The ubiquitous distribution partially results from a versatile and fascinating transmission pattern from diverse mammalian or avian intermediate hosts to the carnivorous definitive hosts but also to other carnivorous or omnivorous intermediate hosts without the necessity to pass through the final host (Figure 1). Definitive hosts are nearly all species of the family Felidae, who sustain the sexual reproduction. In the 'classical' life cycle, cats get infected by ingesting tissue cysts from infected prey. The parasite is released from the cyst and invades epithelial cells of the small intestine, where it eventually differentiates into microgametes and macrogametes. The gametes fuse and form an oocyst, which is shed with the faeces (reviewed in Dubey, 2007). The oocyst sporulates in the presence of oxygen within a few days and then harbours infective sporozoites. Oocysts are highly resistant to adverse environmental conditions and can remain infectious for a year or longer (Dubey et al., 1998; Kniel et al., 2002). After accidental ingestion by the intermediate host, the released sporozoites penetrate small intestine enterocytes, enter the Lamina propria, where they can invade a variety of cells, and eventually convert into asexually replicating tachyzoites. After six to seven fast division cycles, the host cell lyses and tachyzoites egress, which quickly infect neighbouring cells (reviewed in Black and Boothroyd, 2000). Due to the parasites ability to infect and replicate within nearly 
any nucleated cell, the acute phase of infection is characterised by a rapid increase in parasite numbers and dissemination throughout the body of the host. The ensuing inflammatory immune response however controls and even kills the majority of tachyzoites but a few of them will convert into slow replicating bradyzoites and evade host immunity. This semidormant stage is encysted within so-called tissue cysts, which characterise the chronic phase of infection. They are most commonly formed in the brain and muscles, where they can persist for the host's life. Predation and ingestion of tissue cysts from infected intermediate hosts by cats will complete the life cycle. As indicated above, bradyzoites within tissue cysts can also be productively transmitted to naïve carnivorous or omnivorous intermediate hosts thus representing an important shortcut within the parasite's life cycle.

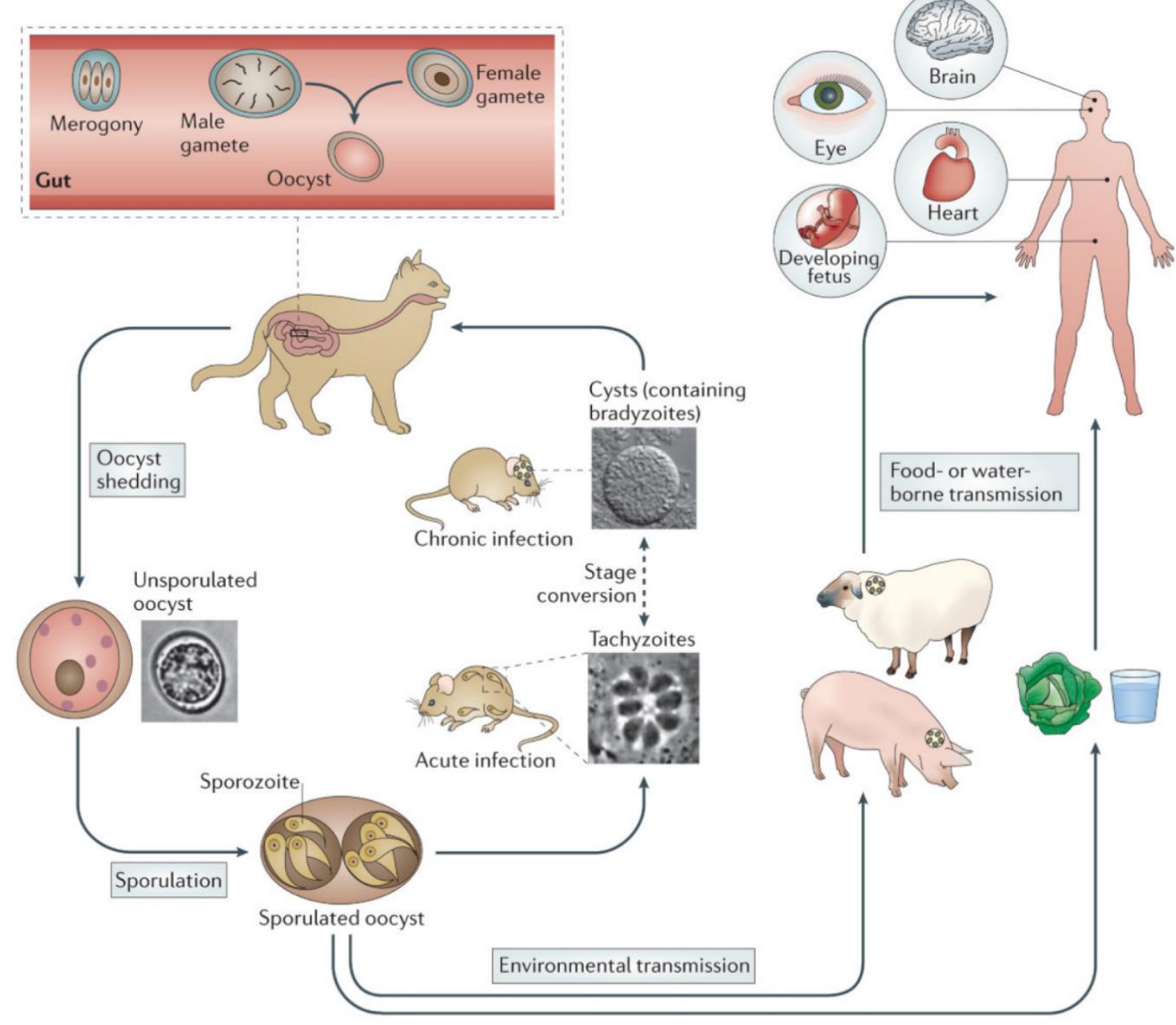

Figure 1: The complex life cycle and transmission ways of Toxoplasma gondii (Hunter and Sibley, 2012). 


\subsection{Public health and T. gondii infection}

Toxoplasma gondii is a remarkably successful parasite that is able to infect nearly every warm-blooded vertebrate, including humans, where it causes the disease toxoplasmosis. The majority of human T. gondii infections occur by accidental ingestion of oocysts from contaminated food, water or soil, or by ingestion of $T$. gondii tissue cysts in undercooked meat of infected life stock (Figure 1) (Guo et al., 2015). Congenital infection can occur through vertical transmission when a woman with no previous exposure to the parasite becomes infected during pregnancy. Uncommon routes of transmission include those via organ transplants or blood transfusions. Up to $30 \%$ of the world's human population is estimated to be infected, with higher rates in South and Central America and Continental Europe (50-80\%) (Tenter et al., 2000; Pappas et al., 2009). The prevalence of T. gondii antibodies varies significantly between geographical regions, as rates of infection are influenced by climate, hygiene, exposure to cats and eating habits, e.g. consumption of undercooked meat. In Germany, the seroprevalence is estimated to be analogous to people's age (Wilking et al., 2016). Apart from the risk of acquiring a T. gondii infection, the development of symptomatic toxoplasmosis is influenced by the prevalence of immunosuppressive condition and may be also influenced by differences in the virulence of atypical T. gondii strains found all over the world (Khan et al., 2006; Demar et al., 2012).

Toxoplasma gondii infection in immunocompetent individuals rarely requires drug treatment. Infections are predominantly clinically asymptomatic or present as self-limiting lymphadenopathy, which may be accompanied by fever and myalgia. As indicated above, following primary infection, $T$. gondii establishes a chronic infection characterised by tissue cysts, in which the parasite resides quiescent as dormant stage. Sites of cyst formation are predominantly the brain, skeletal and heart muscle cells. The impact of persisting $T$. gondii brain infection on mental health and human behaviour in immunocompetent hosts are matters of intense research. A diverse range of mental disorders or behavioural abnormalities are considered to be associated with latent T. gondii infection ( reviewed in Hsu et al., 2014; Tedford and McConkey, 2017; and Del Grande et al., 2017), but no causal relationship has been established yet. Severe and life-threatening manifestations mostly occur by reactivation of persisting tissue cysts in immunosuppressed individuals as those with AIDS or under immunosuppressive drug treatment, indicating that $T$. gondii is considered mainly an opportunistic pathogen. The most frequent and severe clinical presentation in these patients is Toxoplasma encephalitis, which typically present with multiple necrotic lesions in the central nervous system. Ocular and pulmonary diseases are the most common extra-cerebral consequences of infection. Reactivation of ocular cysts can lead to retinochorioiditis, which may result in vision loss due to retinal scarring. Primary or reactivated maternal infection during pregnancy can be transmitted transplacentally and cause congenital toxoplasmosis (Jones et al., 2003). The risk of diaplacental infection is related to the size of the placenta and thus increases continuously 
with gestational age. On the other hand, clinical manifestations are more severe when transmission occurrs early during pregnancy, probably being related to the stage of foetal development and maturity of its immune system (Ambroise-Thomas and Pelloux, 1993). Congenital toxoplasmosis can lead to foetal death and abortion. In infants, the classic triad includes retinochorioiditis, hydrocephalus and intracranial calcifications (Jones et al., 2003). Although most newborns infected in utero are born with no signs of toxoplasmosis, individuals may develop neurocognitive deficits and visual disabilities later in life (Jones et al., 2003).

First-line therapy consists of combined treatment with pyrimethamine and sulfazdiazine which can be replaced by clindamycin, atovaquone or azithromycin when indicated (Alday and Doggett, 2017). However, one major challenge for drug therapy is to reach therapeutic concentrations within cysts. Furthermore, due to the reduced metabolism and the quiescent state of bradyzoites, latent infection is normally not eradicated, leaving the risk of relapse. Improvement of toxoplasmosis therapy and its prevention by immunisation are active areas of research. They explore effectiveness of novel drugs and DNA vaccines and the utility of nanomaterials in infection management (Sun et al., 2011; Alday and Doggett, 2017; Sa et al., 2017; Ahmadpour et al., 2017; Assolini et al., 2017).

\subsection{Intracellular life style of $T$. gondii}

Toxoplasma gondii is an obligate intracellular parasite and therefore, host cell invasion is of paramount importance for its survival. The phase of intracellular residence and replication is followed by active egress from the host cell and rapid re-entry into neighbouring cells. T. gondii is equipped with key molecules for these fundamental processes, i.e. attachment to and invasion of host cells, establishment of the intracellular niche and survival (reviewed in Lüder and Seeber, 2016). These molecules are partially released in a sequential fashion from specialised secretory organelles, namely the micronemes, the rhoptries, and the dense granules (Carruthers and Sibley, 1997).

Host cell contact will stimulate the discharge of microneme proteins (MICs) that facilitate firm attachment of the parasite to the host cell (Figure 2). Further, they form a molecular bridge between the host cell surface and the parasites' motility machinery, which is essential for active invasion (reviewed in Lüder and Seeber, 2016). During active entry (Morisaki et al., 1995), the parasite triggers an invagination of the host cell plasma membrane, forming the parasitophorous vacuole (PV) surrounded by the parasitophorous vacuole membrane (PVM) (Suss-Toby et al., 1996). This process is accompanied by close apposition of the invading parasite and the host cell membrane, establishing a tight constriction site, called moving junction (MJ) (reviewed in Shen and Sibley, 2012). This interface appears to function as a molecular sieve, as most host cell surface transmembrane proteins are 
selectively excluded from the growing PVM during passage (Mordue, Desai, et al., 1999). This modification likely prevents activation of the endocytic fusion machinery. The second wave of parasite protein secretion is initiated rapidly after intimate host cell contact. Based on their specific localisation within the rhoptry organelle, rhoptry neck proteins (RONs) and rhoptry bulb proteins (ROPs) are distinguished. RONs localise specifically to the moving junctions, where they likely serve as an anchor, facilitating parasite movement during invasion (reviewed in Bradley and Sibley, 2007; Boothroyd and Dubremetz, 2008). Further, RONs are considered as candidates for controlling access of the host cell surface components to the vacuole (Sibley et al., 2013). The ROPs are diverse and comprise numerous enzymes, including kinases, pseudokinases, phosphatases, proteases and others (reviewed in Lüder and Seeber, 2016). They are discharged into the lumen of the PV or injected into the host cells cytosol, where they can locate to the PVM or even target the host cell nucleus (Saffer et al., 1992; Beckers et al., 1994; Taylor et al., 2006; Gilbert et al., 2007; Saeij et al., 2007). One ROP protein is directly involved in the intimate interaction of the PVM of type I parasites with host mitochondria and endoplasmatic reticulum (ER), which is thought to facilitate nutrient acquisition (Sinai et al., 1997; Sinai and Joiner, 2001). Several ROP proteins serve as virulence factors and play vital roles in modifying many immunity-related host cell functions (Saeij et al., 2007; Fentress et al., 2010; Fleckenstein et al., 2012). Rhoptry proteins can also be injected into cells, which are not productively invaded. The priming with rhoptry effectors may modify host cell functions even in the absence of invasion (Koshy et al., 2012). During the final wave of protein secretion, the dense granules are discharged. Dense granule proteins (GRAs) occupy the lumen of the vacuole, localise to the membranous tubular network that forms within the vacuole or decorate the PVM. These modifications have been regarded to contribute to PV maturation to fulfil the requirements for nutrient uptake and parasite growth (reviewed in Sibley et al., 2013; Gold et al., 2015). It is only recently, that a still increasing repertoire of GRA proteins is assigned effector activity on host cell signaling (Rosowski et al., 2011). Remarkably, some GRAs even regulate the ability of other effectors to traffic across the PVM and accumulate in the host cell nucleus where they regulate gene expression (Bougdour et al., 2013; Braun et al., 2013). 


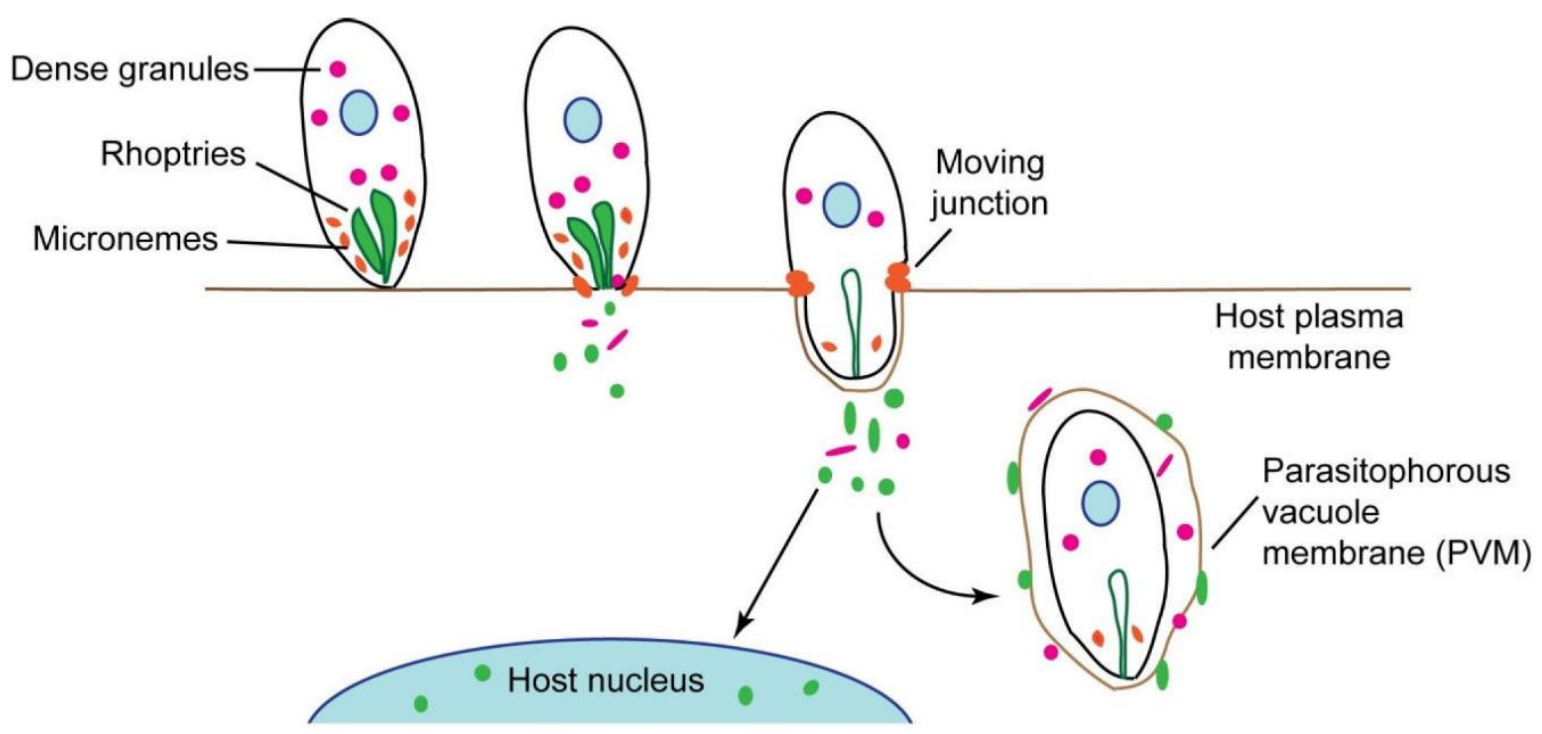

Figure 2: Toxoplasma invasion and protein secretion into the host cell (Rosowski, 2013).

\subsection{The innate immune response to $T$. gondii infection in mice}

The host's innate immune response limits parasite growth and promotes the development of a strong adaptive immunity, which is required to control tachyzoite growth and to establish a long-term resistance to T. gondii infection (reviewed in Tait and Hunter, 2009). Following oral ingestion of infectious T. gondii oocysts or tissue cysts, the parasite is released and readily infects enterocytes of the host's small intestine (Dubey, 1998). The infection stimulates enterocytes and invading myeloid cells to produce an array of cytokines and chemokines which further attract immune cells such as neutrophils, dendritic cells (DCs), monocytes and T cells, to the parasite-infected tissue (Mennechet et al., 2002; Buzoni-Gatel and Werts, 2006). DCs and macrophages (M $\phi)$ provide the first line of cell-mediated defence. They are equipped with a multitude of Toll-like receptors (TLRs) which specifically recognise so-called pathogen-associated molecular patterns (PAMPs) (reviewed in Kawai and Akira, 2010). A distinct set of these receptors recognise the conserved T.gondii antigens profilin and glycosylphosphatidylinositol-anchored proteins and can also be activated by T. gondii RNA and DNA (Yarovinsky et al., 2005; Debierre-Grockiego et al., 2007; Koblansky et al., 2013; Andrade et al., 2013). In response to $T$. gondii, high levels of the pro-inflammatory cytokine interleukin-12 (IL-12) are secreted, predominantly by DCs (Gazzinelli et al., 1994; Scharton-Kersten et al., 1996; Reis e Sousa et al., 1997; Scott and Hunter, 2002; Liu et al., 2006; Yarovinsky, 2008; Mashayekhi et al., 2011). IL-12 stimulates the production of the cytokine interferon- $\gamma$ (IFN- $\gamma$ ) by natural killer (NK) cells during the innate response and by $\mathrm{CD}^{+}$and $C D 8^{+} \mathrm{T}$ cells during the adaptive immune response (Gazzinelli et al., 1991; Hunter et al., 1994). IFN- $\gamma$ is the major mediator of resistance against $T$. gondii and its continuous production is critical 
for control of acute and chronic infection (Jones et al., 1986; Suzuki et al., 1988). The cytokine induces a variety of antimicrobial defence mechanisms, in both haematopoietic and non-haematopoietic cells, with cell type- and species-specific differences (Yap and Sher, 1999; reviewed in Miller et al., 2009). However, IFN- $\gamma$ is believed to control toxoplasmosis primarily through its ability to activate $M \phi$.

Macrophages are most critical for the course of T. gondii infection (reviewed in Masek and Hunter, 2013). They represent an important reservoir for T. gondii replication and haematogenous dissemination, but they also express an array of anti-parasitic effector mechanisms which promote control of parasite replication or even killing of the pathogen. Furthermore, macrophages are important in bridging innate and acquired immunity due to their functions as potent phagocytes, professional antigen-presenting cells (APCS) and producers of immunomodulatory cytokines. Among the IFN- $\gamma$ mediated protective functions of macrophages during toxoplasmosis is the upregulation of GTPases, including immunity-related p47 GTPases (IRGs) and p65 guanylate binding proteins (GBPs). The IRGs are loaded onto the parasitophorous vacuole in a GBP-guided fashion, where they can promote the lysis of the PVM and pave the way for elimination of the parasite by lysosome-mediated degradation (Martens et al., 2005; Ling et al., 2006; Yamamoto et al., 2012). Nitric oxide (NO) produced by the IFN- $\gamma$-inducible NO synthase readily passes the parasites membranes and inhibits essential mitochondrial and nuclear enzymes, while IFN- $\gamma$-dependent indolamine 2,3-dioxygenase (IDO) degrades tryptophan, thereby effectively starving the tryptophan-auxotroph parasite (Pfefferkorn, 1984; Pfefferkorn et al., 1986; Habara-Ohkubo et al., 1993). In addition, other pro-inflammatory cytokines, e.g. IL-1, IL-6 and tumor necrosis factor- $\alpha$ (TNF- $\alpha$ ), synergise with IFN- $\gamma$ to potentiate the immune response against Toxoplasma (Sibley et al., 1991; Langermans et al., 1992; Halonen et al., 1998). Mice deficient for IL-12, IFN- $\psi$, T cells or specific GTPases rapidly succumb due to an overwhelming parasite burden (Gazzinelli et al., 1994; Scharton-Kersten et al., 1996; Collazo et al., 2001; Collazo et al., 2002) thus highlighting the significance of the innate and adaptive responses to $T$. gondii. The pro-inflammatory responses are eventually dampened by anti-inflammatory cytokines, e.g. IL-10, IL-27 and transforming growth factor-B (TGF-ß) to provide the appropriate balance between protection against the parasite and avoidance of immunopathology (Gazzinelli et al., 1992; Gazzinelli et al., 1994; Suzuki et al., 2000).

\subsection{IFN- - -induced STAT1-dependent signaling}

The major signalling molecule activated by IFN- $\gamma$ is the transcription factor signal transducer and activator of transcription 1 (STAT1). Many IFN- $\gamma$ functions are mediated by direct activation of immune effector genes by STAT1, including those encoding for microbicidal molecules, phagocytic receptors, chemokines, cytokines, and antigen presenting molecules (Hu and Ivashkiv, 2009). 
IFN- $-\gamma$ signaling is initiated by binding of the cytokine to its cognate cell surface receptor, i.e. the interferon- $\gamma$ receptor (IFNGR) (Langer and Pestka, 1988) (Figure 3). Upon ligand binding, the two receptor subunits dimerise and Janus kinases (Jaks) which are constitutively associated with the cytoplasmic tails of the IFNGR subunits become activated. They specifically phosphorylate tyrosine residues on the receptor, thereby creating docking sites for the recruitment of cytoplasmic STAT1 (Greenlund et al., 1995). STAT1 becomes phosphorylated at the signature tyrosine residue Y701 in the carboxy-terminal transactivation domain, resulting in STAT1 activation (Schindler et al., 1992; Shuai et al., 1992; Shuai et al., 1993). Tyrosine-phosphorylated STAT1 then dissociates from the receptor and subsequently forms homodimers (Shuai et al., 1994), the so-called gamma interferon-activated factor (GAF). These complexes associate with importin-5a (Sekimoto et al., 1997; Fagerlund et al., 2002) and are readily imported into the nucleus where they accumulate and facilitate transcriptional activation or repression of IFN- $\gamma$-responsive genes. GAF binds with high affinity to a palindromic sequence, the gamma-activated site (GAS) (Horvath et al., 1995) in promoters and enhancer regions. Early during the phase of activation, STAT1 becomes also phosphorylated on the serine residue S727. This modification is required for maximal transcriptional activity, but dependence on this additional booster varies between STAT1-activated genes (Wen et al., 1995; Varinou et al., 2003).

A number of proteins are found to interact with STAT1 and modulate its transcriptional activity (reviewed in Shuai, 2000), e.g. the coactivators CREB-binding protein (CBP) and p300 (Zhang et al., 1996) which have histone acetyltransferase activity, or the corepressor protein inhibitor of activated STAT y (PIASy) which represses STAT1-mediated gene activation without blocking DNA binding activity (Liu et al., 2001). GAF can recruit another GAF to adjacent GAS motifs (Vinkemeier et al., 1996), thereby facilitating binding as tetramers or even as higher-order oligomers. This polymerisation, also referred to as cooperative binding, requires specific interaction between the amino-terminal interaction domains of adjacent STAT1 dimers. Cooperative binding stabilises DNA binding and has been recognised to be indispensable for efficient IFN- $y$ signaling (Begitt et al., 2014).

The transcriptional response to IFN- $\gamma$ is extraordinary complex (Boehm et al., 1997). IFN- - -responsive genes are expressed in waves and the first responders are termed primary response genes (PRGs). Their expression relies on activated STAT1, does not require de novo protein synthesis and some of them can be induced within minutes of stimulation. A second, far larger group of consecutively expressed genes requires de novo protein synthesis and they are thus called secondary response genes (SRGs). Many STAT1-induced PRGs encode potent transcription factors and the secondary and tertiary transcriptional responses to IFN- $\gamma$ partially depend on their expression. As a consequence, IFN- $\gamma$-induced gene expression profiles vary dramatically during the course of stimulation and on top of that, distinct genes tend to show specific expression patterns (Kota et al., 2006). 


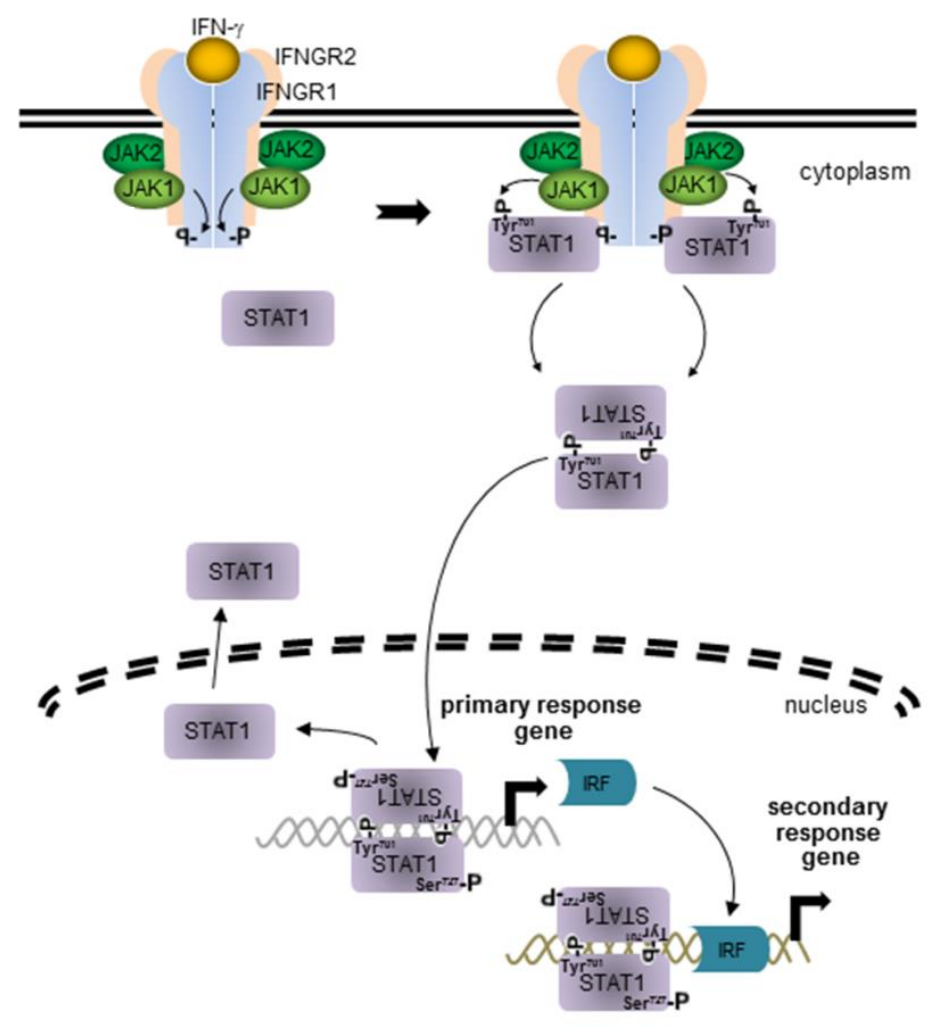

Figure 3: IFN- $/$ /STAT1 signaling (Adapted from Lüder et al. (2015)).

Duration and magnitude of STAT1 gene activation in response to IFN- $\gamma$ is controlled on cytoplasmic and nuclear levels (reviewed in Levy and Darnell, 2002). Inactivation of nuclear STAT1 occurs rapidly following activation of gene transcription. The GAF complex dissociates from chromatin and undergoes a conformational change (Staab et al., 2013) which results in exposure of the critical phosphorylated Y701 residues. Subsequently, STAT1 is dephosphorylated by the T cell protein phosphatase Tc-45 (ten Hoeve et al., 2002). Dephosphorylated STAT1 exits the nucleus and depending on the activation status of the IFN-p receptor, participates in subsequent rounds of cytosolic reactivation, nuclear re-import and inactivation (Meyer et al., 2003). STAT1 signalling is down-regulated by an auto-regulatory negative feedback loop involving suppressors of cytokine signaling 1 (SOCS1). IFN- $\gamma$-induced SOCS1 directly binds to the IFNGR-associated JAKs, thereby inhibiting their activation and STAT1 signaling (Endo et al., 1997; Starr et al., 1997; Song and Shuai, 1998; Alexander et al., 1999). Another mechanism involves protein inhibitor of activated STAT1 (PIAS1) which is thought to directly interact with GAF complexes. PIAS1 blocks DNA binding activity of STAT1 and facilitates co-repressor binding, but inhibition of gene regulation seems to be selective (Liu et al., 1998; Liu et al., 2004). 
STAT1 signaling has been identified to be essential in host resistance to T. gondii. STAT1 deficient mice fail to upregulate important IFN- $\gamma$-dependent immune effector molecules and they are unable to control parasite replication and readily succumb to infection (Lieberman et al., 2004; Gavrilescu et al., 2004).

\subsection{Epigenetic regulation during IFN- $\gamma$ responses}

The conformation of chromatin has a decisive regulatory role enabling cell type-specific functions and responses to a variety of stimuli. DNA in eukaryotic cells is organised into highly condensed chromatin, the fundamental subunits of which are approximately 147 base pairs of DNA wrapped around a histone core, i.e. the nucleosome (Kornberg, 1974; Luger et al., 1997) (Figure 4A). Gene transcription in response to an external stimulus, e.g. IFN- $p$ requires extensive remodelling of the higher order chromatin structure in order to facilitate or preclude accessibility to regulatory factors and assembly of the transcriptional machinery at respective promoters. At the heart of this regulation is the interaction between DNA and histone proteins which is tightly controlled by chemical interactions and epigenetic regulatory mechanisms. Bird (2007) proposed a unifying definition of epigenetic events as "the structural adaptation of chromosomal regions so as to register, signal or perpetuate altered activity states". Chromatin modifiers and chromatin remodelers operate in concert to reversibly switch the chromatin conformation between 'open' and 'closed'. Remodelers mainly use the energy from ATP hydrolysis to mobilise nucleosomes in order to change their position on DNA, destabilise, evict or reassemble them (reviewed in Yodh, 2013). These ATPases are usually associated with several proteins in multimeric complexes, including a variety of chromatin-modifying enzymes. A major regulatory mechanism of chromatin structure and function is the post-translational modification (PTM) of histones. The covalent modifications map to distinct residues and include most abundantly methylation, acetylation, phosphorylation and ubiquitination, although many others have been reported (reviewed in Arnaudo and Garcia, 2013). These reversible 'marks' are added or removed by an array of chromatinmodifying enzymes termed 'writers', e.g. histone acetyltransferases (HATs), histone methyltransferases (HMTs) and kinases, and 'erasers', e.g. histone deacetylases (HDACs), histone demethylases (HDMs) and phosphatases. Importantly, the distinct pattern of PTMs occurring at the same or on another histone tail are thought to function combinatorial constituting a 'histone code' or signature that is indicative of the chromatin state at a given locus (Strahl and Allis, 2000). PTMs have been recognised as critical factors for transcriptional control as they directly manipulate the accessibility of DNA and/or frequently function as docking sites for selective binding of non-histone proteins that are required for transcriptional activation or repression. High levels of histone acetylation are generally associated with active gene transcription. For example, acetylation of lysine in histone globular domains is thought to affect the secondary structure of the histone, resulting in weaker histone-DNA interactions, increased 
nucleosome mobility, and DNA unwrapping (reviewed in Rothbart and Strahl, 2014) (Figure 4B). Histone tail localised $\mathrm{H} 3 \mathrm{~K} 9 \mathrm{ac}$ and $\mathrm{H} 3 \mathrm{~K} 27 \mathrm{ac}$ locate in the region surrounding the transcriptional start site (TSS) while H4K16ac is elevated in the promoter and transcribed regions of active genes (Wang et al., 2008). On the other hand, methylations can be both activating and repressing marks, depending on the site and degree. For instance, mono-, di- and tri-methylation of H3K4 are found at active transcription sites (reviewed in Black et al., 2012) whereas H3K9me2-3 are indicative for repressed genes (Wang et al., 2008). Importantly, 'chromatin marks' are selectively recognised and interpreted by a plethora of chromatin-modifying and/or regulatory factors termed 'readers', which harbour specialised binding domains and direct downstream events, thereby partially acting as 'writers' (reviewed in Zhang et al., 2015). For instance, the bromodomain of HAT p300/CBP binds H3K14ac and its intrinsic activity subsequently acetylates other residues, e.g. H3K18 and H3K27 (Jin et al., 2011). The DNA can also be modified by methylation of the 5 th position of the pyrimidine ring of cytosine $(5 \mathrm{mC})$. This modification is catalysed by DNA methyltransferases (DNTMs) and almost entirely occurs in context of CpG dinucleotides. DNA methylation, especially at promoters and enhancers, can directly repress transcription by precluding binding of transcriptional activators to their cognate DNA sequence. MethylCpG-binding proteins (MBPs) recruit transcriptional co-repressors to modify the surrounding chromatin and silence transcription (reviewed in Klose and Bird, 2006).

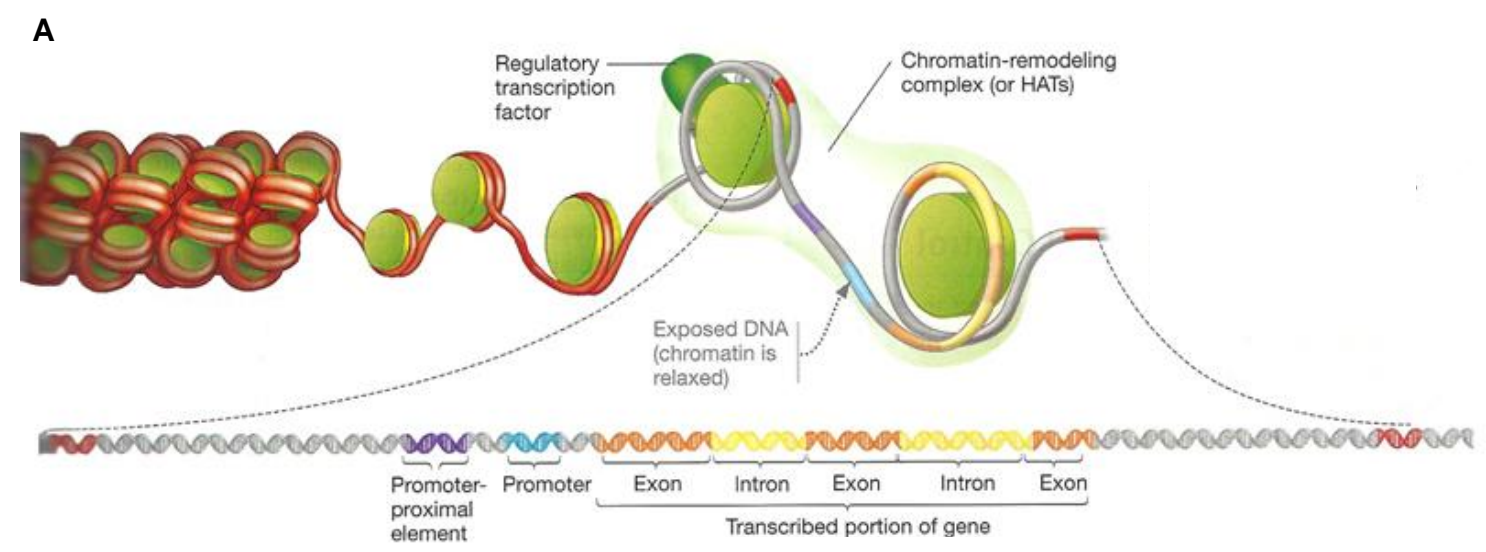

Figure 4: Chromatin remodeling and post-translational modification of histones.

(continuing on the next page) 
B

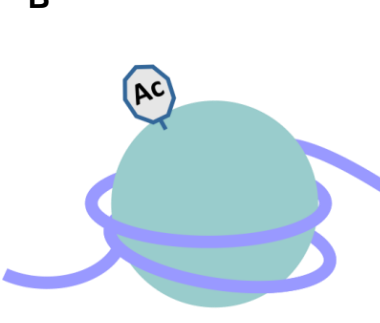

HAT

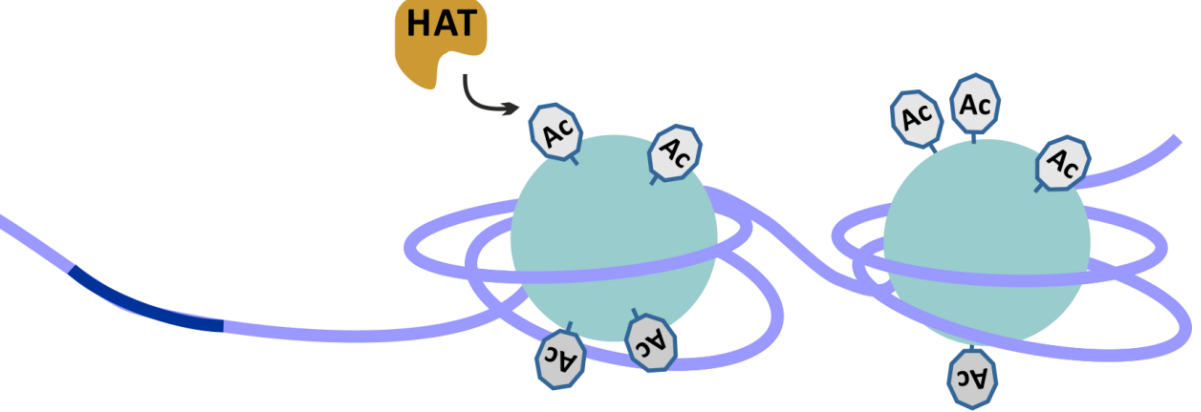

Figure 4: Chromatin remodeling and post-translational modification of histones.

(A) Chromatin remodeling complexes perturb or reposition nucleosomes and facilitate accessibility of DNA regulatory sequence elements. (Adapted from www.discoveryandinnovation.com)

(B) Acetylation (AC) of residues in the histone-DNA interface by histone acetyltransferases (HATs) results in weakened histoneDNA interactions and unwrapping of DNA.

The transcriptional response to IFN- $\gamma$ is controlled by this highly complex interplay of different epigenetic mechanisms, at least partly in a gene-specific fashion. While genome-wide approaches to study patterns and relationships of histone modifications and chromatin-modifying enzymes are advancing, our current understanding of causal relationships in epigenetic regulation of transcriptional IFN- $-\gamma$ response is limited to a few intensively investigated examples. For instance, it was shown that a subset of IFN- $\gamma$-inducible promoters exhibited constitutive binding of brahma-related gene 1 (BRG1), an ATPase subunit of the BRG1/BRM associated factor (BAF) complex (a mammalian homologue of the yeast SWI/SNF chromatin remodeling complex) (Pattenden et al., 2002; Ni et al., 2005). Binding of BRG1 is in these cases critical for IFN- $\mu$-induced promoter accessibility and is a prerequisite for STAT1 recruitment (Ni et al., 2005). In case of $g b p 1$ and $g b p 2$, transcriptional activation is accompanied by promoter histone 4 hyperacetylation in a STAT1-dependent manner (Varinou et al., 2003). Paradoxical, the gbp genes were identified to require histone deacetylase 1 (HDAC1) activity for IFN- $\gamma$-induced expression (Zupkovitz et al., 2006). Consistently, activated STAT1 was found associated with the histone acetyltransferase CBP and HDAC1 (Zhang et al., 1996; Varinou et al., 2003; Nusinzon and Horvath, 2003). Ramsauer and colleagues (2007) proposed a model where STAT1 primarily must directly contribute to gbp2 promoter activation by creating a permissive chromatin environment for RNA pol II assembly through the recruitment of CBP (and possibly other HATs) and HDAC1. Subsequently, transcription factor IRF1 binds and contacts RNA pol II-containing transcriptional complexes. Several of these events appear to be similar in transcriptional activation of the ciita promoter IV. The promoter employs the chromatin remodeling activity of BRG1 and CBP/p300 HAT activity (Pattenden et al., 2002; Ni et al., 2005). Importantly, detailed histone modification studies revealed a complex pattern of IFN- - -induced promoter acetylation and tri-methylation (Morris et al., 2002; Ni et al., 2005; Mehta, 2010). For instance, specifically $\mathrm{H} 3 \mathrm{~K} 9, \mathrm{H} 3 \mathrm{~K} 18$ and $\mathrm{H} 4 \mathrm{~K} 8$ are modified at the ciita promoter IV resulting in a rapid 
and sustained histone $\mathrm{H} 4$ and $\mathrm{H} 3$ hyperacetylation, indicative for active transcription. In parallel, depletion of repressive hypermethylation of $\mathrm{H3}$ lysine 9 (H3K9me3) and lysine 27 (H3K27me3) in response to IFN- $\gamma$ continues until reaching baseline level (Mehta, 2010). Consistently, the ciita promoter was found to interact with the catalysing histone methyltransferase enhancer of zeste homolog 2 (EZH2) (Holling et al., 2007) and its promoter occupancy declined upon treatment with IFN-p (Mehta et al., 2011). Little is known about the epigenetic mechanisms how IFN- $\gamma$ directly represses target gene expression. Only recently it was unravelled that IFN- $\gamma$ silences a small group of genes by introducing H3K27me3 marks in their promoters (Qiao et al., 2016). Consistently, IFN- $\gamma$ induces recruitment of EZH2 to these promoters. It is known that $\mathrm{H} 3 \mathrm{~K} 27$ me3 recruits polycomb repressive complex 1 (PRC1), which adds another repressive histone mark H2AK119u1 to further reinforce gene repression (reviewed in Zhang et al., 2015). Consistent with this model, H2AK119u1 was enriched at promoters of the investigated genes (Qiao et al., 2016).

\subsection{Immune evasion strategies of $T$. gondii}

Toxoplasma gondii would not have been able to establish itself as one of the most successful parasites without evolving an array of strategies to counterbalance regulatory and effector functions of the host immune system (Lang et al., 2007; Hunter and Sibley, 2012). The intracellular lifestyle of $T$. gondii contributes largely to its ability to evade the host's immune response to infection. For instance, the process of host cell invasion is completed within 20 - 30 seconds thereby dramatically shortening the time of exposure to antibodies and complement and outflanking phagocytic cells attempting to engulf the pathogen (Morisaki et al., 1995; Mordue, Håkansson, et al., 1999). Further, the parasite selectively excludes host cell transmembrane proteins from the nascent PVM during the invasion process, a mechanism aiding T. gondii to reside in a fusion-incompetent vacuole. The PV hence resists phagosomelysosome fusion and does not acidify thereby protecting the parasite from degradation (Jones and Hirsch, 1972; Sibley et al., 1985; Mordue, Håkansson, et al., 1999).

T. gondii must nevertheless evoke a protective innate immune response to ensure host survival and establishment of chronic infection. At the same time however, it must avoid an overly strong proinflammatory response that may lead to severe immunopathology and sterilizing anti-microbial activity. To manipulate its host's immune response, $T$. gondii activates distinct signal transduction pathways and simultaneously suppresses others (reviewed in Miller et al., 2009; Leng, Butcher, and Denkers, 2009). For instance, $T$. gondii activates host anti-apoptotic pathways, thereby rendering infected cell resistant to programmed cell death (Nash et al., 1998; reviewed in Lüder and Gross, 2005). Furthermore, T. gondii infection upregulates secretion of anti-inflammatory cytokines, e.g. the potent IFN- $\gamma$ antagonist IL-10 
and TGF-ß (Bermudez et al., 1993; Khan et al., 1995; Langermans et al., 2001) and induces expression of negative regulators of pro-inflammatory cascades, including SOCS1 (Zimmermann et al., 2006). Various immune evasion strategies are facilitated by effector proteins, secreted into the host cell during invasion, which are partly polymorphic and represent strain-specific virulence factors (reviewed in Melo et al., 2011; Hunter and Sibley, 2012; and Hakimi et al., 2017). For instance, the kinase ROP18 from type I parasites together with ROP5 and GRA7 inhibit IRG accumulation on the PVM, thereby preserving vacuolar integrity and protecting T. gondii from destruction (Fentress et al., 2010; Steinfeldt et al., 2010; Behnke et al., 2012; Reese et al., 2014; Hermanns et al., 2016). Another example is the rapid and sustained activation of STAT3 by ROP16 from type I and III parasites. The direct upregulation of this antiinflammatory pathway prevents production of pro-inflammatory IL-12 (Butcher, Kim, et al., 2005; Saeij et al., 2007), thus limiting protective $T_{H} 1$-biased response. The importance of IL-12 inhibition is further demonstrated by type I parasite-mediated inhibition of LPS-triggered NF-KB signalling (Butcher et al., 2001).

A critical immune evasion strategy is the interference with IFN- $\gamma$-induced STAT1 signaling, where the parasite effectively silences the transcriptional response on a genome-wide level (Kim et al., 2007; Lang et al., 2012) and thereby counteracts simultaneously multiple host resistance functions. T. gondii for instance down-regulates the IFN- $\gamma$-induced MHC class II expression in different antigen-presenting cells (Lüder et al., 1998; Lüder et al., 2001). Other examples for counteracting IFN- $\psi$-mediated anti-parasitic effector functions are the inhibition of iNOS-mediated NO production (Lüder et al., 2003) and upregulation of p47 GTPases (Butcher, Greene, et al., 2005). A mechanistic analysis revealed that T. gondii likely inhibits the assembly of the chromatin remodelling complex at STAT1-regulated promoters of a subset of secondary response genes (Lang et al., 2012) suggesting parasite-imposed changes in the epigenetic landscape of its host cell. Recently, the effector protein T. gondii inhibitor of STAT1-dependent transcription (TgIST) was found to mediate the interaction of activated STAT1 with transcriptional corepressors and the chromatin-remodelling and deacetylase (NuRD) complex, which contains distinct chromatin-modifying proteins (Olias et al., 2016; Gay et al., 2016). Detailed studies demonstrated that TgIST is both necessary and sufficient for inhibition of distinct IFN- $\gamma$-dependent gene transcription (Olias et al., 2016). However, the IFN- $\gamma$ stimulated expression of distinct primary response genes is independent from BRG1-mediated chromatin remodelling (Wang et al., 2011), indicating that the parasite may utilise different inhibition mechanisms (Rosowski and Saeij, 2012). It was subsequently indeed observed that T. gondii promotes higher levels of activated, tyrosine-phosphorylated STAT1 in the nuclei of infected cells (Rosowski and Saeij, 2012) and that the transcription factor is specifically enriched in the chromatin fraction (Rosowski et al., 2014). Therefore, it was hypothesised that $T$. gondii disrupts IFN- $\gamma$ signaling by inhibiting STAT1 dissociation from DNA, which would preclude STAT1 recycling and anew activation (Rosowski et al., 2014). 
The evolution of these remarkably complex immune evasion strategies enables $T$ gondii to transform its host cell into a safe niche and to establish a long-lasting infection within the intermediate host, the prerequisite for transmission to its final or next intermediate host.

\subsection{Objectives of this project}

Toxoplasma gondii has evolved several strategies to partially evade the host's immune system, and they allow the parasite to establish a chronic infection. Genome-wide dysregulation of the transcriptional response to IFN- $\gamma$, which is the major mediator of host resistance against $T$. gondii, represents one of these strategies. Previous work has shown that parasite infection does not impede proximal IFN- $\gamma$ triggered STAT1 activation or its nuclear translocation, but how the parasite alters STAT1-induced gene expression within the host nucleus has been largely elusive. The aim of the present study therefore was to further elucidate the molecular mechanism(s) employed by the parasite to inhibit IFN- $\gamma$ signalling of its host. Specifically, in this work, I have determined the impact of native host chromatin and characteristics thereof on the parasite-imposed inhibition of IFN- $\gamma$-regulated gene expression in murine macrophages. Moreover, the impact of $T$. gondii infection on the regulation of distinct epigenetic histone marks at promoters of primary and secondary IFN- $\gamma$ response genes has been characterized. Finally, I conducted an in-depth analysis of STAT1, its IFN- $\gamma$-triggered activation and DNA-binding activities, and its modulation by $T$. gondii after infection.

Elucidating the mechanism which underlies the parasite-mediated unresponsiveness of host cells to IFN$\checkmark$ has helped to better understand the complex interaction $T$. gondii with its mammalian host. 


\section{MATERIALS AND METHODS}

\subsection{Materials}

\subsubsection{Chemicals and reagents}

Table 1: List of chemicals and reagents

\begin{tabular}{|c|c|}
\hline Name & Company \\
\hline Acetic acid & Carl Roth, Karlsruhe, Germany \\
\hline Agar agar & Carl Roth, Karlsruhe, Germany \\
\hline Agarose & Carl Roth, Karlsruhe, Germany \\
\hline Aminocapronic acid & Carl Roth, Karlsruhe, Germany \\
\hline Ampicillin & Sigma-Aldrich, Taufkirchen, Germany \\
\hline Aprotinin & Sigma-Aldrich, Taufkirchen, Germany \\
\hline APS (ammonium persulfate) & Merck Millipore, Darmstadt, Germany, \\
\hline Bacto Tryptone & Becton Dickinson, Franklin Lakes, USA \\
\hline Bacto Yeast extract & Becton Dickinson, Franklin Lakes, USA \\
\hline Boric acid & Carl Roth, Karlsruhe, Germany \\
\hline Bromophenol blue & Ameresco, Solon, USA \\
\hline BSA (bovine serum albumin) & Carl Roth, Karlsruhe, Germany \\
\hline $\mathrm{CaCl}_{2}$ (calcium chloride) & Carl Roth, Karlsruhe, Germany \\
\hline Complete Mini Protease inhibitor cocktail & Roche, Basel, Switzerland \\
\hline D-(+)-glucose & Merck Millipore, Darmstadt, Germany \\
\hline DABCO (1,4-diazabicyclo-[2,2,2]-octane) & Carl Roth, Karlsruhe, Germany \\
\hline $\begin{array}{l}\text { Deoxy-ATP (adenosine triphosphate) } 5^{\prime}-\left[\mathrm{a}^{33} \mathrm{P}\right]- \\
\text { labelled }\end{array}$ & Hartmann Analytic, Braunschweig, Germany \\
\hline DMSO (diethyl sulphoxide) & Sigma-Aldrich, Taufkirchen, Germany \\
\hline dNTP (deoxynucleotide triphosphate) & Carl Roth, Karlsruhe, Germany \\
\hline DTT (dithiothreitol) & Sigma-Aldrich, Taufkirchen, Germany \\
\hline
\end{tabular}


MATERIAL AND METHODS

Dynabeads Protein A

EDTA (ethylenediaminetetraacetic acid)

EDTA (ethylenediaminetetraacetic acid) in PBS

w/o $\mathrm{Ca}^{2+}$ w/o $\mathrm{Mg}^{2+}$

Ethanol

FCS (foetal calf serum)

Ficoll

Formaldehyde solution, $37 \%$

Geneticin (G 418)

Glycerol

Glycine

HEPES (4-(2-hydroxyethyl)-1-

piperazineethanesulphonic acid)

Hydrochloric acid, 37\%

Hygromycin B

Immersion oil

Isopropanol

Igepal CA-630

$\mathrm{KCl}$ (potassium chloride)

Laminin (murine)

Leupeptin

LiCl (lithium chloride)

Loading Dye (6 x Orange LD)

Magnesium acetate

Methanol

$\mathrm{MgCl}_{2}$ (magnesium chloride)

Midori Green

Mowiol 4-88
Invitrogen, Carlsbad, USA

Sigma-Aldrich, Taufkirchen, Germany

Biochrom, Berlin, Germany

Carl Roth, Karlsruhe, Germany

Biochrom, Berlin, Germany

Amersham Bioscience, Freiburg, Germany

Sigma-Aldrich, Taufkirchen, Germany

Biochrom, Berlin, Germany

Sigma-Aldrich, Taufkirchen, Germany

Carl Roth, Karlsruhe, Germany

Biochrom, Berlin, Germany

Merck Millipore, Darmstadt, Germany

Calbiochem, San Diego, USA

Sigma-Aldrich, Taufkirchen, Germany

Carl Roth, Karlsruhe, Germany

Sigma-Aldrich, Taufkirchen, Germany

Merck Millipore, Darmstadt, Germany

Sigma-Aldrich, Taufkirchen, Germany

Sigma-Aldrich, Taufkirchen, Germany

Fluka, Buchs, Switzerland

Thermo Fisher, Waltham, USA

Carl Roth, Karlsruhe, Germany

Carl Roth, Karlsruhe, Germany

Merck Millipore, Darmstadt, Germany

Nippon Genetics, Dueren, Germany

Calbiochem, San Diego, USA 
MATERIAL AND METHODS

$\mathrm{NaCl}$ (sodium chloride)

NaF (sodium fluoride)

$\mathrm{NaOH}$ (sodium hydroxide)

Na-pyruvate (sodium pyruvate)

$\mathrm{Na}_{3} \mathrm{VO}_{4}$ (sodium orthovanadate)

NEAA (non-essential amino acids)

$\mathrm{NH}_{4} \mathrm{Cl}$ (ammonium chloride)

Nonidet P40 substitute

PBS (phosphate buffered saline) w/o $\mathrm{Ca}^{2+} \mathrm{w} / \mathrm{o} \mathrm{Mg}^{2+}$

Pefabloc

Penicillin $(10,000 \mathrm{U} / \mathrm{ml}) /$ streptomycin $(10,000 \mu \mathrm{g} / \mathrm{ml})$

Pepstatin A

Pierce Streptavidin Ultralink Resin

PMSF (phenylmethylsulfonyl fluoride)

Poly(dldC) (poly(deoxyinosinic-deoxycytidylic) acid)

Puromycin

Ponceaus

Propidium iodide

Protease Inhibitor Cocktail 'complete', EDTA-free

RNasin

Rotiphorese Gel 30 (30\% Acrylamide/ bisacrylamide (37.5:1)-solution)

Rotiphorese Gel 40 (40\% Acrylamide/ bisacrylamide (29:1)-solution)

Saponin

SDS (sodium dodecyl sulphate)

Skim milk powder

Sodium deoxycholate
Carl Roth, Karlsruhe, Germany

Merck Millipore, Darmstadt, Germany

Merck Millipore, Darmstadt, Germany

Biochrom, Berlin, Germany

Sigma-Aldrich, Taufkirchen, Germany

Biochrom, Berlin, Germany

Merck Millipore, Darmstadt, Germany

Fluka, Buchs, Switzerland

Biochrom, Berlin, Germany

Roche, Basel, Switzerland

Biochrom, Berlin, Germany

Sigma-Aldrich, Taufkirchen, Germany

Thermo Fisher, Waltham, USA

Sigma-Aldrich, Taufkirchen, Germany

Sigma-Aldrich, Taufkirchen, Germany

Sigma-Aldrich, Taufkirchen, Germany

Sigma-Aldrich, Taufkirchen, Germany

Sigma-Aldrich, Taufkirchen, Germany

Roche, Basel, Switzerland

Promega, Madison, USA

Carl Roth, Karlsruhe, Germany

Carl Roth, Karlsruhe, Germany

Sigma-Aldrich, Taufkirchen, Germany

Carl Roth, Karlsruhe, Germany

Carl Roth, Karlsruhe, Germany

Sigma-Aldrich, Taufkirchen, Germany 
Sodium-cacodylate

Sodium pyrophosphate

Staurosporin

Sucrose

TEMED (tetramethylethylenediamine)

Tris (Tris(hydroxymethyl)-aminomethan)

Triton X-100

Trypan blue

Trypsin w/o Ca ${ }^{2+}$ w/o $\mathrm{Mg}^{2+}$

Tween-20
Carl Roth, Karlsruhe, Germany

Sigma-Aldrich, Taufkirchen, Germany

Sigma-Aldrich, Taufkirchen, Germany

Merck Millipore, Darmstadt, Germany

Carl Roth, Karlsruhe, Germany

Carl Roth, Karlsruhe, Germany

Merck Millipore, Darmstadt, Germany

Biochrom, Berlin, Germany

Biochrom, Berlin, Germany

Sigma-Aldrich, Taufkirchen, Germany

\subsubsection{Culture media}

Table 2: List of culture media

Name

Company

DMEM (Dulbecco's modified Eagle's medium) containing 4,5 g/l D- Biochrom, Berlin, Germany (+)-glucose, $580 \mathrm{mg} / \mathrm{l} \mathrm{L-glutamine} \mathrm{(supplemented} \mathrm{with} 3700 \mathrm{mg} / \mathrm{l}$ $\mathrm{NaHCO}_{3}$ and $476 \mathrm{mg} / \mathrm{l} \mathrm{HEPES}$, adjusted to $\mathrm{pH}$ 7.2)

RPMI 1640 (Roswell Park Memorial Institute) containing 300 mg/l L- Biochrom, Berlin, Germany glutamine (supplemented with $3700 \mathrm{mg} / \mathrm{I} \mathrm{NaHCO}$, adjusted to $\mathrm{pH} 7.2)$

\subsubsection{Commercial kits}

Table 3: List of kits

\begin{tabular}{|c|c|}
\hline Name & Company \\
\hline Amersham ECL Western Blotting Detection Reagent & GE Healthcare, Chicago, USA \\
\hline DNase I Amplification Grade & Sigma-Aldrich, Taufkirchen, Germany \\
\hline GenElute ${ }^{T M}$ Mammalian Genomic DNA Miniprep Kit & Sigma-Aldrich, Taufkirchen, Germany \\
\hline GenElute $^{\mathrm{TM}}$ Mammalian Total RNA Miniprep Kit & Sigma-Aldrich, Taufkirchen, Germany \\
\hline LightCycler ${ }^{\circledR}$ FastStart DNA Master ${ }^{\text {PLUS }}$ SYBR Green I & Roche, Basel, Switzerland \\
\hline
\end{tabular}


Luciferase Assay System

Mega Tran 1.0 transfection reagent

Omniscript RT Kit

QIAquick Gel Extraction Kit

QIAquick PCR Purification Kit

Pierce BCA Protein Assay Kit

T4 DNA Ligase

X-tremeGENE HP DNA Transfection reagent
Promega, Madison, USA

Origene, Rockville, USA

Qiagen, Venlo, Netherlands

Qiagen, Venlo, Netherlands

Qiagen, Venlo, Netherlands

Thermo Fisher, Waltham, USA

Thermo Fisher, Waltham, USA

Roche, Basel, Switzerland

\subsubsection{Equipment}

Table 4: List of equipment

\begin{tabular}{ll}
\hline Name & Company \\
\hline Agarose gel running system & Keutz, Reiskirchen, Germany \\
Biological safety cabinet & BDK, Sonnenbuehl-Genkingen, Germany \\
Centrifuge 5424, 5417 R & Eppendorf, Hamburg, Germany \\
Centrifuge Megafuge 2.0 RS & Heraeus, Hanau, Germany \\
CO incubator BB6220 & Heraeus, Hanau, Germany \\
Electrophoresis chamber & Biometra, Göttingen, Germany \\
Electrophoresis power supply EPS 500/400 & Pharmacia fine chemicals, Piscataway, \\
USA & Thermo Fisher, Waltham, USA \\
FLA-5100 scanner & Fuji, Duesseldorf, Germany \\
Gel documentation system GelDoc XRS & Bio Rad, Hercules, USA \\
Haemocytometer improved 0.1 mm & Blau Brand, Wertheim, Germany \\
Incubator hood TH 30 & Edmund Buhler, Hechlingen, Germany \\
Inverted contrasting microscope DM IL & Leica, Wetzlar, Germany \\
Laser scanning microscope SPII & Leica Microsystems, Heidelberg, \\
Germany
\end{tabular}


MATERIAL AND METHODS

Luminescent image analyser LAS4000

Magnetic rack

Magnetic stirrer RTC basic

Mercury vapour lamp HBO 50W/AC L2

Microplate reader Victor ${ }^{3} \mathrm{~V}$

Microtiter shaker MTS4

Multistep dispenser pipet

Overhead shaker REAX 2

Photometer SevenCompact pH/Ion meter S220

Pipet aid Pipetboy

Pipet aid Pipetus

Pipet type Research (P1000, P100, P10)

Real-time cycler LightCycler 1.5

Rocking platform Duomax 1030

Scale LP6200S-OCE, CPA224S

SDS page gel running system

Sonifier Bioruptor plus

Sonifier Branson Sonifier 250

Spectrophotometer Nanodrop 2000c

Transilluminator AL.16.T.0.10521

Transmitted light microscope Axiostar plus

Thermomixer compact

Ultrapure water system Arium pro VF

Universal shaker SM 30

Vortex genie

Vortex Reax top

Water bath 1083
Fujifilm, Tokyo, Japan

Bio Rad, Hercules, USA

IKA, Staufen, Germany

Osram, Munich, Germany

PerkinElner, Waltham, USA

IKA, Staufen, Germany

Eppendorf, Hamburg, Germany

Heidolph, Schwabach, Germany

Mettler Toledo, Columbus, USA

Integra Bioscience, Biebertal, Germany

Hirschmann, Eberstadt, Germany

Eppendorf, Hamburg, Germany

Roche, Basel, Switzerland

Heidolph, Schwabach, Germany

Sartorius, Göttingen, Germany

Biometra, Göttingen, Germany

Diagenode; Liège, Belgium

Branson, St. Louis, USA

Thermo Fisher, Waltham, USA

INTAS, Göttingen, Germany

Zeiss, Göttingen, Germany

Eppendorf, Hamburg, Germany

Sartorius, Göttingen, Germany

Edmund Buhler, Hechlingen, Germany

Bender + Hobein, Bruchsal, Germany

Heidolph, Schwabach, Germany

GFL, Burgwedel, Germany 
MATERIAL AND METHODS

\subsubsection{Disposable materials}

Table 5: List of disposable materials

\begin{tabular}{|c|c|}
\hline Name & Company \\
\hline Cell culture dish, $\varnothing 100 \mathrm{~mm}$ & Greiner, Frickenhausen, Germany \\
\hline Cell culture flask, $25 \mathrm{~cm}^{2}, 75 \mathrm{~cm}^{2}, 175 \mathrm{~cm}^{2}$ & Greiner, Frickenhausen, Germany \\
\hline Cell culture plate, 6-well, 12-well, 24-well & Greiner, Frickenhausen, Germany \\
\hline Cell scraper, $300 \mathrm{~mm}$ & TPP, Trasadingen, Austria \\
\hline Cryogenic vial & Nunc, Roskilde, Denmark \\
\hline Dispenser tip, $10 \mathrm{ml}$ & Eppendorf, Hamburg, Germany \\
\hline Falcon tube, $15 \mathrm{ml}$ & Greiner, Frickenhausen, Germany \\
\hline Falcon tube, $30 \mathrm{ml}$ & Sarstedt, Nümbrecht, Germany \\
\hline Filter system $0.22 \mu \mathrm{m}, 0.45 \mu \mathrm{m}$ pore & Corning Incorporated, Corning, USA \\
\hline Glass cover slip, $\varnothing 13 \mathrm{~mm}$ & Menzel, Braunschweig, Germany \\
\hline Glass microscopic slide, $76 \times 26 \mathrm{~mm}$ & Menzel, Braunschweig, Germany \\
\hline Haemocytometer cover slip, 22×22 mm & Menzel, Braunschweig, Germany \\
\hline Illustra-MicrospinSpin-G-25 column & GE Healthcare, Chicago, USA \\
\hline Microplate for luminescence assay, black & NUNK, Roskilde, Denmark \\
\hline Membrane filter, 3.0 $\mu \mathrm{m}$ pore & Merck Millipore, Darmstadt, Germany \\
\hline Microreaction tube, $0.5 \mathrm{ml}, 1.5 \mathrm{ml}, 2 \mathrm{ml}$ & Sarstedt, Nümbrecht, Germany \\
\hline Nitrocellulose membrane, Hybond ECL $0.45 \mu \mathrm{m}$ pore & Amersham Bioscience, Freiburg, Germany \\
\hline Parafilm & Bemis, Neenah, USA \\
\hline Pasteur capillary pipets, $230 \mathrm{~mm}$ & WU Mainz, Bamberg, Germany \\
\hline Pipette Filter Tip, $1000 \mu \mathrm{l}, 100 \mu \mathrm{l}, 10 \mu \mathrm{l}$ & Sarstedt, Nümbrecht, Germany \\
\hline pH test stripe, $\mathrm{pH} 0-14$ & Omnilabs, Gehrden, Germany \\
\hline Scalpel & HMD Healthcare, Horsham, UK \\
\hline Sonication Tube TPX & Diagenode; Liège, Belgium \\
\hline Syringe, $50 \mathrm{ml}, 30 \mathrm{ml}, 10 \mathrm{ml}, 1 \mathrm{ml}$ & Terumo, Tokyo, Japan \\
\hline Syringe filter, $0.22 \mu \mathrm{m}, 0.45 \mu \mathrm{m}$ pore & Corning Incorporated, Corning, USA \\
\hline
\end{tabular}


Weighing paper

Whatman filter paper, 20 - $25 \mu \mathrm{m}$ pore
Macherey Nagel, Dueren, Germany

Rettberg, Göttingen, Germany

\subsubsection{Oligonucleotides and primers}

All oligonucleotides and primers were purchased from Sigma Aldrich. The online tool NCBI blast was used to design the primers.

\subsubsection{Hybridised oligonucleotides}

Hybridisation was achieved through mixing equal amounts of complementary oligonucleotides, heating and slow, gradual cooling to room temperature. Exact parameters are indicated in the respective method description.

Table 6: List of oligonucleotides for electromobility shift assay

\begin{tabular}{|c|c|c|}
\hline Name & & Sequence \\
\hline \multirow[t]{2}{*}{ GAS (M67) } & Sense & 5'-TTT TCG ACA TTT CCC GTA AAT CTG-3' \\
\hline & Antisense & 5'-TTT TCA GAT TTA CGG GAA ATG TCG-3' \\
\hline \multirow[t]{2}{*}{$2 \times G A S$} & Sense & $\begin{array}{l}\text { 5'-TTT TCG TTT CCC CGA AAT TGA CGG ATT TCC CCG AAA C- } \\
3^{\prime}\end{array}$ \\
\hline & Antisense & $\begin{array}{l}\text { 5'-TTT TGT TTC GGG GAA ATC CGT CAA TTT CGG GGA AAC G- } \\
3^{\prime}\end{array}$ \\
\hline \multirow[t]{2}{*}{ GAS-nonGAS } & Sense & 5'-TTT TCG TTT CCC CGA AAT TGA CGG ATT TAC CCC AAC-3' \\
\hline & Antisense & 5'-TTT TGT TGG GGT AAA TCC GTC AAT TTC GGG GAA ACG-3' \\
\hline \multirow[t]{2}{*}{ 2xnonGAS } & Sense & 5'-TTT TCG TTT ACC CCA AAT TGA CGG ATT TAC CCC AAC-3' \\
\hline & Antisense & 5'-TTT TGT TGG GGT AAA TCC GTC AAT TTG GGG TAA ACG-3' \\
\hline
\end{tabular}

Grade of purification: Desalted

Table 7: List of oligonucleotides for oligonucleotide precipitation assay

\begin{tabular}{lll}
\hline Name & Sequence \\
\hline GAS & Sense & 5'-[Btn]GAT GTA TTT CCC CGA AAA G-3' \\
& Antisense & 5'-CTT TTC GGG GAA ATA CAT C-3'
\end{tabular}




$\begin{array}{lll}\text { nonGAS } & \text { Sense } & \text { 5'-[Btn]GAT GTA TTT ACC CCA AAA G-3' } \\ & \text { Antisense } & \text { 5'-CTT TTG GGG TAA ATA CAT C-5' } \\ \text { 2xGAS } & \text { Sense } & \text { 5'-[Btn]GAT GTA TTT CCC CGA AAT TGA CGG ATT TCC CCG AAA AG } \\ & \text { Antisense } & \text { 5'-CTT TTC GGG GAA ATC CGT CAA TTT CGG GGA AAT ACA TC-3' } \\ \text { GAS-nonGAS } & \text { Sense } & \text { 5'-[Btn] GAT GTA TTT CCC CGA AATTGA CGG ATT TAC CCC AAA AG } \\ & \text { Antisense } & \text { 5'-CTT TTG GGG TAA ATC CGT CAA TTT CGG GGA AAT ACA TC-3' } \\ & \text { Sense } & \text { 5'-[Btn]GAT GTA TTT ACC CCA AAT TGA CGG ATT TAC CCC AAA AG- } \\ & & \\ & & \\ & \text { Antisense } & \text { 5'-CTT TTG GGG TAA ATC CGT CAA TTT GGG GTA AAT ACA TC-3' }\end{array}$

Grade of purification: HPLC

\subsubsection{Oligonucleotide primers for PCR}

Table 8: List of oligonucleotide primers for ChIP analysis

\begin{tabular}{|c|c|c|c|}
\hline Gene & Localisation & & Sequence \\
\hline \multirow[t]{2}{*}{$a c t b$} & distal & Forward & 5'-ATC AGG CAG TTC TCC AAA AGT-3' \\
\hline & & Reverse & 5'-TTG CAA GAA GAT GCC TCC AGA TA-3' \\
\hline \multirow[t]{4}{*}{ ciita } & distal & Forward & 5'-CAC AGT GGG CTC AGG GGA ATA TC-3' \\
\hline & & Reverse & 5'-GAC CTC GGA TGA CAG TGG TTA CT-3' \\
\hline & proximal & Forward & 5'-TGC CTT TGG CCC AAA GCT GA-3' \\
\hline & & Reverse & 5'-TTC TGA GTC GTG CCT GCA TGC-3' \\
\hline \multirow[t]{2}{*}{ irf1 } & distal & Forward & 5'-GCT GAA GTA GGT GTC ATA GAA-3' \\
\hline & & Reverse & 5'-GGA ACA CCT TGT TCT TAT G-3' \\
\hline \multirow[t]{2}{*}{$\operatorname{irf8}$} & distal & Forward & 5'-GAA ACC TAG CCG TAT ACT TCT TGT A-3' \\
\hline & & Reverse & 5'-CTC TCA CCC GTC TGG CTT TTA-3' \\
\hline \multirow[t]{2}{*}{$g b p 2$} & distal & Forward & 5'-AGA TGT CAG TCT CAG TTT TG-3' \\
\hline & & Reverse & 5'-CCA GTC ATT TGT AGT ATG TT-3' \\
\hline
\end{tabular}




\begin{tabular}{|c|c|c|c|}
\hline \multirow{2}{*}{\multicolumn{2}{|c|}{ proximal }} & Forward & 5'-GCT GGC AAC TTC ACA AAA CA-3' \\
\hline & & Reverse & 5'-TGC CAG AGA ACT TGT GAG GA-3' \\
\hline \multirow[t]{2}{*}{ stat1 } & \multirow[t]{2}{*}{ distal } & Forward & 5'-ACG GGA GAA GGG TAG ATA AG-3' \\
\hline & & Reverse & 5'-TAC ACA ATT GAC ACC TCC ATT AC-3' \\
\hline
\end{tabular}

Grade of purification: HPLC

Table 9: List of oligonucleotide primers for analysis of transcriptional regulation in myocardial fibroblasts

\begin{tabular}{lll}
\hline Gene & & Sequence \\
\hline actb & Forward & 5'-GAT GAC CCA GAT CAT GTT TGA GAC-3' \\
& Reverse & 5'-TGC TCG AAG TCT AGA GCA ACA TAG-3' \\
ciita & Forward & 5'-GTG AGC GCT GGT AGA CAG AAC-3' \\
& Reverse & 5'-GCC TTT TGG TTC ACA CCC AGG-3' \\
h2-ab & Forward & 5'-CAG GAC AGA GGC CCT CAA CCA C-3' \\
& Reverse & 5'-GAG GAA GAT CAC CCC AAG CAC GC-3' \\
irf1 & Forward & 5'-GGT TCC CAA GCC AGT GAA ATG-3' \\
& Reverse & 5'-TAG TCA AGA GTC ACG CCA AGG-3' \\
irf8 & Forward & 5'-CCT TGT CCA GCT CCA TAC CC-3' \\
& Reverse & 5'-TCT GCC CCT GTT GTG TAC TG-3'
\end{tabular}

Grade of purification: HPLC

Table 10: List of oligonucleotide primers for sequence verification

\begin{tabular}{lll}
\hline Name & & Sequence \\
\hline pGL3_RVprimer3 & Forward & 5'-CTA GCA AAA TAG GCT GTC C-3' \\
pGL4.27_RVprimer3 & Forward & 5'-TAG CAA AAT AGG CTG TCC C-3' \\
LucGene & Reverse & 5'-CGC CGG GCC TTT CTT TAT G-3' \\
Grade of purification: HPLC & &
\end{tabular}




\subsubsection{Enzymes and recombinant proteins}

Table 11: List of enzymes

\begin{tabular}{ll}
\hline Name & Company \\
\hline Klenow fragment & New England Biolabs, Ipswich, USA \\
Kpn I & New England Biolabs, Ipswich, USA \\
Nhe I & New England Biolabs, Ipswich, USA \\
Proteinase K & AppliChem, Darmstadt, Germany \\
RNase A & Sigma-Aldrich, Taufkirchen, Germany \\
T4 DNA polymerase & New England Biolabs, Ipswich, USA
\end{tabular}

Table 12: List of recombinant proteins

\begin{tabular}{ll}
\hline Name & Company \\
\hline IFN-y, human, recombinant from E. coli & Biomol, Hamburg, Germany \\
IFN-y, murine, recombinant from E. coli & R\&D Systems, Wiesbaden, Germany
\end{tabular}

\subsubsection{Molecular weight markers}

Table 13: List of molecular weight marker

\begin{tabular}{ll}
\hline Name & Company \\
\hline DNA 100 bp Ladder & New England Biolabs, Ipswich, USA \\
DNA 1 kb Ladder & New England Biolabs, Ipswich, USA \\
Prestained Protein Marker, Broad Range & New England Biolabs, Ipswich, USA
\end{tabular}

\subsubsection{Antibodies}

Table 14: List of primary antibodies for immunofluorescence staining

\begin{tabular}{ll}
\hline Name & Origin \\
\hline anti-Toxoplasma gondii, serum & $\begin{array}{l}\text { Institute for Medical Microbiology, Göttingen; } \\
\text { Germany }\end{array}$
\end{tabular}


MATERIAL AND METHODS

Table 15: List of primary antibodies for ChIP analysis

\begin{tabular}{lll}
\hline Name & Company & Cat-No. \\
\hline anti-Acetyl-Histone H4 & Merck Millipore, Darmstadt, & 06-866 \\
& Germany & \\
anti-Acetyl-Histone H3 (K9) & $\begin{array}{l}\text { Merck Millipore, Darmstadt, } \\
\text { Germany }\end{array}$ & 17-658 \\
anti-Phospho-Histone H3 (S10), clone CMA312 & $\begin{array}{l}\text { Merck Millipore, Darmstadt, } \\
\text { Germany }\end{array}$ & 17-685 \\
anti-Trimethyl-Histone H3 (K4) & Merck Millipore, Darmstadt, & 17-678 \\
& Germany &
\end{tabular}

Table 16: List of primary antibodies for Western blot analysis

\begin{tabular}{lll}
\hline Name & Company & Cat-No. \\
\hline anti-pan Actin (Clone C4) & Kind gift from Dr. James Lessard, & \\
& Cincinnati, USA & \\
anti-Brg-1 (H-88) & SantaCruz, Santa Cruz, USA & sc-10768 \\
anti-GAPDH (14C10) & Cell Signaling, Leiden, Netherlands & 2118 \\
anti-Phospho-Stat1(pS727) & Cell Signaling, Leiden, Netherlands & 9177 \\
anti-Phospho-Stat1 (pY701) (Clone 14/ & Becton Dickinson, Franklin Lakes, & 612132 \\
P-STAT1 (RUO)) & USA & \\
anti-STAT1 $\alpha$ p91 (M-23) & SantaCruz, Santa Cruz, USA & sc-591
\end{tabular}

Table 17: List of primary antibodies for electrophoretic mobility shift assays

\begin{tabular}{lll}
\hline Name & Company & Cat-No. \\
\hline anti-STAT1 $\alpha$ p91 (M-23) & SantaCruz, Santa Cruz, USA & sc-591 \\
anti-STAT3 (H-190) & SantaCruz, Santa Cruz, USA & sc-7179
\end{tabular}


MATERIAL AND METHODS

Table 18: List of secondary antibodies for immunofluorescence staining

\begin{tabular}{|c|c|c|}
\hline Name & Company & Cat-No. \\
\hline Donkey $\mathrm{F}\left(\mathrm{ab} \mathrm{b}^{\prime}\right)_{2}$ anti-Rabbit IgG $(\mathrm{H}+\mathrm{L})$-Alexa Fluor 647 & $\begin{array}{l}\text { Jackson } \\
\text { ImmunoResearch, West } \\
\text { Grove, USA }\end{array}$ & $711-606-152$ \\
\hline Donkey $\mathrm{F}\left(\mathrm{ab} \mathrm{b}^{\prime}\right)_{2}$ anti-Rabbit $\lg \mathrm{G}(\mathrm{H}+\mathrm{L})$-Alexa Fluor 488 & $\begin{array}{l}\text { Jackson } \\
\text { ImmunoResearch, West } \\
\text { Grove, USA }\end{array}$ & $711-546-152$ \\
\hline
\end{tabular}

Table 19: List of secondary antibodies for Western blot analysis

\begin{tabular}{lll}
\hline Name & Company & Cat-No. \\
\hline Donkey IgG anti-Rabbit IgG (H+L)-HRPO & $\begin{array}{l}\text { Jackson ImmunoResearch, West } \\
\text { Grove, USA }\end{array}$ & 711-035-152 \\
Goat IgG anti-Mouse IgG (H+L)-HRPO & $\begin{array}{l}\text { Jackson ImmunoResearch, West } \\
\text { Grove, USA }\end{array}$ & 115-035-003
\end{tabular}

\subsubsection{Plasmids and constructs}

Table 20: List of plasmids and constructs

\begin{tabular}{|c|c|c|}
\hline Name & Description & Company \\
\hline pGL4.27[luc2P/minP/Hygro] & $\begin{array}{l}\text { Luciferase reporter construct. Vector } \\
\text { contains a MCS upstream of a minimal } \\
\text { promoter and the luc } 2 P \text { gene }\end{array}$ & $\begin{array}{l}\text { Promega, Madison, } \\
\text { USA }\end{array}$ \\
\hline pGL27.4-4XGAS-Iuc & $\begin{array}{l}\text { 4-times repeat of the GAS consensus } \\
\text { sequence cloned into pGL } 4.27 \text { vector } \\
\text { (Promega) }\end{array}$ & $\begin{array}{l}\text { ATG Biosynthetics, } \\
\text { Merzhausen, } \\
\text { Germany }\end{array}$ \\
\hline Name & Description & Reference \\
\hline pmCIITAp1.4(WT)-luc & $\begin{array}{l}\text { Mouse ciita full length type IV promoter } \\
(-1404 \text { to }+83 \text { ) fragment cloned into the } \\
\text { luciferase reporter construct pGL3 } \\
\text { (Promega) }\end{array}$ & $\begin{array}{l}\text { (O'Keefe et al., 2001); } \\
\text { Kind gift from Prof. } \\
\text { Joel D. Ernst, New } \\
\text { York }\end{array}$ \\
\hline
\end{tabular}




\begin{tabular}{|c|c|c|}
\hline pSTAT1- $\triangle \mathrm{C}-\mathrm{GFP}$ & $\begin{array}{l}\text { Human STAT1ß (residues } 1 \text { - 712), a STAT1 } \\
\text { splice variant lacking the carboxy-terminal } \\
\text { transactivation domain of STAT1 } \alpha \text {, cloned } \\
\text { into the pEGFP-N1 vector (Clonetech } \\
\text { Laboratories Inc., Mountain View, USA) }\end{array}$ & $\begin{array}{l}\text { (Lödige et al., 2005); } \\
\text { Kind gift from Prof. } \\
\text { Thomas Meyer, } \\
\text { Göttingen, Germany }\end{array}$ \\
\hline pSTAT1- $\triangle N-G F P$ & $\begin{array}{l}\text { Amino-terminally truncated human STAT1 } \alpha \\
\text { (residues } 127 \text { - 747) cloned into the pEGFP- } \\
\text { N1 vector (Clonetech Laboratories Inc., } \\
\text { Mountain View, USA) }\end{array}$ & $\begin{array}{l}\text { (Lödige et al., 2005); } \\
\text { Kind gift from Prof. } \\
\text { Thomas Meyer, } \\
\text { Göttingen, Germany }\end{array}$ \\
\hline pSTAT1-WT-GFP & $\begin{array}{l}\text { Full-length human STAT1 } \alpha \text { protein fused to } \\
\text { green fluorescent protein in carboxy- } \\
\text { terminal orientation and cloned into the } \\
\text { pEGFP-N1 vector (Clontech) }\end{array}$ & $\begin{array}{l}\text { (Begitt et al., 2014); } \\
\text { Kind gift from Prof. } \\
\text { Thomas Meyer, } \\
\text { Göttingen, Germany }\end{array}$ \\
\hline
\end{tabular}

\subsubsection{Cell lines}

Table 21: List of eukaryotic cell lines

\begin{tabular}{|c|c|c|}
\hline Name & Characteristics & Origin \\
\hline L929 & Murine adherent fibroblasts & $\begin{array}{l}\text { Institute for Medical } \\
\text { Microbiology, Göttingen, } \\
\text { Germany }\end{array}$ \\
\hline NIH/3T3-Stat1 $\alpha-G F P$ & $\begin{array}{l}\text { murine adherent NIH/3T3 fibroblasts; } \\
\text { stably transfected with a construct of } \\
\text { Stat1 } \alpha \text { conjugated to GFP }\end{array}$ & $\begin{array}{l}\text { (Köster and Hauser, } \\
\text { 1999); Kind gift from Dr. } \\
\text { M. Köster, Braunschweig, } \\
\text { Germany }\end{array}$ \\
\hline RAW264.7 & $\begin{array}{l}\text { murine adherent leukaemia } \\
\text { monocyte/macrophages (TIB71) }\end{array}$ & ATCC, Rockville MD, USA \\
\hline RAW264.7-CIITApIV.D1-luc & $\begin{array}{l}\text { RAW264.7 stably cotransfected with } \\
\text { pCDNA3.1neo (Invitrogen) and a } \\
\text { construct of }-477 \text { to }+83 \text { of the ciita } \\
\text { promoter IV driving a luciferase gene }\end{array}$ & $\begin{array}{l}\text { (Kincaid and Ernst, 2003); } \\
\text { Kind gift from Prof. } \\
\text { J.D. Ernst, New York, USA }\end{array}$ \\
\hline STAT1 $1^{\mathrm{F} 77 \mathrm{~A} / \mathrm{F} 77 \mathrm{~A}}$ & $\begin{array}{l}\text { murine adherent myocardial fibroblasts; } \\
\text { expressing a mutated STAT1 protein with } \\
\text { a substitution of phenylalanine at } \\
\text { position } 77 \text { to alanine, }\end{array}$ & $\begin{array}{l}\text { Kind gift from Prof. } \\
\text { T. Meyer, Göttingen, } \\
\text { Germany }\end{array}$ \\
\hline
\end{tabular}


MATERIAL AND METHODS

STAT1 ${ }^{\text {WT/WT }}$

U3A
Murine adherent myocardial fibroblasts

human adherent epithelioid fibrosarcoma line; deficient in STAT1 expression and unresponsive to IFN- $y$
Kind gift from Prof.

T. Meyer, Göttingen, Germany

(McKendry et al., 1991); Kind gift from Prof.

T. Meyer, Göttingen, Germany

Table 22: List of Toxoplasma gondii strains

\begin{tabular}{lll}
\hline Name & Characteristics & Origin \\
\hline RH-Toxoplasma gondii & Mouse-virulent strain type I & Sabin (1941), USA; \\
& & (Sabin, 1941) \\
NTE-Toxoplasma gondii & Mouse-avirulent strain type II & Gross (1990), Germany; \\
& & (Gross et al., 1991) \\
CEP-Toxoplasma gondii & Mouse-avirulent strain type III & Parmley (1994), USA; \\
& & (Parmley et al., 1994)
\end{tabular}

Table 23: List of competent bacteria

\begin{tabular}{ll}
\hline Name & Company \\
\hline NEB 5-alpha competent E. coli & New England Biolabs, Ipswich, USA
\end{tabular}

\subsubsection{Software}

Table 24: List of software

\begin{tabular}{lll}
\hline Name & Description & Company \\
\hline CorelDraw 16 & Vector Graphics editor & $\begin{array}{l}\text { Corel Corporation, } \\
\text { Ottawa, Canada }\end{array}$ \\
& & \\
Fiji & Ad-on to ImageJ software with focus & Public domain, ad-on \\
& on biological-image analysis & to ImageJ (Schindelin \\
& & et al., 2012) \\
Geneious 11.1.4 & Analysis and organisation software & Biomatters, Auckland, \\
& for sequence data & New Zealand
\end{tabular}


MATERIAL AND METHODS

\begin{tabular}{|c|c|c|}
\hline ImageJ & $\begin{array}{l}\text { Java-based image processing } \\
\text { program }\end{array}$ & $\begin{array}{l}\text { Public domain, } \\
\text { developed at NIH by } \\
\text { Wayne Rasband } \\
\text { (Schneider et al., 2012) }\end{array}$ \\
\hline Image Reader LAS-4000 2.0 & $\begin{array}{l}\text { Operating and analysis software for } \\
\text { LAS- } 4000\end{array}$ & Fujifilm, Tokyo, Japan \\
\hline $\begin{array}{l}\text { Leica Confocal Software (1997 - } \\
\text { 2004) }\end{array}$ & $\begin{array}{l}\text { Operating and analysis software for } \\
\text { TCS SPII }\end{array}$ & $\begin{array}{l}\text { Leica Microsystems, } \\
\text { Heidelberg, Germany }\end{array}$ \\
\hline LightCycler Software 3.5 & $\begin{array}{l}\text { Operating and analysis software for } \\
\text { LightCycler } 1.5\end{array}$ & $\begin{array}{l}\text { Roche, Basel, } \\
\text { Switzerland }\end{array}$ \\
\hline Microsoft Excel & Spreadsheet analysis program & $\begin{array}{l}\text { Microsoft Corporation, } \\
\text { Redmond, USA }\end{array}$ \\
\hline Nanodrop 2000/2000c & $\begin{array}{l}\text { Operating and analysis software for } \\
\text { Nanodrop 2000c }\end{array}$ & $\begin{array}{l}\text { Thermo Fischer, } \\
\text { Waltham, USA }\end{array}$ \\
\hline Quantity One 4.6 & $\begin{array}{l}\text { Operating and analysis software for } \\
\text { GelDoc XRS }\end{array}$ & Bio Rad, Hercules, USA \\
\hline SigmaPlot & Graphics software & $\begin{array}{l}\text { Systat Software GmbH, } \\
\text { Erkrath, Germany }\end{array}$ \\
\hline Statistica 13 & Statistics software & $\begin{array}{l}\text { StatSoft, Hamburg, } \\
\text { Germany }\end{array}$ \\
\hline Wallac 1240 workstation3.0 & $\begin{array}{l}\text { Operating and analysis software for } \\
\text { VICTOR }^{3} \vee 1420\end{array}$ & $\begin{array}{l}\text { Perkin Elmer, } \\
\text { Waltham, USA }\end{array}$ \\
\hline
\end{tabular}

\subsection{Methods}

\subsubsection{Cell culture}

All cell culture work was performed under strict sterile conditions in Class II Biosafety Laboratories. The maintenance of cell lines and T. gondii strains was carried out in a humidified $5 \% \mathrm{CO}_{2}$ atmosphere at $37^{\circ} \mathrm{C}$.

\subsubsection{Maintenance of established cell lines} L929

Murine L929 fibroblasts were cultured in 6-well cell culture plates and were used as host cells for routine propagation of $T$. gondii tachyzoites. The subculturing of confluent monolayers was performed twice a 
week. To this end, the adherent cells were scraped off into the growth medium, resuspended, and a fraction was transferred to each well of a new 6-well plate to obtain the desired cell density. Cells were cultured in DMEM medium supplemented with $100 \mathrm{U} / \mathrm{ml}$ Penicillin, $100 \mathrm{\mu g} / \mathrm{ml}$ Streptomycin, 1\% (v/v) heat-inactivated FCS, 1 mM sodium pyruvate and $1 \mathrm{X}$ non-essential amino acids.

\section{RAW264.7}

RAW264.7 cells are a murine monocyte/macrophage cell line. The subculturing of sub-confluent (70 - 80\%) cultures was performed two to three times a week in $75 \mathrm{~cm}^{2}$ cell culture flasks. To this end, the adherent cells were scraped off into the growth medium, resuspended, and a fraction was transferred to new culture flasks to obtain the desired cell density. Cells were cultured in RPMI medium supplemented with $100 \mathrm{U} / \mathrm{ml}$ Penicillin, $100 \mu \mathrm{g} / \mathrm{ml}$ Streptomycin, 10\% (v/v) heat-inactivated FCS, 1 mM sodium pyruvate, additional 2,5 g/l D-(+)-glucose and 10 mM HEPES pH 7.2.

RAW264.7-mCIITApIV.D1-luc cells, stably transfected with a luciferase reporter construct under control of nucleotides -477 to +83 of the ciita promoter IV (Kincaid and Ernst, 2003), were cultured as described above. To constantly select for transfectants, the culture medium was additionally supplemented with $400 \mu \mathrm{g} / \mathrm{ml} \mathrm{G} 418$.

\section{NIH/3T3-STAT1 $\alpha-G F P$}

The NIH/3T3-Stat1 $\alpha$-GFP cell line are murine fibroblasts stably transfected with a construct of STAT1 $\alpha$ conjugated to GFP (Köster and Hauser, 1999). The subculturing of sub-confluent (70 - 80\%) cultures was performed two to three times a week. To this end, the growth medium was removed, and the adherent cells were rinsed with $1 \%(\mathrm{w} / \mathrm{v})$ EDTA. Thereafter, cells were detached by incubation in $0.25 \%(\mathrm{w} / \mathrm{v})$ trypsin. The proteolytic reaction was stopped by adding pre-warmed culture medium. After collecting the cells, they were sedimented for 5 minutes at $400 \times \mathrm{g}$. The cells were then resuspended in culture medium and a fraction was transferred to new culture flasks to obtain the desired cell density. NIH/3T3Stat1 $\alpha$-GFP cells were cultured in DMEM medium supplemented with $100 \mathrm{U} / \mathrm{ml}$ Penicillin, $100 \mu \mathrm{g} / \mathrm{ml}$ Streptomycin, 10\% (v/v) heat-inactivated FCS, 1 mM sodium pyruvate and $1 \mathrm{X}$ non-essential amino acids. To constantly select for transfectants, the culture medium was additionally supplemented with $2.5 \mu \mathrm{g} / \mathrm{ml}$ puromycin.

\section{U3A}

U3A cells are mutated human fibroblasts, which are deficient for STAT1 expression and unresponsive to IFN- $\gamma$ (McKendry et al., 1991). The subculturing of sub-confluent (70 - 80\%) cultures was performed two to three times a week as described above for NIH/3T3-STAT1 $\alpha$-GFP cells. U3A cells were cultured in DMEM medium supplemented with $100 \mathrm{U} / \mathrm{ml}$ Penicillin, $100 \mathrm{\mu g} / \mathrm{ml}$ Streptomycin and 10\% (v/v) heat- 
inactivated FCS. To constantly select for mutants, the culture medium was additionally supplemented with $0.04 \mu \mathrm{g} / \mathrm{ml}$ puromycin.

\section{STAT1-WT and STAT1-F77A fibroblasts}

The STAT1-F77A cells are murine mutated myocardial fibroblasts. STAT1-F77A cells express a mutated STAT1 protein with a substitution of phenylalanine at position 77 to alanine, which is deficient for cooperative DNA binding. The STAT1-WT cells are murine wildtype myocardial fibroblasts. The subculturing of sub-confluent (70 - 80\%) cultures was performed two to three times a week as described above for NIH/3T3-STAT1 $\alpha$-GFP cells. STAT1-WT and STAT1-F77A cells were cultured in DMEM medium supplemented with $100 \mathrm{U} / \mathrm{ml}$ Penicillin, $100 \mu \mathrm{g} / \mathrm{ml}$ Streptomycin and 10\% (v/v) heat-inactivated FCS.

\subsubsection{Harvesting of cells}

RAW264.7-, NIH/3T3-, U3A-, STAT1 ${ }^{\text {WT/WT }}$ and STAT1 ${ }^{\text {F77A/F77A }}$ cells were scraped off or enzymatically detached as described above. Thereafter, cells were sedimented by centrifugation at $400 \times \mathrm{g}$ for 5 minutes and were washed once with the respective pre-warmed culture medium. To determine the number of viable cells, a cell suspension aliquot was stained with an equal volume of $0.1 \%(\mathrm{w} / \mathrm{v})$ trypan blue. The mixture was subjected to cell counting using a Neubauer haemocytometer grid.

\subsubsection{In vitro cultivation of $T$. gondii tachyzoites}

For most of the experiments the T. gondii strain NTE, a European clinical isolate belonging to the clonal type II was used. Some experiments included also the strains RH (type I) and CEP (type III). For routine propagation of T. gondii, L929 host cells were harvested twice a week, distributed into the wells of a 12well cell culture plate and infected with extracellular tachyzoites from previous L929/T. gondii cocultures after initiation of host cells lysis. Co-cultures were incubated in RPMI medium supplemented with $100 \mathrm{U} / \mathrm{ml}$ Penicillin, $100 \mathrm{\mu g} / \mathrm{ml}$ Streptomycin and 1\%(v/v) heat-inactivated FCS. To constantly provide viable parasites for experimental infections, L929 cells and T. gondii tachyzoites were mixed at different parasite to host cell ratios. Depending on the ratio, parasite egress and host cell lysis were nearly completed about 5 to 12 days after infection.

\subsubsection{Harvesting of $T$. gondii tachyzoites}

For infection assays, viable and infectious, extracellular tachyzoites were isolated from appropriate L929/T. gondii co-cultures. To this end, contaminating host cells and host cell debris were separated from parasites by centrifugation for 5 minutes at $35 \times \mathrm{g}$. After transferring the parasite-containing supernatant into a new centrifuge tube, tachyzoites were sedimented by centrifugation for 10 minutes at $1300 \times \mathrm{g}$ and washed once with pre-warmed culture medium of those host cells to be infected. To determine the parasite density, a suspension aliquot was subjected to tachyzoite counting using a Neubauer haemocytometer grid. 


\subsubsection{Thawing of established cell lines}

To thaw cells, a cryopreserved sample was taken out from liquid nitrogen storage $\left(-196^{\circ} \mathrm{C}\right)$ and immediately thawed in a water bath at $37^{\circ} \mathrm{C}$. The nearly liquid content was transferred into pre-warmed culture medium and centrifuged for 5 minutes at $400 \times \mathrm{g}$. The cells were resuspended in culture medium, transferred to suitable culture vessels and were allowed to grow.

\subsubsection{Freezing of cell lines}

For the cryopreservation of cells, $1 \times 10^{7} / \mathrm{ml}$ isolated cells were mixed with an equal volume of freezing medium (40\% (v/v) culture medium, 40\% (v/v) heat-inactivated FCS, 20\% (v/v) DMSO). The cells were transferred into cryovials and frozen in a two-step process: first, a gradual freezing in a $-80^{\circ} \mathrm{C}$ freezer overnight, followed by transfer and final storage in liquid nitrogen $\left(-196^{\circ} \mathrm{C}\right)$.

\subsubsection{Transient transfection of cultured cells with plasmid DNA}

To evaluate the impact of $T$. gondii on transcriptional activation of different IFN- $\gamma$-responsive promoters, RAW264.7 cells were transiently transfected with specific luciferase reporter constructs. A chemical transfection procedure was employed using the X-treme GENE HP DNA Transfection Reagent (ROCHE) according to the manufacturer's recommendation. Preliminary experiments were performed to determine the optimal ratio of plasmid DNA ( $p D N A)$ to transfection reagent and incubation periods.

For the transfection of cells in a well of a 6 well plate, $2 \mu \mathrm{g}$ of pDNA were diluted in $100 \mu \mathrm{l} \mathrm{RPMI}$ medium without supplements. The transfection complex was formed by adding $6 \mu \mathrm{l}$ of transfection reagent and vigorous mixing for 2 seconds. Optimal transfection reagent-to-DNA complex formation was determined after incubation for 15 minutes. Twenty-four hours prior to transfection, 1 × 10 RAW264.7 cells had been allowed to adhere and to grow in each well of a 6 -well plate. Immediately prior to transfection, the culture medium was replaced by $2 \mathrm{ml}$ fresh culture medium and the transfection complex was added to the cells in a drop-wise manner. Thereafter, cells were incubated for 8 hours at $37^{\circ} \mathrm{C}$. The cells were then scraped off and equal numbers of cells were transferred to wells of a 12-well plate. The transiently transfected cells were allowed to recover for 12 hours at $37^{\circ} \mathrm{C}$ before being experimentally treated as specified in the result section and subsequent luciferase assay (see section 2.2.7).

In order to determine which regions of STAT1 contribute to the formation of non-canonical GAF complexes, U3A cells were transiently transfected with specific STAT1-constructs. To this end, a chemical transfection procedure was employed using the MegaTran 1.0 transfection reagent (Origene) according to the manufacturer's recommendation. For the transfection of cells in a well of a 6 well plate, $1.6 \mu \mathrm{g}$ of pDNA were diluted in $160 \mu 150 \mathrm{mM} \mathrm{NaCl}$. The transfection complex was formed by adding $4.8 \mu \mathrm{l}$ of transfection reagent and vigorous mixing. Optimal transfection reagent-to-DNA complex formation was determined after incubation for 10 minutes. The transfection complex was added to cells 
that had grown to $50-70 \%$ confluence. The cells were cultured for 24 hours before being subjected to IFN- $\gamma$ stimulation and subsequent protein extraction.

\subsubsection{Protein biochemistry}

\subsubsection{Preparation of complete host cell protein extracts}

For determining the impact of $T$. gondii infection on the expression and activation of STAT1, complete host cell protein extracts were prepared. To this end, two different methods were applied. To solubilise and isolate proteins, a lysis buffer with mild detergent was used. Briefly, after experimental treatment of cells as specified in the results section, cells were harvested and washed with ice-cold wash buffer (1 $\mathrm{mM} \mathrm{Na}_{3} \mathrm{VO}_{4}$ in PBS). After centrifugation for 5 minutes at $400 \mathrm{xg}$ at $4^{\circ} \mathrm{C}$ and resuspension in a defined volume of $1 \mathrm{mM} \mathrm{Na}_{3} \mathrm{VO}_{4}$ in PBS, the number of viable cells was determined using a haemocytometer grid. After centrifugation, cells were then resuspended at $7.5 \times 10^{4}$ cells $/ \mu$ l of ice-cold lysis buffer ( $1 \%$ (v/v) Triton X-100, $0.15 \mathrm{M} \mathrm{NaCl}, 50 \mathrm{mM}$ Tris $\mathrm{pH} 8,50 \mathrm{mM} \mathrm{NaF}, 5 \mathrm{mM}$ sodium pyrophosphate, $1 \mathrm{mM}$ PMSF, $1 \mathrm{mM} \mathrm{Na} \mathrm{VO}_{4}, 5 \mathrm{\mu g} / \mathrm{ml}$ pepstatin, $1 \mu \mathrm{g} / \mathrm{ml}$ leupeptin, $5 \mathrm{\mu g} / \mathrm{ml}$ aprotinin, $1 \mathrm{mM}$ EDTA pH 8) and incubated for 1 hour on ice. During incubation, samples were vigorously vortexed every 15 minutes. After centrifugation for 5 minutes at $12,000 \times \mathrm{g}$ at $4^{\circ} \mathrm{C}$, the supernatants were stored as complete cell protein extracts at $-80^{\circ} \mathrm{C}$ until further use.

Alternatively, complete cell protein extracts were prepared by cell sonoporation in harsh detergentcontaining buffer. Briefly, after experimental treatment of cells as specified in the results section, cells were harvested and washed with ice-cold wash buffer (1 $\mathrm{mM} \mathrm{Na}_{3} \mathrm{VO}_{4}$ in PBS). After centrifugation for 5 minutes at $400 \times \mathrm{g}$ at $4^{\circ} \mathrm{C}$ and resuspension in a defined volume of PBS, $1 \mathrm{mM} \mathrm{Na}_{3} \mathrm{VO}_{4}$, the number of viable cells was determined using a haemocytometer grid. Cells were centrifuged for 30 seconds at $12,000 \times \mathrm{g}$ at $4^{\circ} \mathrm{C}$ and then resuspended at $4 \times 10^{4}$ in SDS-sample buffer $(62.5 \mathrm{mM}$ Tris $\mathrm{pH} 6.8,6 \%(\mathrm{v} / \mathrm{v})$ glycerol, $0.5 \%(\mathrm{w} / \mathrm{v}) \mathrm{DTT}, 2 \%(\mathrm{w} / \mathrm{v}) \mathrm{SDS}, 0.01 \%(\mathrm{w} / \mathrm{v})$ bromophenol blue) supplemented with $1 \mathrm{mM}$ $\mathrm{Na}_{3} \mathrm{VO}_{4}$. To effectively disrupt the cells, samples were placed in ice-water slurry supplemented with common table salt and subjected to sonication (Branson Sonifier 250). The impulse was applied for 15 seconds with a duty cycle of $30 \%$ and an output level of 1 . Thereafter, the samples were stored at $-80^{\circ} \mathrm{C}$. Prior to protein separation by SDS-PAGE (see section 2.2.2.3), samples were denatured for 5 minutes at $99^{\circ} \mathrm{C}$ and centrifuged for 5 minutes at $14,000 \times g$ at $4^{\circ} \mathrm{C}$.

\subsubsection{Preparation of cytosolic and nuclear protein fractions}

To analyse the impact of T. gondii infection on the subcellular distribution of STAT1 and the DNA binding activity of nuclear STAT1, cytosolic and nuclear protein fractions were prepared. 
In most of the experiments, cells were fractionated as described previously (Lang et al., 2012) with slight modifications. Briefly, after experimental treatment of cells as specified in the results section, cells were harvested and washed with ice-cold wash buffer (0.1 $\mathrm{mM} \mathrm{Na}_{3} \mathrm{VO}_{4}$ in PBS). After centrifugation for 5 minutes at $400 \times \mathrm{g}$ at $4^{\circ} \mathrm{C}$ and resuspension in a defined volume of $1 \mathrm{mM} \mathrm{Na}_{3} \mathrm{VO}_{4}$ in PBS, the number of viable cells was determined using a haemocytometer grid. For Western blot analysis cells were resupended at $4 \times 10^{4}$ cells $/ \mu$ in ice-cold lysis buffer $(10 \mathrm{mM} \mathrm{HEPES} \mathrm{pH} \mathrm{7.8,} 10 \mathrm{mM} \mathrm{KCl}, 2 \mathrm{mM} \mathrm{MgCl}$, $1 \mathrm{mM}$ DTT, $0.1 \mathrm{mM}$ EDTA, $0.1 \mathrm{mM}$ PMSF, $0.1 \mathrm{mM} \mathrm{Na}_{3} \mathrm{VO}_{4}$ ) and for EMSA experiments at $7 \times 10^{4}$ cells $/ \mu \mathrm{l}$. The samples were then incubated 15 minutes on ice before adding $0.6 \%(\mathrm{v} / \mathrm{v})$ Nonidet-P40. Thereafter, samples were vigorously mixed and complete cell lysis was confirmed microscopically by staining a sample aliquot with an equal volume of $0.1 \%(\mathrm{w} / \mathrm{v})$ trypan blue. After centrifugation for 30 seconds at $12.000 \times \mathrm{g}$ at $4^{\circ} \mathrm{C}$, the supernatant was stored as cytosolic protein fraction at $-80^{\circ} \mathrm{C}$ or in case of EMSA experiments was discarded. The pellet containing nuclei and other larger organelles was washed with lysis buffer. Finally, for Western blotting analysis cells were resuspended at $2 \times 10^{5}$ cells $/ \mu \mathrm{l}$ in ice-cold nuclear protein extraction buffer (50 mM HEPES, $50 \mathrm{mM} \mathrm{KCl,} 300 \mathrm{mM} \mathrm{NaCl}, 1 \mathrm{mM}$ DTT, $0.1 \mathrm{mM}$ EDTA, $0.1 \mathrm{mM}$ PMSF, $0.1 \mathrm{mM} \mathrm{Na}_{3} \mathrm{VO}_{4}$ ) and for EMSA experiments at $5 \times 10^{5}$ cells $/ \mu$ l. After incubation for 20 minutes at $4^{\circ} \mathrm{C}$ under constant rotation, the samples were centrifuged for 5 minutes at $12.000 \times \mathrm{g}$ at $4^{\circ} \mathrm{C}$. The supernatant was stored as nuclear protein fraction at $-80^{\circ} \mathrm{C}$.

For experiments with protein extracts from STAT1-reconstituted U3A cells, subcellular fractionation was modified and performed as described previously (Riebeling et al., 2014). Briefly, after experimental treatment of cells as specified in the results section, cells from a well of a 6 well plate were rinsed twice with PBS and directly lysed for 5 minutes in the cell culture vessel using $60 \mu \mathrm{l}$ ice-cold cytosolic protein extraction buffer (20 mM HEPES, $10 \mathrm{mM} \mathrm{KCl}, 1 \mathrm{mM}$ EDTA, $0.1 \mathrm{mM} \mathrm{Na}_{3} \mathrm{VO}_{4}, 10 \%$ glycerol, 0.1\% IGEPAL CA-630, 1X protease inhibitor cocktail (Roche), 3 mM DTT and $0.4 \mathrm{mM}$ Pefabloc (Roche), pH 7.4). Cells were then scraped off and centrifuged for 15 seconds at $16,100 \times \mathrm{g}$ at $4^{\circ} \mathrm{C}$ to pellet heavy organelles including nuclei. After transferring the supernatant into a new tube, it was further cleared by centrifugation for 5 minutes at $16,100 \times \mathrm{g}$ at $4^{\circ} \mathrm{C}$ and collected as cytosolic protein fraction. The pelleted nuclei were then incubated in $60 \mu$ l of ice-cold nucleic protein extraction buffer ( $20 \mathrm{mM} \mathrm{HEPES}, 420 \mathrm{mM}$ $\mathrm{KCl}, 1 \mathrm{mM}$ EDTA, $0.1 \mathrm{mM} \mathrm{Na}_{3} \mathrm{VO}_{4}, 20 \%$ glycerol, $1 \mathrm{X}$ protease inhibitor cocktail, $3 \mathrm{mM} \mathrm{DTT}, 0.4 \mathrm{mM}$ Pefabloc, pH 7.4) for 30 minutes on ice. The extract was then centrifuged for 15 minutes at $16,100 \times \mathrm{g}$ at $4^{\circ} \mathrm{C}$ and the supernatant collected as nuclear protein fraction. Finally, cytosolic and nuclear fractions were pooled as complete cell protein extract and stored at $-80^{\circ} \mathrm{C}$ until further use.

\subsubsection{SDS-polyacrylamide gel electrophoresis}

Proteins in cell lysates and in oligonucleotide-precipitated samples were separated according to their size by means of SDS-polyacrylamide gel electrophoresis (SDS-PAGE). 
To this end, two types of gels were combined, which differed in their pore size. First, the separating gel solution $(0.375 \mathrm{M}$ Tris pH 8.8, 0.2\% (w/v) SDS, 10\% (v/v) acrylamide/ 0.27\% (v/v) bisacrylamide, $0.04 \%(\mathrm{w} / \mathrm{v})$ APS and $0.2 \%(\mathrm{v} / \mathrm{v})$ TEMED) was poured into a vertical gel cassette. The gel was carefully overlaid with isopropanol and allowed to completely polymerise. After removing the isopropanol and rinsing the gel surface with water, the stacking gel solution $(0.125 \mathrm{M}$ Tris $\mathrm{pH} 6.8,0.2 \% \mathrm{SDS}, 5 \%(\mathrm{v} / \mathrm{v})$ acrylamide/ $0.13 \%(\mathrm{v} / \mathrm{v})$ bisacrylamide, $0.04 \%(\mathrm{w} / \mathrm{v})$ APS, $0.4 \%(\mathrm{v} / \mathrm{v})$ TEMED and $0.01 \%(\mathrm{w} / \mathrm{v})$ bromophenol blue) was poured onto the separating gel and a comb was inserted.

Protein extracts were mixed with SDS-sample buffer to a final concentration of $62.5 \mathrm{mM}$ Tris pH 6.8, 6\% $(\mathrm{v} / \mathrm{v})$ glycerol, $0.5 \%(\mathrm{w} / \mathrm{v})$ DTT, $2 \%(\mathrm{w} / \mathrm{v})$ SDS and $0.01 \%(\mathrm{w} / \mathrm{v})$ bromophenol blue and were denaturated for 5 minutes at $95^{\circ} \mathrm{C}$. Pre-stained marker proteins were likewise treated in parallel. Proteins were then separated at $25 \mathrm{~mA}$ per gel $(8 \mathrm{~cm}$ wide, $0.75 \mathrm{~mm}$ thick) in SDS-running buffer $(25 \mathrm{mM}$ Tris, $192 \mathrm{mM}$ glycine, $0.1 \%(\mathrm{w} / \mathrm{v}) \mathrm{SDS}, \mathrm{pH} 8.3$ - $\mathrm{pH} 8.5)$ until the dye front reached the end of the gel.

\subsubsection{Western blotting and immunostaining}

Western blot analysis was used to identify and analyse specific proteins in cell lysates and in oligonucleotide-precipitated protein samples.

After separation by SDS-PAGE (see section 2.2.2.3), proteins were therefore transferred from the polyacrylamide gel onto a nitrocellulose (NC) membrane. The electro-transfer was carried out using a semi-dry blotting device. To this end, a transfer sandwich was assembled in the following order (from anode to cathode): 6 Whatman filter papers (soaked in $0.3 \mathrm{M}$ Tris pH 10.4 and 20\% (v/v) methanol), 3 Whatman filter papers (soaked in $25 \mathrm{mM}$ Tris pH 10.4 and 20\% (v/v) methanol), NC membrane (soaked in $25 \mathrm{mM}$ Tris pH 10.4 and 20\% (v/v) methanol), SDS-polyacrylamid gel and 9 Whatman filter papers (soaked in 40 mM 6-aminocapronic acid pH 7.6 and 20\% (v/v) methanol). The transfer was performed for 90 minutes at $0.8 \mathrm{~mA}$ per $\mathrm{cm}^{2}$ of gel. Afterwards, proteins were stained unspecifically using Ponceau S to control the transfer efficacy. Unspecific binding sites on the NC membrane were then blocked for 1.5 hours with 5\% (w/v) skimmed milk in TBST (0.9\% (w/v) NaCl, $10 \mathrm{mM}$ Tris, 0.1\% (v/v) Tween-20, pH 7.4). Thereafter, the blot was washed with TBST before being incubated with the primary antibody (Table 25) overnight at $4^{\circ} \mathrm{C}$. After having been washed repeatedly with TBST for 5, 10 and 20 minutes, the membrane was then incubated with the appropriate horseradish peroxidase (HRP)conjugated secondary antibody (Table 26) for 1.5 hours. Thereafter, the membrane was washed two times in TBST for 10 minutes each and once for 20 minutes. All washing and incubation steps were carried out under gentle shaking. Enhanced chemiluminescence (ECL) detection (Amersham GE Healthcare) was used to detect bound antibodies. To this end, the ECL detection reagent was prepared as recommended by the manufacturer and poured onto the membrane. After 1 minute, superfluous solution was removed and the membrane was covered with transparent foil. Chemiluminescence was detected using the LAS-4000 (FUJIFILM) gel documentation device and the Image Reader LAS-4000 
software. To subsequently detect another specific protein on the same membrane, bound antibodies were stripped off from the blot. To this end, the membrane was washed in $\mathrm{ddH}_{2} \mathrm{O}$ for 5 minutes, then incubated in $0.2 \mathrm{mM} \mathrm{NaOH}$ for 5 minutes and washed again twice with $\mathrm{dd}_{2} \mathrm{O}$. After re-blocking, the membrane was re-probed with another primary antibody.

Table 25: Primary antibody solutions for Western blot analysis

\begin{tabular}{|c|c|c|}
\hline Antibody & Dilution concentration & Incubation buffer \\
\hline Mouse anti-pan Actin (Clone C4) & $1: 5000$ & $5 \%$ BSA (w/v) in TBST, pH 7.4 \\
\hline Rabbit anti-Brg-1 (H-88) & $2 \mu \mathrm{g} / \mathrm{ml}$ & $5 \%$ BSA (w/v) in TBST, pH 7.4 \\
\hline Rabbit anti-GAPDH (14C10) & 1:1000 & $5 \%$ BSA (w/v) in TBST, pH 7.4 \\
\hline Rabbit anti-phospho-Stat1(pS727) & 1:1000 & $5 \%$ BSA (w/v) in TBST, pH 7.4 \\
\hline Mouse anti-phospho-Stat1 (pY701) & $0.5 \mu \mathrm{g} / \mathrm{ml}$ & $1 \%$ BSA (w/v), $10 \mathrm{mM}$ Tris, $0.1 \mathrm{M}$ \\
\hline (Clone 14/P-STAT1 (RUO)) & & $\mathrm{NaCl}, 0.1 \%(\mathrm{v} / \mathrm{v})$ Tween-20, pH 7.4 \\
\hline Rabbit anti-STAT1 $\alpha$ p91 (M-23) & $1 \mu \mathrm{g} / \mathrm{ml}$ & $5 \%$ BSA (w/v) in TBST, pH 7.4 \\
\hline
\end{tabular}

Table 26: Secondary antibody solutions for Western blot analysis

\begin{tabular}{lll}
\hline Antibody & Dilution concentration & Incubation buffer \\
\hline Donkey IgG anti-Rabbit IgG (H+L)-HRPO & $1: 2000$ & $\begin{array}{l}\text { The incubation solution always } \\
\text { corresponded to the primary } \\
\text { antibody's one. }\end{array}$
\end{tabular}

\subsubsection{Nucleic acid analysis}

\subsubsection{Plasmid amplification}

For amplification of plasmid constructs, chemically competent bacteria NEB5-alpha (NEB), a derivate of the E.coli strain $\mathrm{DH} 5 \alpha$, were transformed by means of heat-shock technique according to the manufacturer's instructions. To this end, a $50 \mu$ l batch of bacteria was thawed on ice and incubated with up to $100 \mathrm{ng}$ of pDNA for 30 minutes on ice before being exposed to heat-shock for 30 seconds at $42^{\circ} \mathrm{C}$. After incubation for 5 minutes on ice, bacteria were mixed with SOC complex growth medium (provided by the manufacturer) and incubated for 60 minutes at $37^{\circ} \mathrm{C}$ and rotation at $250 \mathrm{rpm}$. Thereafter, 
bacteria (in appropriately diluted suspension) were plated on a pre-warmed LB-agar plate $(10 \mathrm{~g} / \mathrm{l}$ tryptone, $5 \mathrm{~g} / \mathrm{l}$ yeast extract, $5 \mathrm{~g} / \mathrm{l} \mathrm{NaCl}, 15 \mathrm{~g} / \mathrm{l}$ agar agar), containing $100 \mathrm{\mu g} / \mathrm{ml}$ ampicillin as antibiotic selection marker and incubated overnight at $37^{\circ} \mathrm{C}$. Five $\mathrm{ml}$ LB-medium $(10 \mathrm{~g} / \mathrm{l}$ tryptone, $5 \mathrm{~g} / \mathrm{l}$ yeast extract, $5 \mathrm{~g} /(\mathrm{NaCl}$ ), supplemented with $100 \mu \mathrm{g} / \mathrm{ml}$ ampicillin, were then inoculated with cells from a single colony and incubated overnight at $37^{\circ} \mathrm{C}$. An aliquot was mixed with an equal volume of $30 \%(\mathrm{v} / \mathrm{v})$ glycerol in LB-medium and frozen as bacterial glycerol stock at $-80^{\circ} \mathrm{C}$. The remaining cells were pelleted by centrifugation for 1 minute at $12,000 \times \mathrm{g}$ and directly subjected to plasmid isolation using the GenELute Plasmid Miniprep Kit (Sigma Aldrich) according to the manufacturer's instructions. Briefly, cells were carefully resuspended in resuspension solution, mixed with lysis solution and incubated for 5 minutes. Thereafter, cell debris and contaminants were precipitated by adding neutralization/binding solution and was pelleted by centrifugation for 10 minutes at $12,000 \mathrm{x}$. Prior to transferring the lysate, a binding column was equilibrated with colum preparation solution. After loading the sample, the column was centrifuged for 1 minute at 12,000 $\mathrm{xg}$ and was then washed with wash solution. Finally, the DNA was eluted with $50 \mathrm{mM}$ Tris $\mathrm{pH} 8$ by centrifugation for 1 minute at 12,000 $\mathrm{xg}$ and was stored at $20^{\circ} \mathrm{C}$ until further use.

\subsubsection{Spectrophotometric analysis of nucleic acids}

To assess the quantity and purity of nucleic acids in solutions, samples were analysed using the microvolume spectrophotometer NanoDrop2000c (Thermo Fisher Scientific) according to the manufacturers' instructions. The absorbance at $260 \mathrm{~nm}$ was measured and allowed calculation of the concentration of dsDNA and RNA. To guarantee nucleic acid quality for downstream applications, its purity was assessed by calculating the ratio between the absorbance at $280 \mathrm{~nm}$ and $260 \mathrm{~nm}$. A value of $\sim 2.0$ was considered as reference value for 'pure' RNA and $~ 1.8$ was accepted as 'pure' DNA.

\subsubsection{Agarose gel electrophoresis}

Nucleic acids were separated according to size by means of agarose gel electrophoresis. To this end, an agarose gel solution was prepared by solubilising agarose in TAE (40 mM Tris, 1\% (v/v) acetic acid, $1 \mathrm{mM}$ EDTA pH 8) by brief boiling. After adding $0.005 \%$ (v/v) Midori Green (NIPPON GENETICS), the agarose solution was poured into a horizontal gel chamber and a comb was inserted. Depending on the nucleic acid sizes to be examined, agarose concentration differed between $1 \%(\mathrm{w} / \mathrm{v})$ for separation of 1 - $10 \mathrm{~kb}$ fragments and up to $2 \%(\mathrm{w} / \mathrm{v})$ for smaller molecules. After polymerization of the gel, samples were mixed with concentrated loading dye, loaded onto the gel and were run at $110 \mathrm{~V}$. Nucleic acids were detected at $260 \mathrm{~nm}$ using the 'Universal Hood II' Molecular Imager Gel Doc System (BIO-RAD) and the Quantity One-4.6.8 software. 


\subsubsection{Preparation of total RNA}

In order to analyse the impact of $T$. gondii on IFN- $\gamma$-induced transcriptional regulation in wild type and mutant STAT1-F77A fibroblasts, total RNA was isolated using the GenElute Mammalian Total RNA kit (Sigma Aldrich) according to the manufacturers' instructions. To digest any contaminating DNA, the isolated RNA samples were further treated with DNase using the Amplification Grade DNase I Kit (Sigma Aldrich).

Briefly, after experimental treatment of cells as specified in the results section, cells were rinsed with PBS and lysed directly in the cell culture vessel. To irreversible denature RNases, the lysis buffer was supplemented with 2-mercaptoethanol at 1:100 (v/v). After incubation for 1 to 2 minutes, the lysate was filtered through a filtration column by centrifuging the samples for 2 minutes at $14,000 \times \mathrm{g}$. The flow-through was then mixed with an equal volume of $70 \%$ ethanol, transferred to a silica resincontaining binding column and was centrifuged for 15 seconds at 14,000 x g. The silica column was then washed once with wash solution 1 and twice with wash solution 2. Centrifugations were carried out for 15 seconds at $14,000 \times$ g. Finally, the binding column was additionally centrifuged for 1 minute to remove all ethanol traces. The RNA was eluted with elution solution and directly subjected to DNase I digestion. To this end, $1 / 10$ volume of $10 \mathrm{X}$ Reaction buffer and $1 / 10$ volume of DNase I $(1 \mathrm{U} / \mu \mathrm{l})$ were mixed with each sample. After incubation for 15 minutes, 1/10 volume of stop solution was added. The samples were heated for 10 minutes at $70^{\circ} \mathrm{C}$ and immediately stored at $-80^{\circ} \mathrm{C}$ or used for downstream applications.

\subsubsection{Reverse transcription}

Messanger (m)RNA was reverse transcribed into cDNA using the Omniscript reverse transcriptase kit (Qiagen) according to the manufacturers' instructions. In a total reaction volume of $20 \mu \mathrm{l}$, up to $2 \mu \mathrm{g}$ isolated total RNA were mixed with $0.5 \mathrm{mM}$ of each dNTPs, $1 \mu \mathrm{M}$ oligo-dT primer and $4 \mathrm{U}$ Omniscript reverse transcriptase in RT buffer. The reaction mixture was additionally supplemented with $10 \mathrm{U}$ of RNase inhibitor (Promega). Reverse transcription of the mRNA template was carried out for 90 minutes at $37^{\circ} \mathrm{C}$. Newly synthesised cDNA was then stored at $-20^{\circ} \mathrm{C}$ until further use.

\subsubsection{DNA sequencing}

DNA sequences were verified by the DNA Sanger sequencing method, which was conducted by SeqLab (Sequence Laboratories, Göttingen, Germany). DNA and sequencing primer were provided at amounts and concentrations as recommended by the company.

\subsubsection{CpG island prediction}

In order to predict $\mathrm{CPG}$ islands in distinct IFN- $\psi$-responsive promoters, the sequences of the DNA regions -200 to +1 and +1 to +200 upstream or downstream of the transcriptional start site, respectively, were retrieved from the DataBase of Transcriptional Start Sites (Yamashita et al., 2012). CpG-rich regions 
were then predicted in silico with the online tool CpG Island Searcher (Takai and Jones, 2003). Thresholds for identifying a $\mathrm{CpG}$ island were set as region of at least $100 \mathrm{bps}$, an observed $\mathrm{CpG} /$ expected $\mathrm{CpG}$ ratio greater than 0.60 , and a GC content of more than $50 \%$.

\subsubsection{Generation of the reporter construct pGL3-mCIITApIV-luc}

The plasmid pGL3-mCIITAp1.4(WT)-luc encodes for luciferase under the control of the full-length type IV promoter of the mouse ciita gene encompassing nucleotides -1404 to +83 (O'Keefe et al., 2001; kind gift from Prof. Joel D. Ernst, New York). For comparison of transiently transfected RAW264.7 cells with those stably transfected (RAW264.7-mCIITApIV.D1-Iuc; see 2.2.1.1) in a luciferase reporter assay (see section 2.2.7), a 5' deletion mutation of the promoter sequence was generated. To this end, pGL3mCIITAp1.4(WT)-luc was digested with the restriction enzymes Kpnl and Nhel (O'Keefe et al., 2001). The linearised vector was then gel purified, blunt-ended and finally re-ligated.

Specifically, pGL3-mCIITAp1.4(WT) plasmid was eluted from filter paper with TE buffer (10 mM Tris, $\mathrm{pH}$ 8, $1 \mathrm{mM}$ EDTA) and $100 \mathrm{ng}$ were used to transform competent bacteria for its amplification. After amplification and isolation (see section 2.2.3.1), 2 mg pGL3-mCIITAp1.4(WT) pDNA were double digested with $10 \mathrm{U} \mathrm{Kpnl}$ and Nhel each (both from NEB) in $1 \mathrm{X}$ Reaction buffer 1.1 (NEB) and 1\% (w/v) BSA in a total volume of $20 \mu \mathrm{l}$ for 3 hours at $37^{\circ} \mathrm{C}$. After heat inactivation for 20 minutes at $80^{\circ} \mathrm{C}$, the linearised plasmid DNA was subjected to overhang fill in and removal, respectively. Blunting was performed in a total volume of $50 \mu \mathrm{l}$ by adding $2 \cup$ T4 DNA polymerase (NEB) and an appropriate volume of 10X Reaction buffer 1.1 (NEB), 1\% (w/v) BSA and $100 \mu \mathrm{M}$ dNTPs each to the restriction reaction, before being incubated for 15 minutes at $12^{\circ} \mathrm{C}$. The T4 polymerase was then inactivated by adding EDTA ( $\mathrm{pH} 8$ ) to a final concentration of $10 \mathrm{mM}$ and heating for 20 minutes at $75^{\circ} \mathrm{C}$. The total amount of reaction mixture was run on an agarose gel (see section 2.2.3.3) and the linearised vector was excised from the gel on a UV-transilluminator. Thereafter, the DNA was extracted and purified with the QIAquick Gel Extraction kit (Qiagen) according to the manufacturer's instructions. Briefly, the gel slice was incubated in 3 volumes of QG buffer (100 mg gel $\sim 100 \mu \mathrm{l}$ buffer) for 10 minutes at $50^{\circ} \mathrm{C}$. The sample was briefly vortexed, supplemented with 1 gel volume isopropanol and loaded onto a QIAquick spin column. After centrifugation for 1 minute at 17,900 x g, the column was washed with PE buffer. DNA was eluted by adding EB buffer (10 mM Tris, $\mathrm{pH}$ 8.5) to the column membrane and subsequent centrifugation. Thereafter, the plasmid DNA was subjected to spectrophotometric analysis (see section 2.2.3.2). From the eluate, $100 \mathrm{ng}$ of plasmid DNA were used for blunt-end ligation with the T4 DNA Ligase kit (Thermo Fischer Scientific) according to the manufacturer's instructions. Briefly, in a total volume of $20 \mu \mathrm{l}, \mathrm{pDNA}$ was mixed with T4 DNA Ligase buffer and supplemented with 5 Weiss $U$ of T4 DNA Ligase and $5 \%(v / v)$ PEG 4000 solution. Thereafter, reactions were incubated for 1 hour at $22^{\circ} \mathrm{C}$. Competent bacteria were 
then transformed with $25 \mathrm{ng}$ of re-ligated vector for plasmid amplification (see section 2.2.3.1). The sequence identity of the plasmid was verified by DNA Sanger Sequencing. To this end, in a total volume of $15 \mu \mathrm{l}, \sim 5 \mu \mathrm{g}$ of pDNA were premixed with the respective primers, either forward pGI3_RVprimer3 or reverse LucGene, to a final primer concentration of $2 \mu \mathrm{M}$. Sequencing was performed by SeqLab (Sequence Laboratories, Göttingen, Germany) (plasmid map see appendix A). The sequence analysis revealed that pGL3-mCIITApIV-Iuc contains a 5' deletion version of the type IV promoter of the mouse ciita gene encompassing nucleotides -403 to +83 .

\subsubsection{Generation of the reporter construct pGL4.27-4XGAS-Iuc}

To generate a luciferase reporter construct under control of a 4XGAS-minimal promoter, a sequence with four adjacent GAS consensus elements was designed $\left(5^{\prime}\right.$ AGTTTCATATTACTCTAAATCAGTTTCATATTACTCTAAATCAGTTTCATATTACTCTAAATCAGTTTCATATTACTCT AAAT-3'; The GAS sequence is indicated in bolt.). The oligonucleotide was synthesised and cloned into the Nhel/HindIII MCS restriction site of pGL4.27[/uc2P/minP/Hygro] luciferase reporter vector (Promega) by ATG Biosynthetics (Merzenhausen, Germany). The correct nucleotide sequence and orientation of the pGL4.27-4XGAS-luc was verified by DNA Sanger Sequencing. To this end, in a total volume of $15 \mu \mathrm{l}, \sim 5 \mu \mathrm{g}$ of pDNA were premixed with the forward pGL4.27_RVprimer3 to a final primer concentration of $2 \mu \mathrm{M}$. Sequencing was performed by SeqLab (Sequence Laboratories, Göttingen, Germany) (plasmid map see appendix B). The sequence analysis revealed a deletion mutation in the sequence of the minimal promoter ('5-TAGAGGGTATATAATGGAAGCTCGACTTCCAG-3'; the deleted base is indicated in bolt.). Cells were transiently transfected with pGL4.27-4XGAS-luc and were directly analysed by luciferase assay (see section 2.2.7) to verify expression of the luciferase reporter.

\subsubsection{Generation of stably transfected RAW264.7-4XGAS-luc cells}

To generate stably transfected RAW264.7-4XGAS-luc cells, RAW264.7 cells were first transiently transfected with pGL4.27-4XGAS-luc (see section 2.2.1.7). Since chromosomal integration into host chromatin is a rare event, stable transfectants were selected with hygromycin B. The resistance was acquired by co-expressing the respective drug resistance gene, encoding for hygromycin B phosphotransferase $\left(\mathrm{Hyg}^{\mathrm{r}}\right)$, on the backbone of the same vector. Optimal selection conditions were determined in preparatory experiments.

Specifically, transfected cells were allowed to grow in culture medium supplemented with $150 \mu \mathrm{g} / \mathrm{ml}$ hygromycin B. The polyclonal population of cells stably expressing the luciferase was directly analysed by means of luciferase assay (see section 2.2.7) to verify expression of the luciferase reporter. Thereafter, cells of luciferase-expressing batches were frozen for long term storage in liquid nitrogen 
(see section 2.2.1.6). To generate clonal cell lines, a limiting dilution with 2 cells/well in a 96-well plate was performed. Cells were regularly monitored microscopically in order to assure that eventually selected cell populations represent clones from a single cell. Multiple clonal lines were propagated and analysed by means of luciferase assay for reporter construct expression. Aliquots of successfully generated RAW264.7-4XGAS-luc clones were frozen in liquid nitrogen for long term storage. Stably transfected cells were then used for luciferase reporter assay experiments (see section 2.2.7).

\subsubsection{Luciferase Reporter Assay}

The impact of $T$. gondii on the transcriptional activation of different promoter constructs which drive a luciferase gene and were either stably or transiently transfected into RAW264.7 cells was measured with the Luciferase Assay System (Promega) according to the manufacturer's instructions. For this, stably transfected RAW264.7-4XGAS-luc (see section 2.2.6) and RAW264.7-mCIITApIV.D1-luc cells, which were experimentally treated as specified in the result section, were scraped off, centrifuged for 5 minutes at $400 \times \mathrm{g}$ at $4^{\circ} \mathrm{C}$ and resuspended in RPMI medium supplemented with $1 \mathrm{mM} \mathrm{Na}_{3} \mathrm{Vo}_{4}$. The number of viable cells was determined, and cells were washed once in ice-cold PBS. After centrifugation as above, cells were then lysed at $4 \times 10^{4}$ cells $/ \mu$ l of lysis buffer (provided with the kit). The samples were vigorously mixed for 15 seconds and centrifuged for 2 minutes at $12,000 \times g$ at $4^{\circ} \mathrm{C}$. The supernatant was collected and stored at $-80^{\circ} \mathrm{C}$ or immediately subjected to the luciferase assay. Likewise, RAW264.7-WT cells transiently transfected with pGL4.27-4XGAS-luc or pGL3-mCIITApIV-luc (see section 2.2.1.7), and RAW264.7-WT cells were rinsed with PBS and lysed directly in the cell culture vessel at $4 \times 10^{4}$ cells $/ \mu$ l of lysis buffer. Thereafter, samples were further processed as described above.

For measuring luciferase activity, $100 \mu \mathrm{l}$ of luciferase substrate (provided with the kit) were transferred to a well of a 96-well Nunc Immuno plate. Twenty $\mu$ l of protein lysate were added, briefly mixed and the light emission was immediately measured using a VICTOR ${ }^{3} \mathrm{~V} 1420$ multilabel counter (Perkin Elmer) and the Wallac 1240 workstation 3.0 software (adjustments included measurement height $8 \mathrm{~mm}$, label technology luminometry; measurement time $10.0 \mathrm{~s}$ and emission aperture $4 \mathrm{~mm}$ ).

\subsubsection{Immunofluorescence staining}

The impact of $T$. gondii infection on the subcellular distribution and nuclear accumulation of Stat1 was assessed on single cell level by means of immunofluorescence staining, using NIH/3T3-Stat1 $\alpha$-GFP cells as eligible tool. Additional to the green fluorescence protein conjugated to STAT1 $\alpha$, parasites were indirectly labelled with specific primary and fluorochrome-conjugated secondary antibodies. This technique was also used to verify the ability of $T$. gondii to infect and replicate within different host cells. 
Visualisation and analysis of florescence signals were done by means of confocal laser scanning microscopy.

To this end, cells were allowed to grow on glass cover slips with a diameter of $13 \mathrm{~mm}$ in wells of a 24well plate. In case of NIH/3T3-Stat1 $\alpha$-GFP cells, prior to seeding, glass cover slips were coated with $15 \mu \mathrm{g} / \mathrm{ml}$ laminin in PBS for 2 hours at $37^{\circ} \mathrm{C}$ to increase cell adhesion. After experimental treatment of cells as specified in the results section, cells were rinsed twice with PBS before being fixed in $4 \%(\mathrm{w} / \mathrm{v})$ paraformaldehyde in $0.1 \mathrm{M}$ sodium cacodylate, $\mathrm{pH} 7.4$ for 1 hour. After having been rinsed twice with PBS, cells were quenched for 10 minutes in $50 \mathrm{mM} \mathrm{NH}_{4} \mathrm{Cl}$ in PBS, followed by washing with PBS. Thereafter, cells were permeabilised and unspecific protein binding sites were blocked for 1 hour in $0.1 \mathrm{mg} / \mathrm{ml}$ saponin in PBS supplemented with 1\% (w/v) BSA. Cells were then incubated for 10 minutes in $0.1 \mathrm{mg} / \mathrm{ml}$ saponin in PBS. Thereafter, cells were incubated in rabbit anti-Toxoplasma serum diluted at $1: 400$ in $0.1 \mathrm{mg} / \mathrm{ml}$ saponin, $1 \%$ (w/v) BSA in PBS for 1 hour, followed by rinsing trice with $0.1 \mathrm{mg} / \mathrm{ml}$ saponin in PBS. Cells were then incubated for 1 hour with an appropriate secondary antibody (Table 27) diluted in $0.1 \mathrm{mg} / \mathrm{ml}$ saponin, 1\% (w/v) BSA in PBS. Cells were then carefully washed trice with $0.1 \mathrm{mg} / \mathrm{ml}$ saponin in PBS and once with PBS. In order to visualize total cell populations, nucleic acids were stained for 4 minutes with $5 \mu \mathrm{g} / \mathrm{ml}$ propidiumiodide in PBS, followed by washing twice with PBS. Finally, the glass cover slips were rinsed in demineralised water and cells were mounted on microscopy slides in Mowiol mounting medium (2 M Mowiol 4-88 in $0.1 \mathrm{M}$ Tris pH 8.5 and 25\% (v/v) glycerol) supplemented with $2.5 \%(\mathrm{w} / \mathrm{v})$ DABCO. The mounting medium was allowed to dry overnight. After that, microscopic slides were stored at $4^{\circ} \mathrm{C}$ in the dark until analysis with a Leica TCS SP2 confocal microscope and Leica Confocal Software.

Table 27: Dilution concentration of secondary antibodies for immunofluorescence staining

\begin{tabular}{ll}
\hline Antibody & Dilution concentration \\
\hline Donkey F(ab') ${ }_{2}$ anti-Rabbit lgG (H+L)-Alexa Fluor 647 & $3.75 \mu \mathrm{g} / \mathrm{ml}$ \\
& \\
Donkey F(ab') ${ }_{2}$ anti-Rabbit IgG $(\mathrm{H}+\mathrm{L})$-Alexa Fluor 488 & $3.75 \mu \mathrm{g} / \mathrm{ml}$
\end{tabular}

\subsubsection{Electrophoretic mobility shift assay}

The impact of T. gondii infection on DNA binding activity of STAT1 was assessed by means of electrophoretic mobility shift assay (EMSA). To this end, protein samples were incubated with radioactively labelled duplex oligonucleotides, followed by electrophoretic separation in a native polyacrylamide gel. 
Double-stranded oligonucleotides were prepared by mixing the respective single-stranded oligonucleotides at a concentration of 100 mM each in DNase-, RNase- and proteinase-free water and heating to $95^{\circ} \mathrm{C}$ in a water bath. They were annealed by leaving the mixture slowly cool to room temperature overnight. The double-stranded oligonucleotides were radioactively labelled at their $3^{\prime}$ ends by an end-filling reaction using the Klenow fragment of E. coli DNA polymerase I (NEB). For this, $5 \mathrm{U}$ of Klenow fragment in $1 \mathrm{X}$ reaction buffer 2 (NEB) and 1 pmol annealed oligonucleotides were mixed with $8 \mu \mathrm{l}$ of radioactively labelled deoxyadenosine $5^{\prime}$-[a- $\left.{ }^{33} \mathrm{P}\right]$ triphosphate (dATP [a- $\left.{ }^{33} \mathrm{P}\right]$ (Hartmann Analytics)) and were incubated for 25 minutes. Thereafter, an excess of non-radioactive dNTPs (6.5 mM of each dNTP) was added and incubated for another 5 minutes. Finally, the reaction was stopped by adding $1 \mu \mathrm{l}$ of $0.5 \mathrm{mM}$ EDTA pH 8. Free nucleotides were removed by centrifugation for 3 minutes at $700 \times \mathrm{g}$ in an Illustra-Microspin-G-25 column (GE Healthcare).

For an electrophoretic mobility shift assay, in a total reaction volume of $13 \mu \mathrm{l}, 4.5 \mu \mathrm{l}$ of protein extract was mixed with $1 \mathrm{ng}\left[{ }^{33} \mathrm{P}\right]$-labelled DNA probe and $2 \mu \mathrm{g}$ poly(dldC) in $20 \mathrm{mM}$ HEPES, $40 \mathrm{mM} \mathrm{KCl}, 1 \mathrm{mM}$ $\mathrm{MgCl}_{2}, 0.5 \mathrm{mM}$ EDTA pH 8, $0.1 \mathrm{mM}$ EGTA, 4\% Ficoll and $1 \mathrm{mM}$ DTT and incubated for 15 minutes. In case of supershift analysis, $0.04 \mu \mathrm{g}$ of specific antibodies were added to the samples und incubation was prolonged to 45 minutes. The STAT1 $\alpha$ p91 (M-23) antibody was used to bind STAT1, while STAT3 (H190) antibody was employed as a negative control. For competition experiments, EMSA reactions were incubated with 750-fold molar excess of unlabelled DNA probes under the conditions indicated in the result section. EMSA reactions were separated in a non-denaturing 4.8\% TBE-polyacrylamide gel (12\% Rotiphorese Gel 40, 2.4\% TBE (89 mM Tris, 89 mM boric acid, 2 mM EDTA pH 8), 2\% APS, 0.1\% TEMED) at $400 \mathrm{~V}$ in $0.25 \%$ TBE. Prior to sample loading, the gel was equilibrated by applying $400 \mathrm{~V}$ for 120 minutes in a vertical electrophoresis chamber with TBE as running buffer. After separation of the samples, the gel was vacuum dried. Finally, the radioactivity signals were visualised by transferring the signal to a phospho-imager plate followed by reading with the FLA-5100 imager and TINA $\vee 2.0$ software.

\subsubsection{Precipitation of oligonucleotide-bound proteins}

The impact of T. gondii infection on DNA binding activity of STAT1 was additionally assessed by means of a pulldown assay. For this, native protein samples were incubated with biotin-conjugated duplex oligonucleotides and then precipitated by avidin-conjugated latex beads.

After experimental treatment as specified in the result section, cells were scraped off, washed with icecold wash buffer ( $1 \mathrm{mM} \mathrm{Na}_{3} \mathrm{VO}_{4}, 10 \mathrm{mM} \mathrm{NaF}$ in PBS) and centrifuged for 5 minutes at $400 \times \mathrm{g}$ at $4^{\circ} \mathrm{C}$. Thereafter, the number of viable cells was determined and $5 \times 10^{7}$ cells were resuspended in $300 \mu \mathrm{l}$ icecold complete lysis buffer (1\% Triton X-100, $150 \mathrm{mM} \mathrm{NaCl}, 50 \mathrm{mM}$ Tris-HCl pH 8.0, 50 mM NaF, 5 mM sodium pyrophosphate, $1 \mathrm{mM}$ PMSF, $1 \mathrm{mM}$ EDTA, $1 \mathrm{mM} \mathrm{Na}_{3} \mathrm{VO}_{4}, 5 \mu \mathrm{g} / \mathrm{ml}$ pepstatin, $1 \mu \mathrm{g} / \mathrm{ml}$ leupeptin, 
$5 \mu \mathrm{g} / \mathrm{ml}$ aprotinin) and incubated for 30 minutes on ice. The samples were then centrifuged at $20,000 \times \mathrm{g}$ for 10 minutes at $4^{\circ} \mathrm{C}$. After collecting the supernatants, $25 \mu \mathrm{l}$ were removed and mixed with an equal volume of 2 X SDS-sample buffer (125 mM Tris-HCl, pH 6.8, 20\% glycerol, 4\% SDS, 65 mM DTT, $0.02 \%$ bromophenol blue), heated for 5 minutes at $95^{\circ} \mathrm{C}$ and were stored as input samples at $-80^{\circ} \mathrm{C}$. The remaining samples were directly incubated with biotin-conjugated duplex oligonucleotides at a final concentration of $30 \mathrm{nM}$ for 2 hours at $4^{\circ} \mathrm{C}$ under constant rotation. Beforehand, hybridisation of oligonucleotides was achieved through mixing equal parts of complementary single-stranded oligonucleotides, heating for 5 minutes at $80^{\circ} \mathrm{C}$ and slow, gradual cooling to room temperature.

Protein-DNA complexes were incubated with $30 \mu \mathrm{l}$ of $50 \%$ slurry of resin-particles conjugated to streptavidin (Thermo Fisher Scientific) for 1 hour at $4^{\circ} \mathrm{C}$ under constant rotation. Complexes were pulled down by centrifugation at 2,000 $\mathrm{g}$ for 2 minutes at $4^{\circ} \mathrm{C}$ and were washed trice with lysis buffer supplemented with $100 \mathrm{mM} \mathrm{KCl}$ and once with lysis buffer. Finally, the DNA-protein complexes were resuspended in $45 \mu \mathrm{l} 1 \mathrm{X}$ SDS-sample buffer, further denaturated at $95^{\circ} \mathrm{C}$ for 5 minutes and centrifuged at $20,000 \times \mathrm{g}$ for 5 minutes. The supernatant was stored at $-80^{\circ} \mathrm{C}$ for further analysis.

\subsubsection{Chromatin immunoprecipitation analysis}

To analyse the impact of $T$. gondii on the regulation of specific histone modifications during IFN- $\gamma$ stimulation, chromatin immunoprecipitation assays were performed.

After experimental treatment of cells as specified in the results section, cells were washed with PBS within the cell culture vessel and immediately fixed and DNA-protein complexes cross-linked using $1 \%$ (v/v) formaldehyde in PBS for 10 minutes. Cross-linking was stopped by adding glycine to a final concentration of $125 \mathrm{mM}$ and gentle shaking for 5 minutes. After washing the cells with ice-cold PBS twice, cells were scraped off and the number of cells was determined. Thereafter, $1 \times 10^{7}$ cells per sample were pelleted by centrifuging for 5 minutes at $400 \times g$ at $4^{\circ} \mathrm{C}$. The cells were carefully resuspended in ice-cold low sucrose buffer $(320 \mathrm{mM}$ sucrose, $5 \mathrm{mM} \mathrm{CaCl}$, $5 \mathrm{mM}$ magnesium acetate, 0.1 mM EDTA pH 8, 10 mM HEPES pH 8, 1 mM DTT, 0.1\% (v/v) Triton X-100 and 1 X protease inhibitor cocktail (Roche)) and centrifuged for 5 minutes at $1000 \times \mathrm{g}$ at $4^{\circ} \mathrm{C}$. The pellets containing the nuclei were washed twice in ice-cold Nelson buffer (140 mM NaCl, 50 mM Tris pH 8, 20 mM EDTA pH 8, 0.5\% (v/v) NP-40, 1\% (v/v) Triton X-100, 1X protease inhibitor cocktail) and centrifuged for 5 minutes at $1000 \times \mathrm{g}$ at $4^{\circ} \mathrm{C}$. Subsequently, the nuclear pellets were resuspended in $300 \mu \mathrm{l}$ ice-cold RIPA buffer ( $140 \mathrm{mM} \mathrm{NaCl}$, $10 \mathrm{mM}$ Tris pH 8, $1 \mathrm{mM}$ EDTA pH 8, 0.1\% (w/v) sodium deoxycholate, 1\% (v/v) Triton X-100 and $1 X$ protease inhibitor cocktail) which was supplemented with freshly prepared SDS to a final concentration of $0.5 \%(\mathrm{w} / \mathrm{v})$ directly before usage. Samples then were transferred into $1.5 \mathrm{ml}$ Sonication Tubes TPX (Diagenode). After incubation for 10 minutes in an end-over-end rotator at $4^{\circ} \mathrm{C}$, samples were 
sonicated using a Sonifier Biorupter Plus (Diagenode) at controlled $4^{\circ} \mathrm{C}$ condition. To effectively shear the chromatin, samples were sonicated 25 - 30 cycles ( 30 seconds ON/ 30 seconds OFF, high power) with brief centrifugations every 5 cycles. Thereafter, the samples were centrifuged for 5 minutes at $18,000 \times \mathrm{g}$ at $4^{\circ} \mathrm{C}$ and the supernatant was aliquoted, snap frozen in liquid nitrogen and was stored at $-80^{\circ} \mathrm{C}$

To estimate shearing efficacy and DNA concentration, $50 \mu \mathrm{l}$ of sheared chromatin were incubated with $20 \mu \mathrm{g}$ Proteinase $\mathrm{K}$ (AppliChem) and $20 \mu \mathrm{g}$ RNase A (Sigma-Aldrich) for 3 hours at $55^{\circ} \mathrm{C}$ and then overnight at $65^{\circ} \mathrm{C}$. DNA was purified with the PCR Purification kit (QIAGEN) according to the manufacturer's instructions. Briefly, samples were supplemented with 5 volumes of PB buffer, carefully mixed and loaded onto a QIAquick spin column. After centrifugation for 1 minute at 17,900 $\times$ g, the column was washed with PE buffer. DNA was eluted by adding EB buffer (10 mM Tris, pH 8.5) to the column membrane and subsequent centrifugation. Thereafter, the DNA concentration was measured (see section 2.2.3.2) and the range of DNA fragment size was analysed on an agarose gel (see section 2.2.3.3). For the intended downstream application, the fragment size was regularly between 200 and $1000 \mathrm{bp}$.

Prior to immunoprecipitation, unspecific binding sites of protein A-coated magnetic beads (Invitrogen) were blocked. To this end, $35 \mu$ l of the bead solution per sample were washed with immunoprecipitation (IP) buffer $(140 \mathrm{mM} \mathrm{NaCl}, 50 \mathrm{mM}$ Tris pH 8, $20 \mathrm{mM}$ EDTA pH 8, 1\% (v/v) NP-40, 0.5\% sodium deoxycholate) and were then incubated for 2 hours at $4^{\circ} \mathrm{C}$ in an end-over-end rotator in IP buffer supplemented with $0.5 \%(\mathrm{w} / \mathrm{v}) \mathrm{BSA}$. The beads were then resuspended in the original volume of IP buffer and stored at $4^{\circ} \mathrm{C}$. All steps requiring collection of the beads were carried out in a magnetic rack. To preclear the sheared chromatin, $100 \mu \mathrm{l}$ were diluted with 9 volumes of IP buffer supplemented with 1X protease inhibitor cocktail and were incubated with $20 \mu \mathrm{l}$ of blocked protein A-coated magnetic beads in an end-over-end rotator for 1 hour at $4^{\circ} \mathrm{C}$. After collection of the beads, the supernatant was aliquoted, snap frozen and stored at $-80^{\circ} \mathrm{C}$.

For immunoprecipitations, including an isotope control, $1000 \mathrm{ng}$ of pre-cleared, sheared chromatin were used and for input samples $100 \mathrm{ng}$. For immunoprecipitation, the chromatin was incubated with antibodies as indicated (Table 28) overnight in an end-over-end rotator at $4^{\circ} \mathrm{C}$. Thereafter, $15 \mu \mathrm{l}$ of blocked protein A-coated magnetic beads were added to each sample and incubated in an end-overend rotator for 1.5 hours at $4^{\circ} \mathrm{C}$. After collecting the beads, they were washed twice in IP buffer which was supplemented with freshly prepared SDS to a final concentration of $0.1 \%(\mathrm{w} / \mathrm{v})$ directly before usage, and trice with wash buffer (100 mM Tris pH 8, 20 mM EDTA pH 8, 1\% (v/v) NP-40, 1\% sodium deoxycholate) which was supplemented with $\mathrm{LiCl}$ to a final concentration of $0.5 \mathrm{M}$ directly before usage. During the third washing step, beads were incubated for 5 minutes at $4^{\circ} \mathrm{C}$ in an end-over-end rotator. After one more washing step with IP buffer, DNA was isolated. To this end, beads and input samples 
were resuspended in $20 \mu \mathrm{l}$ EB buffer $(10 \mathrm{mM}$ Tris $\mathrm{pH}$ 8) supplemented with $0.1 \mu \mathrm{g} / \mu \mathrm{l}$ RNase $\mathrm{A}$ and incubated for 30 minutes at $37^{\circ} \mathrm{C}$ and $450 \mathrm{rpm}$. Thereafter, $20 \mu \mathrm{l} 2 \mathrm{X}$ Wiemann buffer (100 mM Tris pH 8 , $40 \mathrm{mM}$ EDTA) and $20 \mu \mathrm{g}$ Proteinase $\mathrm{K}$ were added to the beads and the input samples and incubated overnight at $65^{\circ} \mathrm{C}$ and $800 \mathrm{rpm}$. The supernatant was then collected, and the beads were once more incubated with $20 \mu \mathrm{l} \mathrm{EB}$ buffer for 10 minutes at $65^{\circ} \mathrm{C}$ and $800 \mathrm{rpm}$. After combining both supernatants, DNA was purified with the PCR Purification kit as described above and stored at $-20^{\circ} \mathrm{C}$ until further use.

Table 28: Amounts of antibodies used per immunoprecipitation

\begin{tabular}{ll}
\hline $\begin{array}{l}\text { Antibody } \\
\text { (isotope control) }\end{array}$ & amount used per immunoprecipitation \\
\hline mouse anti-Trimethyl-Histone H3 (K4) & $2 \mu \mathrm{g}$ \\
(mouse IgG) & $(2 \mu \mathrm{g})$ \\
mouse anti- Phospho-Histone H3 (S10) & $2 \mu \mathrm{g}$ \\
(mouse IgG) & $(2 \mu \mathrm{g})$ \\
rabbit anti-Acetyl-Histone H3 (K9) & $5 \mu \mathrm{g}$ \\
(rabbit IgG) & $(5 \mu \mathrm{g})$ \\
rabbit anti-Acetyl-Histon4 & $5 \mu \mathrm{l}$ \\
(rabbit IgG) & $(5 \mu \mathrm{l})$
\end{tabular}

\subsubsection{Quantitative Real-Time PCR}

In order to analyse the impact of $T$. gondii infection on IFN- $\gamma$-induced transcription and regulation of post-translational modifications of histone, reverse transcribed cDNA or immunoprecipitated DNA, respectively, were subjected to quantitative real-time PCR (real-time qPCR).

PCR reactions were prepared with the SYBR Green I FastStart DNA Master ${ }^{\text {plus }}$ kit (Roche) according to the manufacturer's instructions. The total reaction volume of $20 \mu \mathrm{l}$ consisted of $4 \mu \mathrm{l}$ pre-mix PCR reagent, $0.25 \mu \mathrm{M}$ of each forward and reverse primers, variable volumes of DNA template and nucleasefree water. Samples were transferred into glass capillaries, which were briefly centrifuged and placed in the LightCycler 1.5 (Roche) rotor. A representative LightCycler PCR protocol is shown in Table 29, and specific program parameters depending on primers and target sequence, i.e. annealing temperature $\left(T_{M}\right)$ and elongation time, are indicated in Table 30 and Table 31. Amplification of the DNA was regularly monitored during the PCR, which allowed determination of the crossing point $(C P)$, where the fluorescence signal rose above the background fluorescence. The relative quantification of changes in IFN- - -induced gene expression and modifications of histones in T. gondii-infected and non-infected cells was based on the mathematical model introduced by Pfaffl (Pfaffl, 2001). Briefly, the relative gene expression levels (R) induced by IFN- $\gamma$ were calculated as the fold change between non-stimulated (control) and IFN- $\gamma$-stimulated (sample) cells, and between T. gondii-infected (control) and T. gondii- 
infected, IFN- $\gamma$-stimulated (sample) cells using the equation below (Formula 1), where the target genes were the genes of interest and the reference gene was $\beta$-actin. The PCR amplification efficiency (E) was assumed to be 2 .

$$
\mathrm{R}=\left(\mathrm{E}_{\text {target }}\right)^{\Delta \mathrm{CP} \mathrm{P}_{\text {target }}(\text { non-stimulated }-\mathrm{IFN}-\gamma-\text { treated })} /\left(\mathrm{E}_{\text {ref }}\right) \Delta \mathrm{CP}_{\text {ref }}(\text { non-stimulated }-\mathrm{IFN}-\gamma-\text { treated })
$$

Formula 1: Mathematical equation to calculate the relative gene expression level of a target gene of interest relative to ß-actin.

The ratio $(R)$ is expressed in a sample versus a control in comparison to a reference gene. $E$ represents the realtime PCR efficiency of target or reference gene, respectively. $\triangle C P$ is the $C P$ deviation of control - sample of the target or reference gene transcript, respectively.

The same mathematical model was used to analyse the ChIP data where immunoprecipitated DNA were the sample and the inputs were the control.

A melting curve was recorded routinely after the amplification of DNA in order to assess the homogeneity of amplicons and hence to identify unspecific amplicons or dimer formation.

Table 29: Representative experimental real-time qPCR program

\begin{tabular}{|c|c|c|c|c|}
\hline \multicolumn{4}{|c|}{ Program: Denaturation } & \multirow{2}{*}{$\begin{array}{l}\text { Cycles: } 1 \\
\text { Acquisition mode }\end{array}$} \\
\hline Segment & Temperature target & Hold time & Slope & \\
\hline 1 & $95^{\circ} \mathrm{C}$ & $600 \mathrm{sec}$ & $20^{\circ} \mathrm{C} / \mathrm{s}$ & None \\
\hline
\end{tabular}

\begin{tabular}{lllll}
\hline Program: Amplification & & & Cycles: Variable $^{3}$ \\
\hline Segment & Temperature target & Hold time & Slope & Acquisition mode \\
1 & $95^{\circ} \mathrm{C}$ & $10 \mathrm{sec}$ & $20^{\circ} \mathrm{C} / \mathrm{sec}$ & None \\
2 & Variable $^{1}\left({ }^{\circ} \mathrm{C}\right)$ & $10 \mathrm{sec}$ & $20^{\circ} \mathrm{C} / \mathrm{sec}$ & None \\
3 & $72^{\circ} \mathrm{C}$ & Variable $^{2}(\mathrm{sec})$ & $20^{\circ} \mathrm{C} / \mathrm{sec}$ & Single
\end{tabular}


MATERIAL AND METHODS

\begin{tabular}{|c|c|c|c|c|}
\hline \multicolumn{4}{|c|}{ Program: Melting curve } & \multirow{2}{*}{$\begin{array}{l}\text { Cycles: } 1 \\
\text { Acquisition mode }\end{array}$} \\
\hline Segment & Temperature target & Hold time & Slope & \\
\hline 1 & $95^{\circ} \mathrm{C}$ & $0 \mathrm{sec}$ & $20^{\circ} \mathrm{C} / \mathrm{sec}$ & None \\
\hline 2 & Variable ${ }^{1}\left({ }^{\circ} \mathrm{C}\right)$ & $15 \mathrm{sec}$ & $20^{\circ} \mathrm{C} / \mathrm{sec}$ & None \\
\hline 3 & $99^{\circ} \mathrm{C}$ & $0 \mathrm{sec}$ & $0.1^{\circ} \mathrm{C} / \mathrm{sec}$ & Continuous \\
\hline primer specific & ${ }^{2}$ fragment length & cific & nt on temp & concentration \\
\hline
\end{tabular}

Table 30: Primer and target specific PCR program parameters for ChIP analysis

\begin{tabular}{lcc}
\hline Primer pair & Annealing ( $\left.\mathrm{T}_{\mathrm{M}}\right)$ & Elongation \\
\hline actb distal & $60^{\circ} \mathrm{C}$ & $10 \mathrm{sec}$ \\
ciita distal & $67^{\circ} \mathrm{C}$ & $10 \mathrm{sec}$ \\
ciita proximal & $64^{\circ} \mathrm{C}$ & $10 \mathrm{sec}$ \\
irf1 distal & $55^{\circ} \mathrm{C}$ & $10 \mathrm{sec}$ \\
irf8 distal & $60^{\circ} \mathrm{C}$ & $10 \mathrm{sec}$ \\
gbp2 distal & $55^{\circ} \mathrm{C}$ & $10 \mathrm{sec}$ \\
gbp2 proximal & $62^{\circ} \mathrm{C}$ & $15 \mathrm{sec}$ \\
stat1 distal & $60^{\circ} \mathrm{C}$ & $10 \mathrm{sec}$
\end{tabular}

Table 31: Primer and target specific PCR program parameters for analysis of transcriptional regulation in myocardial fibroblasts

\begin{tabular}{lcc}
\hline Primer pair & Annealing $\left(T_{M}\right)$ & Elongation \\
\hline actb & $63^{\circ} \mathrm{C}$ & $20 \mathrm{sec}$ \\
ciita & $66^{\circ} \mathrm{C}$ & $20 \mathrm{sec}$
\end{tabular}


MATERIAL AND METHODS

$\begin{array}{lll}\text { h2-ab } & 60^{\circ} \mathrm{C} & 15 \mathrm{sec} \\ \text { irf1 } & 66^{\circ} \mathrm{C} & 15 \mathrm{sec} \\ \text { irf8 } & 62^{\circ} \mathrm{C} & 15 \mathrm{sec}\end{array}$

\subsubsection{Statistical Analyses}

Data from replicate experiments are presented as means \pm standard error of the mean (means \pm SEM). To identify significant differences, unpaired Student's $t$-tests or univariant ANOVA and subsequent contrast analysis were performed as indicated by using Statistica (StatSoft). A p-value of less than 0.05 was considered to be statistically significant. Graphs were prepared using Sigmaplot (Systat Software). 


\section{RESULTS}

\subsection{Epigenetic plasticity at IFN- $\gamma$-responsive promoters in Toxoplasma gondii-} infected macrophages

The transcriptional initiation of gene expression in response to external stimuli most often requires extensive changes in the higher order chromatin structure surrounding the promoter. To allow access of transcription factors and the RNA polymerase II machinery, the promoter region undergoes transient chromatin remodelling, usually including post-translational histone modifications. It became evident, that impaired IFN- $\gamma$-induced gene transcription in $T$. gondii-infected macrophages is accompanied with reduced recruitment of Brahma-related gene 1 (BRG1), i.e. the ATPase of the chromatin remodelling complex BAF (a homologue of the yeast SWI/SNF complex) and defective acetylation of histones at promoters of a subset of genes (Lang et al., 2012). Importantly, treatment with histone deacetylase inhibitors rescues infected macrophages from the parasite-imposed inhibition of transcriptional activation of distinct genes. These findings suggest defective chromatin remodelling as underlying mechanism of the T.gondii-mediated unresponsiveness of macrophages to IFN- $\gamma$. The following experiments were performed to determine which impact the host's native chromatin structure and distinct promoter features have on the parasite-imposed inhibitory effect. Furthermore, it was analysed which impact infection with $T$. gondii has on regulation of histone modifications during IFN- $\gamma$ stimulation.

\subsubsection{The T. gondii-mediated inhibition of IFN- $\gamma$-regulated genes largely depends on a native} chromatin structure

To evaluate the impact of native chromatin on T. gondii-mediated inhibition of IFN- - -induced gene transcription, the expression of luciferase reporters either integrated or not into the host cell's genome was compared. To distinguish between primary and secondary IFN- - -responsive promoters, luciferase expression was analysed under the control of two different promoter constructs. Primary responsive promoters were represented by a construct composed of a minimal TATA-box promoter downstream of a 4XGAS response element (Figure 5B). A construct containing the ciita promoter IV was representative for secondary IFN- - -responsive promoters (Figure 5A). In this experiment, RAW264.7 macrophages were either transiently or stably transfected with these representative reporter constructs and subsequently infected or not and stimulated with IFN- $\gamma$ or left non-stimulated. The effect of $T$. gondii on IFN- $\gamma$-induced promoter activity was analysed by means of luciferase activity measurements (Figure 5C). 


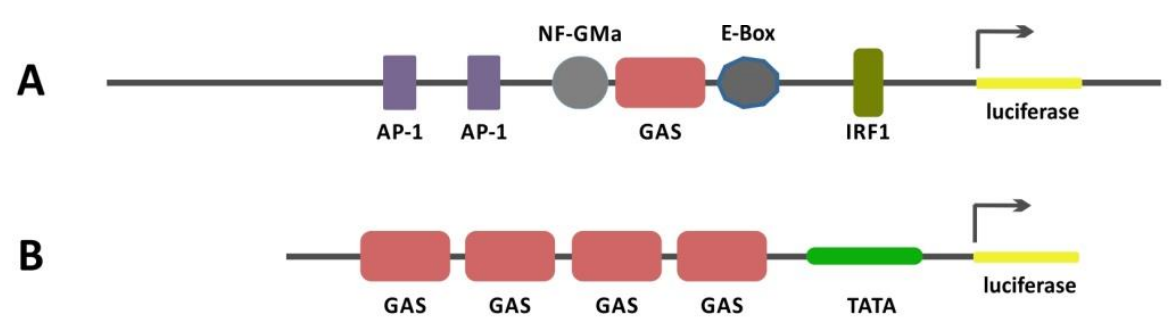

C
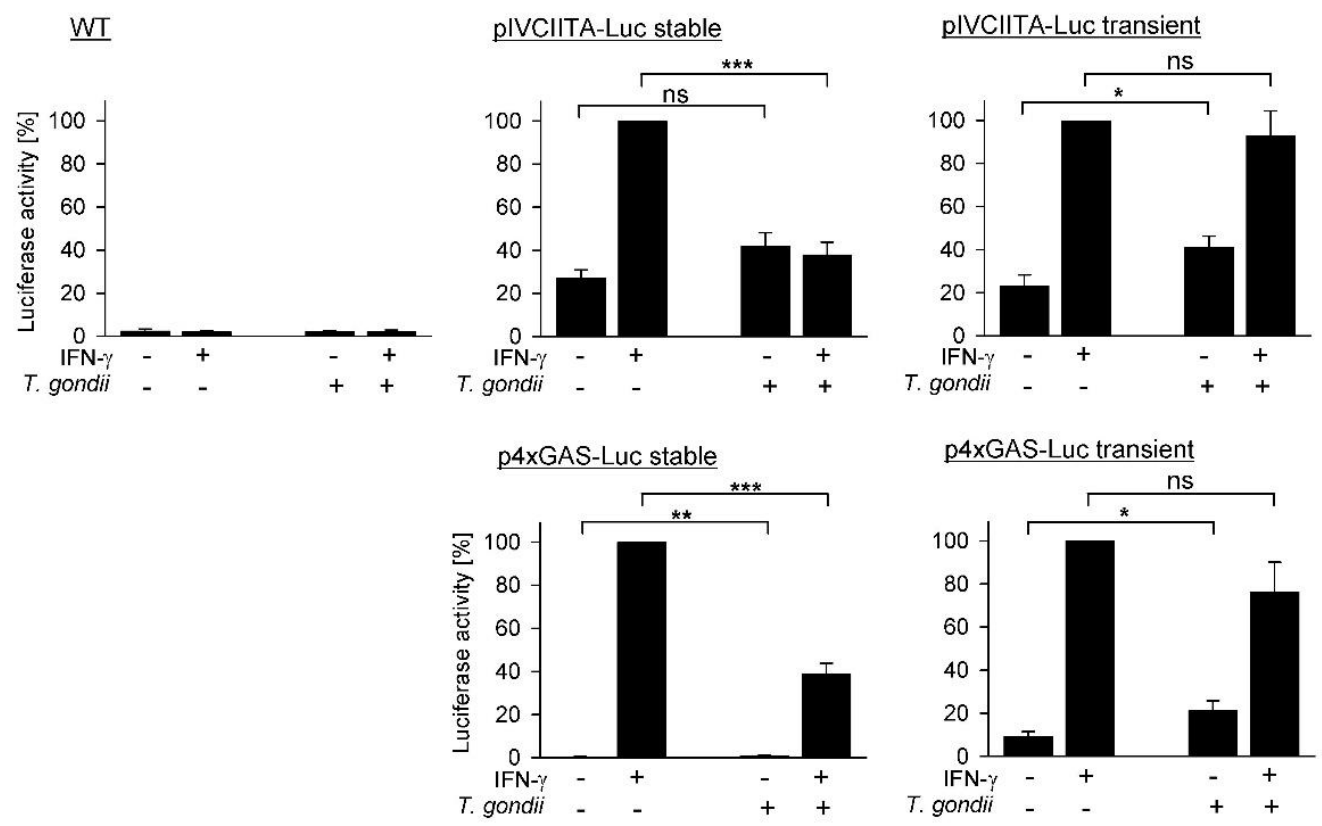

Figure 5: Toxoplasma gondii differentially interferes with luciferase reporter activity, depending on whether reporter constructs are integrated or not into the host's genome.

(A) Schematic representation of the complex ciita promoter IV construct, driving luciferase. AP-1: activator protein 1; NF-GMa: nuclear factor GMa; GAS: gamma activated site; IRF-1: interferon regulatory factor-1 (O'Keefe et al., 2001). (B) Schematic representation of the 4XGAS-minimal promoter construct driving luciferase. GAS: gamma activated site; TATA: TATA box; (C) Stably transfected RAW264.7-4XGAS-luc and RAW264.7-mCIITApIV.D1-luc cells, and RAW264.7-WT cells transiently transfected with pGL4.27-4XGAS-luc or pGL3-mCIITApIV-luc, and RAW264.7-WT cells were infected with T. gondii at a parasite to host cell ratio of 6:1 or were left non-infected. One and a half hour post infection cells were activated with $100 \mathrm{U} / \mathrm{ml}$ IFN- $\gamma$ or were left non-stimulated as indicated. Twenty-four hours post infection, cell lysates were prepared, and luciferase activity was measured by means of luciferase assay. The luciferase activity of non-infected, IFN- - -activated samples was defined as $100 \%$ and the other values were calculated relative to this sample. Bars represent means \pm SEM of at least six independent experiments. Significant differences were identified by Student's t-test $\left({ }^{*} p<0.05,{ }^{* *} p<0.01,{ }^{* * *} p<0.001\right)$.

Cells stably transfected with the ciita promoter IV-luciferase reporter construct showed basal luciferase activity in the absence of exogenous IFN- $\gamma$ which was 3.6-fold increased after activation with IFN- - . Compared to non-infected cells, those infected with $T$. gondii presented a slightly increased basal luciferase activity; however the IFN- $\gamma$-induced upregulation of luciferase expression as observed in noninfected cells was completely abolished $(p<0.001)$. Cells transiently transfected with the ciita promoter IV-luciferase reporter construct which were non-infected, showed a similar luciferase activity 
pattern as stably transfected ones. Thus, constitutive luciferase expression as detected in the absence of IFN- $\gamma$ increased 4.3-fold in response to the specific stimulus. Infection of these cells with $T$. gondii increased $(p<0.05)$ basal luciferase expression as also observed in stably transfected cells. However, in sharp contrast to the latter ones, infection of transiently transfected cells did not diminish the IFN- $\gamma$ induced upregulation of luciferase activity.

Cells with the 4XGAS-minimal promoter-luciferase reporter construct integrated into the genome showed minimal basal luciferase expression and activation of non-infected cells with IFN- $\gamma$ led to a 208fold increase in luciferase activity. Infection with $T$. gondii slightly increased $(p<0.01)$ the basal luciferase activity in the absence of IFN- $\gamma$. More importantly, IFN- $\gamma$-induced luciferase activity was 2.6fold lower in infected cells as compared to non-infected ones $(p<0.001)$. In comparison, cells transiently transfected with the 4XGAS-minimal promoter-luciferase reporter construct, showed higher basal luciferase activity. Furthermore, they up-regulated luciferase activity 10 -fold in response to IFN- $\gamma$ and thus less pronounced than stably transfected cells. In T. gondii-infected cells, basal expression was slightly higher $(p<0.05)$ as in non-infected ones. However, luciferase expression induced by IFN- $\gamma$ was only slightly inhibited by T. gondii infection (1.3-fold; $p>0.05)$ and this clearly differed to those cells stably transfected with the same construct. As expected, non-transfected WT cells showed only a minimal background activity, irrespective of $T$. gondii infection and/or stimulation with IFN- $\gamma$.

Taken together, the results showed that the $T$. gondii-imposed inhibition of IFN- $\gamma$-induced luciferase activity requires integration of the transgene into the host cell genome, whereas expression from a plasmid vector was not significantly inhibited by the parasite. Furthermore, luciferase driven by both primary and secondary promoters integrated into the host genome was similarly inhibited by $T$. gondii infection. This suggests that the T. gondii-mediated inhibition of both primary and secondary IFN- $\gamma$ responsive genes largely depends on native chromatin.

\subsubsection{Strong inhibition of IFN- $\gamma$-induced genes by T. gondii correlates with absence of CpG islands}

It has been established that T. gondii abrogates or counteracts expression of the majority of IFN- $\gamma$ responsive genes in murine macrophages (Lang et al., 2012). However, the genome-wide transcriptional analysis also revealed genes, expression of which was not affected by T. gondii infection. It was thus of interest to identify putative differences in the promoters of genes which were inhibited by $T$. gondii or not. Interestingly, lipopolysaccharide (LPS)-regulated genes with CpG islands in their promoters more often show a reduced occupancy with nucleosomes and promote transcriptional induction independent of extensive chromatin remodelling by the SWI/SNF homologue BAF. In contrast, LPS-mediated 
activation of promoters lacking $\mathrm{CpG}$ islands often depends on BAF-mediated chromatin remodelling (Ramirez-Carrozzi et al., 2009). CpG islands are short interspersed DNA sequences which are GC-rich, CpG-rich, pre-dominantly non-methylated and strongly correlate with transcription initiation (reviewed in Antequera, 2003; Illingworth and Bird, 2009; and in Deaton and Bird, 2011). In humans and mice, approximately $60 \%$ of all promoters contain CpG islands (Antequera, 2003), which often coincide with the transcriptional start side (TSS). The unresponsiveness of $T$. gondii-infected macrophages to IFN- $\gamma$ is accompanied by defects in histone acetylation and defective recruitment of BAF components at a subset of responsive promoters (Lang et al., 2012). It was thus of interest, whether the CpG content differs between promoters which cytokine-induced activity was affected by T. gondii infection or not. To this end, subsets of IFN- $\gamma$-differentially regulated genes, expression of which was counteracted or not by T. gondii, were selected from a previously published microarray data set (Lang et al., 2012; GEO accession number GSE28499). In silico prediction of CpG-rich sequences surrounding the transcriptional start site was performed using the online tools DataBase of Transcriptional Start Sites (Yamashita et al., 2012) and CpG Island Searcher (Takai and Jones, 2003) (Figure 6, see also appendix C). Thresholds for identifying a CpG island were set according to Gardiner-Garden and Frommer (1987) as region of at least 200 bps, an observed CpG/expected CpG ratio of greater than 0.60 and a GC content of greater than $50 \%$.

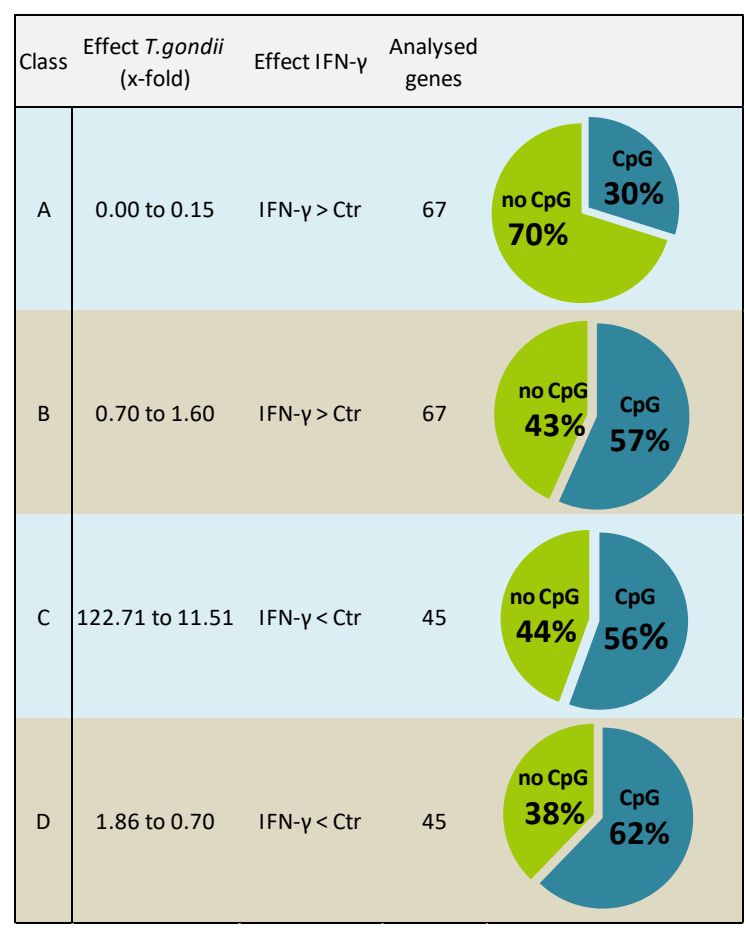

Figure 6: Toxoplasma gondii-mediated inhibition pattern of IFN- $\psi$-regulated genes partly correlate with absence of $\mathrm{CpG}$ islands in their promoters. 
224 genes that are differentially regulated by IFN- $\gamma$ in murine bone marrow-derived macrophages (Lang et al., 2012) were classified and analysed for CpG-island occurrence in the regions -200 to +1 and +1 to +200 relative to the transcriptional start site. Class A: Genes, expression of which was at least 4-fold up-regulated by IFN- $\gamma$ and strongly counteracted by $T$. gondii infection (to 0.00 to 0.15 of non-infected control). Class B: Genes, expression of which was at least 4-fold up-regulated by IFN$\gamma$ and not considerably counteracted by $T$. gondii infection (to 0.70 to 1.60 of non-infected control). Class C: Genes, expression of which was at least 4-fold down-regulated by IFN- $\gamma$ and strongly counteracted by T. gondii infection (to 11.51 to 122.71 of non-infected control). Class D: Genes, expression of which was at least 4-fold down-regulated by IFN- $\gamma$ and not considerably counteracted by $T$. gondii infection (to 1.86 to 0.70 of non-infected control). Thresholds for identifying a CpG island were set as region of at least 200 bps, an observed CpG/expected CpG ratio greater than 0.60 , and a GC content of more than $50 \%$.

Interestingly, only $20(30 \%)$ of those IFN- $\gamma$-induced genes, expression of which was strongly counteracted in T. gondii-infected cells (Class A in Figure 6, see also appendix C) were predicted to contain a CpG island in the regions -200 to +1 and/or +1 to +200 relative to the TSS. In contrast, the other 47 genes (70\%) showed no such feature. The low number of $\mathrm{CpG}$-containing promoters in this group of genes thus greatly deviates from the average ratio of $60 \%$ in murine promoters (Antequera, 2003).

In contrast, among the 67 IFN- - -induced genes that were not strongly counteracted by T. gondii, 38 genes (57\%) were predicted to contain a CpG island in their promoter or proximal gene region (Class B in Figure 6) whereas 29 genes (43\%) lacked them. The number of CpG islands-containing promoters in this group of genes thus accorded with the average ratio previously described.

Genes that were repressed by IFN- $y$ showed a similar distribution of $\mathrm{CpG}$ to non-CpG-promoters as the average ratio in the murine genome irrespective of the impact of $T$. gondii infection (Figure 6). Thus, among those, expression of which was strongly counteracted by T. gondii, 56\% of promoters contained CpG islands (Class C in Figure 6) as compared to 62\% among those not considerably counteracted by parasite infection (Class D in Figure 6).

Taken together, the results suggest a correlation between a strong inhibitory effect of $T$. gondii on IFN$\mathrm{\gamma}$-induced genes and the absence of $\mathrm{CpG}$ islands in their promoters.

\subsubsection{Toxoplasma gondii interferes with distinct histone modifications at IFN- $p$ primary and} secondary response promoters

To better understand the impact of $T$. gondii infection on chromatin remodelling during an IFN- $\gamma$ response, post-translational modifications (PTMs) of histones generally associated with active gene transcription were analysed, including overall acetylation of histone $\mathrm{H} 4(\mathrm{H} 4 \mathrm{ac})$, acetylation of histone $\mathrm{H} 3$ at $\mathrm{Lys}^{9}$ (H3K9ac), tri-methylation of histone $\mathrm{H} 3$ at $\mathrm{Lys}^{4}$ (H3K4me3) and phosphorylation of histone $\mathrm{H} 3$ at $\operatorname{Ser}^{10}$ (H3S10p). Since histone modifications may differ between DNA regions of a distinct promoter, the 
impact of T. gondii on these modifications was determined at distal and/or proximal promoter sequences within - $1 \mathrm{~kb}$ from the transcriptional start site (TSS) (Figure 7).

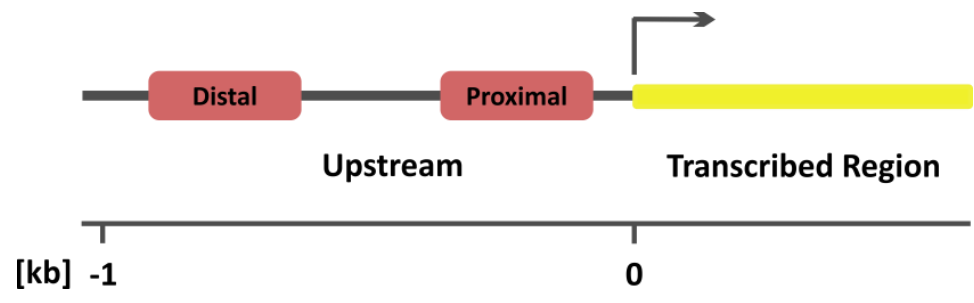

Figure 7: The impact of T. gondii infection on the regulation of histone modifications during IFN- $\gamma$ stimulation was determined at distal and proximal promoter sequences.

Schematic localisation of the analysed promoter regions, relative to the transcriptional start site.

Furthermore, modifications were analysed at promoters from IFN- $\gamma$ primary response genes, i.e. irf1 (interferon regulatory factor 1), irf8 (interferon regulatory factor 8) and stat1 (signal transducer and activator of transcription 1), as well as those from the secondary responsive genes ciita (class ॥ transactivator) and gbp2 (guanylate-binding protein 2). Histone modifications were monitored at multiple time points during 18 hours of IFN- $\gamma$ stimulation. To this end, RAW264.7 macrophages were infected or not and subsequently stimulated with IFN- $\gamma$. Histone modifications were analysed by means of chromatin immunoprecipitation (ChIP) and subsequently quantified by quantitative real-time PCR (Figure 7Figure 10). Quantification was performed by normalizing the results relative to the amount of input DNA. Effects greater than 2-fold up- or downregulation were regarded as enrichment or depletion during stimulation, respectively. 
A

A

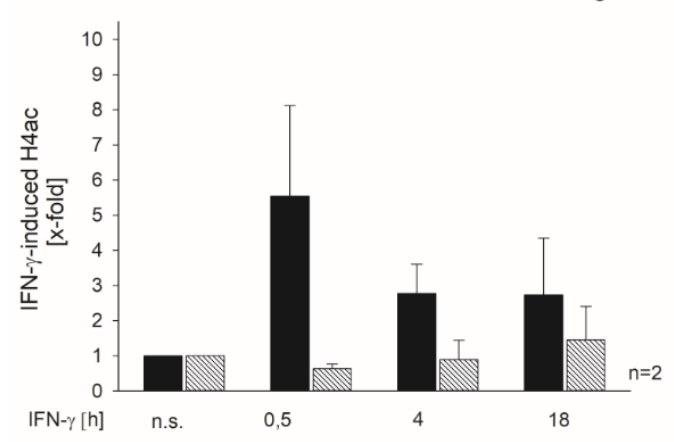

C

ciita (proximal)

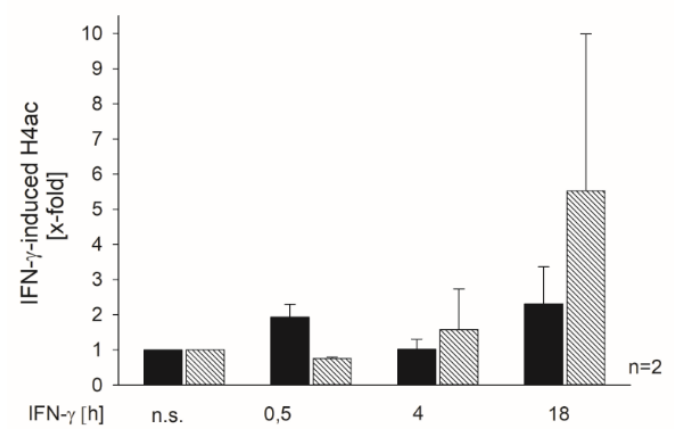

B

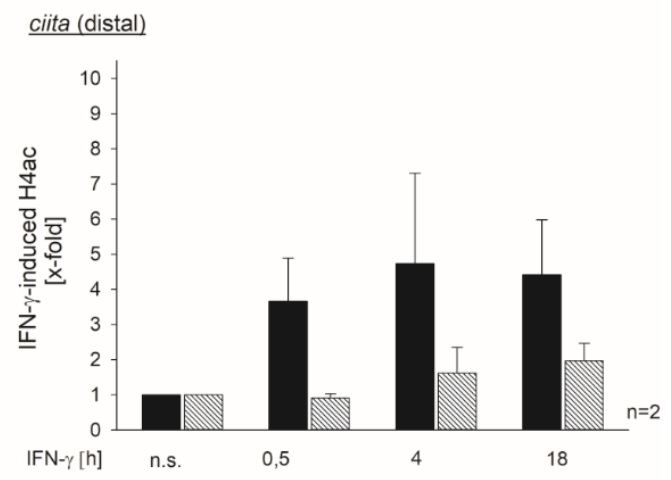

D

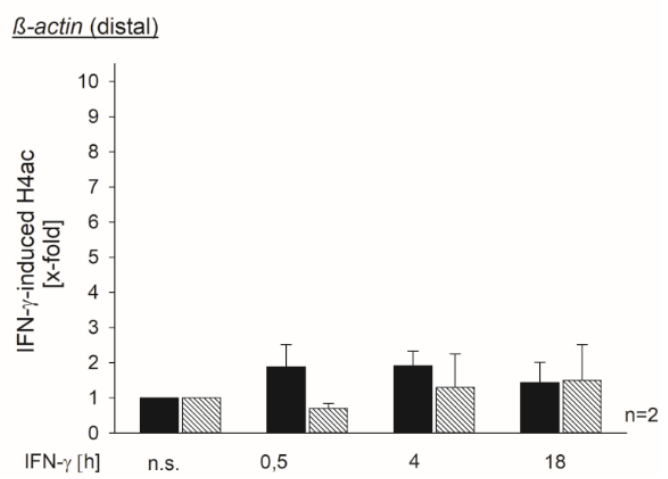

Figure 8: Toxoplasma gondii infection counter-regulates the increased histone $\mathrm{H} 4$ acetylation in response to IFN- $\gamma$.

RAW264.7 cells were infected with $T$. gondii at a parasite to host cell ratio of 5:1 for 24 hours or were left non-infected (n.i.).

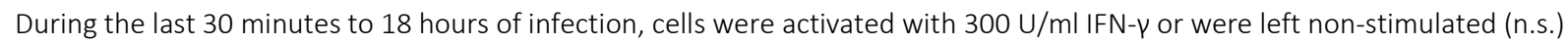
as indicated. After cross-linking DNA-protein complexes, cell lysates were subjected to ChIP analysis using an anti-acetyl-H4 antibody and protein A-coated magnetic beads. A sample incubated with an isotope control antibody was run in parallel. After isolation of DNA from chromatin immunoprecipitates or from input cell lysates, distal and/or proximal promoter fragments of (A) irf1, (B and C) ciita and (D) $\beta$-actin, were amplified by quantitative real-time PCR. IFN- $\gamma$-induced acetylation was quantified according to the ratio $\mathrm{R}=(\mathrm{E})^{\Delta \mathrm{CP} \text { ChIP(non-stimulated }-\mathrm{IFN}-\gamma \text {-treated) }} /(\mathrm{E})^{\triangle \mathrm{CP} \text { input (non-stimulated }-\mathrm{IFN}-\gamma \text {-treated) }}(\mathrm{E}=2)$. Bars represent means \pm SEM of two independent experiments.

Stimulation of non-infected cells with IFN- $p$ upregulated the acetylation of histone $\mathrm{H} 4$ ( $\mathrm{H} 4 \mathrm{ac}$ ) in the distal promoter region of irf1 (Figure 8A). The kinetical analysis revealed that the relative abundance of $\mathrm{H} 4 \mathrm{ac}$ declined after 30 minutes of stimulation but persisted throughout prolonged stimulation for 18 hours. Importantly, infection with $T$. gondii clearly inhibited the upregulation of $\mathrm{H} 4$ acetylation and even completely abolished any regulation of $\mathrm{H} 4 \mathrm{ac}$ during the course of IFN- $\gamma$ stimulation.

In non-infected cells, acetylation marks of $\mathrm{H} 4$ also increased in the distal promoter region of ciita after activation with IFN- $\gamma$ (Figure 8B). The relative abundance of these modifications persisted at a similar level throughout treatment. Again, infection with T. gondii almost completely inhibited an accumulation of this modification during the course of IFN- $\gamma$ stimulation. 
In contrast to the distal promoter region, stimulation with IFN- $\gamma$ was not accompanied by a considerable acetylation of $\mathrm{H} 4$ in the proximal region of the ciita promoter (Figure $8 \mathrm{C}$ ). Furthermore, parasite infection did not interfere with constitutive $\mathrm{H} 4 \mathrm{ac}$ levels during the first 4 hours of stimulation but appeared to promote acetylation after prolonged stimulation for 18 hours. However, this response was quite variable, and changes were not significant.

Control amplifications of a distal region of the housekeeping gene $\beta$-actin revealed no differences in the acetylation of $\mathrm{H} 4$ between non-stimulated and IFN- $\gamma$ treated cells or between infected and non-infected cells as expected (Figure 8D). This indicated that changes in $\mathrm{H} 4$ acetylation in response to IFN- $\gamma$ and/or T. gondii infection are promoter specific.

Taken together, the experiments showed that acetylation of histone $\mathrm{H} 4$ in distal promoter regions of the primary response gene irf1 and secondary response gene ciita are upregulated in macrophages during IFN- $\gamma$ stimulation. No such enrichment was induced in the proximal region of the ciita promoter. Remarkably, T. gondii largely abolished accumulation of these acetylations which are associated with active gene transcription. 
RESULTS

A

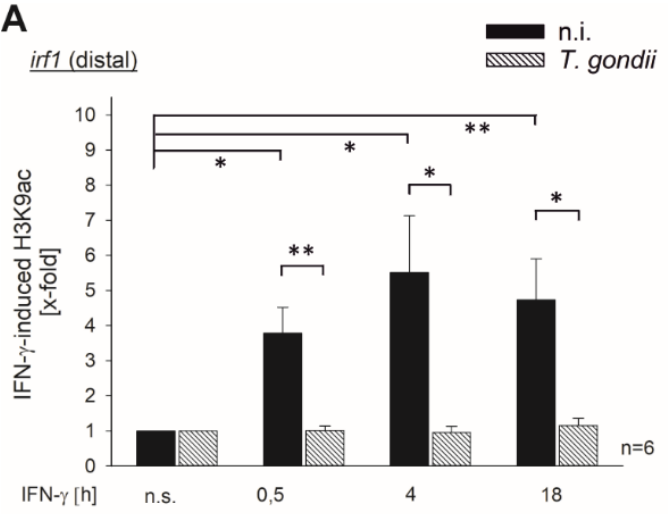

C

iff8 (distal)

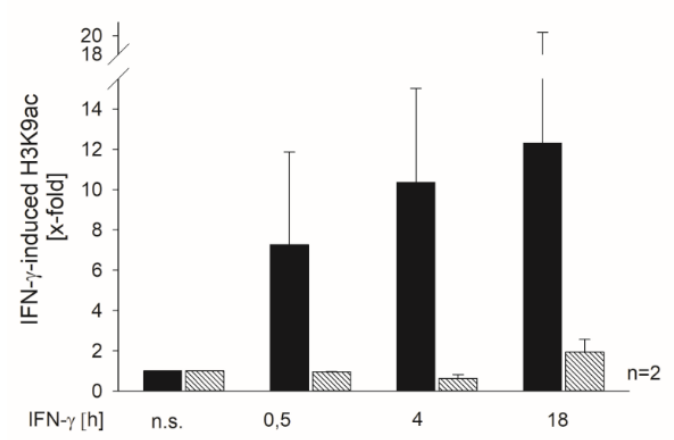

E



G

gbp2 (proximal)

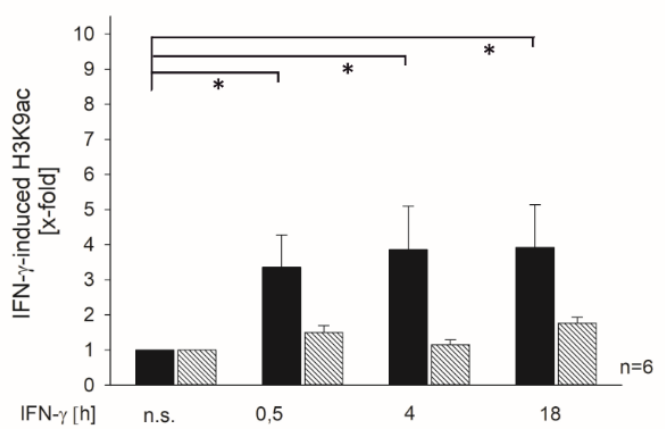

B

stat1 (distal)



D

ciita (distal)

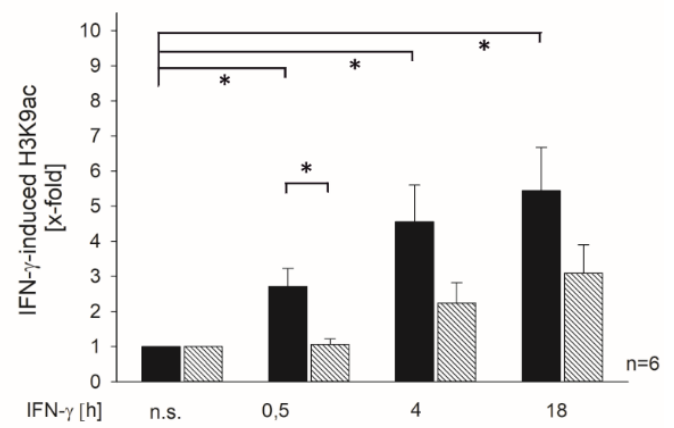

$\mathbf{F}$

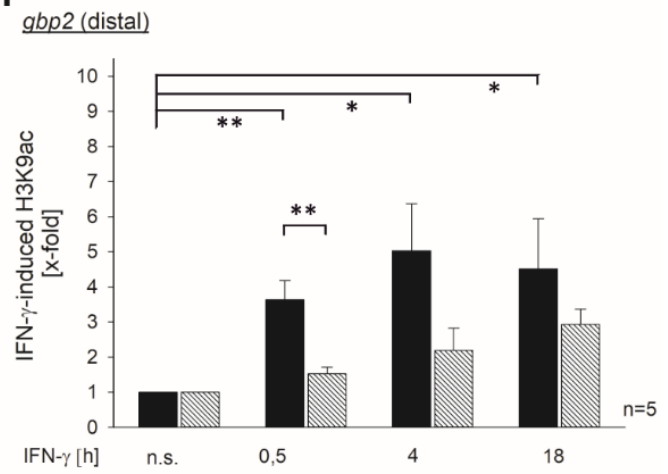

H

B-actin (distal)

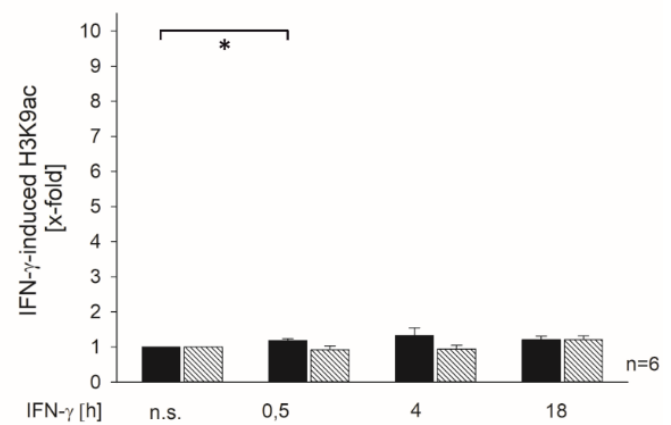

Figure 9: Toxoplasma gondii infection counter-regulates the increased acetylation of histone $\mathrm{H} 3$ at $\mathrm{Lys}^{9}$ in response to IFN- $\gamma$. 
RAW264.7 cells were infected with T. gondii at a parasite to host cell ratio of 5:1 for 24 hours or were left non-infected (n.i.).


as indicated. After cross-linking DNA-protein complexes, cell lysates were subjected to ChIP analysis using an anti-acetyl-H3K9 antibody and protein A-coated magnetic beads. A control sample was incubated with an isotope control antibody in parallel. After isolation of DNA from chromatin immunoprecipitates or from input cell lysates, distal and/or proximal promoter fragments of (A) irf1, (B) stat1, (C) irf8, (D and E) ciita, ( $F$ and G) gbp2 and (H) $\beta$-actin were amplified by quantitative real-time

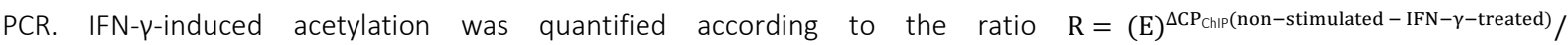
(E) $\triangle \mathrm{CP}_{\text {input }}$ (non-stimulated - IFN- $\gamma$-treated) $(E=2)$. Results are means $\pm \mathrm{SEM}$ of the number of independent experiments as indicated (n). Significant differences between the acetylation in non-stimulated (n.s.) and IFN- $\gamma$-stimulated cells, or between non-infected (n.i.) and infected (T. gondii) cells were identified by Student's t-test $\left({ }^{*} p<0.05,{ }^{* *} p<0.01,{ }^{* * *} p<0.001\right)$.

Stimulation of non-infected cells with IFN-p led to a significant upregulation $(p<0.05)$ of the site-specific acetylation of histone $\mathrm{H} 3$ at $\mathrm{Lys}^{9}$ (H3K9ac) in the distal promoter region of irf1 (Figure 9A). The kinetical analysis revealed that the relative abundance progressively increased in the early phase of stimulation for 30 minutes and 4 hours, but slightly declined during prolonged stimulation for 18 hours. Infection with $T$. gondii significantly inhibited $(p<0.05)$ elevation of H3K9 acetylation levels in response to IFN- - . Remarkably, the parasite even completely abolished any regulation of H3K9ac during the course of stimulation.

A similar pattern of $\mathrm{H} 3 \mathrm{~K} 9 \mathrm{ac}$ regulation was observed in the distal promoter regions of stat1 and irf8 in non-infected cells, although the overall upregulation was slightly higher as compared to the irf1 promoter (Figure 9B and C). Similar to the impact on irf1, T. gondii also prevented any H3K9ac regulation at the stat1 and irf8 promoter sites during IFN- $\gamma$ stimulation.

Acetylation of H3K9 continuously increased $(p<0.05)$ at the distal promoter region of ciita during stimulation of non-infected cells for up to 18 hours with IFN- $\gamma$ (Figure 9D). Infection with T. gondii inhibited accumulation of this modification 2.5- to 1.7-fold during the course of stimulation, with the H3K9 acetylation being significantly inhibited after short stimulation for 30 minutes.

In comparison to the distal promoter region of ciita, elevation of $\mathrm{H} 3 \mathrm{~K} 9$ acetylation levels in response to IFN- $\gamma$ was more moderate at the proximal region of the ciita promoter but it was nevertheless consistent and significant $(p<0.05)$ throughout stimulation (Figure 9E). T. gondii significantly inhibited such H3K9ac upregulation at 30 minutes of stimulation 2.5-fold $(p<0.05)$ but did not inhibit H3K9 acetylation after prolonged activation for 4 to 18 hours.

Stimulation of non-infected cells with IFN- $p$ significantly increased acetylation levels of H3K9 in both the distal and proximal promoter regions of gbp2 (Figure 9F and G). Kinetical analyses revealed that the relative abundance increased during the first 4 hours of stimulation but remained unchanged during prolonged stimulation for 18 hours. Similar to the impact of T. gondii on H3K9ac in the distal region of the ciita promoter, parasite infection inhibited H3K9ac accumulation during the entire course of 
stimulation, with the effect being significant at the distal promoter region after short stimulation for 30 minutes $(p<0.01)$.

IFN- $\gamma$ did not considerably regulate $\mathrm{H} 3 \mathrm{~K} 9$ acetylation in the $\beta$-actin promoter in both non-infected or T. gondii-infected cells, although statistical analysis revealed a significant difference $(p<0.05)$ between its abundance in ChIP precipitates from non-stimulated cells and from those treated with IFN- $\gamma$ for 30 minutes (Figure $9 \mathrm{H}$ ). This suggested that changes in $\mathrm{H} 3 \mathrm{~K} 9$ acetylation in response to IFN- $\gamma$ and/or T. gondii infection are promoter specific.

In summary, the experiments showed that stimulation of macrophages with IFN- $\gamma$ leads to a robust sitespecific acetylation of histone $\mathrm{H} 3$ at $\mathrm{Lys}^{9}$ both at distal and proximal promoter regions of primary and secondary IFN- $\gamma$-responsive genes. T. gondii generally inhibited accumulation of this histone modification that is associated with active gene transcription. It also became clear, that the T. gondiiinduced impact is much stronger at promoters from the primary response genes irf1, stat1 and irf8, where H3K9ac regulation is completely abolished. Parasite-mediated Inhibition of H3K9ac at promoters from the secondary response genes ciita and $g b p 2$ was in contrast largely partial.

A

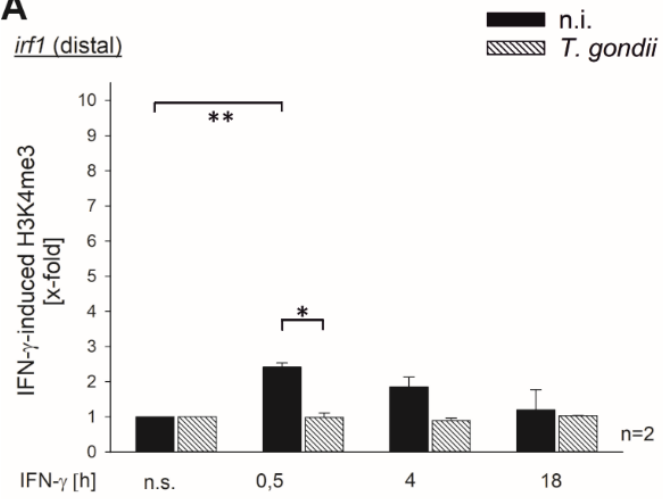

C

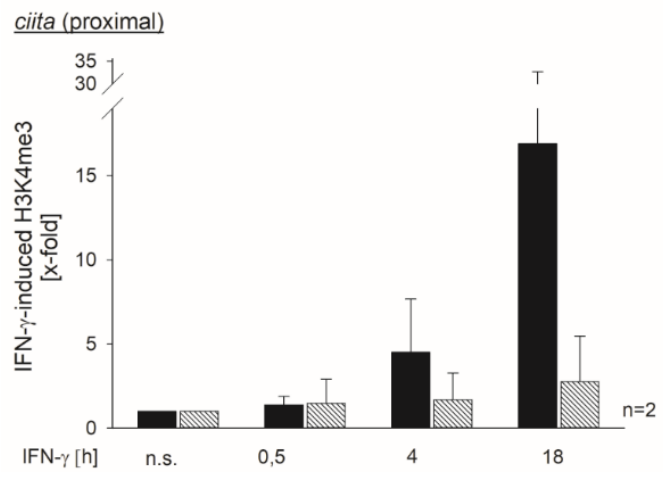

B

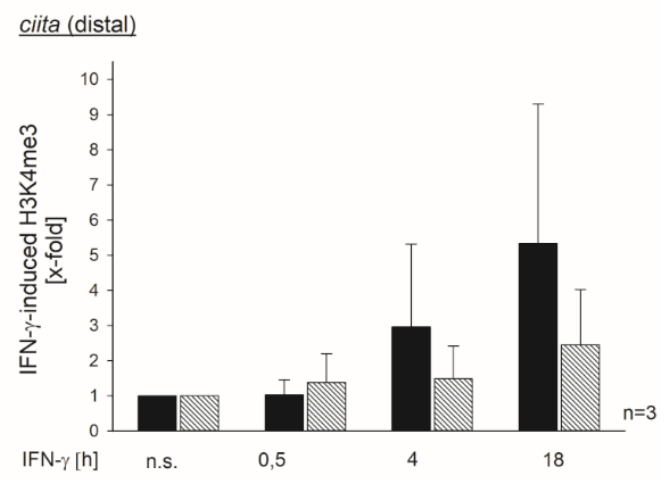

D

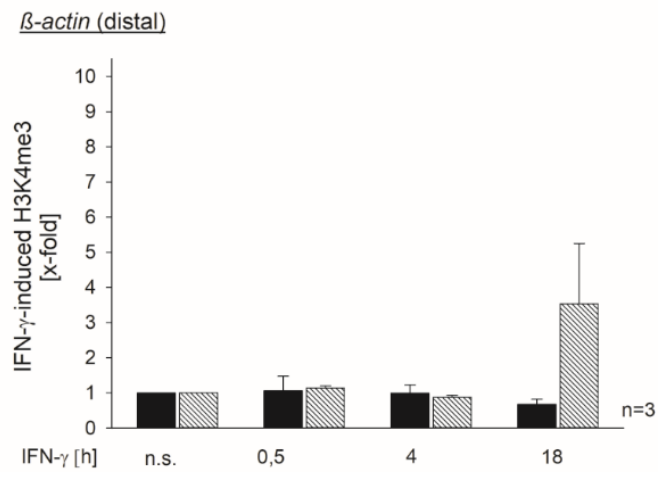

Figure 10: Toxoplasma gondii infection counter-regulates the increased tri-methylation of histone $\mathrm{H} 3$ at $\mathrm{Lys}^{4}$ in response to IFN- $\gamma$. 
RAW264.7 cells were infected with T. gondii at a parasite to host cell ratio of 5:1 for 24 hours or were left non-infected (n.i.).


as indicated. After cross-linking DNA-protein complexes, cell lysates were subjected to ChIP analysis using an anti-methyl-H3K9 antibody and protein A-coated magnetic beads. A control sample incubated with an isotope control antibody was run in parallel. After isolation of DNA from chromatin immunoprecipitates or from input cell lysates, distal and/or proximal promoter fragments of (A) irf1, (B and C) ciita and (D) $\beta$-actin were amplified by quantitative real-time PCR. IFN- $\gamma$-induced methylation

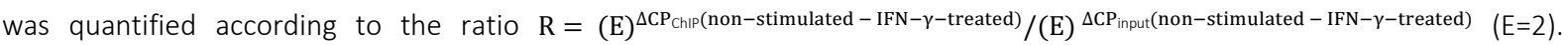
Results are means \pm SEM of at least two to three independent experiments as indicated. Significant differences between the methylation in non-stimulated (n.s.) and IFN- $\gamma$-stimulated, or between non-infected (n.i.) and infected (T. gondii) cells were identified by Student's t-test $(* p<0.05, * * p<0.01)$.

Upon stimulation of non-infected cells with IFN- $\gamma$, tri-methylation of histone H3Lys ${ }^{4}$ (H3K4me3) was significantly increased $(p<0.01)$ in the distal promoter region of irf1, though this enrichment was only modest and declined towards basal level during prolonged treatment (Figure 10A). Importantly, infection with T. gondii completely abolished any cytokine-induced regulation of H3K4me3 during the course of stimulation.

Lys ${ }^{4}$ tri-methylation of histone $\mathrm{H} 3$ showed a clearly different kinetic at both the distal and proximal promoter regions of ciita as compared to the irf1 promoter (Figure 10B and C). H3K4me3 was upregulated only after 4 hours of IFN- $\gamma$ stimulation and further increased during prolonged treatment for 18 hours. H3K4me3 levels appeared higher in the proximal region of the ciita promoter than in the distal region. Similar to irf1, parasite infection almost completely prevented H3K4me3 regulation in cytokine-stimulated cells.

Control amplifications of a distal promoter region of the house-keeping gene $\beta$-actin did not reveal any differences in the H3K4me3 modification in non-infected cells in response to IFN- $\gamma$ (Figure 10D). Interestingly however, T.gondii-infected cells showed 5-fold higher H3K4me3 levels after IFN- $\gamma$ stimulation for 18 hours as compared to non-infected cells. Although this parasite-imposed effect did not reach statistical significance, it might have obscured the inhibition of IFN- - -triggered H3K4 trimethylation by $T$. gondii at IFN- $\gamma$-responsive promoters.

Taken together, the experiments showed that stimulation with IFN- $\gamma$ is accompanied by tri-methylation of histone $\mathrm{H} 3 \mathrm{~K} 4$ at distal and proximal promoter regions of the primary response gene irf1 and the secondary response gene ciita although kinetics clearly differ between primary and secondary response genes. T. gondii infection completely abolished accumulation of this histone modification which is associated with active gene transcription. 
RESULTS

A

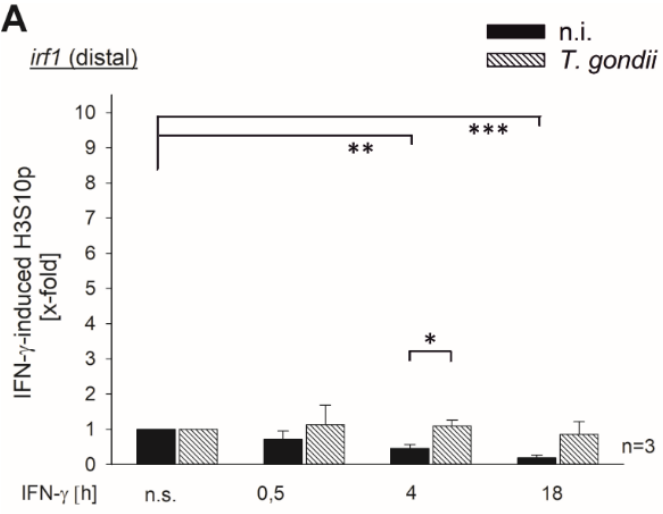

C

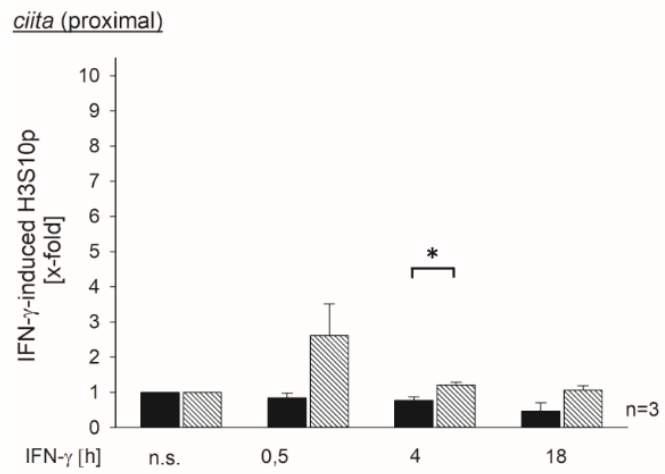

E

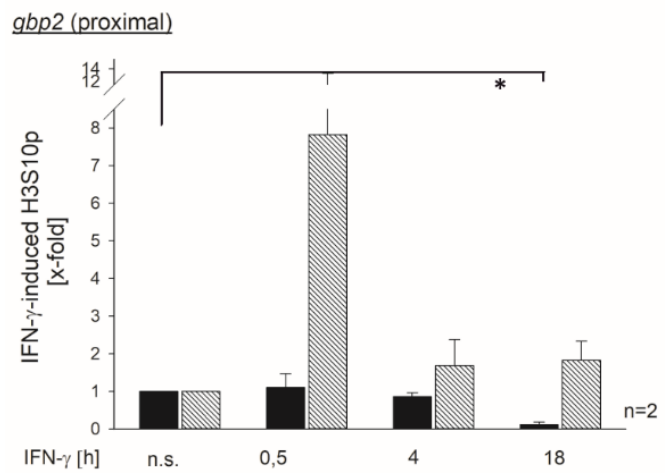

B

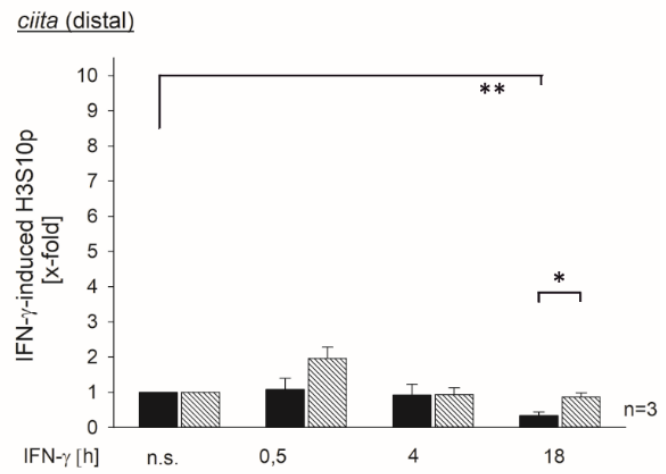

D

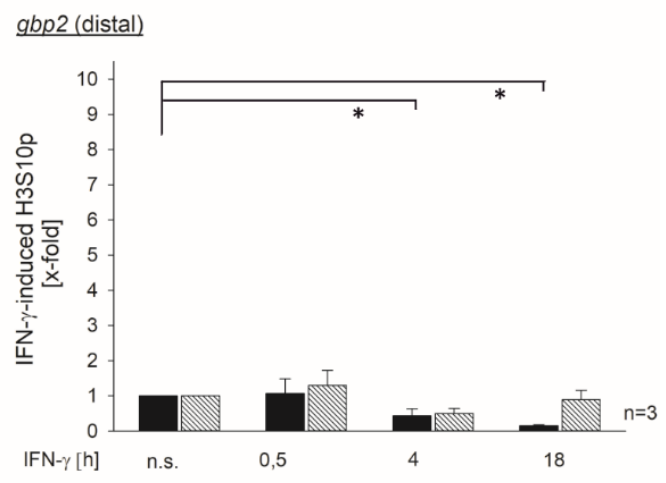

$\mathbf{F}$

$\underline{\text { B-actin (distal) }}$

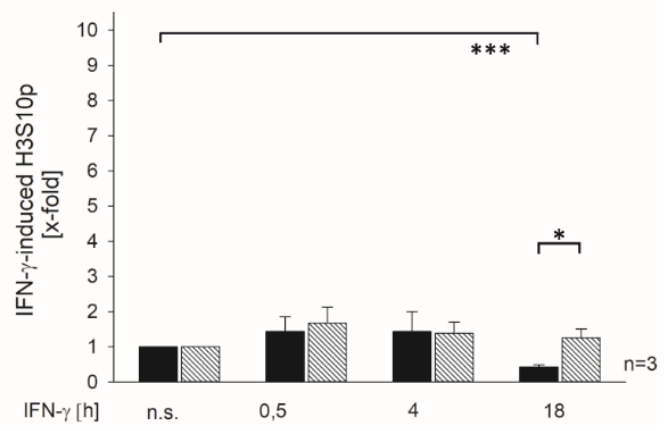

Figure 11: Toxoplasma gondii infection partially counter-regulates the reduced phosphorylation of histone $\mathrm{H} 3$ at Ser ${ }^{10}$ in response to IFN- $\gamma$.

RAW264.7 cells were infected with T. gondii at a parasite to host cell ratio of 5:1 for 24 hours or were left non-infected (n.i.). During the last 30 minutes to 18 hours of infection, cells were activated with $300 \mathrm{U} / \mathrm{ml} \mathrm{IFN-} \gamma$ or were left non-stimulated (n.s.) as indicated. After cross-linking DNA-protein complexes, cell lysates were subjected to ChIP analysis using an anti-phosphoH3S10 antibody and protein A-coated magnetic beads. A sample incubated with an isotope control antibody was run in parallel. After isolation of DNA from chromatin immunoprecipitates or from input cell lysates, distal and/or proximal promoter fragments of (A) irf1, (B and C) ciita, (D and E) gbp2 and (F) $\beta$-actin were amplified by quantitative real-time PCR. IFN- $\gamma$-induced phosphorylation was quantified according to the ratio $R=(E)^{\Delta C P_{\text {chip }}(\text { non-stimulated }- \text { IFN- } \gamma \text {-treated) }}$ / (E) $\triangle \mathrm{CP}_{\text {input }}$ (non-stimulated $-\mathrm{IFN}-\gamma$-treated) $(\mathrm{E}=2)$. Results are means $\pm \mathrm{SEM}$ of two to three independent experiments as indicated. Significant differences between the H3S10 phosphorylation between non-stimulated (n.s.) and IFN- $\gamma$-stimulated, or between non-infected (n.i.) and infected (T. gondii) cells were identified by Student's t-test $\left({ }^{*} p<0.05,{ }^{* *} p<0.01,{ }^{* * *} p<0.001\right)$. 
H3S10 phosphorylation marks in the distal region of the irf1 promoter were progressively depleted $(p<0.01)$ in non-infected cells during prolonged IFN- $\gamma$ stimulation for 4 and 18 hours (Figure 11A). Infection with $T$. gondii completely abolished any regulation of H3S10p during the course of stimulation resulting in H3S10p levels as observed in non-stimulated non-infected cells.

H3S10 in proximal and distal promoter regions of ciita and gbp2 were similarly dephosphorylated in non-infected cells following prolonged treatment with IFN- $\gamma$ for 4 or 18 hours (Figure 11B to E). Such H3S10 dephosphorylation was mostly counteracted by T. gondii. In the proximal promoter regions of ciita and gbp2, T.gondii infection additionally promoted H3S10 phosphorylation during early stimulation with IFN- $\gamma$ for 30 minutes.

Interestingly, control amplifications of the $\beta$-actin distal promoter region also revealed a decrease in the H3S10 phosphorylation in non-infected cells after 18 hours of IFN- $\gamma$ stimulation (Figure 11F; $p<0.001$ ). In addition, infection with $T$. gondii significantly abolished $(p<0.05)$ such H3S10p depletion. Thus, inhibition of H3S10p at irf1, ciita or gbp2 promoters after 18 hours of treatment and its counterregulation by $T$. gondii occurred both in IFN- $\gamma$-responsive and -non-responsive promoters.

Taken together, the experiments showed that H3S10 phosphorylation is not increased in distal and proximal promoter regions of IFN- $\psi$-responsive promoters, but constitutive H3S10p levels are rather diminished during prolonged stimulation independently of IFN- $\gamma$ promoter responsiveness. Infection with $T$. gondii promoted H3S10p in proximal promoter regions of distinct IFN- $\gamma$ secondary response genes. Additionally, it also counteracted the depletion of H3S10p during prolonged IFN- $\gamma$ treatment independently of the IFN- $\gamma$ responsiveness of the promoter.

Considering all experiments from this section, it became clear that $\mathrm{H} 4 \mathrm{ac}$ and site-specific H3K9ac and H3K4me3 are marks indicative for active IFN- $\gamma$-induced gene transcription and T. gondii inhibits their regulation during stimulation. Conversely, phosphorylation of $\mathrm{H} 3 \mathrm{~S} 10$ seems not to be indicative for active IFN- $\gamma$-regulated gene induction and T. gondii had only a moderate promoting effect.

\subsection{Modulation of STAT1 activity by Toxoplasma gondii}

IFN- $\gamma$ stimulation activates the transcription factor STAT1 (signal transducer and activator of transcription 1). Binding of IFN- $y$ to its cell surface receptors will lead to an intracellular phosphorylation cascade which eventually results in phosphorylation of latent STAT1 at the signature residue tyrosine at position 701 (pY701). This modification is obligatory for STAT1 DNA binding activity and initiation of IFNv-dependent transcription (Shuai et al., 1993). In addition, complete activation of STAT1 requires phosphorylation of serine at position 727 (pS727) (Wen et al., 1995). Genome wide transcriptional 
analyses have revealed an almost complete dysregulation of IFN- $\gamma$-inducible genes in $T$. gondii-infected cells (Kim et al., 2007; Lang et al., 2012). Given the importance for transcriptional activation, the following experiments were conducted to assess whether $T$. gondii targets these two critical STAT1 phosphorylations in macrophages.

\subsubsection{Toxoplasma gondii modulates Y701- and S727-phosphorylation of STAT1}

To determine the impact of T. gondii infection on STAT1 activation, RAW264.7 macrophages were infected or not and subsequently IFN- $\gamma$-activated or left non-stimulated. STAT1-Y701- and S727phosphorylation levels, as well as the amount of total STAT1 protein were analysed at multiple time points during 24 hours of IFN- $\gamma$ stimulation. The analysis of complete cell lysates was performed by means of Western blot technique (Figure 12).

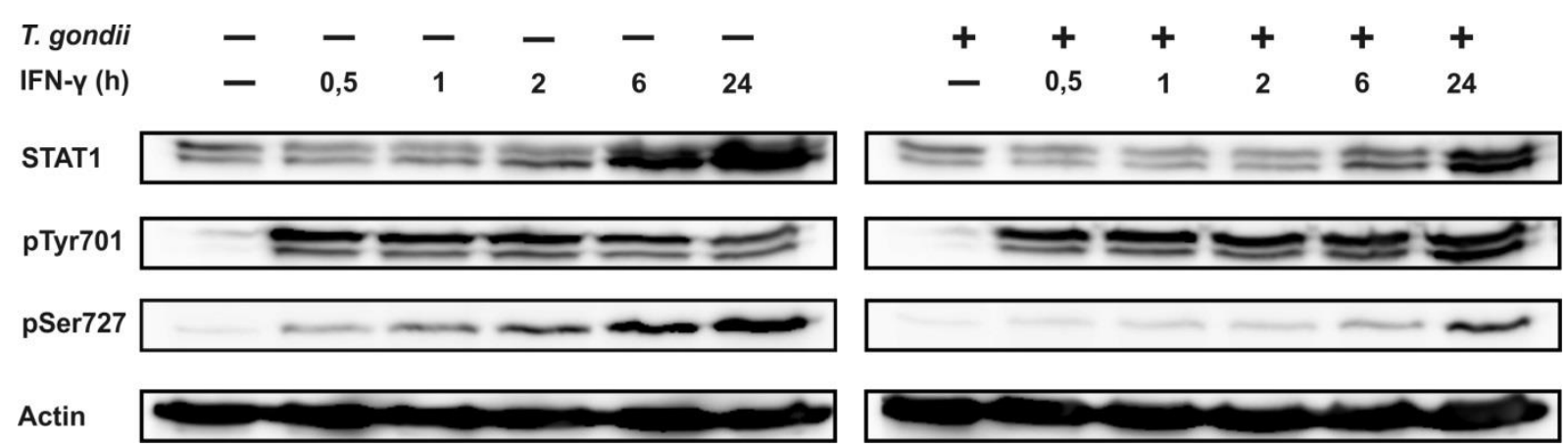

Figure 12: Toxoplasma gondii differentially affects STAT1 phosphorylations.

RAW264.7 cells were infected with $T$. gondii at a parasite to host cell ratio of 6:1 for 25.5 hours or were left non-infected. During the last 30 minutes to 24 hours of infection, cells were activated with $100 \mathrm{U} / \mathrm{ml}$ IFN- $\gamma$ or were left non- stimulated as indicated. Thereafter, complete cell lysates were prepared. Proteins were separated by SDS-PAGE and analysed by immunoblotting using anti-pS727-STAT1, anti-pY701-STAT1 and anti-STAT1 $\alpha$ antibodies. Immunodetection of actin was used as loading control. The results are representative for three independent experiments.

Analysis of lysates of non-infected cells confirmed that total STAT1 $\alpha$ is constitutively expressed. Initial IFN- $\gamma$ stimulation had no effect on STAT1 expression, but after 6 hours to 24 hours of stimulation, a progressive increase in protein amount was detected. This up-regulation corresponds with the positive auto-regulatory loop of STAT1 signalling, where the protein is IFN-p-inducible (Lehtonen et al., 1997; Cheon and Stark, 2009). T. gondii infection had no effect on basal STAT1 expression but counteracted the IFN- - -induced up-regulation of the protein. This result clearly illustrates the inhibitory effect of T. gondii infection on IFN- $\gamma$ regulated gene transcription. 
STAT1 was recognized as a latent factor in resting cells but it became activated upon IFN- $\gamma$ stimulation. Short stimulation for 30 minutes robustly induced activation of STAT1, as indicated by high amounts of tyrosine-phosphorylated STAT1 in both infected and non-infected cells. During the course of stimulation, the level of pY701-phosphorylated STAT1 was stable but was slightly diminished in noninfected cells after prolonged stimulation for 24 hours. T. gondii infection had no effect on the early phosphorylation pattern but counteracted the down-regulation of STAT1 Y701-phosphorylation after prolonged stimulation for 24 hours and instead even slightly promoted tyrosine phosphorylation.

A small portion of STAT1 appeared to be serine phosphorylated in a constitutive fashion. The amount of pS727-STAT1 increased progressively during IFN- $\gamma$ treatment. T. gondii infection had no effect on the STAT1-pS727 level in the absence of stimulus, but constantly counteracted the IFN- $\mu$-induced upregulation of STAT1 serine phosphorylation.

Conclusions about quantities of STAT1 expression and phosphorylation levels were justified by detection of uniform levels of the house-keeping protein actin expression, which confirmed equal sample loading. Taken together, the results showed that $T$. gondii apparently modulates the two critical STAT1 phosphorylations. Whereas serine phosphorylation of STAT1 was constantly inhibited by T. gondii, tyrosine phosphorylation was promoted during prolonged stimulation.

\subsubsection{Representative T. gondii clonal strains all modulate STAT1 phosphorylation}

Toxoplasma gondii isolates from North America and Europe mainly belong to three clonal lineages: type I, type II and type III (Howe and Sibley, 1995). These strains differ in their interference with multiple host signalling pathways (Melo et al., 2011). However, it is known, that the clonal lineages of T. gondii similarly inhibit STAT1 transcriptional activity (Rosowski and Saeij, 2012). To assess whether there are parasite strain-specific differences on IFN- - -induced STAT1 phosphorylation in macrophages, RAW264.7 cells were infected or not with representatives of the three lineages and subsequently IFN- $\gamma$-activated or left non-stimulated. The analysis of STAT1-Y701- and S727-phosphorylation levels, as well as the amount of total STAT1 in complete cell lysates was performed by means of Western blot technique (Figure 13). 

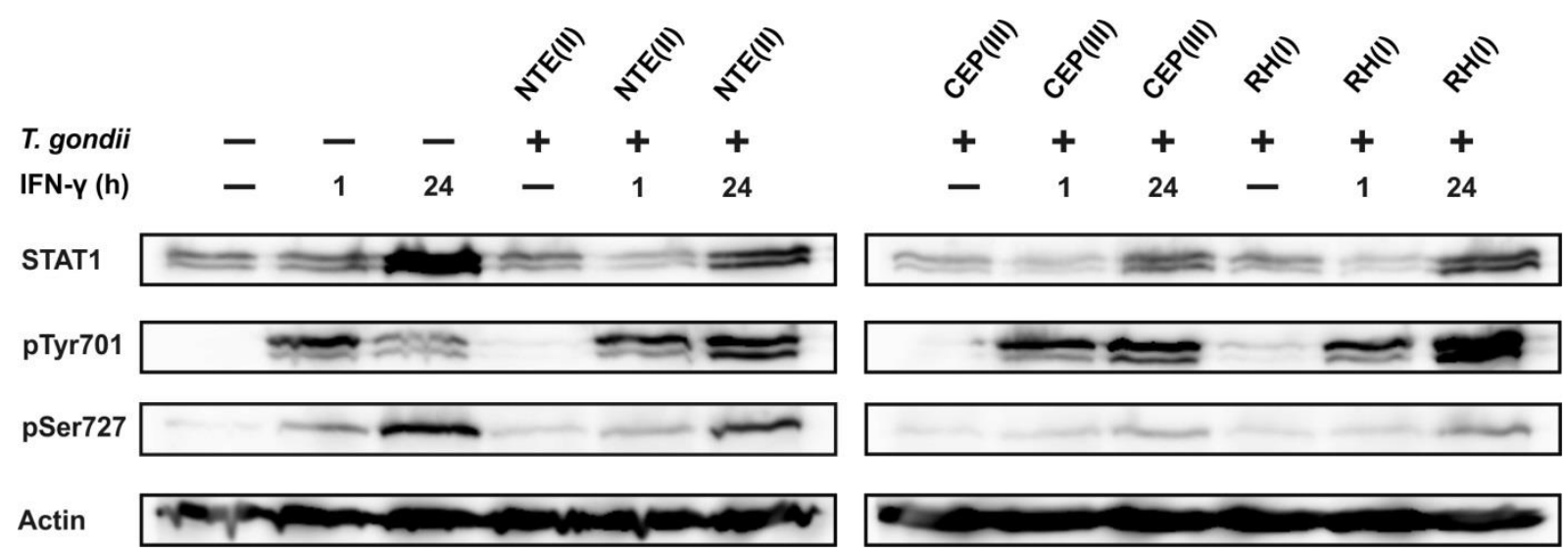

Figure 13: Toxoplasma gondii clonal lineages I, II and III similarly modulate STAT1 phosphorylations.

RAW264.7 cells were infected with T. gondii strains RH(I), NTE(II) or CEP(III) at a parasite to host cell ratio of 6:1 for 25.5 hours or were left non-infected. During the last one or 24 hours of infection, cells were activated with $100 \mathrm{U} / \mathrm{ml} \mathrm{IFN-} \gamma$ or were left non-stimulated as indicated. Thereafter, complete cell lysates were prepared. Proteins were then separated by SDS-PAGE and analysed by immunoblotting using anti-pS727-STAT1, anti-pY701-STAT1 and anti-STAT1 $\alpha$ antibodies. Immunodetection of actin was used as loading control. The results are representative for three independent experiments.

As observed in the previous experiment, samples from non-infected cells contained constitutively expressed total STAT1. Initial stimulation with IFN- $\gamma$ for one hour did not affect the amount of protein, but prolonged stimulation for 24 hours led to a strong increase in STAT1 level. This up-regulation was impaired after infection with representatives of all three $T$. gondii lineages. Compared to the impact of NTE(II) and RH(II) infection, the CEP(III) strain more severely inhibited the STAT1 up-regulation after prolonged stimulation for 24 hours.

Compared to non-infected cells, infections with the RH(I), NTE(II) and CEP(III) had no impact on STAT1 activation by tyrosine-phosphorylation after one hour of IFN- $\gamma$ stimulation but led to higher levels of activated STAT1 after prolonged stimulation for 24 hours. Interestingly, strain-specific differences in the magnitude of regulation were detected, where the increase was more prominent in cells infected with T. gondii strain $\mathrm{RH}(\mathrm{I})$. Furthermore, $\mathrm{RH}(\mathrm{I})$ infection induced weak tyrosine phosphorylation of STAT1 in the absence of IFN- - .

The representatives of the three lineages all inhibited IFN- $\gamma$-induced STAT1 serine phosphorylation. This modification was already suppressed during the early phase of stimulation but was more severely repressed after 24 hours of stimulation. The inhibiting effect was more prominent in cells infected with T. gondii strains $\mathrm{RH}(\mathrm{I})$ and $\mathrm{CEP}(\mathrm{III})$, where $\mathrm{pS727}$ regulation was almost completely abolished.

Conclusions about STAT1 expression and phosphorylation levels were justified by detection of uniform actin expression, which confirmed equal sample loading. 
Taken together, the experiment suggested, that parasites of the different $T$. gondii clonal lineages I, II and III all interfere with IFN- $\gamma$-regulated STAT1 activation in a similar manner. Specifically, they inhibited serine phosphorylation while simultaneously promoting STAT1 tyrosine phosphorylation during prolonged stimulation. However, the strains differed in the extent to which they modulate STAT1 phosphorylations and strain $\mathrm{RH}(\mathrm{I})$ additionally induced STAT1-pY701 in the absence of IFN- $\gamma$. Importantly, the similar patterns of interference confirmed that $T$. gondii strain NTE(II) is an eligible representative to study Toxoplasma-induced modulation of STAT1 activity.

\subsubsection{Toxoplasma gondii increases nuclear localisation of activated STAT1}

\subsubsection{Toxoplasma gondii modulates subcellular distribution of STAT1}

After IFN- $\gamma$ activation, STAT1 is imported into the nucleus and eventually initiates transcription. Thereafter, STAT1 falls off the DNA, gets dephosphorylated and cycles back to the cytoplasm (Meyer et al., 2003). If the IFN- $\gamma$-activated, receptor-associated kinases are still active, STAT1 will then be reactivated and imported back into the nucleus (Meyer et al., 2003; Koch et al., 2012). In that way, duration and magnitude of STAT1-dependent gene activation in response to IFN- $\gamma$ is controlled by cytoplasmic and nuclear levels of activated STAT1. To gain deeper insights into the T. gondii-induced modulation of STAT1 activities, a cell fractionation was conducted. To this end, RAW264.7 macrophages were infected or not with $T$. gondii and subsequently IFN- $\gamma$-activated or left non-stimulated. The impact of infection on levels of total STAT1 and its activation marks pY701 and pS727 in nuclear and cytoplasmic compartments was analysed by means of Western blotting (Figure 14A) and quantified by densitometric analysis (Figure 14B - D). 
A



cytoplasmatic fraction

$\begin{array}{llllll}- & - & - & + & + & +\end{array}$


B

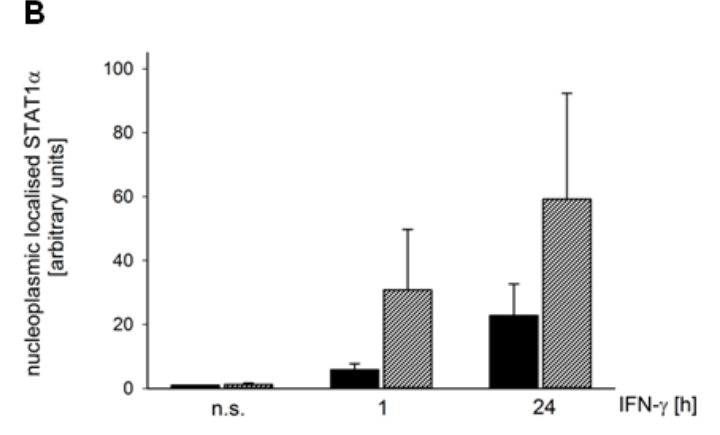

D



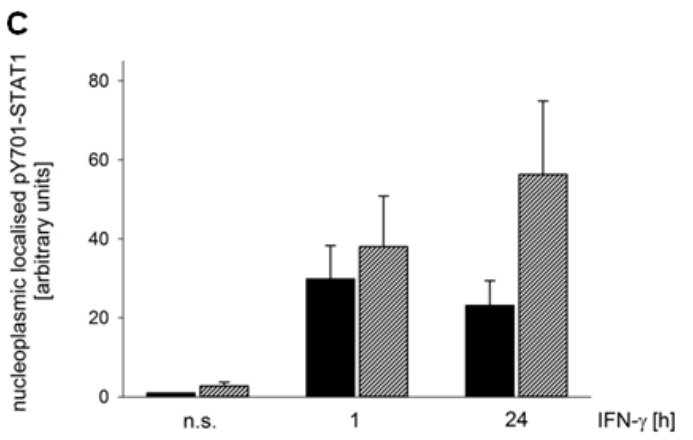

n.i. T. gondii-infected

Figure 14: Toxoplasma gondii elevates IFN- $\gamma$-induced nuclear localisation of STAT1 and its phosphorylated isoforms.

(A) RAW264.7 cells were infected with T. gondii at a parasite to host cell ratio of 6:1 for 25.5 hours or were left non-infected. During the last one or 24 hours of infection, cells were activated with $100 \mathrm{U} / \mathrm{ml} \mathrm{IFN-} \gamma$ or were left non-stimulated as indicated. Thereafter, cytoplasmic and nuclear protein extracts were prepared. Proteins were then separated by SDS-PAGE and analysed by immunoblotting using anti-pS727-STAT1, anti-pY701-STAT1 and anti-STAT1 $\alpha$ antibodies. Immunodetection of BRG1, GAPDH and actin were used as fractionation and loading controls. The results are representative for five independent experiments. (BD) Densitometric analyses of (B) nuclear STAT1a, (C) nuclear STAT1-pY701, (D) nuclear STAT1-pS727 are indicated. Bars represent means \pm SEM of five independent experiments.

Total STAT1 was detected in cytoplasmic extracts from non-infected and T. gondii-infected cells in the absence of IFN- - , with a slightly higher amount in infected cells. IFN- $\gamma$ treatment for one hour had no 
effect on the cytoplasmic level of STAT1 in non-infected cells, but prolonged stimulation for 24 hours led to a strong increase. A similar trend was detected in T. gondii-infected cells, where the amount of STAT1 in the cytoplasmic fraction was not strongly affected during short stimulation but was clearly increased after prolonged treatment for 24 hours.

Total STAT1 was not detected in nuclear extracts from non-infected and T. gondii-infected cells in the absence of IFN- $\gamma$. Upon stimulation of non-infected cells for one hour, STAT1 was detected in the nuclear fraction in very little amount, but it considerably increased after prolonged stimulation for 24 hours. Nuclear fractions of stimulated, T. gondii-infected cells contained clearly more total STAT1 at one and 24 hours of stimulation as compared to non-infected cells. The considerably elevated levels of IFN- $\gamma$ induced nuclear STAT1 in parasite-infected cells were further confirmed by densitometric quantification of independent experiments (Figure 14B).

Activated STAT1-pY701 was detected in the cytoplasmic fraction of non-infected and T. gondii-infected cells only after IFN- $\gamma$ treatment. Stimulation of non-infected cell for one hour induced pY701-activation, which was slightly reduced after 24 hours of treatment. In comparison, comparable amounts of STAT1p701 were detected in IFN- $\gamma$ stimulated, T. gondii-infected cells, though levels were not affected by duration of treatment.

Only after IFN- $y$ treatment was Y701-phosphorylated STAT1 detected in the nuclear fraction of noninfected cells. Compared to the early phase of stimulation for one hour, the level of STAT1-p701 was slightly decreased after 24 hours in these cells. Remarkably, levels of pY701-activated STAT1 were strongly increased in nuclear extracts from stimulated, infected cells as compared to non-infected controls. They did not differ between short and prolonged IFN- $\gamma$ treatment. Interestingly, in contrast to non-infected cells, T. gondii induced a weak induction of STAT1-pY701 in the absence of IFN- $\gamma$. The densitometric quantification of independent experiments confirmed a parasite-induced strong increase of nuclear localised Y701-phosphorylated STAT1 after stimulation (Figure 14C).

STAT1-pS727 was detected in cytoplasmic extracts from non-infected and T. gondii-infected cells in the absence of IFN- $y$, though in very little amount. In non-infected cells, levels of cytoplasmic STAT1-pS727 increased during stimulation with high amounts being detected after prolonged treatment for 24 hours. In comparison, T. gondii-infected cells contained more cytoplasmic pS727-STAT1 after stimulation for one hour but less pS727-STAT1 during prolonged IFN- $\gamma$ treatment. However, the levels of pS727-STAT1 did not change in infected cells between one hour and 24 hours of stimulation.

Similar to the cytoplasmic fraction, little amounts of STAT1-pS727 were detected in nuclear extracts from non-infected and T. gondii-infected cells in the absence of IFN- $\gamma$. The level of nuclear STAT1-pS727 was slightly increased after initial stimulation for one hour in non-infected cells but declined after 
prolonged treatment for 24 hours. In comparison, the nuclear fractions of IFN- - -stimulated, T. gondiiinfected cells contained much higher level of pS727-STAT1 already at one hour after stimulation. S727 phosphorylation of STAT1 further increased during prolonged activation for 24 hours, which was confirmed by densitometric quantification of independent experiments (Figure 14D).

Conclusions about subcellular distribution of total and phosphorylated STAT1 $\alpha$ were justified by uniform actin and glyceraldehyde-3-phosphate dehydrogenase (GAPDH) expression levels, which confirmed equal sample loading. GAPDH is a multifunctional protein which is localised in multiple subcellular compartments (reviewed in Tristan et al., 2011). The clearly higher protein abundance in the cytoplasmic fraction and the uniform expression levels within the distinct fraction samples confirmed efficient fractionation. Further, exclusive detection of Brahma-related gen-1 (BRG1), a component of chromatin modifying enzymatic complexes (Khavari et al., 1993), in the nuclear extract additionally confirmed purity of the cytoplasmic fraction.

Together the results showed, that stimulation of cells with IFN- $\gamma$ leads to an increase of STAT1 and its activated versions STAT1-pY701 and -pS727 in both, the nuclei and the cytoplasm of non-infected cells, as well as in T. gondii-infected cells. When directly compared, it became evident that the infection has no prominent effect on the IFN- - -induced amounts of total STAT1, as well as pY701- and pS727-STAT1 in the cytoplasm. Importantly enough however, infection with $T$. gondii induced a strong accumulation of STAT1 and its activated versions STAT1-pY701 and -pS727 in the nuclei of IFN- $\gamma$-stimulated cells.

\subsubsection{Toxoplasma gondii increases DNA association of activated STAT1}

The previous experiment revealed increased amounts of STAT1, as well as pY701- and pS727-activated STAT1 in nuclei of infected cells, whereas cytoplasmic levels were less affected by the parasite. However, complete cell protein extraction using mild detergent conditions had resulted in decreased amounts of STAT1 $\alpha$ and STAT1-pS727 in T. gondii-infected cells (see section 3.2.1 and 3.2.2). These inconsistent findings could be due to methodological aspects where mild detergent extraction may yield a minor fraction of nuclear STAT1 only. To address this possibility, RAW264.7 macrophages were infected or not with $T$. gondii, subsequently IFN- $\gamma$-activated or left non-stimulated and complete cell protein extracts were prepared by cell lysis under harsh conditions including $0.1 \%(\mathrm{w} / \mathrm{v})$ SDS as a detergent and sonication. The impact of T. gondii infection on levels of total STAT1 and its activation marks pY701 and pS727 was then analysed by SDS-PAGE and Western blotting (Figure 15). 


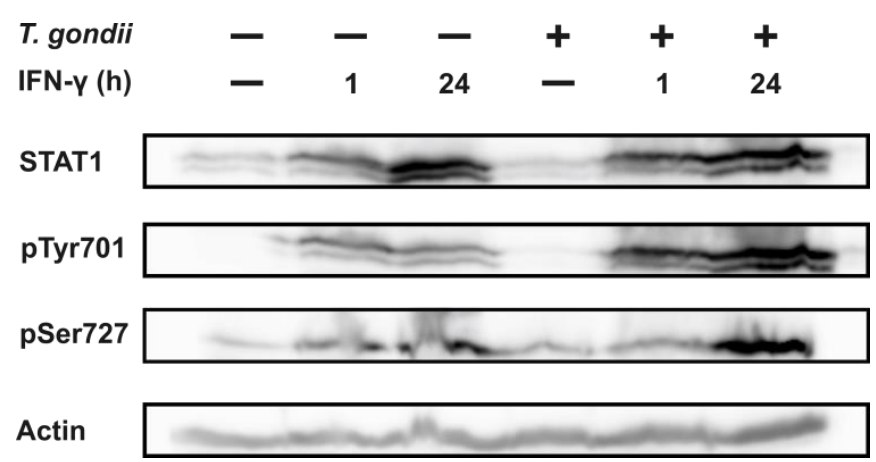

Figure 15: Toxoplasma gondii increases total Y701- and S727-STAT1 phosphorylations.

RAW264.7 cells were infected with T. gondii at a parasite to host cell ratio of 6:1 for 25.5 hours or were left non-infected. During the last one or 24 hours of infection, cells were activated with $100 \mathrm{U} / \mathrm{ml} \mathrm{IFN-} \gamma$ or were left non-stimulated as indicated. Thereafter, complete cell extracts were prepared by lysis in SDS-containing extraction buffer and sonication. Proteins were then separated by SDS-PAGE and analysed by immunoblotting using anti-pS727-STAT1, anti-pY701-STAT1 and anti-STAT1 $\alpha$ antibodies. Immunodetection of actin was used as loading control. The results are representative for two independent experiments.

Under these conditions and in line with the previous results (see section 3.2.1 and 3.2.2), IFN- $\gamma$ stimulation for one and 24 hours induced a progressive increase of total STAT1 and pS727-activated STAT1 in extracts from non-infected cells, whereas pY701-STAT1 level increased after IFN- $\gamma$ treatment for 1 hour and then remained unchanged (Figure 15). In sharp contrast to the previous results however, protein extracts from T. gondii-infected cells prepared under harsh extraction conditions contained comparable amounts of total STAT1 and considerably more pS727-STAT1 and pY701-STAT1 after prolonged IFN- $\gamma$ stimulation as compared to non-infected controls.

This experiment clearly suggested that $T$. gondii-infected cells contain higher IFN- $\gamma$-induced levels of activated STAT1, but this became only evident after shearing of DNA and after harsh protein extraction. Since STAT1 is a DNA-binding protein, the following experiment was performed to test the hypothesis of a T. gondii-induced modulation of the DNA association of STAT1. To this end, RAW264.7 macrophages were infected or not with $T$. gondii and were subsequently IFN- $\gamma$-activated or left non-stimulated. Complete cell protein extracts were prepared using mild detergent-containing buffer as in the initial experiments. To further solubilize DNA-bound proteins, an aliquot was then additionally treated with DNase. The levels of total STAT1 and its activated versions pY701- and PS727-STAT1 were then analysed by means of Western blotting (Figure 16). 
mild detergent lysates

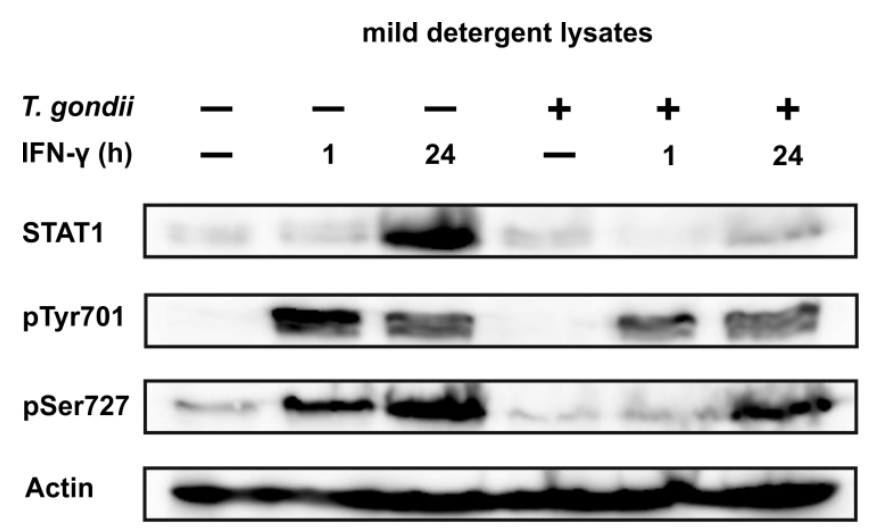

mild detergent lysates treated with DNase



Figure 16: Toxoplasma gondii increases DNA-bound pY701- and pS727-STAT1.

RAW264.7 cells were infected with T. gondii at a parasite to host cell ratio of 6:1 for 25.5 hours or were left non-infected.

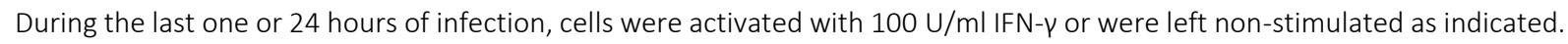
Thereafter, complete cell lysates were prepared in mild detergent lysis buffer. During the last 30 minutes of lysis an aliquot was additionally treated with DNase. Proteins were then separated by SDS-PAGE and analysed by immunoblotting using antipS727-STAT1, anti-pY701-STAT1 and anti-STAT1 $\alpha$ antibodies. Immunodetection of actin was used as loading control. The results are representative for two independent experiments.

Analysis of the IFN- $\gamma$-induced levels of activated STAT1 in non-infected and T. gondii-infected cells extracted under mild detergent conditions led to similar results as in the previous analyses (see section 3.2.1 and 3.2.2). In non-infected cells, the additional DNase digestion had no effect on the relative STAT1, pY701-STAT1 or pS727-STAT1 levels during the time course of stimulation, although the overall amounts of detectable protein were reduced.

Furthermore, the difference in amounts of STAT1 between extracts from non-infected and T. gondiiinfected cells appeared also non-affected by the digestion of DNA. In comparison, extracts from parasite-infected cells contained a lower level of STAT1. However, samples from infected cells, in which DNA had been degraded, yielded higher amounts of pS727-activated STAT1 after prolonged stimulation and the parasite-induced elevation of Y701 phosphorylation was considerably more prominent at one and 24 hours of activation.

Conclusions about STAT1 levels in the different protein samples were justified by uniform actin expression levels, which confirmed equal sample loading.

The latter two experiments revealed that $T$. gondii considerably increases the levels of pS727- and pY701-activated STAT1 particularly after prolonged stimulation for 24 hours. This became however only evident when protein extracts were prepared under conditions where DNA was degraded, indicating that $T$. gondii increases the association of IFN- $\gamma$-activated STAT1 with DNA. 


\subsubsection{Toxoplasma gondii prolongs nuclear accumulation of STAT1}

Western blot analysis of STAT1 subcellular distribution had revealed a strong T. gondii-induced nuclear accumulation of STAT1 during IFN- $\gamma$ stimulation, progressing in a gradual fashion (see section 3.2.3.1). This observation was further analysed on single cell level by means of immunofluorescence microscopy (Figure 17). To this end, murine NIH/3T3 fibroblast cells expressing a STAT1 $\alpha$-GFP fusion protein were used to visualise IFN- $\gamma$-dependent intracellular redistribution of STAT1. The validity of this approach has been previously demonstrated by STAT1-GFP being indistinguishable from its wild-type protein, displaying the same kinetics of nuclear import and export to the cytoplasm (Köster and Hauser, 1999). $\mathrm{NIH} / 3 \mathrm{~T} 3$ cells were thus infected or not with $T$. gondii and subsequently activated with IFN- $\gamma$ or left nonstimulated. In order to assess long term effects of T. gondii-infection on nuclear STAT1 $\alpha$, duration of IFN- $\gamma$ stimulation was extended up to 40 hours.

A

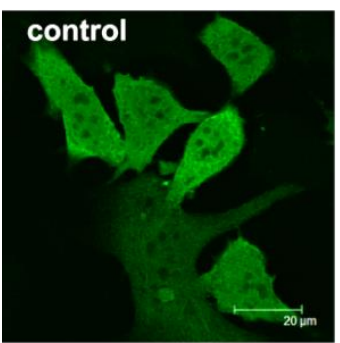

C

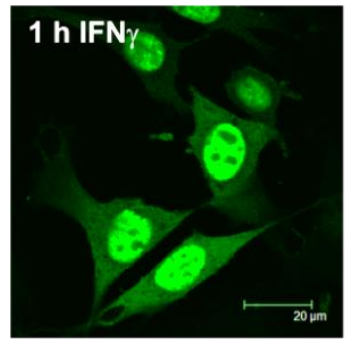

E

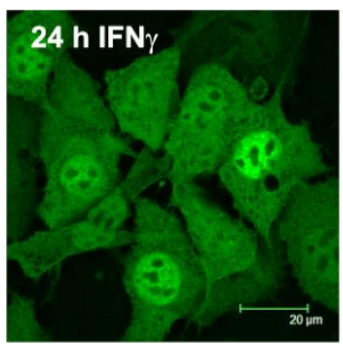

G

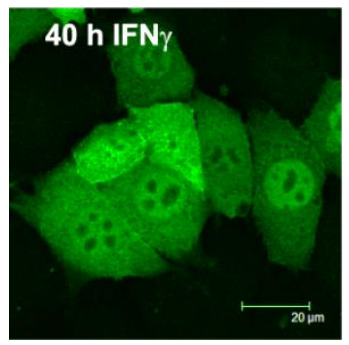

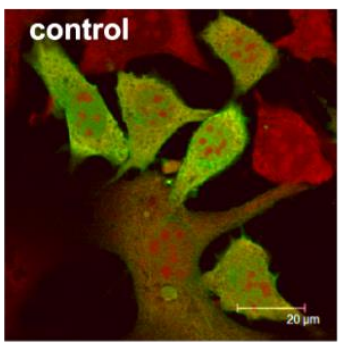
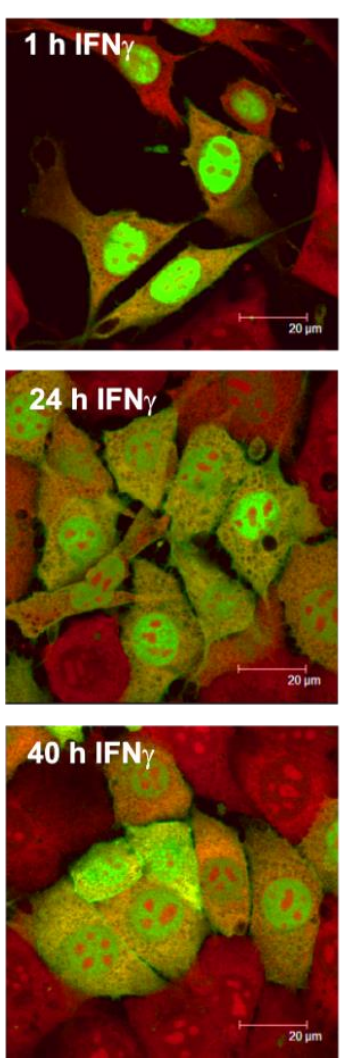

B


D
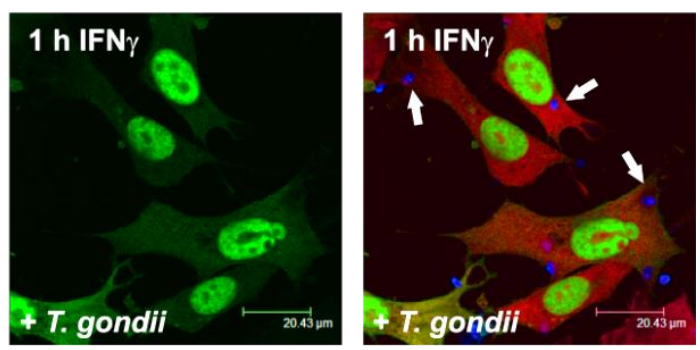

$\mathbf{F}$

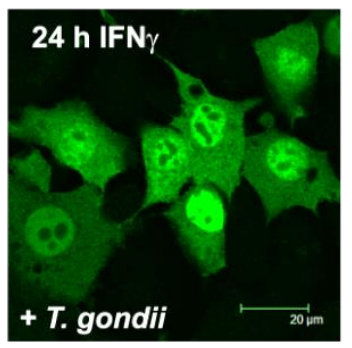

H

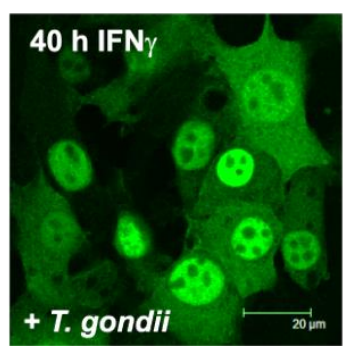

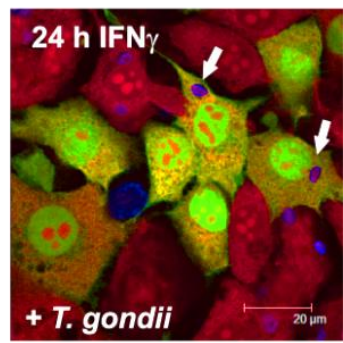

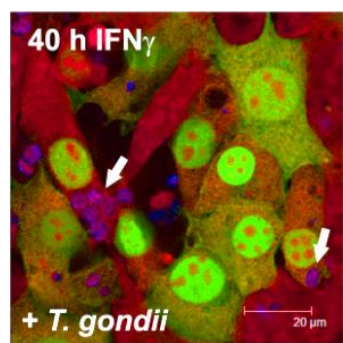

Figure 17: Toxoplasma gondii infection promotes nuclear STAT1 $\alpha$-GFP accumulation after prolonged IFN- $\gamma$ stimulation.

(continuing on the next page) 
I

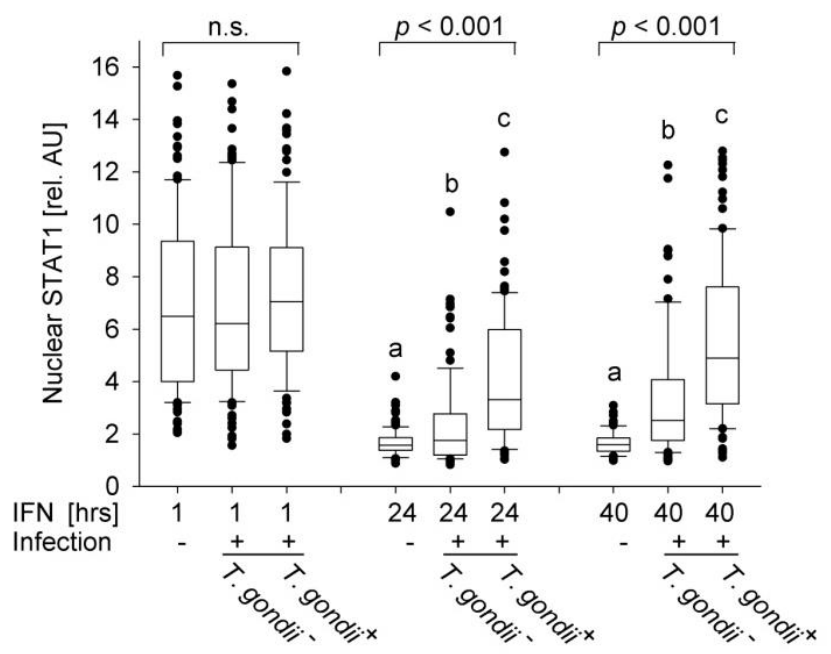

$\mathbf{J}$

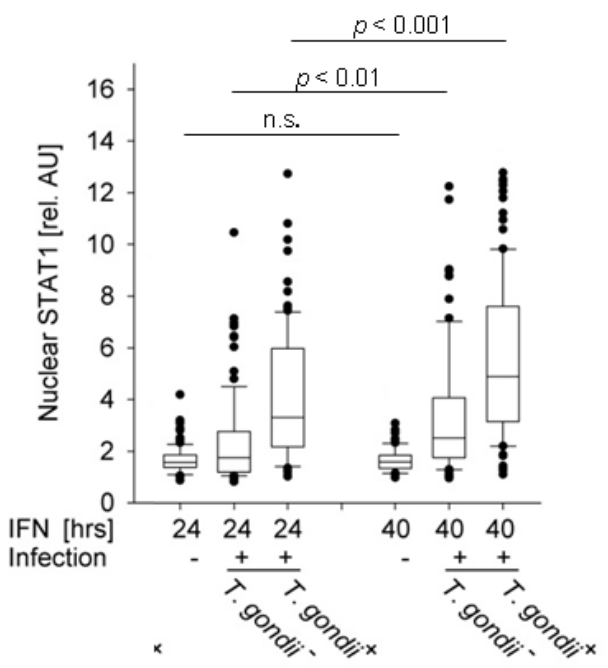

Figure 17: Toxoplasma gondii -infection promotes nuclear STAT1 $\alpha-$ GFP accumulation after prolonged IFN- $\gamma$ stimulation.

(A-H) NIH-3T3 cells stably expressing STAT1 $\alpha$-GFP (green) were infected with $T$. gondii at a parasite to host cell ratio of 5:1 or were left non-infected. Two hours post-infection, cells were activated with $100 \mathrm{U} / \mathrm{ml} \mathrm{IFN-} \gamma$ or were left non-stimulated. Cells were fixed after the indicated periods of IFN- $\gamma$ stimulation. The cells were then permeabilised and stained with anti-T. gondii serum (blue, indicated by white arrows) and propidium iodide (nucleic acids, red). Images of each fluorescence were obtained by confocal laser scanning microscopy. Micrographs of STAT1 -GFP (left columns, green) and merged images (right columns) are indicated. The results are representative for three independent experiments. (I, J) The ratio of nuclear to cytoplasmic STAT1 $\alpha$-GFP was quantified in at least 50 randomly selected cells from non-infected cells as well as parasite-negative (T. gondii) and parasite-positive $\left(T\right.$.gondii ${ }^{+}$) cells from an infected population by comparing the average fluorescence intensity in the nucleus to the average fluorescence intensity of an area of equal size in the cytoplasm. Ratios of nuclear to cytoplasmic fluorescence from two independent experiments are depicted as boxplots, where boxes represent the interquartal range with the central $50 \%$ of data, horizontal lines represent the median; whiskers extend to 10th and 90th percentiles, and dots represent outliers. For (I), significant differences were identified by ANOVA, and groups marked with distinct letters differ significantly. For $(J)$, significant differences were identified by Student's $t$-test.

In non-stimulated NIH/3T3 cells, STAT1 $\alpha$-GFP was predominantly homogenously distributed between nuclei and cytoplasm, being only excluded from nucleoli (Figure 17A). Unphosphorylated STAT1 undergoes constant cycling between the nucleus and cytoplasm in the absence of IFN- $\gamma$ but is primarily located in the cytoplasmic compartment. This explains the finding of STAT1 $\alpha$-GFP being present in the nuclei of non-stimulated cells. The almost equally high level of nuclear STAT1 $\alpha$-GFP as compared to those in the cytosol is likely related to its overexpression in these cells (Köster and Hauser, 1999; Lillemeier et al., 2001; Meyer et al., 2002). The subcellular distribution of STAT1 $\alpha$-GFP in non-stimulated cells was not affected by $T$. gondii-infection (Figure 17, compare A and B). After IFN- $\gamma$ stimulation for one hour, the majority of cytoplasmic STAT1 $\alpha$-GFP was relocated into the nucleus. Nuclear accumulation at this time point was similar in non-infected and T. gondii-infected cells (Figure 17, compare $\mathrm{C}$ and D). Non-infected cells, which were stimulated for 24 hours, were heterogeneous in their STAT1 $\alpha$-GFP distribution (Figure 17E). Distinct cells still presented with a weak nuclear accumulation of STAT1 $\alpha$-GFP whereas others showed almost homogenous distribution of STAT1 $\alpha$-GFP between nucleus 
and cytoplasm. This indicated a clear overall export of nuclear STAT1 $\alpha$-GFP after prolonged stimulation of non-infected cells with IFN- $\gamma$. Export of STAT1 $\alpha$-GFP back into the cytoplasm was also evident in infected cells, but a considerable high number of cells still showed strong STAT1 $\alpha$-GFP accumulation in the nucleus (Figure 17F). After 40 hours of IFN- $\gamma$ treatment, the majority of cells from the non-infected cell population showed almost homogenous STAT1 $\alpha$-GFP distribution with only slightly elevated STAT1 $\alpha$-GFP in the nucleus as compared to the cytoplasm (Figure 17G). Remarkably and in sharp contrast, the population of infected cells had a high proportion of cells with strong nuclear STAT1 $\alpha$-GFP accumulation (Figure 17H).

The nuclear accumulation of STAT1 $\alpha$-GFP was then digitally quantified by measuring nuclear and cytoplasmic fluorescence intensities and subsequently determining the nuclear to cytoplasmic ratio. To further delineate the impact of infection on STAT1 distribution, the infected cell population was differentiated into cells harbouring at least one T. gondii parasite (referred to as T. gondii ${ }^{+}$) and parasitenegative bystander cells (referred to as T. gondii') (Figure 17l). The results verified that there were no significant differences in nuclear accumulation of STAT1 $\alpha$-GFP after one hour of IFN- $\gamma$ stimulation. GFP fluorescence measurements yielded comparable medians and similar dispersion patterns of nuclear to cytoplasmic STAT1 $\alpha$-GFP ratios in non-infected, T. gondii and T. gondii ${ }^{+}$cells. In each case, the median nuclear accumulation was 6-fold to 7-fold higher than in the cytoplasm. Ratios from individual cells differed widely, reflecting significant inhomogeneity of STAT1-GFP redistribution within each of the different cell populations in response to IFN- - . After twenty-four hours of stimulation, the nuclear-tocytoplasmic fluorescence decreased in all groups, but with significant differences among one another (ANOVA, $p<0.001$ ). Such decrease was most prominent and homogenous in non-infected cells, in which it nearly resulted in a pan-cellular STAT1 $\alpha$-GFP distribution. Interestingly, bystander cells from the infected population, which did not harbour a parasite, differed significantly $(p<0.05)$ from the noninfected population. Although T. gondii cells showed a similar median nuclear to cytoplasmic STAT1GFP ratio of 1.8 as cells from the non-infected population, values from individual cells were clearly increased and thus STAT1-GFP more widely distributed. In contrast, T. gondii ${ }^{+}$cells exhibited a significantly higher $(p<0.05)$ nuclear STAT1 $\alpha-$ GFP accumulation, as judged by a median ratio of 3.3 and considerably broader dispersion of nuclear-to-cytoplasmic STAT1-GFP ratios. Treatment with IFN- $\gamma$ for a total of 40 hours had no further effect on nuclear-to-cytoplasmic STAT1 $\alpha$-GFP ratio in cells of the noninfected population, indicating balanced trafficking of STAT1-GFP in the late phase of IFN- $\gamma$ stimulation. Similar to the twenty-four hour stimulation however, T. gondii and T. gondii ${ }^{+}$cells from the infected cell population presented significantly higher $(p<0.05)$ STAT1-GFP nuclear to cytoplasmic ratios than cells from the non-infected population. Interestingly, IFN- $y$ treatment of parasite-positive and parasitenegative bystander cells from an infected culture for 40 hours even led to a further increase $(p<0.01)$ 
in nuclear to cytoplasmic STAT1 $\alpha$-GFP ratios as compared to the ratios at 24 hours of stimulation (Figure 17J). This effect was accompanied by a broadened dispersion of individual cell ratios.

Taken together, the similar nuclear accumulation levels after one hour of IFN- $\gamma$ treatment indicated that T. gondii-infection does not affect nuclear import of STAT1 $\alpha$-GFP during the initial phase of stimulation. After treatment of non-infected cells for 24 hours, IFN- $\gamma$-dependent nuclear STAT1 $\alpha$-GFP was mostly relocated in the cytosol. In sharp contrast, nuclear-to-cytoplasmic relocation of STAT1 $\alpha$-GFP after prolonged stimulation was inhibited in cells from the T. gondii-infected population. Thus, infection promoted long-lasting and strong nuclear accumulation of STAT1 $\alpha$-GFP. Interestingly, this effect was also observed in cells not harbouring a parasite, though to a lower extent.

\subsubsection{Toxoplasma gondii inhibits nuclear export of STAT1}

The previous experiment revealed prolonged nuclear accumulation of STAT1 $\alpha$-GFP in T. gondii-infected cells. This could be due to increased activation/nuclear import of STAT1 or due to retention in the nucleus. The previous results suggested similar nuclear accumulation of STAT1 $\alpha$-GFP during the initial phase of stimulation of infected and non-infected cells. To test the hypothesis of a T. gondii-induced impairment of STAT1 $\alpha$-GFP nuclear export, NIH/3T3 cells were infected or not with T.gondii, subsequently activated with IFN- $\gamma$ or left non-stimulated and treated with staurosporine. Staurosporine is a potent inhibitor of IFN- $\gamma$ signalling (Haspel and Darnell, 1999). It prevents IFN- $\gamma$ receptor-mediated re-activation of STAT1 via the JAK 1 and 2, and prevents subsequent import into the nucleus even in the presence of exogenous IFN- $\gamma$. In contrast, it is expected to not affect nuclear export. Decline in nuclear STAT1 $\alpha$-GFP ratio thereby reflects the nuclear export. The impact of $T$. gondii infection on nuclear-tocytoplasmic STAT1 $\alpha$-GFP ratio in presence of staurosporine was analysed by means of immunofluorescence microscopy and GFP-signal intensity quantification as described in section 3.2.3.3 (Figure 18). 


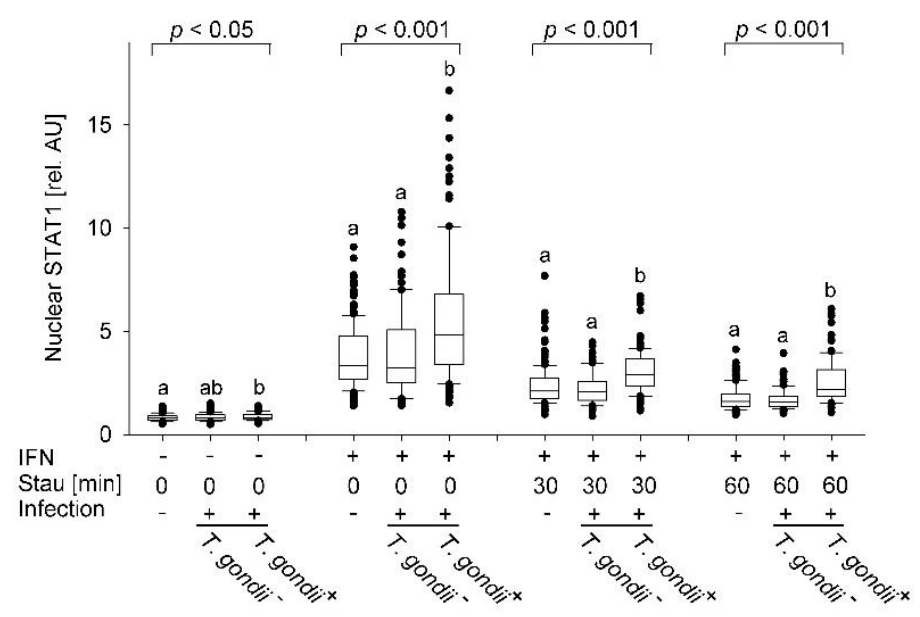

Figure 18: Toxoplasma gondii decelerates overall nuclear export of STAT1 $\alpha$-GFP.

$\mathrm{NIH-3T3}$ cells stably expressing STAT1 $\alpha$-GFP were infected with $T$. gondii at a parasite to host cell ratio of 5:1 for 24 hours or were left non-infected. Twenty-one and a half hours post-infection, cells were activated with $100 \mathrm{U} / \mathrm{ml} \mathrm{IFN-} \mathrm{for} 2.5$ hours or left non-stimulated. During the last 30 or 60 minutes cells were treated with $0.25 \mu \mathrm{g} / \mathrm{ml}$ staurosporine as indicated. Cells were fixed, permeabilised and stained with anti-T. gondii serum. The subcellular distribution of STAT1 $\alpha$-GFP was analysed by confocal laser scanning microscopy. Quantification of STAT1 $\alpha$-GFP fluorescence intensity in the nucleus and in an area of equal size in the cytoplasm was performed for at least 50 randomly selected non-infected, T. gondii- bystander and T. gondii+ cells per treatment. Ratios of nuclear-to-cytoplasmic STAT1-GFP levels from three independent experiments are visualised as boxplot, where boxes represent the interquartal range with the central $50 \%$ of data and horizontal lines the median; whiskers extend to 10th and 90th percentiles, and dots represent outliers. Significant differences were identified by ANOVA. Groups marked with distinct letters differ significantly.

Quantitative analysis of independent experiments verified, that there were significant differences (ANOVA, $p<0.05$ ) in nuclear accumulation of STAT1 $\alpha-$ GFP in the absence of IFN- $\gamma$ (Figure 18). However, non-infected cells as well as T. gondii bystander cells and T. gondii ${ }^{+}$cells from an infected culture showed comparable medians and cell-to-cell homogeneity in nuclear-to-cytoplasmic STAT1 $\alpha$-GFP ratios, calling the biological relevance of the slight differences into question. The low median nuclear accumulation levels confirm that latent STAT1 is distributed with a tendency for cytoplasmic accumulation. IFN- $-\gamma$ stimulation for 2.5 hours induced robust STAT1 $\alpha$-GFP nuclear accumulation but revealed differences between the investigated cell populations. T. gondiit cells had a significantly higher $(p<0.05)$ nuclear-to-cytoplasmic STAT1-GFP ratio and increased accumulation heterogeneity. Cell populations which were stimulated with IFN- $\gamma$ for 2.5 hours and were additionally treated with staurosporine for the last 30 minutes all showed a decline in the median ratio of nuclear accumulated STAT1 $\alpha$-GFP as compared to those not treated with staurosporine, reflecting the ongoing nuclear export while prevention of IFN- - -dependent import. Non-infected and T. gondii' bystander cells presented a similar STAT1-GFP distribution, whereas $T$. gondii ${ }^{+}$cells still had significantly more $(p<0.05)$ STAT1-GFP in their nuclei than parasite-negative cells. The trend of decline in nuclear-to-cytoplasmic STAT1-GFP 
continued when cells were treated with staurosporine for the last 60 minutes of IFN- $\gamma$ stimulation. However, also under these conditions, T. gondii-positive cells still presented significantly higher $(p<0.05)$ median nuclear ratios than T. gondii-negative bystander cells from an infected culture or noninfected cells.

Taken together, the treatment with staurosporine clearly resulted in a progressive nuclear-tocytoplasmic shift of fluorescence in all investigated groups, but STAT1 $\alpha$-GFP was significantly more strongly retained in $T$. gondii ${ }^{+}$cells than in non-infected cells. This experiment suggested that $T$. gondii infection has an inhibitory impact on STAT1 $\alpha$ nuclear export into the cytoplasm.

\subsection{Modulation of GAF and STAT1 DNA binding activity by Toxoplasma gondii}

\subsubsection{Toxoplasma gondii differentially modulates GAF complexes depending on STAT1 conformation}

It was reported that $T$. gondii affects the binding of the gamma activated factor (GAF) in various IFN- $\gamma$ treated host cell lines (Lüder et al., 2001; Lang et al., 2012; Schneider et al., 2013; Olias et al., 2016). The GAF complex is composed of a tyrosine-phosphorylated STAT1 dimer, which sequence-specifically is bound to distinct DNA-binding sites, termed GAS (gamma activated site) sequences. In one of these studies electrophoretic mobility shift assays (EMSA) revealed that the parasite induces a non-canonical complex in the presence of oligonucleotides with the single GAS sequence of the FcyR1 gene (Lang et al., 2012). In order to determine whether T. gondii also modulates the IFN- $\gamma$-induced GAF complex in the murine monocyte/macrophage cell line RAW264.7, nuclear extracts from such cells were subjected to EMSA with oligonucleotides comprising a single, optimal STAT1 binding site (Wagner et al., 1990) (Figure 19A, lanes 1 to 4; Figure 19C). 
A



$\begin{array}{llllllll}1 & 2 & 3 & 4 & 5 & 6 & 7 & 8\end{array}$
B



C

GAS 5 - TTTTCGACATTTCCCGTAAATCTG

$-3$

2xGAS 5:- TTTTCGTTTCCCCGAAATTGACGGATTCCCCGAAAC -'3

Figure 19: Toxoplasma gondii modulates GAS binding of tyrosine-phosphorylated STAT1 dimers and tetramers in the monocyte/macrophage cell line RAW264.7.

(A) RAW264.7 cells were infected with T. gondii at a parasite to host cell ratio of 6:1 or were left non-infected. Twenty-four

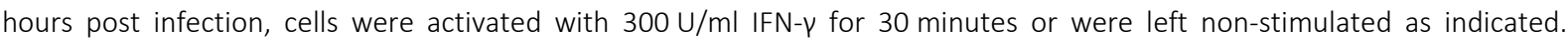
Thereafter, nuclear protein extracts were incubated with [33P]-labelled DNA probes, comprising a single GAS element (referred to as GAS) or two adjacent GAS elements (referred to as 2xGAS). Protein-DNA-complexes were separated by native acrylamide gel electrophoresis and were visualised by autoradiography. (B) Presence of STAT1 within the complex was confirmed by supershift reactions with either anti-STAT1 or anti-STAT3. The results from A and B are representative for three independent experiments. (C) Sequences of the GAS and the 2xGAS oligonucleotides, GAS sites are indicated in blue.

Stimulation with IFN- $\gamma$ led to strong GAS-binding activity in nuclear protein extracts of non-infected cells (Figure 19A, lane 2). The DNA binding was specifically IFN- $\gamma$-induced since no such activity was detectable in protein extracts from non-stimulated cells (Figure 19A, lane 1). STAT1 in extracts from IFN$\gamma$-stimulated cells bound the single GAS probe as dimer, i.e. GAF (Figure 19A, lane 2). However, infection with T. gondii did slightly diminish regular STAT1 binding activity as dimer, indicated by the lower signal intensity in the autoradiogram. Additionally, a second GAS-binding complex with lower electrophoretic mobility was induced (Figure 19A, lane 4). This complex did not correspond to the tetrameric form (Figure 19A; compare lane 4 to lane 6), suggesting the formation of a complex with different composition than the conventional GAF. This result clearly shows that $T$. gondii also modulated the IFN- 
$Y$-induced GAF complex in the monocyte/macrophage cell line RAW264.7 by inducing a non-canonical complex. In contrast to previously published data (Lang et al., 2012), T. gondii infection did however not promote non-canonical GAS-binding activity in the absence of IFN- $\gamma$.

The N-termini of two STAT1 dimers bound to DNA with adjacent GAS sites can interact to facilitate cooperative binding. This reciprocal interaction significantly stabilises STAT1 binding to DNA, facilitating also formation of higher-order oligomers (Vinkemeier et al., 1996; Begitt et al., 2014). In an attempt to further determine whether T.gondii also modulates multimeric GAF complexes, binding to oligonucleotides encompassing two tandem GAS elements of the human and murine interferonregulatory factor 1 promoter (Sims et al., 1993) was assayed (Figure 19A, lanes 5 to 8). Stimulation of cells with IFN- $y$ induced the binding of nuclear proteins to the $2 x$ GAS oligonucleotide in non-infected cells (Figure 19A, lane 6). Under these conditions STAT1 clearly favoured binding in the tetrameric conformation, i.e. $2 \times \mathrm{GAF}$ over the dimer. No binding activity was detectable in protein extracts from non-stimulated cells, irrespective of being infected or not (Figure 19A, lane 5 and 7). Components of protein extracts derived from $T$. gondii-infected, IFN- $\gamma$-stimulated cells bound DNA as an aberrant 2 XGAF complex, characterised by lower electrophoretic mobility as compared to the conventional $2 \times G A F$ (Figure 19A, lane 8). Interestingly, whereas only a portion of dimeric STAT1 was integrated in the noncanonical GAF complex (Figure 19A, lane 4), all STAT1 was bound in the non-canonical 2xGAF complex in the presence of a $2 x G A S$ probe (Figure 19A, lane 8). Thus, T. gondii not only modifies IFN- $\gamma$-induced GAF, but also 2xGAF.

IFN- $\gamma$ is also a weak activator of STAT3, which can lead to STAT1:STAT3 heterodimerisation (Qing and Stark, 2004; Begitt et al., 2014). The conventional and the non-canonical complexes from T. gondiiinfected macrophages bound to single GAS DNA were confirmed previously to contain STAT1 (Lang, 2005; Lang et al., 2012). To confirm the signal specificity for the 2xGAS-binding complexes, supershift reactions with antibodies directed against STAT1 and STAT3 were performed (Figure 19B). Both, the conventional $2 x \mathrm{GAF}$ and the T. gondii-induced non-canonical $2 \times \mathrm{GAF}$ complexes were completely supershifted with anti-STAT1 antibodies (Figure 19B, lane 2 and 4), but not with anti-STAT3 (Figure 19B, lane 1 and 3). This clearly indicates that both complexes specifically contain STAT1.

Taken together, the results showed that in presence of a DNA probe with a single GAS element, only a portion of STAT1 binds as parasite-induced non-canonical GAF. In contrast, all STAT1 bound as noncanonical 2xGAF complex in the presence of 2xGAS oligonucleotides, indicating that $T$. gondii favours formation of non-canonical 2xGAF complexes. 


\subsubsection{Toxoplasma gondii modulates activity and specificity of STAT1 DNA binding}

\subsubsection{Toxoplasma gondii infection promotes STAT1 binding activity to DNA in the absence of IFN- $\gamma$} In principal, unphosphorylated STAT1 can bind to DNA, but the binding activity is very weak and it is thought not to have any physiological relevance as DNA binding protein without the recruitment of cofactors (Wenta et al., 2008). Activation of STAT1 by phosphorylation at Tyr ${ }^{701}$ in response to IFN- $\gamma$ increases its DNA binding activity at least 200-fold (Wenta et al., 2008). Remarkably, Lang et al. (2012) observed that infection of macrophages with T. gondii promoted binding of a non-canonical GAF complex with reduced electrophoretic mobility to oligonucleotides with the single GAS sequence of the FcyR1 gene in the absence of IFN- $\gamma$. In order to determine whether T. gondii also induces DNA binding activity of STAT1 tetramers in the absence of the cytokine, nuclear extracts from RAW264.7 cells were subjected to EMSA with oligonucleotides comprising two tandem GAS elements.

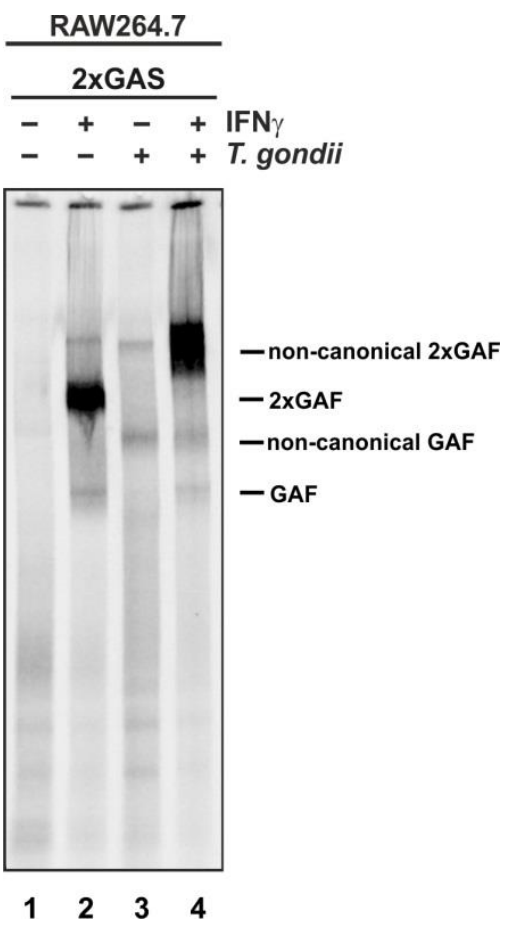

Figure 20: Toxoplasma gondii promotes DNA binding of noncanonical GAF and 2xGAF complexes in the absence of IFN- $\gamma$. RAW264.7 cells were infected with $T$. gondii at a parasite to host cell ratio of 6:1 or were left non-infected. Twenty-four hours post infection cells were activated with $300 \mathrm{U} / \mathrm{ml} \mathrm{IFN-} \mathrm{f}$ for 30 minutes or were left non-stimulated as indicated. Thereafter, nuclear protein extracts were incubated with [33P]labelled DNA probes, comprising two adjacent GAS elements (2xGAS). Protein-DNA-complexes were separated by native acrylamide gel electrophoresis and were visualised by autoradiography. The results are from one experiment.

STAT1 from extracts from IFN- $\gamma$-stimulated, non-infected cells strongly bound to the 2xGAS probe in tetrameric conformation, i.e. 2xGAF, and to a small extent also as a dimer, i.e. GAF (Figure 20, lane 2). The DNA binding in non-infected cells was IFN- $\boldsymbol{\gamma}$-induced since no such activity was detected in protein extracts from non-stimulated cells (Figure 20, lane 1). Infection of IFN- $\gamma$-stimulated cells with T. gondii led to formation of the slower migrating non-canonical GAF and 2xGAF complexes as described above (see section 3.3.1) (Figure 20, lane 4). Remarkably, and in sharp contrast to non-infected cells, parasite infection promoted STAT1 binding activity to GAS-containing oligonucleotides in the absence of IFN- $\gamma$ 
(Figure 20, lane 3), thus confirming previous results (Lang et al., 2012). The altered DNA binding activity appeared to be restricted to T. gondii-modified STAT1 complexes, since exclusively non-canonical GAF and $2 \times G A F$ complexes were detected.

Taken together, the results showed that infection with $T$. gondii induces DNA binding activity of STAT1 in the absence of IFN- $\gamma$ stimulation. However, the low signal intensity indicated that in the absence of the cytokine, extracts from T. gondii-infected cells yield only low levels of DNA-binding STAT1, thus supposedly hindering regular detection in T. gondii infection experiments.

\subsubsection{Toxoplasma gondii infection promotes binding of STAT1 tetramers to DNA without a GAS} motif

GAF can recruit another GAF complex to adjacent GAS sites via cooperative DNA binding (Vinkemeier et al., 1996). This GAF polymerisation is driven rather by protein-protein interactions than by sequence specific DNA binding (Begitt et al., 2014). Cooperative DNA binding therefore can facilitate binding of a second GAF also to imperfect recognition sequences. In the following experiment it was therefore investigated, which DNA specificity is required for formation of the T. gondii-induced non-canonical 2xGAF complex. To this end, nuclear protein extracts from IFN- $\gamma$-stimulated and non-stimulated RAW264.7 cells, being either T. gondii-infected or left non-infected, were incubated with radioactively labelled oligonucleotides, containing adjacent elements with different extents of GAS sequence similarity. The STAT1 binding activity was thus evaluated to DNA encompassing either two GAS elements (2xGAS), one consensus and a mutated GAS element (GAS-nonGAS) or two mutated elements (2xnonGAS) by means of gel shift experiments (Figure 21). 
A

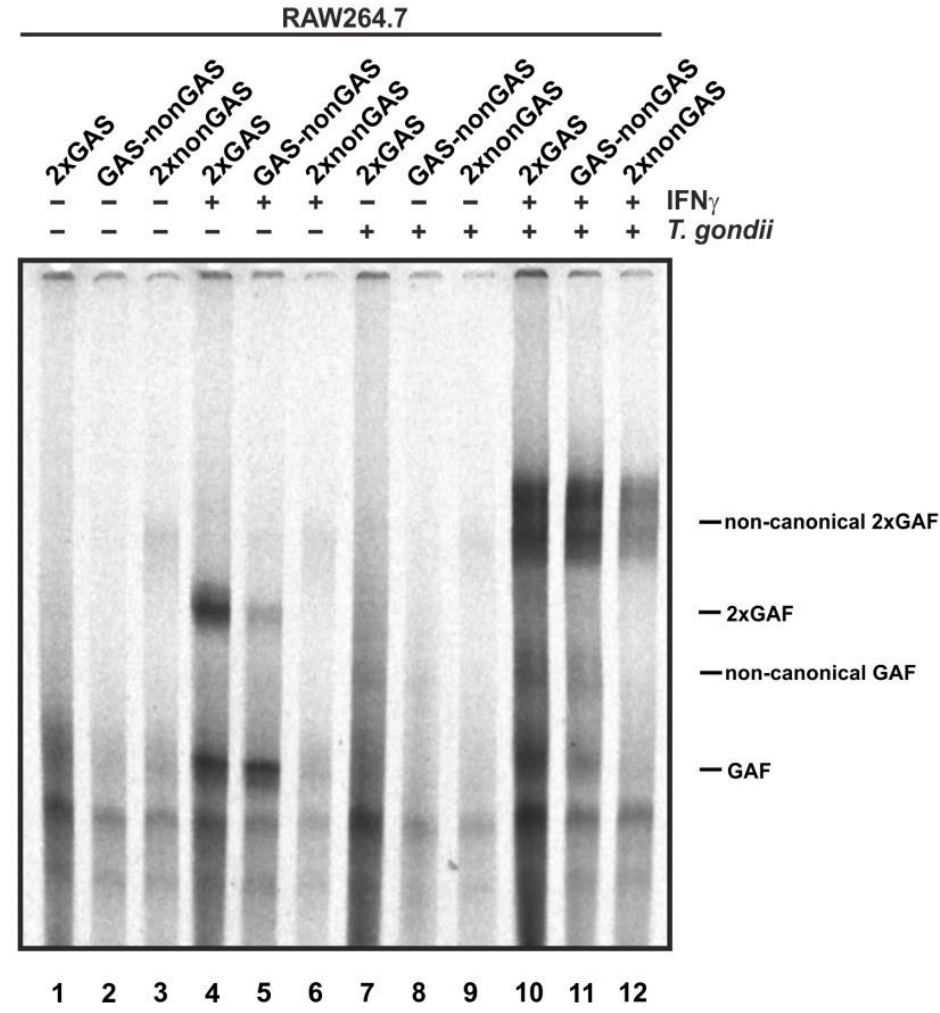

B
GAS consensus $\quad 5^{\prime}-\mathrm{TTCN}_{3-5} \mathrm{GAA}^{-} 3$
2xGAS 5 - TTTTCGTTTCCCCGAATTGACGGATTTCCCCGAAAC -'3
GAS-nongAS 5 - TTTTCGTTTCCCCGAATTGACGGATTTACCCCAAC -'3
2xnonGAS 5’- TTTTCGTTTACCCCAAATTGACGGATTTACCCCAAC -'3

Figure 21: Toxoplasma gondii -induced non-canonical 2xGAF complexes can bind to DNA without a classical GAS site.

(A) RAW264.7 cells were infected with T. gondii at a parasite to host cell ratio of 6:1 or were left non-infected. Twenty-four hours post infection cells were activated with $300 \mathrm{U} / \mathrm{ml} \mathrm{IFN-} \gamma$ for 30 minutes or were left non-stimulated as indicated. Thereafter, nuclear protein extracts were incubated with $\left[{ }^{33} \mathrm{P}\right]$-labeled DNA probes comprising either two GAS elements (2xGAS), one consensus and a mutated GAS element (GAS-nonGAS) or two mutated elements (2xnonGAS). Protein-DNAcomplexes were separated by native acrylamide gel electrophoresis and were visualised by autoradiography. The results are representative for three independent experiments. (B) Sequences of the $2 x G A S$, GAS-nonGAS and the $2 x n o n G A S$ oligonucleotides; the GAS consensus sequence (Begitt et al., 2014) is indicated in blue.

Stimulation with IFN- $y$ specifically led to different STAT1 binding activities in nuclear protein extracts from non-infected cells, depending on the number of GAS consensus sites within the oligonucleotides. STAT1 tetramers bound strongly to DNA with two tandem GAS sites (Figure 21, lane 4) and at intermediate levels to DNA with one consensus followed by one mutated GAS element as expected (Figure 21, lane 5). In contrast, no STAT1 binding was detected to DNA with two mutated GAS sites 
(Figure 21, lane 6). In the presence of 2xGAS oligonucleotides, the autoradiogram signal intensity suggested a stronger binding activity of 2xGAF than single GAF. STAT1 also bound as tetramer to DNA with one consensus and a mutated GAS element, depicting binding activity to imperfect recognition sites due to cooperative binding. However, the proportion clearly was shifted by STAT1 favouring binding as single GAF.

In contrast, IFN- $y$ stimulation of $T$. gondii-infected cells led to formation of the slower migrating noncanonical 2xGAF complex as described above (see section 3.3.1). Remarkably and in sharp contrast to non-infected cells, the parasite-induced non-canonical complex was not only formed in presence of a 2xGAS and a GAS-nonGAS oligonucleotide but also with a 2xnonGAS oligonucleotide (Figure 21, compare lanes 10 to 12 and lanes 4 to 6 ). Furthermore, the non-canonical 2xGAF complex as formed with extracts from infected cells bound a GAS-nonGAS oligonucleotide much stronger than the canonical complex formed in the absence of $T$. gondii (Figure 21, compare lanes 5 and 11). Finally, with all three oligonucleotides, a non-canonical 2xGAF complex but not a canonical one was formed indicating that $T$. gondii favours binding of non-canonical 2xGAF, irrespective of GAS sequence similarity.

Together, these results for the first time established that after T. gondii infection, a GAS consensus sequence is not required for binding of STAT1 as a non-canonical 2xGAF complex. This indicated that STAT1, when incorporated in the aberrant $T$. gondii-modified 2XGAF complex, has reduced sequence specificity, facilitating binding to DNA without any classical GAS motif.

\subsubsection{Toxoplasma gondii enhances DNA-binding activities of STAT1 tetramers to DNA with GAS and non-GAS motifs}

The following experiment was conducted to determine quantitatively which impact infection with T. gondii has on binding activity of STAT1 dimers and tetramers to oligonucleotides encompassing GAS and non-GAS sequences. Therefore, complete protein extracts from IFN- $\gamma$-stimulated and nonstimulated RAW264.7 cells, being either T. gondii-infected or left non-infected, were incubated with tagged oligonucleotides with either a single or a tandem GAS consensus element (GAS, 2xGAS) or mutated versions thereof (nonGAS, GAS-nonGAS, 2xnonGAS). Proteins that had bound to these probes were pulled down and were then analysed by SDS-PAGE and immunoblotting (Figure 22). 
A



B prolonged WB exposure

$90 \mathrm{kDa}$

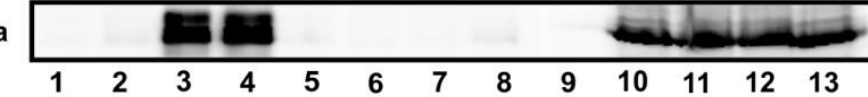
STAT1

C

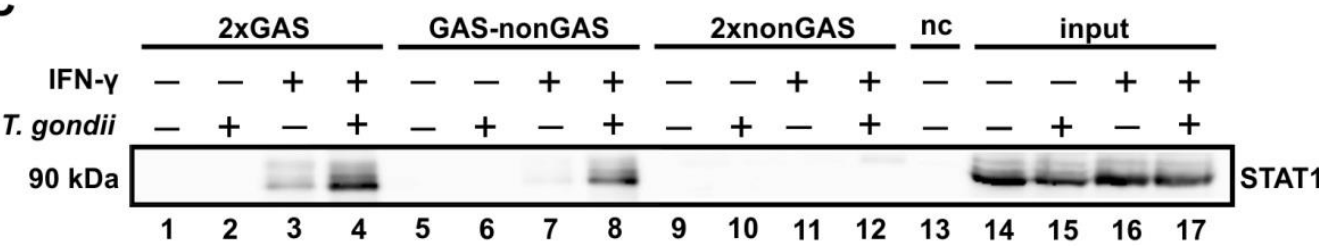

D prolonged WB exposure

$90 \mathrm{kDa}$

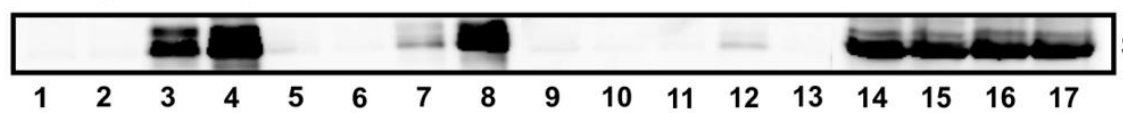
STAT1

E GAS consensus $\quad 5{ }^{\prime}-\mathrm{TTCN}_{3-5} \mathrm{GAA}^{-} 3$

GAS 5 - [Btn]GATGTATTCCCCGAAAAG -'3

nonGAS 5 - [Btn]GATGTATTACCCCAAAAG -'3

2xGAS 5'- [Btn]GATGTATTCCCCGAAATTGACGGATTTCCCCGAAAAG-'3

GAS-nongAS 5'- [Btn]GATGTATTCCCCGAAATTGACGGATTTACCCCAAAAG-'3

2xnongAS 5 - [Btn]GATGTATTACCCCAAATTGACGGATTTACCCCAAAAG-'3

Figure 22: Toxoplasma gondii increases DNA binding of STAT1-tetramer molecules to GAS and non-GAS sites. RAW264.7 cells were infected with T. gondii at a parasite to host cell ratio of 6:1 or were left non-infected. Twenty-four hours


complete cell protein extracts were prepared, and an aliquot each saved as an internal input control. The remaining samples were incubated with biotinylated DNA-probes encompassing different compositions of GAS consensus sequences and mutated versions thereof. (A) Probes comprising a single GAS element (GAS) or a mutated GAS site (nonGAS). (C) Probes comprising two (2xGAS), one (GAS-nonGAS) or no consensus GAS sites (2xnonGAS). In parallel, lysates from non-infected, non-stimulated cells were incubated without any oligonucleotide probe and served as negative control. The protein-DNA-complexes were pulled down with streptavidin-agarose, separated by SDS-PAGE and analysed by immunoblotting using an anti-STAT1 $\alpha$ antibody. Bound antibodies were visualized with a peroxidase-conjugated secondary antibody and enhanced chemiluminescence. Exposure time was partially prolonged as required. (B) corresponds to ( $A$ ) and (D) corresponds to (C) after prolonged immunoblot exposure, respectively. The results are representative for two independent experiments. (E) Sequences of the GAS, nonGAS, 2xGAS, GAS-nonGAS and the 2xnonGAS oligonucleotides, GAS consensus sequence (Begitt et al., 2014) are indicated in blue. 
Stimulation of cells with IFN- $p$ promoted STAT1 binding activity in complete cell protein extracts of noninfected and T. gondii-infected cells to DNA with a single GAS element (Figure 22A, lanes 3 and 4). The same amounts of STAT1 molecules were pulled down from infected and non-infected cells, thus indicating equal DNA binding activities under these conditions. IFN- $\gamma$-stimulation also promoted STAT1 binding (in non-infected and T. gondii-infected cells) in the presence of 2xGAS DNA. Remarkably, the amount of precipitated STAT1 was clearly higher from samples of $T$. gondii-infected cells as compared to those from non-infected controls (Figure 22B, compare lane 3 and 4), indicating increased STAT1 DNA binding activity after parasite infection.

In line with the gel shift experiments (see section 3.3.2.2), prolonged immunoblot exposure confirmed binding activity in extracts of non-infected, IFN- $\gamma$-stimulated cells to GAS-nonGAS oligonucleotides, though low signal intensity indicated weak STAT1 binding (Figure 22C, lane 7). In comparison, much more STAT1 was precipitated by GAS-nonGAS DNA from samples of IFN- $\gamma$-stimulated, $T$. gondii-infected cells (Figure 22C, lane 8). IFN- $\gamma$ treatment of non-infected cells did not promote detectable STAT1 binding to DNA without a consensus GAS site, irrespective whether oligonucleotides comprised one or two tandem mutated elements (Figure 22A, lane 7; 3C, lane 11). However, in T. gondii-infected cells, IFN- $\gamma$ treatment did promote very faint STAT1 binding to DNA with a single mutated GAS element (Figure 22A, lane 8). In addition and in line with the gel shift experiments (see section 3.3.2.2), binding of STAT1 from T. gondii-infected cells was clearly observed to DNA with two mutated GAS sites (Figure 22C, lane 12).

The negative control samples confirmed that STAT1 did not interact with the streptavidin-agarose resin in the absence of any oligonucleotide, thus indicating that precipitated proteins had specifically bound to the oligonucleotides (Figure 22A, lane 9; Figure 22B, lane 13). Furthermore, the input controls confirmed that the different cell extracts contained comparable amounts of total STAT1. Therefore, the amount of precipitated protein reflected differences in DNA binding of activated STAT1 (Figure 22A, lane 10 to 13 ; Figure 22B, lane 14 to 17 ).

Taken together, T. gondii was shown here to clearly modify the DNA binding activity of STAT1. This effect was largely seen at DNA with tandem binding motifs and therefore seems to affect preferably STAT1 molecules in tetrameric conformation. The parasite-induced increase in DNA binding activity was facilitated without prerequisites for GAS sequence similarity and promoted binding to DNA without a classical GAS motif. 


\subsubsection{Toxoplasma gondii differentially modulates GAF dissociation depending on STAT1} conformation

To further investigate the impact of $T$. gondii infection on STAT1 DNA binding activity, dissociation of conventional and non-canonical single and multimeric GAF complexes from infected and non-infected cells were compared by means of EMSA competition assays. To this end, nuclear protein extracts from IFN- $\gamma$-stimulated RAW264.7 cells, being either T. gondii-infected or left non-infected, were incubated with radioactively labelled DNA probes. For competition, a high molar excess of non-labelled oligonucleotide probe was added to the samples. The dissociation of STAT1 from DNA with a single GAS element (GAS), a consensus GAS element followed by a mutated one (GAS-nonGAS), two adjacent consensus GAS elements (2xGAS), or two mutated elements (2xnonGAS) was analysed (Figure 23).

A

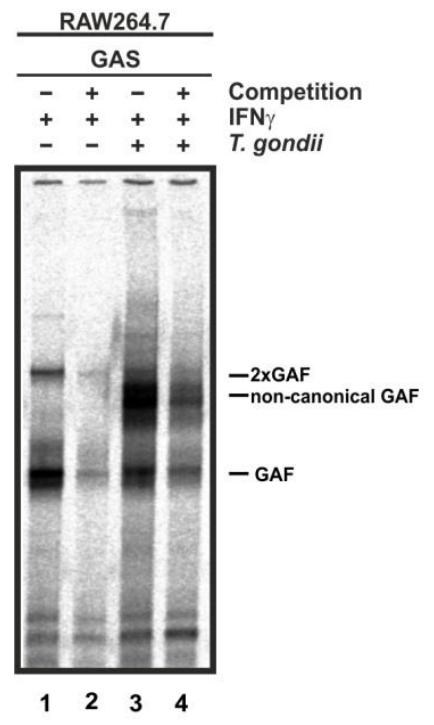

B

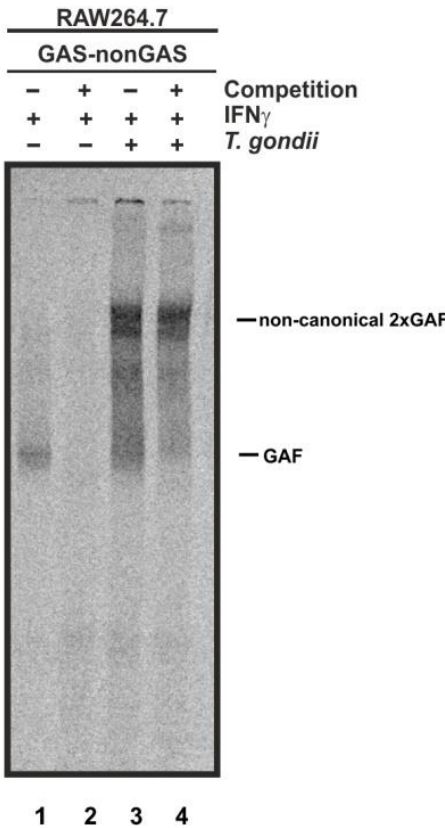

C

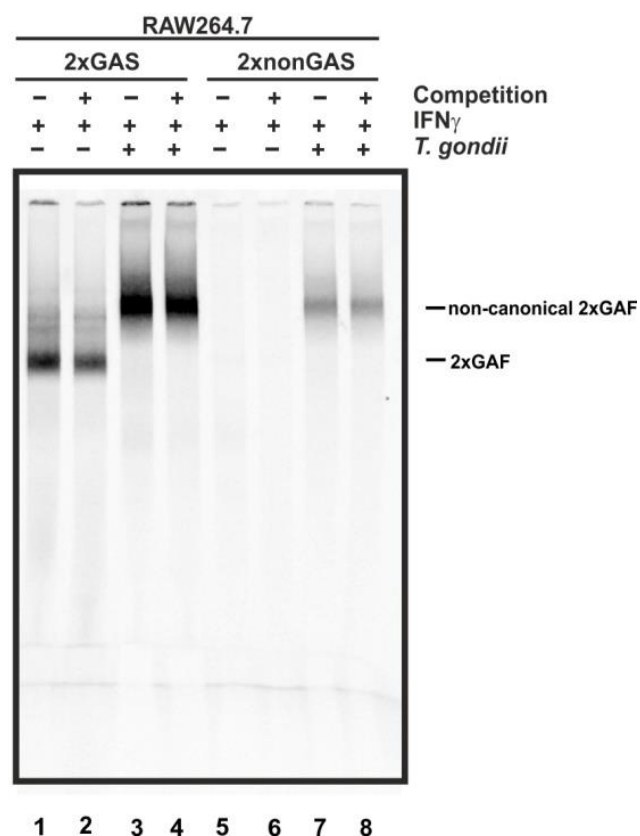

Figure 23: Toxoplasma gondii -induced non-canonical GAF complexes have different DNA dissociation characteristics.

RAW264.7 cells were infected with $T$. gondii at a parasite to host cell ratio of 6:1 or were left non-infected. Twenty-four hours

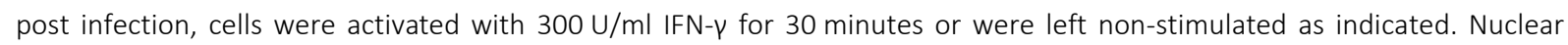
protein extracts were incubated with different [ $\left.{ }^{33} \mathrm{P}\right]$-labelled DNA probes, comprising either a single GAS element (A), a GAS consensus element followed by a mutated version thereof (B) or two GAS elements (2xGAS) or two adjacent mutated versions thereof (2xnonGAS) (C). For competition reactions, samples were incubated with a 750-fold molar excess of unlabelled probe: (A) GAS oligonucleotides, 10 minutes on ice. (B) GAS oligonucleotides, 45 minutes. (C) 2xGAS oligonucleotides, 45 minutes. Protein-DNA-complexes were separated by native acrylamide gel electrophoresis and were visualised by autoradiography. The results are representative for at least two independent experiments. 
STAT1 from nuclear extracts of IFN- $\gamma$ stimulated, non-infected cells bound to oligonucleotides with a single GAS site preferentially as dimer (Figure 23A, lane 1). The signal was markedly reduced in the presence of a high amount of unlabelled GAS DNA, indicating that labelled DNA was nearly completely displaced from STAT1 dimers (Figure 23A, lane 2). IFN- $\gamma$ stimulation of T. gondii-infected cells led to formation of the canonical GAF and the respective parasite-induced non-canonical one (Figure 23A, lane 3). Again, excess of unlabelled oligonucleotides displaced the labelled probes from the conventional GAF complex and to a similar extent also from the parasite-induced non-canonical one (Figure 23A, lane 4). In line with results from the previous experiment, $T$. gondii thus modulates the composition of the single GAF complex but does not considerably increase the DNA binding stability to a short oligonucleotide with a single GAS sequence.

STAT1 dimers from nuclear extracts of IFN- - -stimulated non-infected cells that had bound to GASnonGAS DNA (Figure 23B, lane 1) were completely displaced by an excess of unlabelled GAS DNA (Figure 23B, lane 2). In sharp contrast, the signal intensity from the T. gondii-induced non-canonical 2xGAF complex (Figure 23B, lane 3) was almost unaffected by co-incubating the sample with untagged probe (Figure 23B, lane 4), indicating a high binding stability of the aberrant complex.

STAT1 from nuclear extracts of IFN- - -stimulated non-infected cells bound 2xGAS DNA specifically as tetramers (Figure 23C, lane 1). Excess of an unlabelled high affinity 2xGAS probe displaced the labelled 2xGAS probe only slightly (Figure 23C, lane 2). Similarly, no difference in the signal intensity of the T. gondii-induced non-canonical 2xGAF complex was detected irrespective of the presence of unlabelled probe (Figure 23C, lane 3 and 4).

In line with the requirements for GAS sequence specificity and the binding of STAT1 as revealed by pulldown experiment (see section 3.3.2.2 and 3.3.2.3), no binding activity to 2xnonGAS DNA was detected in extracts from IFN- $\gamma$ stimulated non-infected cells (Figure 23C, lane 5 and 6). In contrast, STAT1 from IFN- $\gamma$ stimulated T. gondii-infected cells clearly bound to 2xnonGAS DNA as non-canonical 2xGAF complexes (Figure 23C, lane 7) and this binding was not abolished when co-incubated with unlabelled 2xGAS oligonucleotides (Figure 23C, lane 8).

Taken together the results suggested that the $T$. gondii-induced non-canonical single GAF complex has a similar dissociation activity as the conventional GAF, but parasite-modified tetrameric STAT1 complexes have a higher DNA binding stability, as compared to the canonical 2xGAF. Remarkably, the increased binding stability was also observed with GAS-nonGAS sequences as well as 2xnonGAS sequences suggesting highly stable binding of STAT1 tetramers to DNA without a classical GAS motif. 


\subsubsection{The STAT1-N-terminal domain is critical for T. gondii-induced modulation of GAF}

\subsubsection{The STAT1-N-terminus is essential for formation of non-canonical GAF complexes}

Compared to canonical GAF and 2xGAF complexes, the T. gondii-induced non-canonical complexes showed lower electrophoretic mobility, suggesting binding of a parasite or parasite-induced host effector interacting with STAT1 (Lang et al., 2012). The following experiment was performed to narrow down which region of STAT1 an effector may bind. The impact of $T$. gondii infection on activated STAT1 lacking the $\mathrm{N}$-terminal or $\mathrm{C}$-terminal domains was analysed in an in vitro co-incubation experiment. To this end, human U3A cells, lacking endogenous STAT1, were transiently transfected with vectors, encoding full length STAT1-GFP reporter constructs or N-terminal or C-terminal deletion mutants thereof (Lödige et al., 2005) according to the established protocol from Riebeling (2016). From these cells complete cell protein extracts were prepared because removal of the $\mathrm{N}$-terminal domain prevents nuclear import of tyrosine-phosphorylated STAT1 (Fagerlund et al., 2002; Meissner et al., 2004; Lödige et al., 2005). In parallel, U3A cells were infected with $T$. gondii. Protein extracts from IFN- $\gamma$-activated U3A cells expressing either one of the STAT1-constructs, were then co-incubated with extracts from non-infected or T. gondii-infected U3A cells. The in vitro formation of 2xGAF complexes was then analysed by means of gel shift experiments (Figure 25).

Although $T$. gondii is known to infect a wide variety of vertebrate cells, it was first verified, whether T. gondii also successfully infects and replicates within mutant U3A cells prior to the attempted experiment. For this, an immunofluorescence staining was performed (Figure 24). 


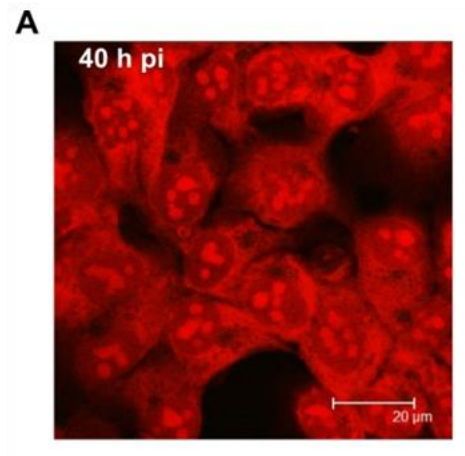

B

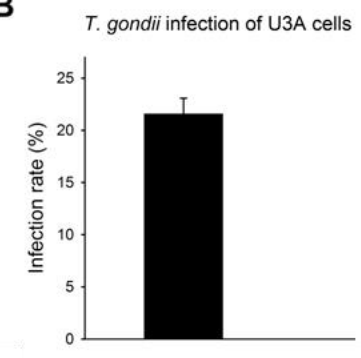

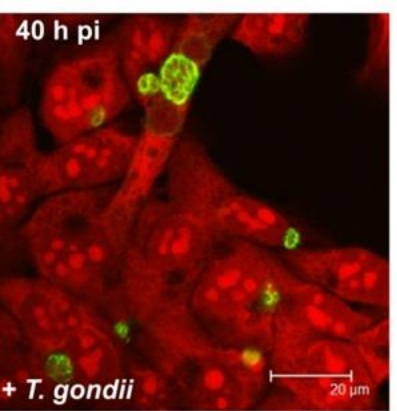

C

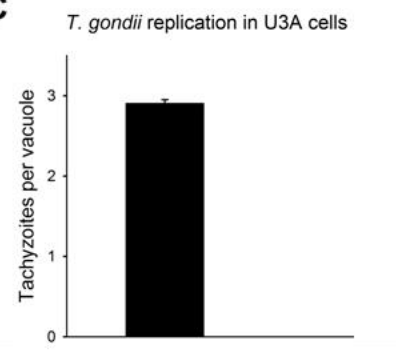

Figure 24: Toxoplasma gondii infects and replicates within mutant U3A cells.

(A) U3A cells were infected with $T$. gondii at a parasite to host cell ratio of 3:1 or were left non-infected. Forty hours post infection, cells were fixed, permeabilised and stained with anti-T. gondii serum (green) and propidiumiodide (nucleic acids, red). Images of each labelling were obtained by confocal laser scanning microscopy and merged. The results are representative for two independent experiments. (B) The infection rate was quantified by analysing at least 980 randomly selected cells. (C) $T$. gondii replication was quantified by counting tachyzoites in at least 475 randomly selected parasitophorous vacuoles. The results are representative for two independent experiments. Bars represent means \pm SEM.

Intracellular parasites were clearly detected at 40 hours post infection thus confirming successful host cell invasion (Figure 24A). Quantitative analyses revealed $21.6 \%$ of the cells being infected by at least one parasite (Figure 24B). Furthermore, the number of parasites per parasitophorous vacuole was determined as a measure for $T$. gondii replication. On average, cells harboured 2.9 parasites per vacuole (Figure 24C). Together, the results confirmed the ability of $T$. gondii to infect mutant U3A cells and to successfully replicate. 
Co-incubation of complete cell protein extracts from IFN- $\gamma$-activated U3A cells reconstituted with the gene for human full-length STAT1 $\alpha$ fused to a GFP-tag (STAT1-WT-GFP)and nuclear extracts from noninfected U3A cells led to formation of single GAF or 2xGAF complexes on oligonucleotides with a single GAS and two GAS elements, respectively (Figure 25, lanes 1 and 3). No DNA binding activity was detected in samples from non-stimulated cells (Figure 25, lane 2). Co-incubation of extracts from IFN- - stimulated cells with extracts from T. gondii-infected U3A cells additionally induced a non-canonical 2xGAF-complex in the presence of 2xGAS DNA (Figure 25, lane 4). This result verified the formation of the parasite-induced non-conventional GAF-complex even in a cell-free in vitro system by co-incubation of pre-formed GAF complexes with the effector molecule.

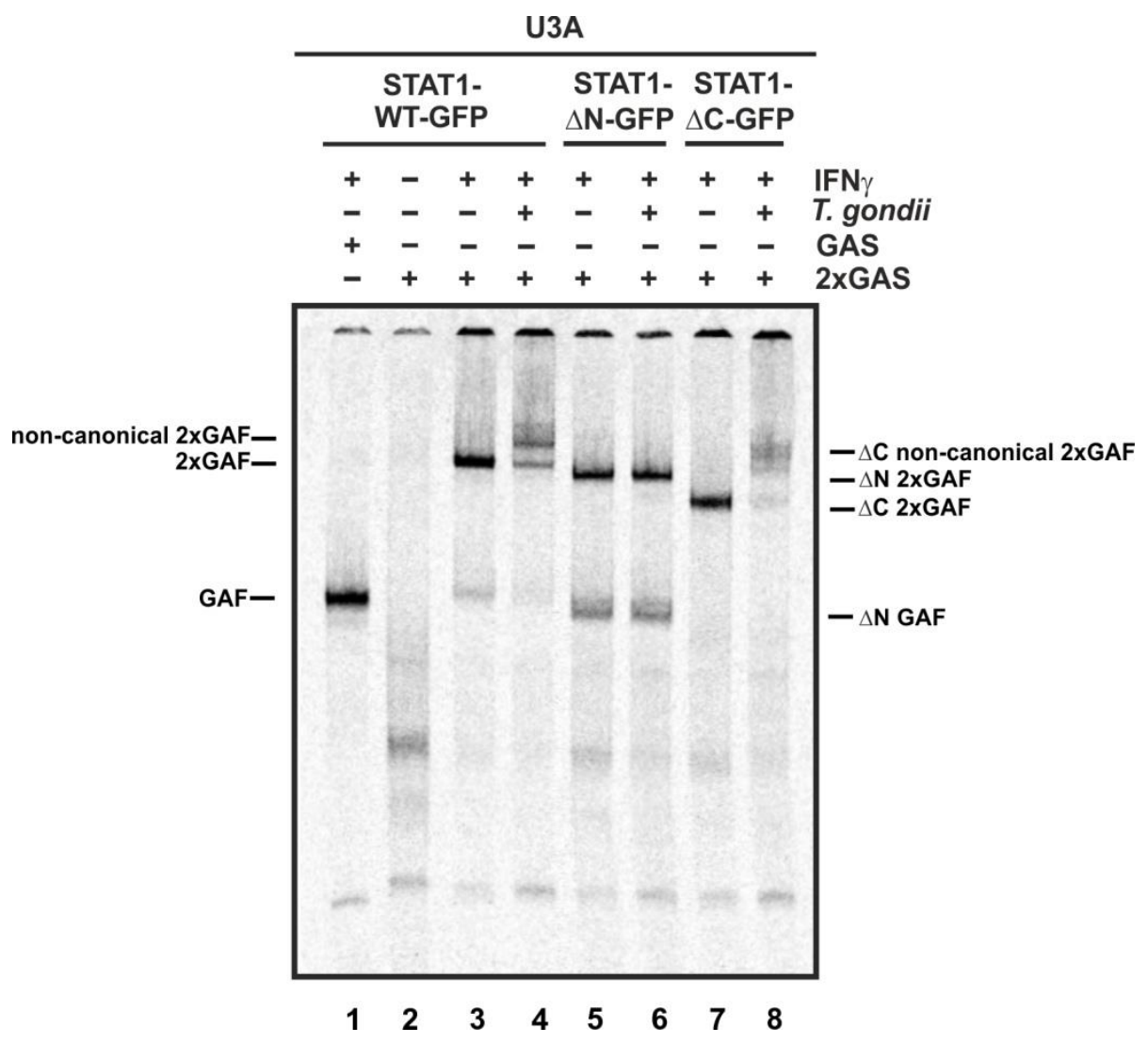

Figure 25: The STAT1 N-terminus, but not the C-terminus is required for formation of the $T$. gondii-induced noncanonical GAF-complexes.

U3A cells were infected with $T$. gondii at a parasite to host cell ratio of 10:1 or were left non-infected. Twenty-four hours post infection, nuclear protein fractions were prepared. In parallel, U3A cells were transiently transfected with different STAT1 constructs as indicated. Twenty-four hours post transfection, cells were activated with $5 \mathrm{ng} / \mathrm{ml} \mathrm{IFN- \gamma}$ for 45 minutes or were left non-stimulated as indicated. Complete cell extracts from these cells were then co-incubated with extracts of nonstimulated infected or non-infected U3A cells at a 1:1 ratio. The samples were incubated with [33P]-labelled DNA probes comprising one GAS (GAS) or two GAS elements (2xGAS) for 45 minutes. Protein-DNA-complexes were separated by native polyacrylamide gel electrophoresis and were visualised by autoradiography. The results are representative for three independent experiments. 
Non-canonical GAF complex formation was then determined with U3A cells expressing STAT1 deletion mutants. The GFP-tagged recombinant human STAT1- $\Delta C$ contains amino acids 1 to 712 and thus lacks the C-terminal transactivation domain. Combining extracts from non-infected U3A cells and IFN- $\gamma$ stimulated ones expressing this mutant STAT1 protein promoted binding of STAT1 to $2 \times G A S$ oligonucleotides as STAT1- $\triangle C$ 2xGAF (Figure 25, lane 7). Compared to the STAT1-WT 2xGAF, the STAT1$\Delta C$ tetramer migrated faster due to the C-terminal truncation. Co-incubation of a sample with activated STAT1- $\Delta C$ and an extract from T. gondii-infected cells led to the predominant formation of the corresponding non-canonical STAT1- $\triangle C$ 2xGAF-complex (Figure 25, lane 8). This indicated that the Cterminal domain of STAT1 is not required for formation of the T. gondii-induced aberrant 2xGAFcomplex, i.e. effector binding.

The GFP-tagged recombinant human STAT1- $\Delta N$ lacks the $\mathrm{N}$-terminal domain and contains amino acids 127 to 747. Combining extracts from non-infected U3A cells and IFN- - -stimulated ones reconstituted with STAT1- $\triangle N$ induced binding predominantly as STAT1- $\triangle N$ 2XGAF but to a smaller extent also as STAT1- $\triangle N$ single GAF (Figure 25, lane 5). As expected, the STAT1- $\Delta N$ complexes showed increased electrophoretic mobility due to the truncation of the amino terminal 126 amino acids. Importantly, after co-incubation of an extract containing activated STAT1- $\Delta N$ with that from $T$. gondii-infected cells, no non-canonical complex formation was detected (Figure 25, lane 6).

Taken together, the STAT1-N-terminus appeared to be essential for the T. gondii-induced modulation of GAF complexes, whereas the C-terminus appeared dispensable.

\subsubsection{Cooperative binding of STAT1 is critical for its parasite-mediated modification}

Due to cooperative binding, tetrameric STAT1 complexes have a higher DNA binding stability, which facilitates binding of 2xGAF complexes also to imperfect GAS sequences. This depends on interactions between the amino-terminal domains of two adjacent STAT1 dimers (Vinkemeier et al., 1996; Begitt et al., 2014). Given the observation that N-terminal truncation of STAT1 prevented 2xGAF modulation by T. gondii (see section 3.3.3.1), it was investigated, whether cooperative binding of STAT1 is required for binding of the parasite or parasite-induced host effector. To this end, a myocardial fibroblast cell line from mice with a mutated STAT1-F77A version was utilised. The exchange of phenylalanine at position 77 to alanine critically weakens the N-terminal mediated binding between two STAT1 dimers (Meyer et al., 2004). To this end, nuclear extracts from IFN- $\gamma$-stimulated or from non-stimulated STAT1-WT and F77A cells, being either T. gondii-infected or left non-infected, were incubated with radioactively labelled oligonucleotides comprising a consensus and a mutated GAS element (GAS-nonGAS). The 
importance of STAT1 cooperative binding on T. gondii-induced non-canonical complex formation was then analysed by means of gelshift experiments (Figure 27).

Control experiments were however first conducted to verify, whether T. gondii infects and replicates within wild-type and mutant STAT1-F77A cells to similar extents. This was done by means of immunofluorescence staining (Figure 26).


Figure 26: Toxoplasma gondii infects and replicates within STAT1-WT and mutant -F77A cells to similar extents. (A) STAT1-WT and (B) STAT1-F77A cells were infected with $T$. gondii at a parasite to host cell ratio of 3:1 or were left noninfected. Forty hours post infection, cells were fixed, permeabilised and stained with anti-T. gondii serum (green) and propidiumiodide (nucleic acids, red). Images of each labelling were obtained by confocal laser scanning microscopy and were merged. The results are representative for two independent experiments. (C) The infection rate was quantified by analysing at least 450 randomly selected cells. (D) T. gondii replication was quantified by counting tachyzoites in at least 500 randomly selected parasitophorous vacuoles. The results are representative for two independent experiments. Bars represent means \pm SEM. 
Intracellular parasites were easily detected in both cell lines at 40 hours post infection (Figure 26A and B). Quantitative analyses revealed $44.8 \%$ of STAT1-WT cells and 53\% of STAT1-F77A cells being infected by at least one parasite (Figure 26C). Furthermore, the number of parasites per parasitophorous vacuole was determined as a measure for T. gondii replication. On average, STAT1-WT cells harboured 2.9 parasites per vacuole whereas STAT1-F77A cells harboured 2.3 parasites per vacuole (Figure 26D). Together, the results confirmed the ability of T. gondii to infect both STAT1-WT and mutant -F77A cells and to replicate within them to a similar extent.

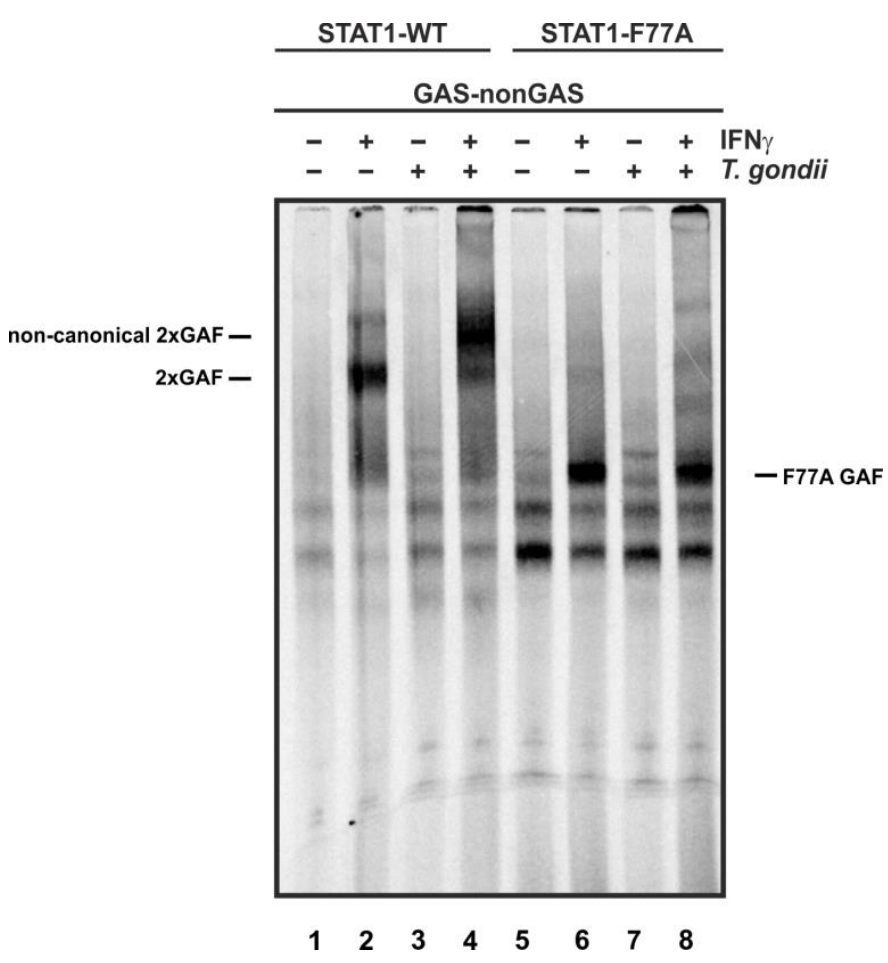

Figure 27: Toxoplasma gondii -induced non-canonical GAF complex formation is largely abolished in STAT1-F77A cells.

Wild-type and STAT1-F77A cells were infected with T. gondii in a parasite to host cell ratio of 6:1 or were left non-infected. Twenty-four hours post infection, cells were activated with $300 \mathrm{U} / \mathrm{ml} \mathrm{IFN-} \gamma$ for 30 minutes or were left non-stimulated as indicated. Nuclear protein extracts were incubated with a [33P]-labelled DNA probe containing one GAS and an adjacent mutated GAS element (GAS-nonGAS). Protein-DNA-complexes were separated by native acrylamide gel electrophoresis and were visualised by autoradiography. The results are representative for three independent experiments.

It was then analysed which impact STAT1 cooperative binding has on T. gondii-induced formation of non-canonical GAF complexes. In the absence of IFN- $\gamma$ stimulation, STAT1 from wild-type cells did not bind to the DNA oligonucleotides, irrespective of whether the cells had been infected or not (Figure 27, lane 1 and 3). IFN- $\gamma$ stimulation specifically promoted binding of STAT1 as 2xGAF to the GAS-nonGAS probe (Figure 27, lane 2). As expected, STAT1 in extracts from IFN- $\gamma$-treated, T. gondii-infected cells 
bound to DNA predominantly as a slower migrating non-canonical 2xGAF complex (Figure 27, lane 4). Mutant STAT1-F77A from non-activated cells did not form DNA-binding GAF complexes irrespective of infection (Figure 27, lane 5 and 7). In contrast to WT cells, after activation by IFN- $\psi$, STAT1-F77A almost exclusively bound as a single GAF complex to DNA whereas cooperative binding as 2xGAF was abolished (Figure 27, lane 6). This confirmed, that cooperative binding via the N-termini of STAT1 is the driving force for stable 2xGAF binding to partially non-specific DNA sequences. Importantly, STAT1-F77A from IFN- $\gamma$-treated, $T$. gondii-infected cells also appeared to bind as a conventional single GAF since the band intensity was similar to that from non-infected cells (Figure 27, compare lane 6 and 8).

Together, these results confirmed that substitution of phenylalanine 77 to alanine in the $\mathrm{N}$-terminus of STAT1 prevents STAT1 cooperative binding. Importantly, this mutation also at least largely, if not completely, abolished formation of a non-canonical GAF complex, i.e. binding of the effector to STAT1. This again highlighted the critical impact of the STAT1 $\mathrm{N}$-terminus for parasite-mediated modulation of STAT1.

\subsubsection{STAT1 cooperative binding is not essential for $T$. gondii to modulate the transcriptional} response to IFN- $-\gamma$

STAT1 cooperative DNA binding is critical for efficient IFN- $\gamma$-induced gene transcription (Begitt et al., 2014). Since the loss of STAT1 cooperativity due to the F77A substitution abolished T. gondii-induced GAF modification at least to a large extent, the following experiment was performed to directly assess the impact of STAT1 cooperative DNA binding on T. gondii-induced inhibition of IFN- - -regulated gene expression. To this end, expression of the primary response genes irf1 (interferon regulatory factor 1) and irf8 (interferon regulatory factor 8 ) as well as the secondary response genes ciita (class II transactivator) and $h 2-a \beta$ (a MHC class II molecule) was compared in parasite infected and non-infected STAT1-F77A cells and WT cells by quantitative real-time PCR (Figure 28). These IFN- $\gamma$-inducible genes were selected since their expression was previously shown to be significantly inhibited by $T$. gondii infection (Lang et al., 2012). 


\section{A}
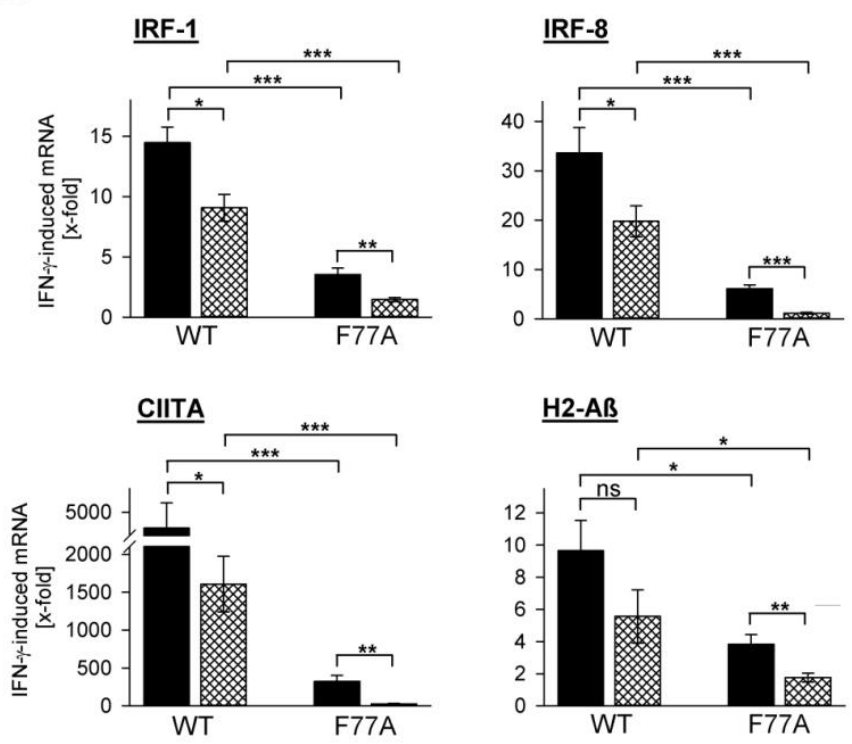

\section{$\underline{H 2-A B}$}

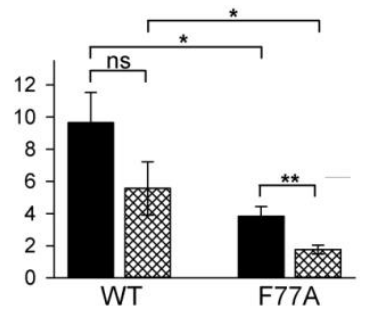

B

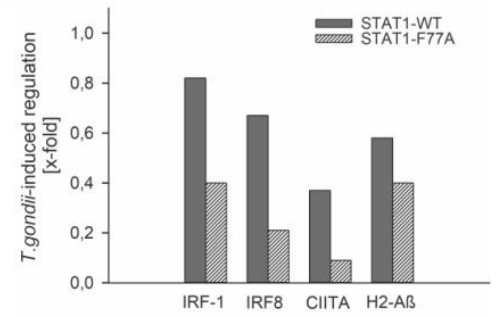

Figure 28: Toxoplasma gondii inhibits residual IFN- $\gamma$-induced transcription in STAT1-F77A cells.

Wild-type and STAT1-F77A cells were infected with T. gondii at a parasite to host cell ratio of 6:1 or were left non-infected. Two and a half hours post infection, cells were activated with $100 \mathrm{U} / \mathrm{ml} \mathrm{IFN-} \gamma$ or were left non-stimulated as indicated. Twentyfour hours post infection, total RNA was isolated, and mRNA was reverse transcribed. cDNA was then used as template together with gene specific primers for quantitative real-time PCR. (A) Transcriptional activation of non-infected (black bars) and $T$. gondii-infected (cross-hatched bars) cells by IFN- $\gamma$ was analysed for irf1, irf8, ciita and $h 2-a \beta$ and was normalized to $\beta$-actin CDNA as internal standard according to ratio $\mathrm{R}=(\mathrm{E})^{\Delta \mathrm{CP} \text { targetgene }(\text { non-stimulated - IFN- } \gamma \text {-treated) }} /(\mathrm{E})^{\Delta \mathrm{CP}_{\beta} \text {-actin(non-stimulated - IFN- } \gamma \text {-treated) }}(\mathrm{E}=2)$. Results are representative for at least six independent experiments. Bars represent means \pm SEM. Significant differences were identified by Student's t-test $(* p<0.05, * * p<0.01, * * * p<0.001)$. (B) The regulation of gene expression by $T$. gondii-infection from the results in (A) was calculated for WT (black bars) and STAT1-F77A (grey bars) cells.

After IFN- $\gamma$ stimulation of non-infected wild-type cells, expression irf1, irf8, ciita and $h 2-a \beta$ was clearly up-regulated although to various extents (Figure 28A). As expected, the transcriptional activation of all investigated genes was reduced in T. gondii-infected WT cells as compared to controls (irf1 0.82-fold, irf8 0.67-fold, ciita 0.37 -fold, $h 2-a \beta 0.58$-fold), and this was statistically significant for irf1, irf8 and ciita $(p<0.05)$. Substitution of Phe ${ }^{77}$ for alanine in the $\mathrm{N}$-terminal domain of STAT1 did not preclude gene transcription per se, but significantly diminished responses of non-infected cells to IFN- $\gamma$ (at least $p<0.05)$. This effect was especially prominent for irf1, irf8 and ciita, where the impairment of gene transcription due to the loss of STAT1 cooperative binding was highly significant $(p<0.001)$. Remarkably, concomitant infection of STAT1-F77A cells with T. gondii also clearly inhibited IFN- $\gamma$ mediated gene transcription as compared to non-infected controls (irf1 0.40-fold, irf8 0.21-fold, ciita 0.09-fold, $h 2-a \beta 0.46$-fold). Furthermore, such parasite-induced silencing of STAT1-F77A responses was highly significant (at least $p<0.01$ ). Compared to T. gondii-infected wild-type cells, infected STAT1-F77A cells showed a significantly diminished transcriptional response (at least $p<0.05$ ). In case of irf1, irf8 
and $h 2-a \beta$, IFN- $\gamma$-induced gene expression was nearly completely abolished after $T$. gondii-infection. When compared to STAT1-WT cells, T. gondii-mediated inhibition of all investigated genes was even stronger in STAT1-F77A cells (Figure 28B).

In summary, the results indicated that the T. gondii-induced transcriptional inhibition of IFN- $\gamma$ responsive genes does not depend on STAT1 cooperativity. In fact, T. gondii infection rendered cooperativity deficient STAT1-F77A cells largely unresponsive to IFN- $\gamma$. 


\section{DISCUSSION}

As one of the most successful parasites which infects up to $30 \%$ of the world's human population, T. gondii is a master manipulator of host cell functions to ensure its survival, replication and transmission to a new host. Recent years have unravelled the existence of several $T$. gondii effector molecules which are directly involved in reprogramming gene transcription in infected cells, including modulation of the IFN- $\gamma$-mediated transcriptional response (Pollard et al., 2009; Melo et al., 2011; Denkers et al., 2012; Hakimi et al., 2017). IFN- $\gamma$ was already highlighted in the 1960s as an important cytokine which is induced by infection with T. gondii (Freshman et al., 1966; Rytel and Jones, 1966) and further work subsequently identified the cytokine as the major mediator of the host defence against the pathogen (Suzuki et al., 1988; Yap and Sher, 1999a). IFN- $\gamma$ is highly pleiotropic and differentially regulates the expression of several hundred genes both related and unrelated to immunity (Boehm et al., 1997; Kim et al., 2007; Lang et al., 2012). Infection with T. gondii elicits a strong IFN- - -driven immune response of its host; however, such immune response is not able to eradicate the infection due to its evasion by the parasite. Some T. gondii strains can directly inhibit the activity of a major IFN- $\gamma$-induced toxoplasmacidal mechanism, i.e. the immunity-related p47 GTPases (IRGs)-dependent lysis of the parasitophorous vacuole membrane through polymorphic effector molecules (Fentress et al., 2010; Steinfeldt et al., 2010; Behnke et al., 2012; Fleckenstein et al., 2012; Reese et al., 2014; Hermanns et al., 2016). However, T. gondii infection already inhibits the IFN- $\gamma$-induced gene expression. First evidence for such an immune evasion mechanism was the observation that $T$. gondii actively down-regulates the IFN- $\gamma$ activated expression of antigen-presenting major histocompatibility complex (MHC) class II molecules in murine macrophages (Lüder et al., 1998) at the level of gene transcription (Lüder et al., 2001). Soon after that it became evident that $T$. gondii interferes with the expression of numerous IFN- $\gamma$-induced genes in different cell types, all known to play important roles in parasite control (Lüder et al., 2001; Lüder et al., 2003; Zimmermann et al., 2006; Lang et al., 2006). Genome-wide analyses of the impact of T. gondii infection on IFN- $\gamma$-induced transcription revealed a complete dysregulation of IFN- $\gamma$ inducible genes in T. gondii-infected human fibroblasts (Kim et al., 2007) and murine macrophages (Lang et al., 2012). Macrophages, i.e. those cells that are particularly important for parasite control but also for immune priming were unable to properly respond to IFN- $\gamma$ when infected with the parasite. Remarkably, the expression of the vast majority of about 1000 genes that were differentially regulated by the cytokine was counteracted by parasite infection (Lang et al., 2012). All three major T. gondii lineages (type I, II and III) inhibit IFN- $\gamma$-induced gene expression in various cell types (Kim et al., 2007; Rosowski and Saeij, 2012) suggesting a key molecular mechanism shared by all strains. 
Early studies investigating the T.gondii-mediated inhibition of the IFN- $\gamma$ transcriptional response proposed that a parasite-secreted protein present in the host cell nucleus might interfere with STAT1 transcriptional activity (Kim et al., 2007). It is now accepted that IFN- - -induced activation, dimerisation and nuclear translocation of the transcription factor occurs normally in T. gondii-infected cells (Lang et al., 2006; Kim et al., 2007; Lang et al., 2012; Rosowski and Saeij, 2012; Rosowski et al., 2014). Furthermore, the activated STAT1 complex, known as gamma-interferon-activated factor (GAF), from infected cells was shown to bind to its recognition site, namely the gamma-interferon-activated site (GAS), in vitro. Remarkably however, the GAF-GAS complex from infected cells showed reduced electrophoretic mobility thus supposedly representing a parasite-modified non-canonical GAF complex (Lüder et al., 2001; Lang et al., 2012; Schneider et al., 2013; Rosowski et al., 2014; Olias et al., 2016). The formation of this aberrant complex was first described by Lang et al. (2012) and was later also reported from infection experiments with different $T$. gondii strains and various host cell types (Schneider et al., 2013; Olias et al., 2016). Several hypotheses on a STAT1-binding molecule were discussed but the identity stayed elusive. Only recently, $T$. gondii was identified to secrete the protein T. gondii inhibitor of STAT1-dependent transcription (TgIST) which accumulates in the host cell nucleus where it directly interacts with STAT1 and specifically recruits the Mi-2/nucleosomal remodelling and deacetylase (NuRD) complex and also the corepressor C-terminal binding proteins (CtBPs) 1 and 2 (Olias et al., 2016). Detailed studies demonstrated that TgIST is both necessary and sufficient for inhibition of IFN- $\gamma$-dependent gene transcription, a function conserved in all T. gondii strains (Olias et al., 2016; Gay et al., 2016). However, the mechanism of how this effector modulates STAT1 yet remained to be uncovered.

\subsection{Toxoplasma gondii modifies GAF and 2xGAF complexes in a STAT1 N-} terminus-dependent manner

In the present work I therefore studied, amongst other issues, which impact $T$. gondii infection has on the formation of GAF complexes and the DNA binding activity of STAT1. The electrophoretic mobility shift assay (EMSA) experiments confirmed previous reports that $T$. gondii infection does not per se inhibit STAT1 DNA binding activity. In fact, the parasite modifies STAT1 leading to an additional, broader and slower migrating complex in murine RAW264.7 macrophages in the presence of oligonucleotides with a single GAS recognition site (Figure 19A). The presence of adjacent GAS sites facilitates STAT1 DNA binding in a multimeric conformation (Xu et al., 1996; Vinkemeier et al., 1996). The tetramerisation or even polymerisation of STAT1 molecules is required for productive promoter occupancy. STAT1 cooperativity strengthens the DNA binding activity and was identified to be indispensable for efficient gene transcription in vitro and in vivo (Begitt et al., 2014). Importantly, my experiments revealed for the 
first time that $T$. gondii also modulates STAT1 tetramer complexes bound to oligonucleotides with two GAS elements (2xGAS) by inducing an aberrant, slower migrating complex in RAW264.7 macrophages (Figure 19A). Anti-STAT1, but not anti-STAT3 antibodies, supershifted both the canonical and noncanonical complex, indicating the presence of STAT1 at the core of the parasite-induced complex (Figure 19B). It must be mentioned, that the present study does not directly prove that the here observed formation of aberrant GAF complexes in T. gondii NTE strain-infected RAW264.7 macrophages results from TgIST binding to STAT1. However, in T. gondii infection experiments with a TgIST knockout line and a fully complemented line, (Olias et al., 2016) demonstrated that the retarded electrophoretic mobility of the non-canonical single GAF complex completely depends on TgIST expression, although the authors did not investigate the impact of TgIST on 2xGAF. For their experiments they used short oligonucleotides with only a single GAS element, but to accommodate STAT1 binding in tetrameric conformation, a DNA scaffold is required that is long enough. Thus, TgIST most likely binds to STAT1 in tetrameric conformation as well, resulting in the here observed altered electrophoretic mobility of 2xGAF. Together, I thus anticipate that indeed TgIST mediates the effects on STAT1 I describe herein, and I will therefore ascribe my findings to it.

I found that infection with T. gondii diminishes the formation of conventional GAF in favour of the TgISTbound, non-canonical complex, which confirms previous observations (Lang et al., 2012; Olias et al., 2016). Remarkably, canonical $2 x G A F$ formation is completely abolished in samples from infected cells and all STAT1 is present in the aberrant 2xGAF complex. This indicates that TgIST binds both, GAF and 2xGAF complexes, but more efficaciously assembles with STAT1 tetramers (Figure 19A). Thus, by preferential binding of TgIST to $2 \times \mathrm{GAF}, T$. gondii seems to particularly target the transcriptional relevant STAT1 complexes (Begitt et al., 2014) and this may be crucial for evasion of the IFN- $p$ response of its host.

By using deletion mutants of STAT1 this study also addressed the question which region of the transcription factor is required for TgIST to bind GAF complexes. TgIST is predicted to be a highly disordered protein, suggesting that it recognises its binding partner by an induced-fit mechanism, which may involve a structural change following binding (Sibley, 2017). I found that the STAT1 N-terminus, but not the C-terminal domain is required for TgIST binding (Figure 25). Indeed, the T. gondii effector protein neither did assemble with STAT1- $\triangle N$ single GAF nor with STAT1- $\triangle N$ 2xGAF, suggesting binding of TgIST to the $\mathrm{N}$-terminal domain of STAT1.

By binding to the amino-terminal domain of STAT1, T. gondii targets the versatile protein interaction domain of utmost importance which regulates a multitude of events during IFN- $\gamma$ signal transduction (Shuai, 2000; Meyer et al., 2004). Among others, the N-terminal domain facilitates reciprocal proteinprotein interactions between two STAT1 dimers on adjacent GAS sites. This oligomerisation on tandem 
binding sites is called cooperative binding and strongly stabilises DNA binding (Vinkemeier et al., 1996; Meyer et al., 2004). As already discussed above, TgIST binds more efficaciously to 2xGAF, i.e. the complex stabilised by cooperative binding through $\mathrm{N}$-terminal interactions, than to GAF. This leads me to hypothesise that the parasite effector may bind STAT1 tetramers by bridging the N-terminal domains, i.e. the dimer-dimer interface. Another interesting issue relates to the conformation in which TgIST binds GAF complexes. Since TgIST preferably assembles with STAT1 tetramers, it is conceivable that TgIST, as a monomer or multimer, possesses two interfaces to bind STAT1 dimers. A simultaneous binding through both sites may increase TgIST-STAT1 binding stability, explaining the different binding activities to GAF and 2xGAF.

As already mentioned, cooperative binding strengthens the DNA binding activity to high-affinity GAS sites (Vinkemeier et al., 1996). Importantly, cooperativity also extends to sequences where a single GAS element is adjacent to an imperfect non-GAS sequence (Meyer et al., 2004). This single-site cooperativity facilitates the tetrameric binding of STAT1 on GAS-nonGAS oligonucleotides, as confirmed in this study (Figure 21A; Figure 22C and D). To further examine the impact of the STAT1 N-terminus and specifically the cooperative binding on TgIST binding activity, another N-terminal mutant was used. STAT1-F77A lacks the critical residue that is needed to facilitate tetramer stabilisation. Due to the substitution of phenylalanine at position 77 to alanine, cooperative binding is abolished (Meyer et al., 2004). The impact of defective cooperativity became evident when STAT1-F77A bound to GAS-nonGAS oligonucleotides exclusively as a dimer, confirming that cooperative binding is the driving force for GAF recruitment to imperfect binding sequences. Efficient DNA binding of STAT1-F77A was identified in T. gondii-infected cells only as canonical single GAF indicating that TgIST did not target single GAF from STAT-F77A cells (Figure 27). The site-specific mutation of STAT1 thus clearly weakened the interaction of TgIST again emphasizing the importance of the N-terminal domain for TgIST binding.

\subsection{Toxoplasma gondii inhibits the residual IFN- $\gamma$ responses in the absence of cooperative DNA binding of STAT1}

Previous analyses have shown that cooperative DNA binding of STAT1 is indispensable for efficient transcriptional activation of the majority of IFN- $\gamma$-regulated genes and that it is mandatory for antibacterial immunity in vivo (Meyer et al., 2004; Begitt et al., 2014). Therefore, I also studied the ability of T. gondii to interfere with IFN- - -mediated gene expression in cooperativity-deficient STAT1-F77A mutant cells (Figure 28). As expected, the responsiveness of these cells to the cytokine was greatly diminished compared to the ones expressing wild-type STAT1, thus confirming the previous observations of Meyer et al. (2004) and Begitt, et al. (2014). Surprisingly, infection with T. gondii further 
abrogated the residual transcriptional activity, resulting in gene expression levels in $T$. gondii infected, IFN- $\gamma$-stimulated STAT1-F77A cells similar to those as observed in non-stimulated wild-type cells. Given the at least strongly reduced levels of TgIST interaction with STAT1-F77A, i.e. non-canonical GAF and non-canonical 2xGAF formation, this suggests two possible scenarios: Firstly, in addition to the TgISTdependent inhibition of the IFN- $\gamma$-responsiveness, the parasite may use a TgIST-independent mechanism to counteract residual IFN- $\gamma$-mediated transcriptional activity. This theory is supported by the observation that TgIST-deficient parasites are still able to counteract cytokine-stimulated gene transcription to a minor extent (Olias et al., 2016; Gay et al., 2016). Alternatively, T. gondii may inhibit IFN- $-\gamma$ responses via TgIST and STAT1 in a cooperative binding-independent way. Despite the lack of detectable TgIST interaction with STAT1-F77A in vitro, the parasite effector protein may still be able to bind mutant STAT1-F77A complexes in vivo. In fact, STAT1-F77A can form a tetrameric conformation at oligonucleotides with tandem GAS elements, where dimers bind independently to either site (Meyer et al., 2004). These complexes do not resist displacement in EMSA competition experiments, indicating that adjacent STAT1-F77A dimers interact only weakly via stabilizing contacts or do not directly interact at all. TgIST was characterized here to preferentially bind STAT1 tetramers, supposedly by bridging the $\mathrm{N}$-terminal domains. The close spatial proximity of two STAT1-F77A dimers on high-affinity adjacent GAS sites in vivo could allow TgIST to bind and to negatively affect the remaining transcriptional activity. In this scenario, reciprocal N-terminal interactions of STAT1 dimers would promote TgIST binding but cooperative binding would not be a prerequisite.

\subsection{Toxoplasma gondii increases the binding affinity of STAT1 to GAS and} facilitates promiscuous DNA binding to nonGAS sequences

This study also addressed an apparent paradox. T. gondii inhibits the IFN- $\gamma$-mediated gene transcription, yet recent findings established that an infection increases the nuclear presence of STAT1 and its association with DNA (Rosowski et al., 2014; Gay et al., 2016). Several of my results indicate that binding of the parasite effector TgIST profoundly affects the transcription factor's DNA binding activities. EMSA experiments revealed that binding of the parasite-induced non-canonical 2xGAF to DNA with two tandem GAS motifs and especially to a single GAS element adjacent to a mutated one is greatly increased as compared to the canonical one (Figure 21A). This was confirmed by a pull-down assay, where STAT1 from infected cells binds much stronger to $2 x G A S$ and GAS-nonGAS oligonucleotides as compared to STAT1 from non-infected controls (Figure $22 \mathrm{C}$ and D). In addition, this was further validated by competition experiments, where parasite-induced non-canonical 2XGAF complexes resist displacement (Figure 23B and C). It is well documented that cooperative binding facilitates STAT1 binding to imperfect sequences but the high-affinity binding of one dimer is prerequisite for the recruitment of another GAF 
to adjacent nonGAS sequences. Remarkably, TgIST enables STAT1 to even bind two adjacent nonGAS motifs, thus dramatically diminishing the demands for sequence specificity. Together, EMSA, pull-down and competition experiments confirmed a strong promiscuous DNA binding activity of STAT1 from T. gondii-infected cells (Figure 21A; Figure 22D; Figure 23C). The parasite-triggered modulation of the DNA binding activity of STAT1 was largely restricted to its tetrameric conformation (see model in Figure 29). T. gondii infection had no obvious impact on the STAT1 binding strength to DNA with a single GAS motif (Figure 19A), which is in line with previous observations (Lang et al., 2012). This was further confirmed by a similar displacement of canonical- and non-canonical GAF complexes as observed in competition experiments (Figure 23A). However, T. gondii unexpectedly seems to facilitate STAT1 dimer binding to a single imperfect DNA sequence, even if only weakly (Figure 22B).

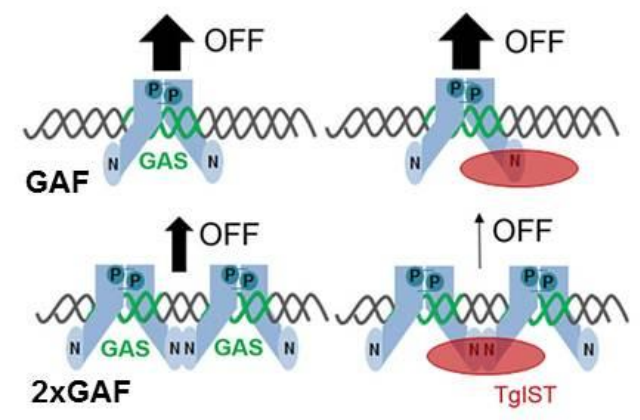

Figure 29: Toxoplasma gondii -mediated modulation of STAT1 DNA binding activity.

In non-infected cells, STAT1 can bind to DNA as dimer, i.e. GAF or as tetramer, i.e. 2xGAF depending on the number of adjacent GAS elements. In T. gondii-infected cells, TgIST binds STAT1 in a N-terminus-dependent manner, forming non-canonical GAF complexes. Although canonical 2xGAF complexes physiologically have a higher affinity to bind to DNA-, as compared to GAF, binding of TgIST further stabilises DNA binding of 2xGAF leading to its sustained association with DNA. The affinities of the different canonical and non-canonical STAT1 complexes to bind to DNA are indicated by different 'off' rates.

The differential parasite-induced modulation of DNA binding strengths of GAF and 2xGAF may relate to different TgIST binding activities to those complexes, as discussed before. Another interesting aspect is, whether the parasite effector itself provides a contact side to the DNA double helix. Such additional interaction may stabilize the STAT1-TgIST-DNA complex. Alternatively, the recruited CtBP corepressors and the Mi-2/NuRD complex may contribute to modulate the DNA binding activity of STAT1. However, the Mi-2/NuRD complex comprises a multitude of protein subunits (reviewed in Dege and Hagman, 2014) and the EMSA experiments do not suggest that the non-canonical complex as observed with extracts from infected cells also compromise such a large complex, indicating that binding of TgIST is sufficient to modulate STAT1 binding activity. 
Recently, in silico analysis revealed that although single GAS sites frequently occur in promoter regions of the mouse genome, multiple GAS sites are rare and not enriched in IFN- $\gamma$ target genes that were identified to require GAF oligomerisation (Begitt et al., 2014). Given the importance of cooperativity for promoter occupancy and gene transcription, the authors concluded that STAT1 polymerisation originates from one high-affinity GAS site and then relies on relaxed additional sequence constrains. Thus, by preferentially targeting 2xGAF complexes, $T$. gondii does not only modulate DNA binding activities of the physiological more relevant GAF complex but also that of the endogenously predominant one. By strengthening the DNA binding of STAT1 in vivo, T. gondii probably promotes cooperative binding, thus propagating progressive bidirectional chain formation resulting in sequestration of supposedly high amounts of STAT1 molecules. In addition, promiscuous binding of STAT1 to nonGAS sequences in T. gondii-infected cells probably sequesters STAT1 at inert genomic regions outside of transcriptional active sites in vivo. In this scenario, a limited number of high-affinity GAS sites compete with a virtually unlimited number of non-GAS sequences. Importantly, this unspecific binding will reduce the pool of activation-competent STAT1 molecules, supposedly resulting in a lower occupancy at GAS-promoters. Recently, conflicting observations were reported concerning the level of STAT1 promoter occupancy in $T$. gondii-infected cells. They range from increased levels over unaffected ones to decreased levels (Rosowski et al., 2014; Olias et al., 2016; Gay et al., 2016) suggesting that T. gondii may affect STAT1 occupancy in a promoter-specific manner. However, the published results are partially inconsistent with each other, clearly indicating that more research is needed to establish the complete promoter occupancy of STAT1 during parasite infection. Based on my findings, I however hypothesise that $T$. gondii also negatively affects promoter occupancy.

Together, these findings lead me to hypothesise that by modulating STAT1 DNA binding activity, T. gondii profoundly disturbs the transduction of the IFN- $\gamma$ signal (see model in Figure 30). In noninfected cells, dissociation of STAT1 from DNA allows repeated binding to GAS motifs or will lead to its inactivation through dephosphorylation of the signature residue $\mathrm{Tyr}^{701}$ by the nuclear tyrosine phosphatase Tc-45 (ten Hoeve et al., 2002), which is a prerequisite for nuclear export and subsequent reactivation at the IFN- $\gamma$ receptor (Figure 30A (2)) (Meyer et al., 2003). In T. gondii-infected cells, the effector TgIST binds to STAT1 and recruits the Mi-2/NuRD repressor complex to GAS-containing promoters thereby blocking transcription of IFN- $\gamma$-regulated genes (Figure 30B (1)) (Olias et al., 2016; Gay et al., 2016). My current working model is that binding of TgIST strongly increases the binding activity of STAT1 tetramers to tandem or single GAS sites in IFN- - -regulated promoters (Figure 30B (2a and b)). Furthermore, TgIST binding facilitates sustained binding of STAT1 tetramers to nonGAS DNA (Figure 30B (3)). Thus, sequestration of the transcription factor at inert genomic loci decreases the pool of STAT1 molecules competent to activate GAS-containing promoters (Figure 30B (4)). The parasite- 
mediated increased binding activity of STAT1 tetramers decelerates its dissociation from DNA and thus nuclear export (Figure 30B (5)). Since the IFN- $\gamma$-induced activation of STAT1 is a paradigm of an affinitydriven process (Greenlund et al., 1995), it is highly sensitive to the reactants' concentrations, i.e. the activated receptor chain and latent STAT1. A fast dissociation from DNA ensures to link DNA release and subsequent dephosphorylation to the transcriptional activation of STAT1 (Koch et al., 2012). Therefore, parasite-infected cells may suffer from cytoplasmic depletion of STAT1, which reduces the association rate of STAT1 with the receptor and hence STAT1 activation. This disturbs efficient transmission of the extracellular IFN- $\gamma$ signal to the transcriptional response. Thus, paradoxically, despite the increased DNA binding affinity of STAT1 and its elevated concentration in the nuclei of T. gondii-infected cells, STAT1 is a weaker transcriptional activator, resulting in the parasite-mediated suppression of gene induction.


Figure 30: Interference of T. gondii with STAT1-dependent gene transcription.

IFN- $\gamma$ stimulated JAK/STAT1 signalling in non-infected cells (A) and T. gondii-infected cells (B). A: After phosphorylation at the IFN- $\gamma$ receptor, STAT1 translocates into the nucleus. There it binds as dimer to GAS- (1a) or forms tetramers on 2xGAS- (1b) and GAS-nonGAS- (1c) containing promoters and eventually initiates gene transcription. Release of STAT1 from DNA allows its dephosphorylation, nuclear export and reactivation (2). B: In T. gondii-infected cells, TgIST binds to GAF and recruits the Mi2/NuRD repressor complex, thereby inhibiting IFN- $\gamma$ regulated transcription (1). Furthermore, interaction of TgIST with STAT1 tetramers increases the binding affinity to $2 x G A S$ (2a) and GAS-nonGAS (2b) DNA in IFN- $y$-responsive promoters. TgIST can also sequester STAT1 tetramers to non-target DNA (3) thereby decreasing the pool of STAT1 for activation of GAS-containing promoters (4). The increased binding of TgIST-STAT1 complexes to DNA hampers the nuclear export and subsequent reactivation of STAT1 (5). 


\subsection{Toxoplasma gondii promotes increased and sustained nuclear} accumulation of activated STAT1

In support of this working model, results of this study also provide several lines of evidence indicating that the modulated DNA binding activities of STAT1 in T. gondii-infected cells indeed result in increased nuclear accumulation of the transcription factor as compared to non-infected cells. Immunofluorescence microscopy revealed that nuclear accumulation of STAT1 strongly declines during prolonged stimulation with IFN- $\gamma$ for 24 and 40 hours in non-infected cells (Figure 17E, G and I). This finding is explained by the down-regulation of STAT1 signalling through synergistic auto-regulatory negative feedback loops (reviewed in Shuai and Liu, 2003; and Rakesh and Agrawal, 2005). In comparison, nuclear STAT1 levels remained significantly elevated in parasite-infected cells (Figure 17F, $\mathrm{H}$ and I). This also indicates that the parasite-mediated nuclear accumulation of STAT1 is a long-lasting effect. Such accumulation was also evident from Western blot analysis, where nuclear protein extracts from IFN- $\gamma$-stimulated T. gondii-infected cells show higher concentrations of STAT1 than those from non-infected cells (Figure 14). By actively disrupting the IFN- $\gamma$ signal transduction with a kinase inhibitor, I was able to show that $T$. gondii infection interferes with the nucleocytoplasmic shuttling of STAT1. Staurosporine is a potent broad spectrum kinase inhibitor (Tamaoki, 1991), but it is frequently used to inhibit the IFN- $\gamma$ receptor associated Janus kinases (JAKs), thus preventing cytokine-stimulated activation of STAT1 by Tyr ${ }^{701}$ phosphorylation (Köster and Hauser, 1999; Haspel and Darnell, 1999; Lillemeier et al., 2001). Although off-target effects cannot be completely excluded, an effective inhibition of STAT1 reactivation is indeed indicated by a progressive decrease of nuclear STAT1 levels, both in T. gondii-infected and non-infected cells (Figure 18). However, in comparison, STAT1 levels remain significantly higher in the nuclei of infected cells, thus arguing for a prolonged nuclear residence of the transcription factor. Since nuclear export of STAT1 initially requires its dissociation from DNA, this prolonged nuclear retention is in line with the observed increased affinity of STAT1 from T. gondiiinfected cells to GAS and nonGAS oligonucleotides. This is further supported by the fact that the nuclear STAT1 from infected cells appears to be fully activated to a large extent. Western blot analysis of nuclear protein extracts revealed high levels of phosphorylation at the signature residues $\operatorname{Tyr}^{701}$ and $\operatorname{Ser}^{727}$ (Figure 14). DNA-bound STAT1 is protected from dephosphorylation at Tyr ${ }^{701}$ (Meyer et al., 2003) and IFN- - -induced Ser ${ }^{727}$ phosphorylation was reported to require a stable chromatin association of STAT1 (Sadzak et al., 2008). Thus, high levels of phosphorylation strongly argue for a DNA bound state of nuclear STAT1 in T. gondii-infected cells, confirming results from Rosowski et al. (2014) who found phosphorylated STAT1 to be enriched in the chromatin fraction of cell extracts. In the past, conflicting results have been reported on the impact of $T$. gondii infection on IFN- $\gamma$-induced phosphorylations of STAT1. They encompass observations of increased $\mathrm{Tyr}^{701}$ and/or Ser ${ }^{727}$ phosphorylation levels in infected 
cells (Schneider et al., 2013; Gay et al., 2016), similar levels (Lüder et al., 2001; Kim et al., 2007; Rosowski and Saeij, 2012) and reduced levels (Zimmermann et al., 2006; Kim et al., 2007). It has to be noted that in this study Western blot analyses of complete cell extracts showed that T. gondii promotes Tyr ${ }^{701}$ phosphorylation after prolonged IFN- $\psi$-stimulation for 24 hours but simultaneously represses STAT1 expression and $\mathrm{Ser}^{727}$ phosphorylation (Figure 12). Infections with representatives from the three T. gondii lineages that dominate in North America and Europe (Howe and Sibley, 1995) have similar effects on STAT1 and its activation pattern but differed slightly in the strength of modulation (Figure 13). These differences probably result from expression or activity of polymorphic virulence factors (Saeij et al., 2007; Rosowski and Saeij, 2012). However, my result and that from Rosowski et al. (2014) clearly argue for a DNA-bound state of nuclear STAT1 in T. gondii-infected cells. Therefore, I wondered if the cell extraction method may specifically affect the yield of STAT1 and its phosphorylated isoforms from parasite-infected cells as compared to non-infected controls. In fact, I found that extracts prepared with a mild detergent buffer yielded only a minor fraction of the total endogenous STAT1 from infected cells. An additional DNase treatment, included to solubilise any DNA-bound proteins, specifically increased the levels of Tyr ${ }^{701}$ - and Ser ${ }^{727}$-phosphorylated STAT1 in extracts from infected cells and exceeded those of non-infected cells (Figure 16). This directly confirms that activated STAT1 in T. gondii-infected cells is to a significant extent bound to DNA. This finding is further supported with yet another methodical approach, where cells were extracted with harsh detergents and were subsequently sonicated (Figure 15). Together, these findings also provide a possible explanation why recent reports on the T. gondiimediated impact on STAT1 phosphorylation levels yielded inconsistent observations.

\subsection{Toxoplasma gondii infection induces nuclear accumulation of STAT1 in parasite-negative bystander cells}

As already mentioned, immunofluorescence microscopy revealed an increased nuclear accumulation of STAT1 in T. gondii-infected cells during prolonged IFN- $\gamma$ stimulation as compared to non-infected cells. Remarkably, a slight but significant elevation of nuclear STAT1 levels was also detected in T. gondiinegative bystander cells from the same infected population (Figure 17F, $\mathrm{H}$ and I). One possible explanation for this phenomenon is the translocation of TgIST from T. gondii-infected cells to noninfected neighbouring cells, although this was not mentioned by Olias et al. (2016) or Gay et al. (2016). A possible mechanism underlying such a scenario is the exosome-based translocation of TgIST from extracellular parasites or from infected host cells to non-infected cells. In line with this, T. gondii is thought to use an exosome-based pathway to secrete distinct proteins (Torres et al., 2012). In fact, extracellular T.gondii parasites, which were incubated with macrophages separated by a 
semipermeable membrane, were able to interfere with the IFN- - -stimulated MHC class II expression in those cells (Lang, 2005). In addition, filtered medium or isolated exosomes from T. gondii-infected cultures influence proliferation and the cell cycle of naïve host cells (Lavine and Arrizabalaga, 2009; reviewed in Długońska and Gatkowska, 2016; Kim et al., 2016). Alternatively, T. gondii may 'inject' TgIST together with a bolus of effector proteins into cells which it does not productively invade. The phenomenon of secreting effector proteins from the early discharged rhoptry organelles into host cells, but then aborting the invasion process was revealed by Koshy et al. (2012) and may represent a parasiteemployed way to systematically manipulate the host. TgIST is thought to be stored in dense granule-like organelles (Olias et al., 2016; Gay et al., 2016). Dense granules are discharged later during invasion, but despite that an 'effector injection but aborted invasion' mechanism was not reported for dense granule proteins so far, some dense granule proteins are known to be secreted early during the invasion process. The present study does not provide direct evidence that the nuclear accumulation of STAT1 in noninfected bystander cells is TgIST-dependent, nor that the IFN- $\gamma$-regulated transcription is inhibited in these cells. However, the ability to dysregulate IFN- - -induced gene transcription also in neighbouring/non-infected cells would possibly provide a selective advantage for the parasite. Rendering potential host cells IFN- $\gamma$-unresponsive before IFN- $\gamma$-secreting NK and T cells arrive to the site of infection may protect the first wave of invading tachyzoites from potent anti-parasitic effector mechanisms downstream of IFN- $\gamma$ and likely aids to enhance T. gondii's intracellular survival and haematogenous dissemination during the acute phase of infection.

\subsection{Toxoplasma gondii induces DNA binding activity of STAT1 in the absence of} IFN- $\gamma$

Results from this study indicated that TgIST also facilitates STAT1 DNA binding activity in the absence of IFN- $y$ activation. I observed the formation of non-canonical complexes in extracts from T. gondiiinfected non-stimulated macrophages in the presence of 2xGAS oligonucleotides, which corresponds to the altered GAF and 2xGAF complexes in infected stimulated cells (Figure 20). This is in line with previous results from Lang et al. (2012), who detected a non-canonical GAF complex in T. gondii-infected nonstimulated macrophages in the presence of oligonucleotides with a single GAS. My experiments indicate however that in the absence of IFN- $\gamma$, extracts from $T$. gondii-infected cells contain only a small amount of DNA binding-competent STAT1. This suggests that low levels of STAT1 with DNA binding activity limits the sensitivity of detection of the non-canonical GAF complexes and explains why their formation was not reported from other infection experiments (Olias et al., 2016) and was also not regularly detected in every experiment presented in this study. It is of major interest which activation status STAT1 has in these non-canonical complexes. It could be possible, that TgIST facilitates DNA binding of latent, i.e. 
non-phosphorylated molecules. Alternatively, and more likely, infection with T. gondii may modulate the phosphorylation status of STAT1 in the absence of IFN- $\gamma$. In support of this, Olias, et al. (2016) and Gay et al. (2016) reported that in a TgIST-dependent manner, non-stimulated infected cells harbour pTyr ${ }^{701}$-activated STAT1 in the nucleus, which seems to be also phosphorylated at $\mathrm{Ser}^{727}$. This was confirmed in the present study, although levels of phosphorylation in nuclear extracts from nonstimulated T. gondii-infected cells were weak (Figure 14). In accordance with the formation of noncanonical GAF and 2xGAF complexes in the absence of IFN- $\gamma$, Gay et al. (2016) also showed that TgIST enhances the occupancy of fully activated STAT1 on GAS-containing loci in the absence of cytokine stimulation. However, such STAT1 from T. gondii-infected cells remain transcriptionally incompetent in the absence of IFN- $\gamma$. Binding of transcriptionally incompetent STAT1 in resting cells in vivo may also contribute to the infection-induced inhibition of IFN- $\psi$-regulated gene transcription: Firstly, by blocking the accessibility of high affinity GAS sites for transcriptionally competent STAT1, i.e. IFN- $\gamma$-activated PTyr ${ }^{701}$-STAT1, and secondly, by reducing the pool of free, activation-competent molecules. The binding of the STAT1-TgIST-Mi-2/NuRD complex may also sterically hinder the constitutive binding of regulatory factors which modify the GAS-containing promoter chromatin in resting cells (discussed in detail in the following section). The aspect of $T$. gondii-mediated modulation of STAT1 DNA binding activity in the absence of IFN- $\gamma$ clearly needs future experimentation. For example, the mechanism employed by T. gondii type II strains to modulate the phosphorylation status of STAT1 in the absence of IFN- $\gamma$ is unknown so far. Interestingly, under these conditions, STAT1 exclusively binds as non-canonical GAF complexes, suggesting that the phosphorylation is directly linked to TgIST binding. TgIST does not contain a common kinase domain (Gay et al., 2016); therefore, T. gondii may co-opt a host kinase and shortcut the IFN- - -triggered JAK-STAT1 signalling cascade. It also needs to be addressed whether and to what extent the parasite renders STAT1 molecules DNA binding-competent yet transcriptionally incompetent during IFN- $\gamma$ signalling. An IFN- - -independent activation of STAT1 DNA binding activity also provides a possible explanation for the unexpected observation that the STAT1 accumulation in nuclei of $T$. gondii-infected cells still increased after prolonged stimulation for 40 hours as compared to 24 hours (Figure 17I). During IFN-y stimulation, synergistic auto-regulatory negative feedback loops lead to the down-regulation of STAT1 signalling, e.g. via inhibition of JAKs by suppressors of cytokine signaling 1 (SOCS1) (Alexander et al., 1999), thereby inhibiting STAT1 reactivation even in the presence of IFNIn line with that, non-infected cells showed no nuclear accumulation after 40 hours of stimulation. A parasite-mediated IFN- $\boldsymbol{\gamma}$-independent DNA binding activity combined with the increased and promiscuous binding may promote a progressive nuclear accumulation. Such mechanism probably also prevents reactivation of the cells by subsequent IFN- $\gamma$ signals. 


\subsection{Toxoplasma gondii mediated inhibition of IFN- $\gamma$-regulated gene expression} depend on host native chromatin

Besides modulation of STAT1 DNA binding activity previous mechanistic analysis of the parasitemediated interference with IFN- - -induced transcription revealed that $T$. gondii likely inhibits the assembly of the BRG1/BRM-associated factor (BAF) chromatin remodelling complex at IFN- $\boldsymbol{\gamma}$-responsive promoters (Lang et al., 2012). Defective recruitment of the BAF core ATPase Brahma-related gene 1 (BRG1) was accompanied by an impaired of histone acetylation in promoter regions of a subset of IFN$\gamma$ target genes. These observations provided first evidence pointing to parasite-imposed changes in the epigenetic landscape at IFN- $\gamma$-regulated promoters. When recently TgIST was uncovered to bind to STAT1, it was also shown to recruit the Mi-2/nucleosomal remodelling and deacetylase (NuRD) complex and the corepressor C-terminal-binding protein (CtBP) to STAT1 (Olias et al., 2016; Gay et al., 2016). The $\mathrm{Mi}-2 / \mathrm{NuRD}$ complex is an important epigenetic regulator of chromatin structure and gene expression. This multi-subunit complex contains key epigenetic regulators, which for instance mobilise nucleosomes via ATP-dependent chromatin remodelling, deacetylate histones, and recruit additional regulatory proteins (Xue et al., 1998; Zhang et al., 1999; Shi et al., 2004; Dege and Hagman, 2014). The Mi-2/NuRD complex is normally not involved in regulation of STAT1-mediated transcription; therefore, its recruitment may lead to the parasite-imposed interference with epigenetic regulation of promoter activity during IFN- $\gamma$ stimulation. In the present study, I therefore also investigated which impact a T. gondii infection has on chromatin remodelling/epigenetic plasticity of macrophages during stimulation with IFN- $\gamma$. Firstly, however, construction of IFN- $\gamma$-inducible luciferase reporter genes in different DNA contexts allowed me to study which general impact native chromatin has on the parasiteimposed inhibition of IFN- $\gamma$-regulated gene expression. To this end, the effect of $T$. gondii on promoter constructs representing primary and secondary response genes, either from stably replicating templates, or from transiently transfected templates where chromatin does not properly form (reviewed in Smith and Hager, 1997), was compared (Figure 5C). The results for the first time experimentally revealed that the inhibitory effect of the parasite on IFN- - -induced transcription clearly depends on native chromatin within the host cell. Thus, T. gondii significantly inhibits IFN- $\gamma$-induced transcription of reporter constructs, which are embedded in the higher order chromatin structure of the host's genome. In contrast, $T$. gondii does not significantly diminish IFN- $\gamma$-regulated transcription, when the reporter construct is transcribed from a transiently transfected plasmid. Furthermore, it was shown that parasite-imposed inhibition of both primary and secondary response genes depends on native host chromatin, suggesting a common molecular mechanism to regulate both types of IFN- $\gamma$ response genes. Importantly, these results provide the first direct evidence that components and/or 
characteristics of the host's native chromatin structure are critical for the ability of $T$. gondii to inhibit IFN- - -regulated gene transcription.

\subsection{Promoters of IFN- $\gamma$-response genes which are strongly inhibited by T. gondii often lack CpG islands}

In line with these findings, in silico analyses revealed a correlation between a strong repression of IFN$\gamma$-induced transcription by $T$. gondii and the absence of $\mathrm{CpG}$ islands. $\mathrm{CpG}$ islands are thought to provide an accessible chromatin environment that favours rapid gene induction in response to external stimuli without the requirement of the chromatin remodelling machinery (reviewed in Blackledge and Klose, 2011). Approximately $60 \%$ of all human and murine promoters are associated with CpG islands (Antequera, 2003). Specifically, a strong T.gondii-imposed inhibition of IFN- $\gamma$-stimulated gene expression negatively correlates with the presence of a $\mathrm{CpG}$ island surrounding the transcriptional start site (TSS) (Figure 6). Thus, the majority of genes whose expression was heavily counteracted by $T$. gondii appears to have a more closed promoter state. Since induction of at least pro-inflammatory genes with non-CpG island promoters rely more often on BAF-mediated chromatin remodelling (Ramirez-Carrozzi et al., 2009; reviewed in Blackledge and Klose, 2011), T. gondii may inhibit transcription of those genes by preventing proper recruitment of BRG1, like it was observed in case of ciita (Lang et al., 2012). T. gondii also counteracts the IFN-Y-induced repression of genes (Lang et al., 2012). Unfortunately, the mechanisms underlying IFN- $\gamma$-induced gene repression are still poorly understood and, to my knowledge, the impact of chromatin remodelling has not been addressed so far. In this study, no correlation between a strong counter-regulatory effect of $T$. gondii on transcription of IFN- $\gamma$-repressed gens and non- $\mathrm{CpG}$ island promoters was observed. My findings therefore do not reveal a general correlation between the magnitude of the parasite-imposed counteraction on gene transcription and the absence of $\mathrm{CPG}$ islands in the promoters. With regard to the assumption that non-CpG island promoters depend on chromatin remodelling, my findings therefore argue against a $T$. gondii-employed mechanism solely relying on the recruitment of the chromatin remodelling machinery. In support of this contention, irf1, transcription of which is inhibited by the parasite, was shown to be BRG1-independent (Pattenden et al., 2002; Wang et al., 2011). To further investigate the correlation between T. gondiimediated inhibition of IFN- $\gamma$-regulated gene expression and chromatin remodelling dependency on a global scale, I propose future DNaselhypersensitivity experiments and BRG1 chromatin immunoprecipitation followed by high-throughput DNA sequencing (ChIP-seq analysis). 


\subsection{Toxoplasma gondii remodels the epigenetic landscape at IFN- $\gamma$-responsive}

\section{promoters by abolishing transcription-activating histone modifications}

The finding of host native chromatin being a prerequisite for the $T$. gondii-imposed inhibition of IFN- $\gamma$ regulated gene expression accords with the previous observation that infection with $T$. gondii leads to severely impaired histone $\mathrm{H} 3$ and $\mathrm{H} 4$ acetylation levels in promoter regions of a subset of secondary response genes during IFN- $y$ stimulation (Lang et al., 2012). Importantly, histone deacetylase inhibitor (HDACi) treatment partially restores IFN- $\gamma$ responsiveness in infected macrophages (Lang et al., 2012; Sumpf et al., 2017), suggesting that interference with this post-translational modification (PTM) of histones is critical for the parasite-mediated inhibition. Transcriptional activation of IFN- $\gamma$ target genes is governed by a complex interplay of different histone PTMs. Therefore, I investigated by means of ChIP mapping experiments whether T. gondii interference with gene expression may involve dysregulation of other histone modifications during IFN- $y$ stimulation. I found that distinct histone modifications, which are known to be associated with active transcription, are also indicative for IFN- $\gamma$-induced gene transcription. Specifically, acetylation of $\mathrm{H} 4$, as well as the site-specific modifications $\mathrm{H} 3 \mathrm{~K} 9 \mathrm{ac}$ and H3K4me3, are upregulated in the promoters of irf1, irf8, stat1, ciita and gbp2 following IFN- $y$ treatment (Figure 8, Figure 9 and Figure 10). Post-translational acetylation of histones seems to be crucial during IFN-y-mediated transcription since levels of $\mathrm{H} 4 \mathrm{ac}$ and $\mathrm{H} 3 \mathrm{~K} 9 \mathrm{ac}$ were elevated at all investigated gene promoters. In contrast, tri-methylation of H3K4 seems to be regulated in a gene-specific manner at the ciita promoter only. These three chromatin marks frequently overlap spatially but their distribution pattern nevertheless varies. $\mathrm{H} 3 \mathrm{~K} 9 \mathrm{ac}$ and $\mathrm{H} 3 \mathrm{~K} 4 \mathrm{me} 3$ were found in distal and proximal promoter regions suggesting that they cover the entire $1 \mathrm{~kb}$ region upstream of the transcriptional start site (TSS), whereas $\mathrm{H} 4 \mathrm{ac}$ was found only more distal in the $1 \mathrm{~kb}$ upstream region of the TSS. Although further ChIP mapping experiments have to determine the extent of this distribution, my results indicate that the regions upstream of the TSS of IFN- $\gamma$-induced genes are frequently associated with transcriptionactivating histone acetylations, known to contribute to a permissive chromatin state. The kinetical analysis revealed that levels of $\mathrm{H} 4 \mathrm{ac}, \mathrm{H} 3 \mathrm{~K} 9 \mathrm{ac}$ and $\mathrm{H} 3 \mathrm{~K} 4 \mathrm{me} 3$ are positively regulated largely during the entire 18 hours of IFN- $\gamma$ stimulation and that they overlap temporally.

Levels of histone acetylations are elevated as early as 30 minutes after IFN- $\gamma$ stimulation, suggesting that they become immediately upregulated. Specifically, the magnitude and kinetic of H4ac and H3K9ac levels at the ciita promoter IV (pIV) in non-infected macrophages as observed in the present study are concordant with the regulation reported by other authors from IFN- - -stimulated HeLa cells (Morris et al., 2002; Ni et al., 2005). Remarkably, the infection with T. gondii completely abolishes or largely inhibits $\mathrm{H} 4 \mathrm{ac}$ and $\mathrm{H3K9ac}$ upregulation, respectively, during cytokine stimulation (Figure 8B and C, Figure 9D and $\mathrm{E})$. It has to be noted that the parasite does not deplete these acetyl marks below constitutive levels 
as observed in the absence of IFN- $\gamma$. Consistently, the parasite does not substantially diminish levels of any of the here investigated modification below those of non-stimulated cells, regardless of which gene or which promoter region was analysed (Figure 8, Figure 9, Figure 10 and Figure 11). This indicates that T. gondii may specifically inhibit IFN- $\gamma$-dependent regulation of histone post-translational modifications. Regulation of histone PTMs is probably largely catalysed by chromatin modifiers recruited to the promoter in the context of promoter assembly and transcriptional initiation. A plethora of general transcription factors and transcriptional co-factors are known to associate with chromatin modifiers, e.g. STAT1 and IRF1 interact with CBP/p300 histone acetyltransferases (HATs) (Zhang et al., 1996; reviewed in Shuai, 2000; reviewed in Levy and Darnell, 2002; Varinou et al., 2003). Since the parasite completely abolishes the increase of histone acetylations as early as 30 minutes after IFN- $\gamma$ stimulation, T. gondii may hence prevent the acetylation of histones catalysed by early recruited modifiers. In agreement, STAT1 was shown to bind to ciita pIV within 10 minutes of IFN- $\gamma$ stimulation (Morris et al., 2002; Ni et al., 2005) and binding strongly correlates with the rapid increase of $\mathrm{H} 3$ and $\mathrm{H} 4$ acetylation (Morris et al., 2002). STAT1 recruitment and rapid histone acetylation also coincides at another IFN- - responsive promoter, i.e. gbp2 (Ramsauer et al., 2007) which was here identified to by hypo-acetylated at H3K9 in parasite-infected cells (Figure 9F and G). Together, these data and my findings lead me to hypothesise that T. gondii interferes with the activity of STAT1-associated HATs to abolish early promoter acetylation. Besides a parasite-induced inhibition of early HAT enzyme activity, binding of TgIST and the recruitment of the multi-subunit Mi-2/NuRD complex to STAT1 may diminish histone acetylation. For example, the STAT1-TgIST-Mi-2/NuRD complex could sterically hinder binding of the CBP/p300 HAT to STAT1. In support of this, in vitro studies found CBP to interact with the $\mathrm{N}$ - and Cterminal portions of STAT1 (Zhang et al., 1996) and the present work identified the N-terminal domain to be involved in the interaction with TgIST.

Post-translational acetylation of histones is governed by a delicate interplay of HATs and histone deacetylases (HDACs). Thus, alternatively or additionally to the direct interference with recruitment or activity of HATs, the aberrant acetylations in T. gondii-infected cells could result from an imbalance of modifying HDAC and HAT enzymes. Involvement of HDACs in the parasite-mediated inhibition of IFN- $\gamma$ responsiveness is supported by earlier findings that treatment of infected cells with HADC inhibitors restored $\mathrm{H} 4 \mathrm{ac}$ levels and partially abrogated the IFN- $\gamma$ unresponsiveness at the promoters of a subset of inducible genes (Lang et al., 2012). However, a recent genome-wide study unravelled that inhibition of HDAC 1 and 2 does not generally abolish the unresponsiveness of $T$. gondii-infected macrophages to IFN- $\gamma$ (Sumpf et al., 2017). This finding clearly argues against the possibility that the parasite misuses HDACs as a sole mechanism to inhibit IFN- $\gamma$-mediated transcription. It does however not rule out the possibility that HDACs and possibly particularly the histone deacetylase 1 and 2 included in the Mi- 
2/NuRD complex are involved in counteracting histone acetylation levels at distinct STAT1-dependent promoters.

Analysis of H3K9ac during stimulation with IFN- $\gamma$ revealed clear differences in the $T$. gondii-mediated inhibition between primary and secondary response genes (Figure 9). The parasite completely abolishes H3K9 acetylation already after 30 minutes of stimulation at promoters of both primary and secondary response genes. However, in case of promoters of the primary response genes irf1, stat1 and irf8 this inhibitory effect persists during the entire period of stimulation. The rapid induction of primary response genes is partly explained by their constitutively open chromatin state (reviewed in Fowler et al., 2011; and Mehta and Jeffrey, 2015), and it is thought that initial chromatin remodelling and epigenetic regulation at primary response promoters quickly overcome the critical thresholds which are required to activate gene expression. T. gondii may early and effectively inhibit transcription of primary response genes by preventing to reach these thresholds. Conversely, prolonged stimulation for 4 and 18 hours clearly weakens the inhibitory effect of $T$. gondii at promoters of the secondary response genes ciita and gbp2 resulting in $\mathrm{H} 3 \mathrm{~K} 9 \mathrm{ac}$ accumulation. Compared to primary response genes, expression of secondary response genes is induced with delayed kinetics, consistent with the requirement for transcription factors, which have to be synthesised de novo in a STAT1-dependent manner. For instance, in case of ciita pIV activation, STAT1 binds within 10 minutes after IFN- $\gamma$ stimulation, whereas IRF1 binds to the promoter only after 1 hour (Ni et al., 2005) and coincides with recruitment of the CBP/p300 HATs and significant histone acetylation (reviewed in Wright and Ting, 2006). Importantly, this correlates with further epigenetic regulations including an increase of $\mathrm{H} 3 \mathrm{~K} 4 \mathrm{me} 3$ and depletion of the repressive trimethylation of H3 (K9 and K27) (Mehta et al., 2011). Obviously, the on-going promoter modification during IFN- $\gamma$ stimulation fine-tunes the activity of ciita pIV and synchronises assembly of co-activators and the transcriptional machinery. It is also known that in this context already deposited histone PTMs get reinforced during the promoter's transcriptional activation (reviewed in Zhang et al., 2015). I assume, that $T$. gondii thus prevents the acetylation of histones catalysed by modifiers recruited early during stimulation but may not be able to efficiently affect H3K9ac marks deposited by modifiers recruited later during stimulation. It is difficult to estimate which impact such resumed epigenetic modification in the later phase of a biphasic promoter activation has when the early phase is already disturbed by the parasite. Supposedly, the inhibition would still at least partially abolish reaching certain thresholds thereby negatively affecting promoter accessibility and recruitment of co-factors and transcription factors.

The complex combination of different modifications occurring at the same or another histone tail is proposed to constitute a 'histone code'. It is thought that distinct histone PTMs influence each other in a synergistic or an antagonistic fashion. Importantly, the 'writers' which catalyse modifications are often 
modular proteins that can also bind to preexisting marks due to their unique chromatin-reading domains. For instance, bromodomains of histone-modifying enzymes bind acetyl-lysine, chromodomains bind methyl-lysines and BRCA1 C terminus-(BRCT) domains bind phosphoserine (reviewed in Rothbart and Strahl, 2014; and Zhang et al., 2015). Such crosstalk between histone marks can result in positive and negative feedback loops. For instance, $\mathrm{H} 3 \mathrm{~K} 4 \mathrm{me} 3$ and H3/H4 acetylation often coexist at promoters and transcriptional start sites of actively transcribed genes. H3K4me3 'reader' domains have been identified in several HATs and it has been suggested that tri-methylation of H3K4 promotes downstream $\mathrm{H} 3 / \mathrm{H} 4$ acetylation. In this study, I found $\mathrm{H} 3 \mathrm{~K} 4 \mathrm{me} 3$ not to be upregulated in the promoter of irf1 and this is also not modulated by T. gondii during IFN- $\gamma$ stimulation under the conditions used herein. In contrast, other authors reported H3K4me3 to be downregulated in the irf1 promoter in the response to cytokine stimulation but to significantly enrich in parasite-infected cells (Gay et al., 2016). Here, I found H3K4me3 to be specifically upregulated in the promoter IV of ciita after prolonged IFN- $\gamma$ stimulation (Figure 10B and C) indicating to be involved in the biphasic promoter activation. This observation accords with previous findings indicating a H3K4me3 increase at ciita pIV after 6 hours of stimulation in HeLa cells (Ni et al., 2005). Infection with T. gondii largely abolishes the H3K4me3 upregulation during the course of IFN- $\gamma$ stimulation. This inhibition could be due to interference with histone methyltransferases (HMT). Another possible mechanism is that HMT recruitment is sterically hindered by binding of the STAT1-TgIST-Mi-2/NuRD complex to chromatin. Based on the assumption that tri-methylation of $\mathrm{H} 3 \mathrm{~K} 4$ promotes downstream $\mathrm{H} 3 / \mathrm{H} 4$ acetylation, parasite-mediated interference with H3K4me3 upregulation may negatively affect $\mathrm{H} 3 \mathrm{~K} 9 \mathrm{ac}$ levels in the promoter regions, as observed in this study. The dynamic positive and/or negative crosstalk between histone marks makes it more difficult to evaluate the impact of $T$. gondii infection on regulation of distinct histone PTMs and to elucidate the underlying mechanism. It has to be considered that the parasite-induced impaired regulation of a specific histone mark could result in or is the result of impaired crosstalk, indicating the parasite's potential to comprehensively disturb the epigenetic landscape at IFN- $\boldsymbol{y}$-responsive promoters.

Phosphorylation of $\mathrm{H} 3$ at $\mathrm{S} 10$ has been associated with $\mathrm{H} 3$ acetylation, strongly implicating this modification with transcriptional activation (reviewed in Rossetto et al., 2012). In dendritic cells and macrophages, induction of a subset of NF-KB target genes following LPS stimulation is accompanied by H3S10 phosphorylation (Saccani et al., 2002; Leng, Butcher, Egan, et al., 2009), indicating a potential role of this modification in activating a pro-inflammatory transcription program in immune cells. Importantly, T. gondii blocks enrichment of H3S10p marks in the promoter region of tumor necrosis factor (tnf)- $\alpha$ during lipopolysaccharide (LPS) stimulation, coinciding with parasite-mediated transcriptional inhibition (Leng, Butcher, Egan, et al., 2009). In the present study, I found no evidence that phosphorylation of $\mathrm{H} 3 \mathrm{~S} 10$ is indicative for transcriptional activation in response to IFN- $\gamma$. On the 
contrary, constitutive H3S10p chromatin marks were progressively diminished in all investigated promoter regions during prolonged IFN- $\gamma$ stimulation for 4 and 18 hours (Figure 11), arguing against a role of H3S1Op modification in activation of IFN- - -responsive genes. Interestingly, $T$. gondii can counteract this regulation in different ways, i.e. by inhibiting H3S10 dephosphorylation, but also by promoting H3S10p marks in proximal promoter regions of the secondary response genes ciita and gbp2 during early stimulation. My findings together with the data from Leng et al. (2009) indicate that the local histone code at gene promoters is differentially altered during stimulation with distinct proinflammatory stimuli, i.e. LPS and IFN-y, consistent with the promoters being accessible for different transcription and co-regulatory factors. They further suggest that the impact of $T$. gondii infection on regulation of distinct epigenetic histone modifications differs in the context of the up-stream signalling pathway and, importantly, can counteract positive and negative regulations.

Together, my findings show that $T$. gondii profoundly impairs the epigenetic landscape around IFN- $\gamma$ responsive promoters (see model in Figure 31). During cytokine stimulation, multiple post-translational histone modifications, i.e. acetylation of $\mathrm{H} 4$ and $\mathrm{H} 3 \mathrm{~K} 9$ as well as tri-methylation of $\mathrm{H} 3 \mathrm{~K} 4$, are upregulated in responsive promoters of non-infected cells. Infection with T. gondii counteracts these epigenetic modifications by largely abolishing their enrichment. I propose a model, where in the absence of IFN- $\gamma$, cytokine-responsive genes and their promoters are embedded in basically open but transcriptionally non-permissive chromatin (Figure 31A). During IFN- $\gamma$-stimulation, chromatin modifying factors are recruited and extensively modify the chromatin architecture around responsive promoters, e.g. the CBP/p300 histone acetyltransferase (HAT) associates with STAT1 and hyper-acetylates neighbouring nucleosomes at GAS-containing loci. Elevated levels of H4ac, H3K9ac and H3K4me3 contribute to shape chromatin into an open permissive state, allowing promoter activation and initiation of gene transcription (Figure 31B). In T. gondii-infected cells, regulation of these histone modifications is inhibited, thereby negatively affecting chromatin decondensation and the transcriptional competence of the responsive promoters. The mechanism underlying this parasite-induced inhibition has yet to be unravelled. T. gondii may directly interfere with the activity of enzymes catalysing the positioning or removing of histone acetylation and tri-methylation marks. Alternatively, binding of the large and highly altered STAT1-TgIST-Mi-2/NuRD complex to GAS-containing promoter regions may displace cognate coactivators/chromatin modifiers, thus inhibiting the transition to a transcriptionally permissive chromatin environment and hence preventing IFN- $\gamma$-regulated gene transcription (Figure 31C). Furthermore, the Mi-2/NuRD complex contains among others, ATPases implicated in nucleosome remodelling and histone deacetylases (reviewed in Dege and Hagman, 2014). Thus, the Mi-2/NuRD complex may also function, in a promoter-specific manner, as co-repressor enhancing chromatin compaction and transcriptional repression. 
A

B

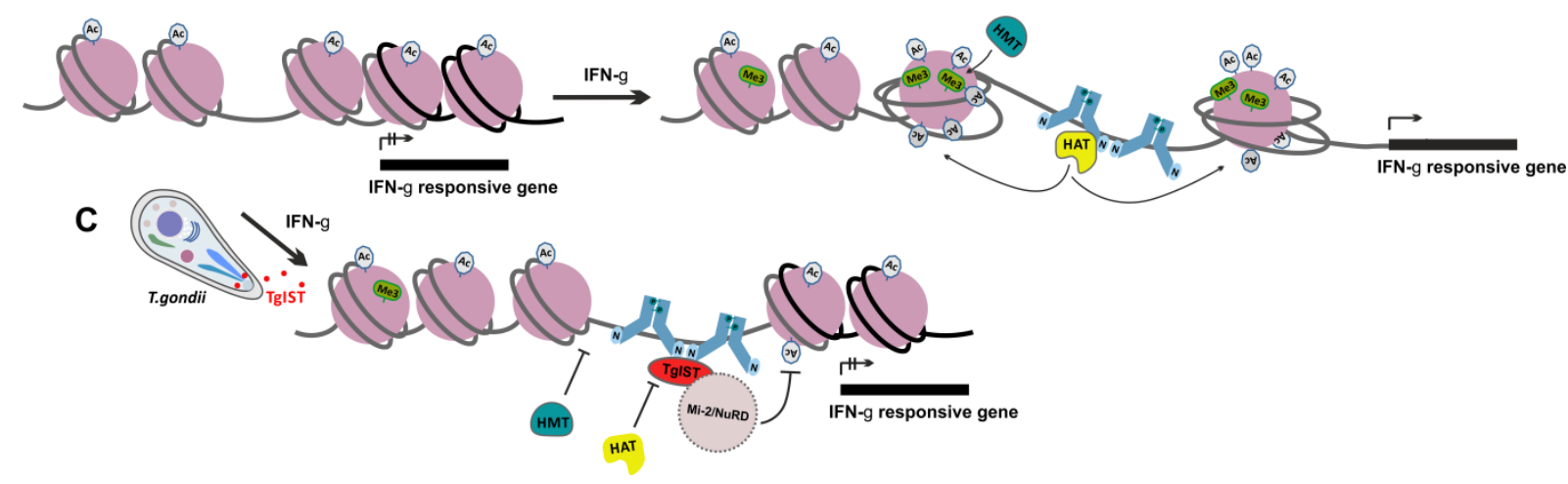

Figure 31: Interference of $T$. gondii with the epigenetic landscape at IFN- $\gamma$-responsive promoters.

$\mathrm{A}$ : In the absence of IFN- $\gamma$, stimulus-responsive genes and their promoters are embedded in transcriptionally non-permissive chromatin architecture. B: In non-infected cells, histone methyltransferases (HMTs) and histone acetyltransferases (HATs) are recruited to responsive promoters during IFN- $\gamma$ stimulation and catalyse the deposition of tri-methylation (Me3) and acetylation (Ac) marks on histones. These modifications will contribute to shape the higher-order chromatin into a transcriptionally permissive state. C: In T. gondii-infected cells, upregulation of these histone modifications is counteracted. Binding of TgIST alone or of the TgIST-Mi-2/NuRD complex to STAT1 in promoter chromatin may inhibit the recruitment of chromatin-modifying co-factors, thereby preventing enrichment of transcription-activating histone modifications. Furthermore, in a promoter-specific manner, components of the Mi-2/NuRD complex, i.e. histone deacetylases, may contribute to hypo-acetylate histones. The parasite-mediated interference with the epigenetic regulation of promoter activation will negatively affect efficient gene transcription.

Few epigenetic studies have addressed levels of histone modifications at IFN- $\gamma$-responsive promoters in non-stimulated cells. For instance, H3K4me1 and H3K27ac were found to be constitutively deposited at regulatory elements of IFN- $\gamma$-induced genes contributing to an open chromatin architecture (Robertson et al., 2008; Heintzman et al., 2009; Ostuni et al., 2013; Langlais et al., 2016). Specifically, the IFN-Yinducible ciita pIV has been documented to contain low to moderate levels of constitutively acetylated histones H3 (K9 and K18) and H4 (K8) (Morris et al., 2002; Ni et al., 2005; reviewed in Wright and Ting, 2006). Consistently, the silent ciita promoter IV associates with CBP/p300 HATs (Ni et al., 2005). This basal acetylation of promoter nucleosomes allows constitutive binding of the ubiquitous factor USF-1 to ciita pIV which cooperatively binds STAT1 in an IFN- - -dependent manner (Muhlethaler-Mottet et al., 1998). The ChIP mapping experiments performed in the present study did not determine the levels of constitutively modified H4ac, H3K9ac, H3K4me3 and H3S1Op in non-infected or T. gondii-infected macrophages not stimulated with the cytokine but focused on their regulation during IFN- $\gamma$ stimulation. The similarity of my results regarding ciita pIV histone PTM regulation in non-infected cells with the data from Morris et al. (2002) and Ni et al. (2005) nevertheless indicates that H4 and H3K9 may also be to some extent constitutively acetylated at ciita pIV in murine macrophages. Likewise, other gene 
promoters including those analysed in the present study could also constitutively contain distinct histone modifications. Such constitutive transcription-supporting or-repressing histone PTMs are thought to contribute to a basic permissive or poised chromatin state. Thus, it has to be considered that the parasite infection may have an impact on the IFN- $\mu$-independent constitutive histone PTM pattern. Recently, conflicting observations were reported on the impact of $T$. gondii on histone acetylation in resting cells. Gay et al. (2016) reported that levels of H3K9ac, H3K27ac and H4ac in distinct promoters including irf1 and ciita remained unchanged after parasite infection. In contrast, Olias et al. (2016) reported that $T$. gondii inhibits constitutive levels of H3ac marks in promoter regions of a subset of IFN$\gamma$-regulated genes in a TgIST-dependent manner. Interestingly, the levels do not change when infected cells are IFN- $\gamma$-stimulated, resulting in a strongly reduced acetylation status, compared to non-infected cells. This unresponsiveness is thus similar to the parasite-imposed impact on histone acetylation observed in this study. As already discussed before, Gay et al. (2016) showed, that STAT1 binds to distinct promoter GAS sites in a TgIST-dependent manner also in the absence of IFN- $\gamma$. Furthermore, Olias et al. (2016) discovered that components of Mi-2/NuRD are associated with STAT1 in the absence of the stimulus. Together, these observations suggest that $T$. gondii may interfere with constitutive epigenetic marks in an STAT1-TgIST-Mi-2/NuRD-dependent manner by inhibiting accessibility for chromatin modifying factors and/or the recruitment of HDACs. I propose future histone PTM ChIP mapping experiments including silent chromatin control regions to further investigate this issue. An interference of $T$. gondii with constitutive modification of chromatin marks would probably more generally sabotage cell-type specific priming of the transcriptional activity in macrophages.

\subsection{Conclusions and outlook}

In summary, the results obtained in this work further characterise the highly complex interaction of T. gondii with its host. They reveal that the host's native chromatin plays a decisive role in the T. gondiimediated inhibition of IFN- - -regulated gene transcription. Consistently, the parasite profoundly impairs

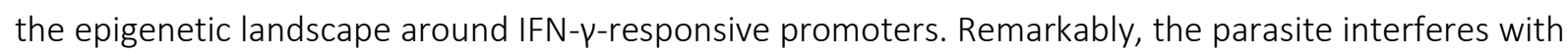
multiple post-translational histone modifications by largely abolishing any regulation during IFN- $\gamma$ stimulation. T. gondii counteracts enrichment of histone modifications which are indicative for active IFN- - -stimulated transcription, i.e. H4ac, H3K9ac and H3K4me3. In contrast, H3S1Op and under distinct conditions also some of the other chromatin marks are promoted by the parasite. The underlying mechanism(s) of the parasite-mediated effects on histone modifications has yet to be resolved. It could either result from direct parasite interference with the activity of the catalysing enzymes, or else from steric hindrance of recruitment of chromatin modifiers to promoter regions through binding of the STAT1/TgIST/NuRD complex. Finally, indirect effects by a disturbed crosstalk may also contribute to the 
dysregulated histone code. The present study additionally reveals that the parasite effector TgIST not only targets IFN- $\gamma$-induced GAF but even preferentially binds to the transcriptional more relevant 2xGAF complex. Binding of TgIST requires the N-terminus, but not the C-terminal domain of STAT1 and profoundly changes the DNA binding activity of the transcription factor. Firstly, non-canonical 2xGAF complexes exhibit strongly increased DNA binding activity at high affinity GAS motifs and secondly, TgIST dramatically diminishes demands for sequence specificity, thus facilitating promiscuous STAT1 binding to imperfect nonGAS sequences. Consistent with increased DNA binding, infection with $T$. gondii prolongs nuclear accumulation of STAT1, which appears to be fully activated by Tyr ${ }^{701}$ and Ser ${ }^{727}$ phosphorylation to a large extent, and which is tightly associated with DNA. Finally, T. gondii infection also affects STAT1 activity in the absence of IFN- $\gamma$. Firstly, the parasite induces small quantities of Tyr ${ }^{701}$ phosphorylated STAT1 in the nuclei of non-stimulated cells and secondly, these STAT1 molecules appear to bind to DNA with high affinity GAS sites as non-canonical GAF complexes.

Further experiments are clearly needed to elaborate our knowledge about the T. gondii-employed mechanism to interfere with IFN- $\gamma$-regulated gene transcription. It is of utmost importance to establish which impact the sustained and promiscuous DNA binding activity has on the occupancy of the host genome in general with STAT1. This includes a thorough analysis of the complete occupancy of TgIST on STAT1-dependent promoters. Such information will provide further insights into the compromised STAT1-dependent promoter activation and also whether the parasite effector TgIST mediates the widespread dysregulation of IFN- $\gamma$-dependent gene transcription described by Kim et al. (2007) and Lang et al. (2012). Furthermore, T. gondii infection experiments in mutant host cells deficient for components of the Mi-2/NuRD complex will allow elucidation of whether and how this complex contributes to the T. gondii-mediated inhibition of IFN- - -regulated gene transcription. It is also of importance to characterise whether the interference with the epigenetic regulation of IFN- $\gamma$-responsive promoters depends on the TgIST-Mi-2/NuRD complex. Therefore, histone PTM ChIP experiments from wild-type and $\Delta$ TgIST-T. gondii-infected cells, as well as, the analysis of T. gondii's impact on chromatin modifications in IFN- $\gamma$-regulated non-GAS promoters may provide crucial information. Future experiments should also consider investigating the promoter recruitment of histone modifying enzymes, STAT1 co-activators, general transcription factors and RNA polymerase II. This will certainly contribute to an improved understanding of the infection-induced inhibition of promoter activation. 


\section{REFERENCES}

Ahmadpour, E., Sarvi, S., Hashemi Soteh, M.B., Sharif, M., Rahimi, M.T., Valadan, R., et al. (2017) Evaluation of the immune response in BALB/c mice induced by a novel DNA vaccine expressing GRA14 against Toxoplasma gondii. Parasite Immuno/ 39.

Alday, H., and Doggett, J. (2017) Drugs in development for toxoplasmosis: advances, challenges, and current status. Drug Des Devel Ther 11: 273-293.

Alexander, W.S., Starr, R., Fenner, J.E., Scott, C.L., Handman, E., Sprigg, N.S., et al. (1999) SOCS1 is a critical inhibitor of interferon gamma signaling and prevents the potentially fatal neonatal actions of this cytokine. Cell 98: 597-608.

Ambroise-Thomas, P., and Pelloux, H. (1993) Toxoplasmosis - congenital and in immunocompromised patients: A parallel. Parasitol Today 9: 61-63.

Andrade, W.A., Souza, M. do C., Ramos-Martinez, E., Nagpal, K., Dutra, M.S., Melo, M.B., et al. (2013) Combined action of nucleic acid-sensing Toll-like receptors and TLR11/TLR12 heterodimers imparts resistance to Toxoplasma gondii in mice. Cell Host Microbe 13: 42-53.

Antequera, F. (2003) Structure, function and evolution of CpG island promoters. Cell Mol Life Sci 60: 1647-58.

Arnaudo, A.M., and Garcia, B.A. (2013) Proteomic characterization of novel histone post-translational modifications. Epigenetics Chromatin 6: 24.

Assolini, J.P., Concato, V.M., Gonçalves, M.D., Carloto, A.C.M., Conchon-Costa, I., Pavanelli, W.R., et al. (2017) Nanomedicine advances in toxoplasmosis: diagnostic, treatment, and vaccine applications. Parasitol Res 116: 1603-1615.

Beckers, C.J., Dubremetz, J.F., Mercereau-Puijalon, O., and Joiner, K.A. (1994) The Toxoplasma gondii rhoptry protein ROP 2 is inserted into the parasitophorous vacuole membrane, surrounding the intracellular parasite, and is exposed to the host cell cytoplasm. J Cell Biol 127: 947-61.

Begitt, A., Droescher, M., Meyer, T., Schmid, C.D., Baker, M., Antunes, F., et al. (2014) STAT1-cooperative DNA binding distinguishes type 1 from type 2 interferon signaling. Nat Immunol 15: 168-176.

Behnke, M.S., Fentress, S.J., Mashayekhi, M., Li, L.X., Taylor, G.A., and Sibley, L.D. (2012) The polymorphic pseudokinase ROP5 controls virulence in Toxoplasma gondii by regulating the active kinase ROP18. PLoS Pathog 8: e1002992.

Bermudez, L.E., Covaro, G., and Remington, J. (1993) Infection of murine macrophages with Toxoplasma gondii is associated with release of transforming growth factor beta and downregulation of expression of tumor necrosis factor receptors. Infect Immun 61: 4126-30.

Bird, A.P. (2007) Perceptions of epigenetics. Nature 447: 396-8.

Black, J.C., Rechem, C. Van, and Whetstine, J.R. (2012) Histone lysine methylation dynamics: establishment, regulation, and biological impact. Mol Cell 48: 491-507. 
Black, M.W., and Boothroyd, J.C. (2000) Lytic cycle of Toxoplasma gondii. Microbiol Mol Biol Rev 64: $607-23$.

Blackledge, N.P., and Klose, R.J. (2011) CpG island chromatin: a platform for gene regulation. Epigenetics 6: 147-52.

Boehm, U., Klamp, T., Groot, M., and Howard, J.C. (1997) Cellular responses to interferon-gamma. Annu Rev Immunol 15: 749-95.

Boothroyd, J.C., and Dubremetz, J.-F. (2008) Kiss and spit: the dual roles of Toxoplasma rhoptries. Nat Rev Microbiol 6: 79-88.

Bougdour, A., Durandau, E., Brenier-Pinchart, M.-P., Ortet, P., Barakat, M., Kieffer, S., et al. (2013) Host cell subversion by Toxoplasma GRA16, an exported dense granule protein that targets the host cell nucleus and alters gene expression. Cell Host Microbe 13: 489-500.

Bradley, P.J., and Sibley, L.D. (2007) Rhoptries: an arsenal of secreted virulence factors. Curr Opin Microbiol 10: 582-7.

Braun, L., Brenier-Pinchart, M.-P., Yogavel, M., Curt-Varesano, A., Curt-Bertini, R.-L., Hussain, T., et al. (2013) A Toxoplasma dense granule protein, GRA24, modulates the early immune response to infection by promoting a direct and sustained host p38 MAPK activation. J Exp Med 210: 2071-86.

Butcher, B.A., Greene, R.I., Henry, S.C., Annecharico, K.L., Weinberg, J.B., Denkers, E.Y., et al. (2005) p47 GTPases regulate Toxoplasma survival in activated macrophages. Infect Immun 73: 3278-86.

Butcher, B.A., Kim, L., Johnson, P.F., and Denkers, E.Y. (2001) Toxoplasma tachyzoites inhibit proinflammatory cytokine induction in infected macrophages by preventing nuclear translocation of the transcription factor NF-kappa B. J Immunol 167: 2193-201.

Butcher, B.A., Kim, L., Panopoulos, A.D., Watowich, S.S., Murray, P.J., and Denkers, E.Y. (2005) IL-10independent STAT3 activation by Toxoplasma gondii mediates suppression of IL-12 and TNF-alpha in host macrophages. J Immunol 174: 3148-52.

Buzoni-Gatel, D., and Werts, C. (2006) Toxoplasma gondii and subversion of the immune system. Trends Parasitol 22: 448-52.

Carruthers, V.B., and Sibley, L.D. (1997) Sequential protein secretion from three distinct organelles of Toxoplasma gondii accompanies invasion of human fibroblasts. Eur J Cell Biol 73: 114-23.

Cheon, H., and Stark, G.R. (2009) Unphosphorylated STAT1 prolongs the expression of interferoninduced immune regulatory genes. Proc Natl Acad Sci U S A 106: 9373-8.

Collazo, C.M., Yap, G.S., Hieny, S., Caspar, P., Feng, C.G., Taylor, G.A., and Sher, A. (2002) The function of gamma interferon-inducible GTP-binding protein IGTP in host resistance to Toxoplasma gondii is Stat1 dependent and requires expression in both hematopoietic and nonhematopoietic cellular compartments. Infect Immun 70: 6933-9.

Collazo, C.M., Yap, G.S., Sempowski, G.D., Lusby, K.C., Tessarollo, L., Woude, G.F. Vande, et al. (2001) Inactivation of LRG-47 and IRG-47 reveals a family of interferon gamma-inducible genes with essential, pathogen-specific roles in resistance to infection. J Exp Med 194: 181-8.

Deaton, A.M., and Bird, A.P. (2011) CpG islands and the regulation of transcription. Genes Dev 25: 101022. 
Debierre-Grockiego, F., Campos, M.A., Azzouz, N., Schmidt, J., Bieker, U., Resende, M.G., et al. (2007) Activation of TLR2 and TLR4 by glycosylphosphatidylinositols derived from Toxoplasma gondii. J Immunol 179: 1129-37.

Dege, C., and Hagman, J. (2014) Mi-2/NuRD chromatin remodeling complexes regulate B and Tlymphocyte development and function. Immunol Rev 261: 126-40.

Demar, M., Hommel, D., Djossou, F., Peneau, C., Boukhari, R., Louvel, D., et al. (2012) Acute toxoplasmoses in immunocompetent patients hospitalized in an intensive care unit in French Guiana. Clin Microbiol Infect 18: E221-31.

Denkers, E.Y., Bzik, D.J., Fox, B.A., and Butcher, B.A. (2012) An inside job: Hacking into Janus kinase/signal transducer and activator of transcription signaling cascades by the intracellular protozoan Toxoplasma. Infect Immun 80: 476-482.

Długońska, H., and Gatkowska, J. (2016) Exosomes in the context of Toxoplasma gondii - host communication. Ann Parasitol 62: 169-174.

Dubey, J.P. (1998) Advances in the life cycle of Toxoplasma gondii. Int J Parasitol 28: 1019-24.

Dubey, J.P. (2007) The History and Life Cycle of Toxoplasma gondii. In Toxoplasma Gondii. Elsevier, pp. $1-17$.

Dubey, J.P. (2009) Toxoplasmosis of Animals and Humans. Second edi., CRC Press, .

Dubey, J.P., Lindsay, D.S., and Speer, C.A. (1998) Structures of Toxoplasma gondii tachyzoites, bradyzoites, and sporozoites and biology and development of tissue cysts. Clin Microbiol Rev 11: 267299.

Endo, T.A., Masuhara, M., Yokouchi, M., Suzuki, R., Sakamoto, H., Mitsui, K., et al. (1997) A new protein containing an SH2 domain that inhibits JAK kinases. Nature 387: 921-4.

Fagerlund, R., Mélen, K., Kinnunen, L., and Julkunen, I. (2002) Arginine/lysine-rich nuclear localization signals mediate interactions between dimeric STATs and importin alpha 5. J Biol Chem 277: 30072-8.

Fentress, S.J., Behnke, M.S., Dunay, I.R., Mashayekhi, M., Rommereim, L.M., Fox, B.A., et al. (2010) Phosphorylation of immunity-related GTPases by a Toxoplasma gondii-secreted kinase promotes macrophage survival and virulence. Cell Host Microbe 8: 484-95.

Ferguson, D.J.P. (2009) Toxoplasma gondii: 1908-2008, homage to Nicolle, Manceaux and Splendore. Mem Inst Oswaldo Cruz 104: 133-148.

Fleckenstein, M.C., Reese, M.L., Könen-Waisman, S., Boothroyd, J.C., Howard, J.C., and Steinfeldt, T. (2012) A Toxoplasma gondii pseudokinase inhibits host IRG resistance proteins. PLoS Biol 10: e1001358.

Fowler, T., Sen, R., and Roy, A.L. (2011) Regulation of primary response genes. Mol Cell 44: 348-60.

Freshman, M.M., Merigan, T.C., Remington, J.S., and Brownlee, I.E. (1966) In vitro and in vivo antiviral action of an interferon-like substance induced by Toxoplasma gondii. Proc Soc Exp Biol Med 123: 8626.

Gardiner-Garden, M., and Frommer, M. (1987) CpG islands in vertebrate genomes. J Mol Biol 196: 26182. 
Gavrilescu, L.C., Butcher, B.A., Rio, L. Del, Taylor, G.A., and Denkers, E.Y. (2004) STAT1 is essential for antimicrobial effector function but dispensable for gamma interferon production during Toxoplasma gondii infection. Infect Immun 72: 1257-64.

Gay, G., Braun, L., Brenier-Pinchart, M.-P., Vollaire, J., Josserand, V., Bertini, R.-L., et al. (2016) Toxoplasma gondii TgIST co-opts host chromatin repressors dampening STAT1-dependent gene regulation and IFN- $\gamma$-mediated host defenses. J Exp Med 213: 1779-98.

Gazzinelli, R.T., Hakim, F.T., Hieny, S., Shearer, G.M., and Sher, A. (1991) Synergistic role of CD4+ and CD8+ T lymphocytes in IFN-gamma production and protective immunity induced by an attenuated Toxoplasma gondii vaccine. J Immunol 146: 286-92.

Gazzinelli, R.T., Oswald, I.P., James, S.L., and Sher, A. (1992) IL-10 inhibits parasite killing and nitrogen oxide production by IFN-gamma-activated macrophages. J Immunol 148: 1792-6.

Gazzinelli, R.T., Wysocka, M., Hayashi, S., Denkers, E.Y., Hieny, S., Caspar, P., et al. (1994) Parasiteinduced IL-12 stimulates early IFN-gamma synthesis and resistance during acute infection with Toxoplasma gondii. J Immunol 153: 2533-43.

Gilbert, L.A., Ravindran, S., Turetzky, J.M., Boothroyd, J.C., and Bradley, P.J. (2007) Toxoplasma gondii targets a protein phosphatase $2 \mathrm{C}$ to the nuclei of infected host cells. Eukaryot Cell 6: 73-83.

Gold, D.A., Kaplan, A.D., Lis, A., Bett, G.C.L., Rosowski, E.E., Cirelli, K.M., et al. (2015) The Toxoplasma Dense Granule Proteins GRA17 and GRA23 Mediate the Movement of Small Molecules between the Host and the Parasitophorous Vacuole. Cell Host Microbe 17: 642-652.

Grande, C. Del, Galli, L., Schiavi, E., Dell'Osso, L., and Bruschi, F. (2017) Is Toxoplasma gondii a Trigger of Bipolar Disorder? Pathogens 6: 3.

Greenlund, A.C., Morales, M.O., Viviano, B.L., Yan, H., Krolewski, J., and Schreiber, R.D. (1995) Stat recruitment by tyrosine-phosphorylated cytokine receptors: an ordered reversible affinity-driven process. Immunity 2: 677-87.

Gross, U., Müller, W.A., Knapp, S., and Heesemann, J. (1991) Identification of a virulence-associated antigen of Toxoplasma gondii by use of a mouse monoclonal antibody. Infect Immun 59: 4511-4516.

Guo, M., Dubey, J.P., Hill, D., Buchanan, R.L., Gamble, H.R., Jones, J.L., and Pradhan, A.K. (2015) Prevalence and risk factors for Toxoplasma gondii infection in meat animals and meat products destined for human consumption. J Food Prot 78: 457-76.

Habara-Ohkubo, A., Shirahata, T., Takikawa, O., and Yoshida, R. (1993) Establishment of an antitoxoplasma state by stable expression of mouse indoleamine 2,3-dioxygenase. Infect Immun 61: 1810-3.

Hakimi, M.-A., Olias, P., and Sibley, L.D. (2017) Toxoplasma effectors targeting host signaling and transcription. Clin Microbiol Rev 30: 615-645.

Halonen, S.K., Chiu, F.C., and Weiss, L.M. (1998) Effect of cytokines and quercetin on Toxoplasma gondii cyst induction in murine astrocytes. J Eukaryot Microbiol 46: 83S-84S.

Haspel, R.L., and Darnell, J.E. (1999) A nuclear protein tyrosine phosphatase is required for the inactivation of Stat1. Proc Natl Acad Sci U S A 96: 10188-93. 
Heintzman, N.D., Hon, G.C., Hawkins, R.D., Kheradpour, P., Stark, A., Harp, L.F., et al. (2009) Histone modifications at human enhancers reflect global cell-type-specific gene expression. Nature 459: 10812.

Hermanns, T., Müller, U.B., Könen-Waisman, S., Howard, J.C., and Steinfeldt, T. (2016) The Toxoplasma gondii rhoptry protein ROP18 is an Irga6-specific kinase and regulated by the dense granule protein GRA7. Cell Microbiol 18: 244-59.

Hoeve, J. ten, Ibarra-Sanchez, M. de J., Fu, Y., Zhu, W., Tremblay, M., David, M., and Shuai, K. (2002) Identification of a nuclear Stat1 protein tyrosine phosphatase. Mol Cell Biol 22: 5662-8.

Holling, T.M., Bergevoet, M.W.T., Wilson, L., Eggermond, M.C.J.A. Van, Schooten, E., Steenbergen, R.D.M., et al. (2007) A role for EZH2 in silencing of IFN-gamma inducible MHC2TA transcription in uveal melanoma. J Immunol 179: 5317-25.

Horvath, C.M., Wen, Z., and Darnell, J.E. (1995) A STAT protein domain that determines DNA sequence recognition suggests a novel DNA-binding domain. Genes Dev 9: 984-94.

Howe, D.K., and Sibley, L.D. (1995) Toxoplasma gondii comprises three clonal lineages: correlation of parasite genotype with human disease. J Infect Dis 172: 1561-6.

Hsu, P.-C., Groer, M., and Beckie, T. (2014) New findings: depression, suicide, and Toxoplasma gondii infection. J Am Assoc Nurse Pract 26: 629-37.

Hu, X., and Ivashkiv, L.B. (2009) Cross-regulation of Signaling Pathways by Interferon- $\gamma$ : Implications for Immune Responses and Autoimmune Diseases. Immunity 31.

Hunter, C.A., and Sibley, L.D. (2012) Modulation of innate immunity by Toxoplasma gondii virulence effectors. Nat Rev Microbiol 10: 766-778.

Hunter, C.A., Subauste, C.S., Cleave, V.H. Van, and Remington, J.S. (1994) Production of gamma interferon by natural killer cells from Toxoplasma gondii-infected SCID mice: regulation by interleukin10, interleukin-12, and tumor necrosis factor alpha. Infect Immun 62: 2818-24.

Illingworth, R.S., and Bird, A.P. (2009) CpG islands-'a rough guide'. FEBS Lett 583: 1713-20.

Jin, Q., Yu, L.-R., Wang, L., Zhang, Z., Kasper, L.H., Lee, J.-E., et al. (2011) Distinct roles of GCN5/PCAFmediated $\mathrm{H} 3 \mathrm{~K} 9 \mathrm{ac}$ and $\mathrm{CBP} / \mathrm{p} 300-$ mediated $\mathrm{H} 3 \mathrm{~K} 18 / 27 \mathrm{ac}$ in nuclear receptor transactivation. EMBO J 30 : 249-62.

Jones, J.L., Lopez, A., and Wilson, M. (2003) Congenital toxoplasmosis. Am Fam Physician 67: 21312138.

Jones, T.C., Bienz, K.A., and Erb, P. (1986) In vitro cultivation of Toxoplasma gondii cysts in astrocytes in the presence of gamma interferon. Infect Immun 51: 147-56.

Jones, T.C., and Hirsch, J.G. (1972) The interaction between Toxoplasma gondii and mammalian cells. II. The absence of lysosomal fusion with phagocytic vacuoles containing living parasites. J Exp Med 136: 1173-94.

Kawai, T., and Akira, S. (2010) The role of pattern-recognition receptors in innate immunity: update on Toll-like receptors. Nat Immunol 11: 373-84. 
Khan, A., Jordan, C., Muccioli, C., Vallochi, A.L., Rizzo, L. V., Belfort, R., et al. (2006) Genetic divergence of Toxoplasma gondii strains associated with ocular toxoplasmosis, Brazil. Emerg Infect Dis 12: 942-9.

Khan, I.A., Matsuura, T., and Kasper, L.H. (1995) IL-10 mediates immunosuppression following primary infection with Toxoplasma gondii in mice. Parasite Immunol 17: 185-95.

Khavari, P.A., Peterson, C.L., Tamkun, J.W., Mendel, D.B., and Crabtree, G.R. (1993) BRG1 contains a conserved domain of the SWI2/SNF2 family necessary for normal mitotic growth and transcription. Nature 366: 170-4.

Kim, M.J., Jung, B.-K., Cho, J., Song, H., Pyo, K.-H., Lee, J.M., et al. (2016) Exosomes Secreted by Toxoplasma gondii-Infected L6 Cells: Their Effects on Host Cell Proliferation and Cell Cycle Changes. Korean J Parasitol 54: 147-54.

Kim, S.-K., Fouts, A.E., and Boothroyd, J.C. (2007) Toxoplasma gondii Dysregulates IFN-r Inducible Gene Expression in Human Fibroblasts: Insights from a Genome-Wide Transcriptional Profilin. J Immunol 178: 5154-5165.

Kincaid, E.Z., and Ernst, J.D. (2003) Mycobacterium tuberculosis exerts gene-selective inhibition of transcriptional responses to IFN-gamma without inhibiting STAT1 function. J Immunol 171: 2042-9.

Klose, R.J., and Bird, A.P. (2006) Genomic DNA methylation: the mark and its mediators. Trends Biochem Sci 31: 89-97.

Kniel, K.E., Lindsay, D.S., Sumner, S.S., Hackney, C.R., Pierson, M.D., and Dubey, J.P. (2002) Examination of attachment and survival of Toxoplasma gondii oocysts on raspberries and blueberries. J Parasitol 88: 790-3.

Koblansky, A.A., Jankovic, D., Oh, H., Hieny, S., Sungnak, W., Mathur, R., et al. (2013) Recognition of Profilin by Toll-like Receptor 12 Is Critical for Host Resistance to Toxoplasma gondii. Immunity 38: 119130.

Koch, V., Staab, J., Ruppert, V., and Meyer, T. (2012) Two glutamic acid residues in the DNA-binding domain are engaged in the release of STAT1 dimers from DNA. BMC Cell Biol 13: 22.

Kornberg, R.D. (1974) Chromatin structure: a repeating unit of histones and DNA. Science (80- ) 184: $868-71$

Koshy, A.A., Dietrich, H.K., Christian, D.A., Melehani, J.H., Shastri, A.J., Hunter, C.A., and Boothroyd, J.C. (2012) Toxoplasma co-opts host cells it does not invade. PLoS Pathog 8: 18.

Köster, M., and Hauser, H. (1999) Dynamic redistribution of STAT1 protein in IFN signaling visualized by GFP fusion proteins. Eur J Biochem 260: 137-44.

Kota, R.S., Rutledge, J.C., Gohil, K., Kumar, A., Enelow, R.I., and Ramana, C. V. (2006) Regulation of gene expression in RAW 264.7 macrophage cell line by interferon-gamma. Biochem Biophys Res Commun 342: 1137-46.

Lang, C. (2005) Interference of Toxoplasma gondii with IFN- $\gamma$-regulated gene expression of its host cell. Georg Göttingen, Ger .

Lang, C., Algner, M., Beinert, N., Gross, U., and Lüder, C.G.K. (2006) Diverse mechanisms employed by Toxoplasma gondii to inhibit IFN-gamma-induced major histocompatibility complex class II gene expression. Microbes Infect 8: 1994-2005. 
Lang, C., Gross, U., and Lüder, C.G.K. (2007) Subversion of innate and adaptive immune responses by Toxoplasma gondii. Parasitol Res 100: 191-203.

Lang, C., Hildebrandt, A., Brand, F., Opitz, L., Dihazi, H., and Lüder, C.G.K. (2012) Impaired chromatin remodelling at STAT1-regulated promoters leads to global unresponsiveness of Toxoplasma gondiiinfected macrophages to IFN- $\gamma$. PLoS Pathog 8.

Langer, J.A., and Pestka, S. (1988) Interferon receptors. Immunol Today 9: 393-400.

Langermans, J.A., Hulst, M.E. van der, Nibbering, P.H., and Furth, R. van (1992) Endogenous tumor necrosis factor alpha is required for enhanced antimicrobial activity against Toxoplasma gondii and Listeria monocytogenes in recombinant gamma interferon-treated mice. Infect Immun 60: 5107-12.

Langermans, J.A., Nibbering, P.H., Vuren-van der Hulst, M.E. van, and Furth, R. van (2001) Transforming growth factor-beta suppresses interferon-gamma-induced toxoplasmastatic activity in murine macrophages by inhibition of tumour necrosis factor-alpha production. Parasite Immunol 23: 169-75.

Langlais, D., Barreiro, L.B., and Gros, P. (2016) The macrophage IRF8/IRF1 regulome is required for protection against infections and is associated with chronic inflammation. I Exp Med 213: jem.20151764.

Lavine, M.D., and Arrizabalaga, G. (2009) Induction of mitotic S-phase of host and neighboring cells by Toxoplasma gondii enhances parasite invasion. Mol Biochem Parasitol 164: 95-9.

Lehtonen, A., Matikainen, S., and Julkunen, I. (1997) Interferons up-regulate STAT1, STAT2, and IRF family transcription factor gene expression in human peripheral blood mononuclear cells and macrophages. J Immunol 159: 794-803.

Leng, J., Butcher, B.A., and Denkers, E.Y. (2009) Dysregulation of macrophage signal transduction by Toxoplasma gondii: past progress and recent advances. Parasite Immuno/ 31: 717-28.

Leng, J., Butcher, B.A., Egan, C.E., Abi Abdallah, D.S., and Denkers, E.Y. (2009) Toxoplasma gondii prevents chromatin remodeling initiated by TLR-triggered macrophage activation. J Immuno/ 182: 48997.

Levine, N.D. (1970) Taxonomy of the sporozoa. J Parasitol 56: 208-209.

Levy, D.E., and Darnell, J.E. (2002) Stats: transcriptional control and biological impact. Nat Rev Mol Cell Biol 3: 651-62.

Lieberman, L.A., Banica, M., Reiner, S.L., and Hunter, C.A. (2004) STAT1 plays a critical role in the regulation of antimicrobial effector mechanisms, but not in the development of Th1-type responses during toxoplasmosis. J Immunol 172: 457-63.

Lillemeier, B.F., Köster, M., and Kerr, I.M. (2001) STAT1 from the cell membrane to the DNA. EMBO J 20: 2508-2517.

Ling, Y.M., Shaw, M.H., Ayala, C., Coppens, I., Taylor, G.A., Ferguson, D.J.P., and Yap, G.S. (2006) Vacuolar and plasma membrane stripping and autophagic elimination of Toxoplasma gondii in primed effector macrophages. J Exp Med 203: 2063-71.

Liu, B., Gross, M., Hoeve, J. ten, and Shuai, K. (2001) A transcriptional corepressor of Stat1 with an essential LXXLL signature motif. Proc Natl Acad Sci U S A 98: 3203-7. 
Liu, B., Liao, J., Rao, X., Kushner, S.A., Chung, C.D., Chang, D.D., and Shuai, K. (1998) Inhibition of Stat1mediated gene activation by PIAS1. Proc Natl Acad Sci U S A 95: 10626-31.

Liu, B., Mink, S., Wong, K.A., Stein, N., Getman, C., Dempsey, P.W., et al. (2004) PIAS1 selectively inhibits interferon-inducible genes and is important in innate immunity. Nat Immunol 5: 891-8.

Liu, C.-H., Fan, Y., Dias, A., Esper, L., Corn, R.A., Bafica, A., et al. (2006) Cutting edge: dendritic cells are essential for in vivo IL-12 production and development of resistance against Toxoplasma gondii infection in mice. J Immunol 177: 31-5.

Lödige, I., Marg, A., Wiesner, B., Malecová, B., Oelgeschläger, T., and Vinkemeier, U. (2005) Nuclear export determines the cytokine sensitivity of STAT transcription factors. J Biol Chem 280: 43087-99.

Lüder, C.G.K., Algner, M., Lang, C., Bleicher, N., and Gross, U. (2003) Reduced expression of the inducible nitric oxide synthase after infection with Toxoplasma gondii facilitates parasite replication in activated murine macrophages. Int J Parasito/ 33: 833-44.

Lüder, C.G.K., and Gross, U. (2005) Apoptosis and its modulation during infection with Toxoplasma gondii: molecular mechanisms and role in pathogenesis. Curr Top Microbiol Immunol 289: 219-37.

Lüder, C.G.K., Lang, T., Beuerle, B., and Gross, U. (1998) Down-regulation of MHC class II molecules and inability to up-regulate class I molecules in murine macrophages after infection with Toxoplasma gondii. Clin Exp Immunol 112: 308-16.

Lüder, C.G.K., and Seeber, F. (2016) Toxoplasma. In Molecular Parasitology. Walochnik, J., and Duchêne, M. (eds). Springer Vienna, Vienna. pp. 217-239.

Lüder, C.G.K., Sumpf, K., and Nast, R. (2015) Releasing the Brake on IFN- $\gamma$ Signaling on Infection. Trends Parasitol 31: 456-459.

Lüder, C.G.K., Walter, W., Beuerle, B., Maeurer, M.J., and Gross, U. (2001) Toxoplasma gondii downregulates MHC class II gene expression and antigen presentation by murine macrophages via interference with nuclear translocation of STAT1alpha. Eur J Immunol 31: 1475-84.

Luger, K., Mäder, A.W., Richmond, R.K., Sargent, D.F., and Richmond, T.J. (1997) Crystal structure of the nucleosome core particle at 2.8 A resolution. Nature 389: 251-60.

Martens, S., Parvanova, I., Zerrahn, J., Griffiths, G., Schell, G., Reichmann, G., and Howard, J.C. (2005) Disruption of Toxoplasma gondii parasitophorous vacuoles by the mouse p47-resistance GTPases. PLoS Pathog 1: e24.

Mashayekhi, M., Sandau, M.M., Dunay, I.R., Frickel, E.M., Khan, A., Goldszmid, R.S., et al. (2011) CD8a(+) dendritic cells are the critical source of interleukin-12 that controls acute infection by Toxoplasma gondii tachyzoites. Immunity 35: 249-59.

McKendry, R., John, J., Flavell, D., Müller, M., Kerr, I.M., and Stark, G.R. (1991) High-frequency mutagenesis of human cells and characterization of a mutant unresponsive to both alpha and gamma interferons. Proc Natl Acad Sci U S A 88: 11455-9.

Mehta, N.T. (2010) Early Epigenetic Regulation of the Adaptive Immune Response Gene CIITA. .

Mehta, N.T., Truax, A.D., Boyd, N.H., and Greer, S.F. (2011) Early epigenetic events regulate the adaptive immune response gene CIITA. Epigenetics 6: 516-25. 
Mehta, S., and Jeffrey, K.L. (2015) Beyond receptors and signaling: epigenetic factors in the regulation of innate immunity. Immunol Cell Biol 93: 233-44.

Meissner, T., Krause, E., Lödige, I., and Vinkemeier, U. (2004) Arginine methylation of STAT1: a reassessment. Cell 119: 587-9; discussion 589-590.

Melo, M.B., Jensen, K.D.C., and Saeij, J.P.J. (2011) Toxoplasma gondii effectors are master regulators of the inflammatory response. Trends Parasitol 27: 487-95.

Mennechet, F.J.D., Kasper, L.H., Rachinel, N., Li, W., Vandewalle, A., and Buzoni-Gatel, D. (2002) Lamina propria CD4+ $T$ lymphocytes synergize with murine intestinal epithelial cells to enhance proinflammatory response against an intracellular pathogen. J Immunol 168: 2988-96.

Meyer, T., Gavenis, K., and Vinkemeier, U. (2002) Cell type-specific and tyrosine phosphorylationindependent nuclear presence of STAT1 and STAT3. Exp Cell Res 272: 45-55.

Meyer, T., Hendry, L., Begitt, A., John, S., and Vinkemeier, U. (2004) A single residue modulates tyrosine dephosphorylation, oligomerization, and nuclear accumulation of stat transcription factors. J Biol Chem 279: 18998-9007.

Meyer, T., Marg, A., Lemke, P., Wiesner, B., and Vinkemeier, U. (2003) DNA binding controls inactivation and nuclear accumulation of the transcription factor Stat1. Genes Dev 17: 1992-2005.

Miller, C.M., Boulter, N.R., Ikin, R.J., and Smith, N.C. (2009) The immunobiology of the innate response to Toxoplasma gondii. Int J Parasitol 39: 23-39.

Mordue, D.G., Desai, N., Dustin, M., and Sibley, L.D. (1999) Invasion by Toxoplasma gondii establishes a moving junction that selectively excludes host cell plasma membrane proteins on the basis of their membrane anchoring. J Exp Med 190: 1783-92.

Mordue, D.G., Håkansson, S., Niesman, I., and Sibley, L.D. (1999) Toxoplasma gondii resides in a vacuole that avoids fusion with host cell endocytic and exocytic vesicular trafficking pathways. Exp Parasitol 92: 87-99.

Morisaki, J.H., Heuser, J.E., and Sibley, L.D. (1995) Invasion of Toxoplasma gondii occurs by active penetration of the host cell. J Cell Sci 108 ( Pt 6: 2457-64.

Morris, A.C., Beresford, G.W., Mooney, M.R., and Boss, J.M. (2002) Kinetics of a gamma interferon response: expression and assembly of CIITA promoter IV and inhibition by methylation. $\mathrm{Mol} \mathrm{Cell}$ Biol 22: 4781-91.

Nash, P.B., Purner, M.B., Leon, R.P., Clarke, P., Duke, R.C., and Curiel, T.J. (1998) Toxoplasma gondiiinfected cells are resistant to multiple inducers of apoptosis. J Immunol 160: 1824-30.

Ni, Z., Karaskov, E., Yu, T., Callaghan, S.M., Der, S., Park, D.S., et al. (2005) Apical role for BRG1 in cytokine-induced promoter assembly. Proc Natl Acad Sci U S A 102: 14611-6.

Nicolle, C., and Manceaux, L. (1908) Sur une infection à corps de Leishman (ou organismes voisins) du gondi. Comptes Rendus l'Académie des Sci 147: 763-766.

Nicolle, C., and Manceaux, L. (1909) Sur un protozoaire nouveau du gondi. Comptes Rendus l'Académie des Sci 148: 369-372. 
Nusinzon, I., and Horvath, C.M. (2003) Interferon-stimulated transcription and innate antiviral immunity require deacetylase activity and histone deacetylase 1. Proc Natl Acad Sci U S A 100: 14742-7.

O'Keefe, G.M., Nguyen, V.T., Ping Tang, L.L., and Benveniste, E.N. (2001) IFN-gamma regulation of class II transactivator promoter IV in macrophages and microglia: involvement of the suppressors of cytokine signaling-1 protein. J Immunol 166: 2260-9.

Olias, P., Etheridge, R.D., Zhang, Y., Holtzman, M.J., and Sibley, L.D. (2016) Toxoplasma Effector Recruits the Mi-2/NuRD Complex to Repress STAT1 Transcription and Block IFN- $\gamma$-Dependent Gene Expression. Cell Host Microbe 20: 72-82.

Ostuni, R., Piccolo, V., Barozzi, I., Polletti, S., Termanini, A., Bonifacio, S., et al. (2013) Latent enhancers activated by stimulation in differentiated cells. Cell 152: 157-71.

Pappas, G., Roussos, N., and Falagas, M.E. (2009) Toxoplasmosis snapshots: Global status of Toxoplasma gondii seroprevalence and implications for pregnancy and congenital toxoplasmosis. Int J Parasitol 39: 1385-1394.

Parmley, S.F., Gross, U., Sucharczuk, A., Windeck, T., Sgarlato, G.D., and Remington, J.S. (1994) Two alleles of the gene encoding surface antigen P22 in 25 strains of Toxoplasma gondii. J Parasitol 80: 293301.

Pattenden, S.G., Klose, R.J., Karaskov, E., and Bremner, R. (2002) Interferon-gamma-induced chromatin remodeling at the CIITA locus is BRG1 dependent. EMBO J 21: 1978-86.

Pfaffl, M.W. (2001) A new mathematical model for relative quantification in real-time RT-PCR. Nucleic Acids Res 29: e45.

Pfefferkorn, E.R. (1984) Interferon gamma blocks the growth of Toxoplasma gondii in human fibroblasts by inducing the host cells to degrade tryptophan. Proc Natl Acad Sci U S A 81: 908-12.

Pfefferkorn, E.R., Eckel, M., and Rebhun, S. (1986) Interferon-gamma suppresses the growth of Toxoplasma gondii in human fibroblasts through starvation for tryptophan. Mol Biochem Parasitol 20 : 215-24.

Pollard, A.M., Knoll, L.J., and Mordue, D.G. (2009) The role of specific Toxoplasma gondii molecules in manipulation of innate immunity. Trends Parasitol 25: 491-4.

Qiao, Y., Kang, K., Giannopoulou, E., Fang, C., and Ivashkiv, L.B. (2016) IFN- - Induces Histone 3 Lysine 27 Trimethylation in a Small Subset of Promoters to Stably Silence Gene Expression in Human Macrophages. Cell Rep 16: 3121-9.

Qing, Y., and Stark, G.R. (2004) Alternative activation of STAT1 and STAT3 in response to interferon- - . J Biol Chem 279: 41679-41685.

Rakesh, K., and Agrawal, D.K. (2005) Controlling cytokine signaling by constitutive inhibitors. Biochem Pharmacol 70: 649-57.

Ramirez-Carrozzi, V.R., Braas, D., Bhatt, D.M., Cheng, C.S., Hong, C., Doty, K.R., et al. (2009) A unifying model for the selective regulation of inducible transcription by $\mathrm{CpG}$ islands and nucleosome remodeling. Cell 138: 114-28. 
Ramsauer, K., Farlik, M., Zupkovitz, G., Seiser, C., Kröger, A., Hauser, H., and Decker, T. (2007) Distinct modes of action applied by transcription factors STAT1 and IRF1 to initiate transcription of the IFNgamma-inducible gbp2 gene. Proc Natl Acad Sci U S A 104: 2849-2854.

Reese, M.L., Shah, N., and Boothroyd, J.C. (2014) The Toxoplasma pseudokinase ROP5 is an allosteric inhibitor of the immunity-related GTPases. J Biol Chem 289: 27849-58.

Reis e Sousa, C., Hieny, S., Scharton-Kersten, T.M., Jankovic, D., Charest, H., Germain, R.N., and Sher, A. (1997) In vivo microbial stimulation induces rapid CD40 ligand-independent production of interleukin 12 by dendritic cells and their redistribution to T cell areas. J Exp Med 186: 1819-29.

Riebeling, T. (2016) Cellular responses mediated by the transcription factor STAT1 in murine inflammatory diseases. .

Riebeling, T., Staab, J., Herrmann-Lingen, C., and Meyer, T. (2014) DNA binding reduces the dissociation rate of STAT1 dimers and impairs the interdimeric exchange of protomers. BMC Biochem 15: 28.

Robertson, A.G., Bilenky, M., Tam, A., Zhao, Y., Zeng, T., Thiessen, N., et al. (2008) Genome-wide relationship between histone $\mathrm{H} 3$ lysine 4 mono- and tri-methylation and transcription factor binding. Genome Res 18: 1906-17.

Rosowski, E.E. (2013) Modulation of innate immune signaling pathways by the intracellular pathogen Toxoplasma gondii. .

Rosowski, E.E., Lu, D., Julien, L., Rodda, L., Gaiser, R.A., Jensen, K.D.C., and Saeij, J.P.J. (2011) Strainspecific activation of the NF-kappaB pathway by GRA15, a novel Toxoplasma gondii dense granule protein. J Exp Med 208: 195-212.

Rosowski, E.E., Nguyen, Q.P., Camejo, A., Spooner, E., and Saeij, J.P.J. (2014) Toxoplasma gondii Inhibits gamma interferon (IFN- $\gamma$ )- and IFN- $\beta$-induced host cell STAT1 transcriptional activity by increasing the association of STAT1 with DNA. Infect Immun 82: 706-19.

Rosowski, E.E., and Saeij, J.P.J. (2012) Toxoplasma gondii Clonal Strains All Inhibit STAT1 Transcriptional Activity but Polymorphic Effectors Differentially Modulate IFNY Induced Gene Expression and STAT1 Phosphorylation. PLoS One 7: e51448.

Rossetto, D., Avvakumov, N., and Côté, J. (2012) Histone phosphorylation: a chromatin modification involved in diverse nuclear events. Epigenetics 7: 1098-108.

Rothbart, S.B., and Strahl, B.D. (2014) Interpreting the language of histone and DNA modifications. Biochim Biophys Acta 1839: 627-43.

Rytel, M.W., and Jones, T.C. (1966) Induction of interferon in mice infected with Toxoplasma gondii. Proc Soc Exp Biol Med 123: 859-62.

Sa, Q., Ochiai, E., Tiwari, A., Mullins, J., Shastri, N., Mercier, C., et al. (2017) Determination of a Key Antigen for Immunological Intervention To Target the Latent Stage of Toxoplasma gondii. J Immunol 1700062 .

Sabin, A.B. (1941) Toxoplasmic encephalitis in children. J Am Med Assoc 116: 801.

Saccani, S., Pantano, S., and Natoli, G. (2002) p38-Dependent marking of inflammatory genes for increased NF-kappa B recruitment. Nat Immunol 3: 69-75. 
Sadzak, I., Schiff, M., Gattermeier, I., Glinitzer, R., Sauer, I., Saalmüller, A., et al. (2008) Recruitment of Stat1 to chromatin is required for interferon-induced serine phosphorylation of Stat1 transactivation domain. Proc Natl Acad Sci U S A 105: 8944-8949.

Saeij, J.P.J., Coller, S., Boyle, J.P., Jerome, M.E., White, M.W., and Boothroyd, J.C. (2007) Toxoplasma coopts host gene expression by injection of a polymorphic kinase homologue. Nature 445: 324-7.

Saffer, L.D., Mercereau-Puijalon, O., Dubremetz, J.F., and Schwartzman, J.D. (1992) Localization of a Toxoplasma gondii rhoptry protein by immunoelectron microscopy during and after host cell penetration. J Protozoo/ 39: 526-30.

Scharton-Kersten, T.M., Wynn, T.A., Denkers, E.Y., Bala, S., Grunvald, E., Hieny, S., et al. (1996) In the absence of endogenous IFN-gamma, mice develop unimpaired IL-12 responses to Toxoplasma gondii while failing to control acute infection. J Immunol 157: 4045-54.

Schindelin, J., Arganda-Carreras, I., Frise, E., Kaynig, V., Longair, M., Pietzsch, T., et al. (2012) Fiji: an open-source platform for biological-image analysis. Nat Methods 9: 676-82.

Schindler, C., Shuai, K., Prezioso, V.R., and Darnell, J.E. (1992) Interferon-dependent tyrosine phosphorylation of a latent cytoplasmic transcription factor. Science (80- ) 257: 809-13.

Schneider, A.G., Abi Abdallah, D.S., Butcher, B.A., and Denkers, E.Y. (2013) Toxoplasma gondii triggers phosphorylation and nuclear translocation of dendritic cell STAT1 while simultaneously blocking IFNYinduced STAT1 transcriptional activity. PLoS One 8: e60215.

Schneider, C.A., Rasband, W.S., and Eliceiri, K.W. (2012) NIH Image to ImageJ: 25 years of image analysis. Nat Methods 9: 671-5.

Scott, P., and Hunter, C.A. (2002) Dendritic cells and immunity to leishmaniasis and toxoplasmosis. Curr Opin Immunol 14: 466-470.

Sekimoto, T., Imamoto, N., Nakajima, K., Hirano, T., and Yoneda, Y. (1997) Extracellular signal-dependent nuclear import of Stat1 is mediated by nuclear pore-targeting complex formation with NPI-1, but not Rch1. EMBO J 16: 7067-77.

Shen, B., and Sibley, L.D. (2012) The moving junction, a key portal to host cell invasion by apicomplexan parasites. Curr Opin Microbiol 15: 449-55.

Shi, Y., Lan, F., Matson, C., Mulligan, P., Whetstine, J.R., Cole, P.A., et al. (2004) Histone demethylation mediated by the nuclear amine oxidase homolog LSD1. Cell 119: 941-53.

Shuai, K. (2000) Modulation of STAT signaling by STAT-interacting proteins. Oncogene 19: 2638-44.

Shuai, K., Horvath, C.M., Huang, L.H., Qureshi, S.A., Cowburn, D., and Darnell, J.E. (1994) Interferon activation of the transcription factor Stat91 involves dimerization through SH2-phosphotyrosyl peptide interactions. Cell 76: 821-8.

Shuai, K., and Liu, B. (2003) Regulation of JAK-STAT signalling in the immune system. Nat Rev Immunol 3: 900-11.

Shuai, K., Schindler, C., Prezioso, V.R., and Darnell, J.E. (1992) Activation of transcription by IFN-gamma: tyrosine phosphorylation of a 91-kD DNA binding protein. Science (80- ) 258: 1808-12. 
Shuai, K., Stark, G.R., Kerr, I.M., and Darnell, J.E. (1993) A single phosphotyrosine residue of Stat91 required for gene activation by interferon-gamma. Science (80- ) 261: 1744-6.

Sibley, L.D. (2017) Genetic analysis of pathogenesis in Toxoplasma gondii. In Experimental Biology 2017 Meeting Abstracts. .

Sibley, L.D., Adams, L.B., Fukutomi, Y., and Krahenbuhl, J.L. (1991) Tumor necrosis factor-alpha triggers antitoxoplasmal activity of IFN-gamma primed macrophages. J Immunol 147: 2340-5.

Sibley, L.D., Charron, A., Håkansson, S., and Mordue, D.G. (2013) Invasion and intracellular survival by Toxoplasma. Madame Curie Biosci Database https://www.ncbi.nlm.nih.gov/books/NBK6450/.

Sibley, L.D., Weidner, E., and Krahenbuhl, J.L. (1985) Phagosome acidification blocked by intracellular Toxoplasma gondii. Nature 315: 416-9.

Sims, S.H., Cha, Y., Romine, M.F., Gao, P.Q., Gottlieb, K., and Deisseroth, A.B. (1993) A novel interferoninducible domain: structural and functional analysis of the human interferon regulatory factor 1 gene promoter. Mol Cell Biol 13: 690-702.

Sinai, A.P., and Joiner, K.A. (2001) The Toxoplasma gondii protein ROP2 mediates host organelle association with the parasitophorous vacuole membrane. J Cell Biol 154: 95-108.

Sinai, A.P., Webster, P., and Joiner, K.A. (1997) Association of host cell endoplasmic reticulum and mitochondria with the Toxoplasma gondii parasitophorous vacuole membrane: a high affinity interaction. J Cell Sci 110: 2117-2128.

Smith, C.L., and Hager, G.L. (1997) Transcriptional regulation of mammalian genes in vivo. A tale of two templates. J Biol Chem 272: 27493-6.

Song, M.M., and Shuai, K. (1998) The suppressor of cytokine signaling (SOCS) 1 and SOCS3 but not SOCS2 proteins inhibit interferon-mediated antiviral and antiproliferative activities. J Biol Chem 273: 3505662.

Splendor, A. (1908) Un nuovo protozoa parassita de' conigli. incontrato nelle lesioni anatomiche d'une malattia che ricorda in molti punti il Kala-azar dell' uomo. Nota Prelim pel Rev Soc Sci Sao Paulo 3: 109112.

Splendor, A. (2009) A new protozoan parasite in rabbits. Int J Parasito/ 39: 861-2.

Staab, J., Herrmann-Lingen, C., and Meyer, T. (2013) A rapid conformational rearrangement of STAT1 dimers is required for termination rather than for amplification of interferon- $\gamma$ signaling. JAK-STAT 2: e23576.

Starr, R., Willson, T.A., Viney, E.M., Murray, L.J., Rayner, J.R., Jenkins, B.J., et al. (1997) A family of cytokine-inducible inhibitors of signalling. Nature 387: 917-21.

Steinfeldt, T., Könen-Waisman, S., Tong, L., Pawlowski, N., Lamkemeyer, T., Sibley, L.D., et al. (2010) Phosphorylation of mouse immunity-related GTPase (IRG) resistance proteins is an evasion strategy for virulent Toxoplasma gondii. PLOS Biol 8: e1000576.

Strahl, B.D., and Allis, C.D. (2000) The language of covalent histone modifications. Nature 403: 41-5. 
Sumpf, K., Nast, R., Downie, B., Salinas, G., and Lüder, C.G.K. (2017) Histone deacetylase inhibitor MS275 augments expression of a subset of IFN- - -regulated genes in Toxoplasma gondii-infected macrophages but does not improve parasite control. Exp Parasitol 180: 45-54.

Sun, X.-M., Zou, J., A A, E.S., Yan, W.-C., Liu, X.-Y., Suo, X., et al. (2011) DNA vaccination with a gene encoding Toxoplasma gondii GRA6 induces partial protection against toxoplasmosis in BALB/C mice. Parasit Vectors 4: 213.

Suss-Toby, E., Zimmerberg, J., and Ward, G.E. (1996) Toxoplasma invasion: the parasitophorous vacuole is formed from host cell plasma membrane and pinches off via a fission pore. Proc Natl Acad Sci U S A 93: 8413-8.

Suzuki, Y., Orellana, M.A., Schreiber, R.D., and Remington, J.S. (1988) Interferon-gamma: the major mediator of resistance against Toxoplasma gondii. Science (80- ) 240: 516-8.

Suzuki, Y., Sher, A., Yap, G.S., Park, D., Neyer, L.E., Liesenfeld, O., et al. (2000) IL-10 is required for prevention of necrosis in the small intestine and mortality in both genetically resistant BALB/C and susceptible C57BL/6 mice following peroral infection with Toxoplasma gondii. J Immunol 164: 5375-82.

Tait, E.D., and Hunter, C.A. (2009) Advances in understanding immunity to Toxoplasma gondii. Mem Inst Oswaldo Cruz 104: 201-10.

Takai, D., and Jones, P.A. (2003) The CpG island searcher: a new WWW resource. In Silico Bio/ 3: 23540.

Tamaoki, T. (1991) Use and specificity of staurosporine, UCN-O1, and calphostin C as protein kinase inhibitors. In Protein Phosphorylation Part B: Analysis of Protein Phosphorylation, Protein Kinase Inhibitors, and Protein Phosphatases. Hunter, T., and Sefton, B.M. (eds). pp. 340-347.

Taylor, S., Barragan, A., Su, C., Fux, B., Fentress, S.J., Tang, K., et al. (2006) A secreted serine-threonine kinase determines virulence in the eukaryotic pathogen Toxoplasma gondii. Science (80- ) 314: 177680.

Tedford, E., and McConkey, G. (2017) Neurophysiological Changes Induced by Chronic Toxoplasma gondii Infection. Pathogens 6: 19.

Tenter, A.M., Heckeroth, A.R., and Weiss, L.M. (2000) Toxoplasma gondii: from animals to humans. Themat Issue Emerg Parasit Zoonoses 30: 1217-1258.

Torres, M., Ducournau, C., and Dimier-Poisson, I. (2012) Toxoplasma gondii: qualified to secrete exosomes? In Scientific Program 2012 ISEV meeting Wednesday 18th April, Journal of Extracellular Vesicles. Taylor \& Francis, p. 18182.

Tristan, C., Shahani, N., Sedlak, T.W., and Sawa, A. (2011) The diverse functions of GAPDH: views from different subcellular compartments. Cell Signal 23: 317-23.

Varinou, L., Ramsauer, K., Karaghiosoff, M., Kolbe, T., Pfeffer, K., Müller, M., and Decker, T. (2003) Phosphorylation of the Stat1 transactivation domain is required for full-fledged IFN-gamma-dependent innate immunity. Immunity 19: 793-802.

Vinkemeier, U., Cohen, S.L., Moarefi, I., Chait, B.T., Kuriyan, J., and Darnell, J.E. (1996) DNA binding of in vitro activated Stat1 alpha, Stat1 beta and truncated Stat1: interaction between NH2-terminal domains stabilizes binding of two dimers to tandem DNA sites. EMBO J 15: 5616-26. 
Wagner, B.J., Hayes, T.E., Hoban, C.J., and Cochran, B.H. (1990) The SIF binding element confers sis/PDGF inducibility onto the c-fos promoter. EMBO J 9: 4477-84.

Wang, Y., Gao, B., Xu, W., and Xiong, S. (2011) BRG1 is indispensable for IFN- - -induced TRIM22 expression, which is dependent on the recruitment of IRF-1. Biochem Biophys Res Commun 410: 54954.

Wang, Z., Zang, C., Rosenfeld, J.A., Schones, D.E., Barski, A., Cuddapah, S., et al. (2008) Combinatorial patterns of histone acetylations and methylations in the human genome. Nat Genet 40: 897-903.

Wen, Z., Zhong, Z., and Darnell, J.E. (1995) Maximal activation of transcription by Stat1 and Stat3 requires both tyrosine and serine phosphorylation. Cell 82: 241-50.

Wenta, N., Strauss, H., Meyer, S., and Vinkemeier, U. (2008) Tyrosine phosphorylation regulates the partitioning of STAT1 between different dimer conformations. Proc Natl Acad Sci U S A 105: 9238-43.

Wilking, H., Thamm, M., Stark, K., Aebischer, T., and Seeber, F. (2016) Prevalence, incidence estimations, and risk factors of Toxoplasma gondii infection in Germany: a representative, cross-sectional, serological study. Sci Rep 6: 22551.

Wright, K.L., and Ting, J.P.-Y. (2006) Epigenetic regulation of MHC-II and CIITA genes. Trends Immunol 27: 405-12.

Xu, X., Sun, Y.-L., and Hoey, T. (1996) Cooperative DNA Binding and Sequence-Selective Recognition Conferred by the STAT Amino-Terminal Domain. Science (80- ) 273: 794-797.

Xue, Y., Wong, J., Moreno, G.T., Young, M.K., Côté, J., and Wang, W. (1998) NURD, a novel complex with both ATP-dependent chromatin-remodeling and histone deacetylase activities. Mol Cell 2: 851-61.

Yamamoto, M., Okuyama, M., Ma, J.S., Kimura, T., Kamiyama, N., Saiga, H., et al. (2012) A cluster of interferon- - -inducible p65 GTPases plays a critical role in host defense against Toxoplasma gondii. Immunity 37: 302-13.

Yamashita, R., Sugano, S., Suzuki, Y., and Nakai, K. (2012) DBTSS: DataBase of Transcriptional Start Sites progress report in 2012. Nucleic Acids Res 40: D78-81.

Yap, G.S., and Sher, A. (1999a) Cell-mediated Immunity to Toxoplasma gondii: Initiation, Regulation and Effector Function. Immunobiology 201: 240-247.

Yap, G.S., and Sher, A. (1999b) Effector cells of both nonhemopoietic and hemopoietic origin are required for interferon (IFN)-gamma- and tumor necrosis factor (TNF)-alpha-dependent host resistance to the intracellular pathogen, Toxoplasma gondii. J Exp Med 189: 1083-92.

Yarovinsky, F. (2008) Toll-like receptors and their role in host resistance to Toxoplasma gondii. Immunol Lett 119: 17-21.

Yarovinsky, F., Zhang, D., Andersen, J.F., Bannenberg, G.L., Serhan, C.N., Hayden, M.S., et al. (2005) TLR11 activation of dendritic cells by a protozoan profilin-like protein. Science (80- ) 308: 1626-9.

Yodh, J. (2013) ATP-Dependent Chromatin Remodeling. In DNA Helicases and DNA Motor Proteins, Advances in Experimental Medicine and Biology. Spies, M. (ed.). Springer New York, New York, NY. 
Zhang, J.J., Vinkemeier, U., Gu, W., Chakravarti, D., Horvath, C.M., and Darnell, J.E. (1996) Two contact regions between Stat1 and CBP/p300 in interferon gamma signaling. Proc Natl Acad Sci U S A 93: 150926.

Zhang, T., Cooper, S., and Brockdorff, N. (2015) The interplay of histone modifications - writers that read. EMBO Rep 16: 1467-1481.

Zhang, Y., Ng, H.H., Erdjument-Bromage, H., Tempst, P., Bird, A.P., and Reinberg, D. (1999) Analysis of the NuRD subunits reveals a histone deacetylase core complex and a connection with DNA methylation. Genes Dev 13: 1924-35.

Zimmermann, S., Murray, P.J., Heeg, K., and Dalpke, A.H. (2006) Induction of suppressor of cytokine signaling-1 by Toxoplasma gondii contributes to immune evasion in macrophages by blocking IFNgamma signaling. J Immunol 176: 1840-7.

Zupkovitz, G., Tischler, J., Posch, M., Sadzak, I., Ramsauer, K., Egger, G., et al. (2006) Negative and positive regulation of gene expression by mouse histone deacetylase 1. Mol Cell Biol 26: 7913-28. 
Appendix A: $\quad$ pGL3-mCIITApIV-luc Plasmid map

A

B

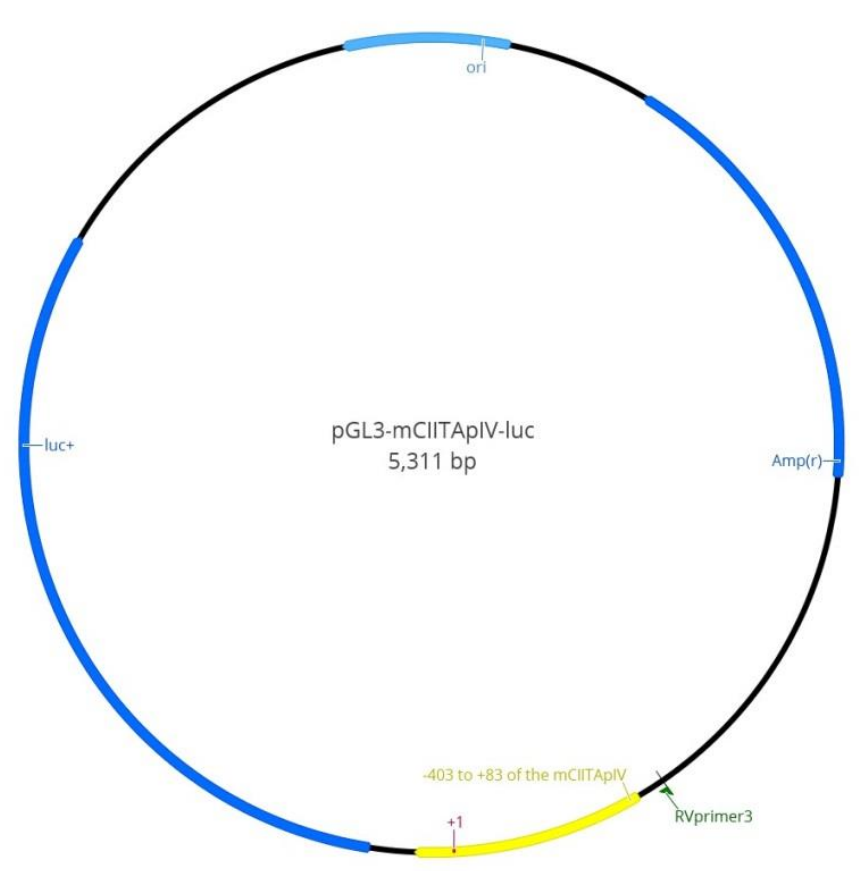

AGCAGATCTCAGGTTTAAATACCTATCTTTGTGGTTGGGCTGAGATAGAGTGAAATAG

A GAGCCACCAGGGGTGTAGATGAGGTGGCTTACAAACCAAACACCTGCCTTGGAATTC

AGTTCTACTGGCTCAAATCTGTCGTCCTCTCCTCCTGAGCAGGGACTGGTCTAAGTGA

GATCTGCCTGTAGGGAGGGGTCCTCTGGAAAGACTCAGTCCAAGCAAACTTGGGTTGC

ATGTGGCAGCTTCTGAGAAAGCACGTGGTGGATATCACTTTTCAGGGGAGGAGGGGTT

C CTGCCTAGCTCTGCCTTTGGCCCAAAGCTGAAGGTGTAGACAGAAAGTGAAAGGGG

AAAAGCGCCACAGATACTCCCTATTTGTGAGATAGCTGCCAGGAGACTGCCCGCCCCA

A GCTCCTAGGAGCCACGGAGCTGGCGGCAGGGAGACTGCATGCAGGCAGCACTCAGAA

GCACGGGGCACAGCCACAGCCGCGAAGCCGAATTCTGCAGATATCCATCACACTGGCG

A: pGL3-mCIITApIV-Iuc plasmid map. Amp(r): gene conferring ampicillin resistance in E. coli; ori: origin of plasmid replication in E. coli; luct: cDNA encoding the modified firefly luciferase; RVprimer3: binding site for forward sequencing primer; -403 to +83 of the mCIITApIV: 5 ' deletion version of the type IV promoter of the mouse ciita gene encompassing nucleotides -403 to +83 .

B: Sequence of the 5 ' deletion version of the type IV promoter of the mouse ciita gene encompassing nucleotides -403 to +83 . 
Appendix B: $\quad$ pGL4.27-4XGAS-luc Plasmid map

A

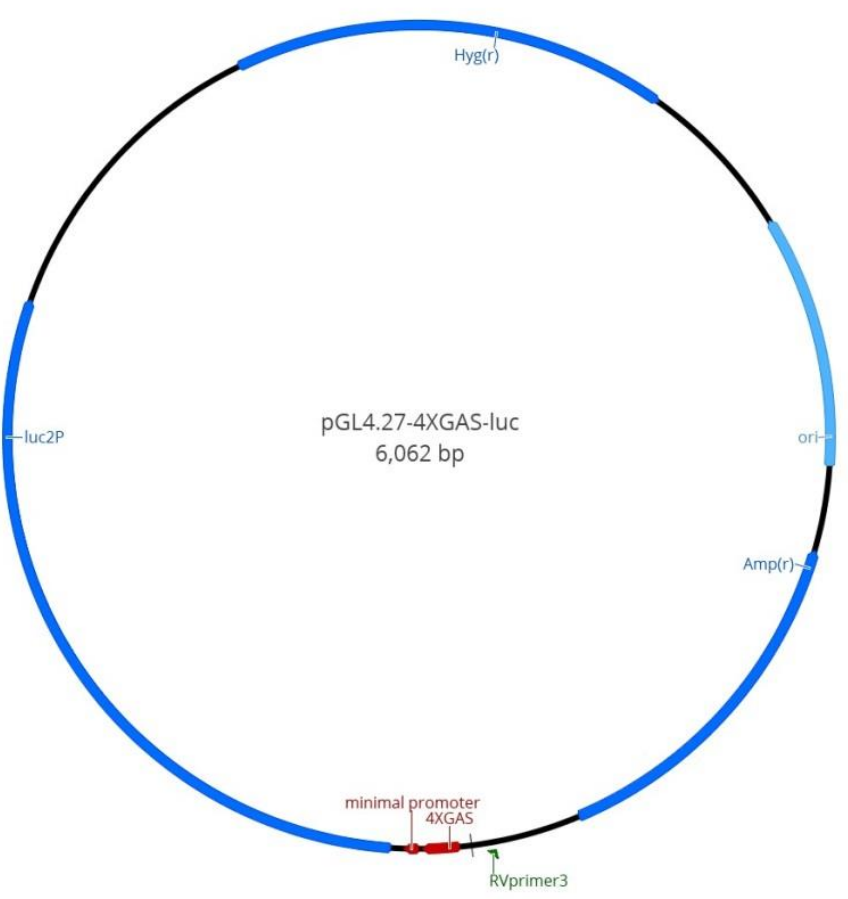

B

A: pGL4.27-4XGAS-luc plasmid map. Amp(r): gene conferring ampicillin resistance in E. coli; ori: origin of plasmid replication in E. coli; luc2P: cDNA encoding the modified firefly luciferase; $\mathrm{Hyg}(\mathrm{r})$ : gene conferring hygromycin resistance in eukaryotic cells; RVprimer3: binding site for forward sequencing primer; minimal promoter: promoter; 4XGAS: inserted response element containing four adjacent GAS consensus elements.

B: The 4XGAS response element was cloned into the Nhel/HindIII MCS restriction site of pGL4.27[luc2P/minP/Hygro]. The sequences of the 4XGAS response element and of the minimal promoter are shown. The minimal promoter of pGL4.27-4XGASluc contains a deletion mutation as compared to pGL4.27[luc2P/minP/Hygro] (the deletion is indicated by the yellow mark). 
Appendix C: $\quad$ Results of the CpG island in silico prediction analysis with the online tool CpG Island Searcher (Takai and Jones, 2003)

224 genes that are differentially regulated by IFN- $\gamma$ in murine bone marrow-derived macrophages are shown (Lang et al., 2012). Class A: Genes which expression was at least 4-fold up-regulated by IFN- $\gamma$ and counteracted 0.00 to 0.15 -fold by T. gondii infection. Class B: Genes which expression was at least 4-fold up-regulated by IFN- $\gamma$ and counteracted 0.70 to 1.60 -fold by T. gondii infection. Class C: Genes which expression was at least 4-fold down-regulated by IFN- $\gamma$ and counteracted 122.70 to 11.51-fold by T. gondii infection. Class D: Genes which expression was at least 4-fold down-regulated by IFN- $\gamma$ and counteracted 1.86 to 0.70 -fold by T. gondii infection. Column 3: Reference sequence of the mRNA. Column 4: Effect of $T$ gondii infection on mRNA level. Column 5: Effect of IFN- $\gamma$ on mRNA level. Columns 7 and 8: Ratio of the number of observed CpGs to the number expected if the CpGs were randomly distributed, for the regions from -200 to +1 (column 7) and +1 to +200 (column 8) relative to the transcriptional start site. Column 9 and 10: Percentages of GC bps in these same regions. Column 6: Identification of CpG-islands, as regions defined by distance greater than $100 \mathrm{bps}$, observed CpG/expcted CpG greater than 0.60 , and percentages of GC bps greater than 50 . 


\begin{tabular}{|c|c|c|c|c|c|c|c|c|c|}
\hline \multirow{2}{*}{ Class } & \multirow{2}{*}{ Gene } & \multirow{2}{*}{ Reference Sequence } & \multirow{2}{*}{$\begin{array}{l}\text { Effect T. gondii } \\
\quad(x-f o l d)\end{array}$} & \multirow{2}{*}{$\begin{array}{c}\text { IFN- } p>\text { Ctr } \\
(x-\text { fold })\end{array}$} & \multirow[b]{2}{*}{ CpG-island } & \multicolumn{2}{|c|}{ CpG/Expected } & \multicolumn{2}{|c|}{$\% \mathrm{GC}$} \\
\hline & & & & & & $-200 /+1$ & $+1 /+200$ & $-200 /+1$ & $+1 /+200$ \\
\hline & Ptgs2 & NM_011198 & 0.00 & 59.39 & yes & 0.64 & & 53.20 & \\
\hline & Gbp4 & NM_008620 & 0.01 & 4544.27 & no & & & & \\
\hline & Timd4 & NM_178759 & 0.01 & 239.15 & no & & & & \\
\hline & Gbp1 & NM_010259 & 0.03 & 1690.03 & no & & & & \\
\hline & ligp1 & NM_021792 & 0.03 & 427.49 & no & & & & \\
\hline & C1s & NM_001097617 & 0.03 & 30.93 & no & & & & \\
\hline & |tgal & NM_008400 & 0.04 & 37.47 & no & & & & \\
\hline & Igtp & NM_018738 & 0.04 & 88.57 & no & & & & \\
\hline & $\operatorname{Scd} 2$ & NM_009128 & 0.04 & 10.48 & yes & & 0.78 & & 51.20 \\
\hline & Clec9a & NM_172732 & 0.04 & 1040.27 & no & & & & \\
\hline & Dna2 & NM_177372 & 0.04 & 6.01 & yes & 1.13 & 0.98 & 72.10 & 72.10 \\
\hline & Wars & NM_011710 & 0.05 & 45.59 & no & & & & \\
\hline & Mpa2l & NM_194336 & 0.05 & 237.48 & no & & & & \\
\hline & H2-DMa & NM_010386 & 0.05 & 37.02 & no & & & & \\
\hline & Ly6f & NM_008530 & 0.05 & 400.26 & no & & & & \\
\hline & Gbp3 & NM_018734 & 0.06 & 153.46 & no & & & & \\
\hline & Smpdl3b & NM_133888 & 0.06 & 36.62 & yes & 0.62 & 0.66 & 51.20 & 66.20 \\
\hline & Rnase6 & NM_030098 & 0.06 & 71.34 & no & & & & \\
\hline & Itpka & NM_146125 & 0.07 & 33.47 & yes & 0.89 & 0.93 & 75.10 & 80.60 \\
\hline & Trpm2 & NM_138301 & 0.07 & 10.32 & no & & & & \\
\hline & Fam26f & NM_175449 & 0.07 & 145.40 & no & & & & \\
\hline & Pstpip2 & NM_013831 & 0.08 & 11.87 & yes & 0.91 & 0.84 & 73.60 & 68.30 \\
\hline & Stat1 & NM_009283 & 0.08 & 19.98 & yes & 0.83 & 0.75 & 64.20 & 63.20 \\
\hline & Tgtp & NM_011579 & 0.08 & 162.83 & no & & & & \\
\hline & Tnni3 & NM_009406 & 0.08 & 4.94 & no & & & & \\
\hline & Irf1 & NM_008390 & 0.09 & 50.14 & yes & 1.13 & 1.24 & 65.20 & 64.20 \\
\hline & Ppargc1b & NM_133249 & 0.09 & 10.84 & yes & 0.82 & 0.90 & 74.60 & 69.70 \\
\hline & Dnase1/3 & NM_007870 & 0.09 & 158.26 & no & & & & \\
\hline & KIhl6 & NM_183390 & 0.09 & 5.17 & no & & & & \\
\hline & Gbp2 & NM_010260 & 0.09 & 443.01 & no & & & & \\
\hline & KIf2 & NM_008452 & 0.09 & 4.12 & yes & 0.89 & 0.65 & 70.10 & 65.70 \\
\hline & Pim1 & NM_008842 & 0.10 & 7.67 & yes & 0.83 & 0.85 & 75.10 & 73.60 \\
\hline & Ciita & NM_007575 & 0.10 & 32.04 & no & & & & \\
\hline$A$ & Slamf8 & NM_029084 & 0.11 & 19.26 & no & & & & \\
\hline & KIra2 & NM_008462 & 0.11 & 17.90 & no & & & & \\
\hline & Ly6a & NM_010738 & 0.11 & 282.94 & no & & & & \\
\hline & II 4 ra & NM_001008700 & 0.11 & 6.27 & yes & 0.90 & 0.75 & 62.20 & 70.10 \\
\hline & Pion & NM_175437 & 0.12 & 5.07 & yes & & 0.70 & & 64.70 \\
\hline & $\mathrm{Ccl} 8$ & NM_021443 & 0.12 & 51.07 & no & & & & \\
\hline & Myh10 & NM_175260 & 0.12 & 11.57 & yes & 0.63 & 0.81 & 61.70 & 66.20 \\
\hline & Irgm2 & NM_019440 & 0.12 & 16.56 & no & & & & \\
\hline & KIrk1 & NM_001083322 & 0.12 & 152.24 & no & & & & \\
\hline & Tap1 & NM_013683 & 0.12 & 20.71 & yes & 1.04 & & 61.20 & \\
\hline & Txn1 & NM_011660 & 0.13 & 7.87 & yes & & 1.06 & & 68.70 \\
\hline & Saa3 & NM_011315 & 0.13 & 56.83 & no & & & & \\
\hline & $\mathrm{FbxI5}$ & NM_178729 & 0.13 & 4.96 & yes & 1.15 & 0.97 & 82.10 & 73.60 \\
\hline & Mmp25 & NM_001033339 & 0.13 & 50.79 & yes & 0.70 & & 70.10 & \\
\hline & H2-Ab1 & NM_207105 & 0.13 & 74.48 & no & & & & \\
\hline & |rg1 & NM_008392 & 0.13 & 99.73 & no & & & & \\
\hline & Ly6i & NM_020498 & 0.13 & 344.80 & no & & & & \\
\hline & Tnfrsf14 & NM_178931 & 0.13 & 7.72 & no & & & & \\
\hline & Serpina3f & NM_001033335 & 0.13 & 2286.61 & no & & & & \\
\hline & Upp1 & NM_009477 & 0.13 & 5.46 & no & & & & \\
\hline & Ankrd33 & NM_144790 & 0.13 & 5.06 & no & & & & \\
\hline & H2-Eb1 & NM_010382 & 0.14 & 42.09 & no & & & & \\
\hline & Etv2 & NM_007959 & 0.14 & 4.75 & no & & & & \\
\hline & Apol7c & NM_175391 & 0.14 & 9.99 & no & & & & \\
\hline & Ifi47 & NM_008330 & 0.14 & 27.60 & no & & & & \\
\hline & Gpd2 & NM_010274 & 0.14 & 6.11 & yes & 0.63 & 1.02 & 67.20 & 76.60 \\
\hline & H2-DMb1 & NM_010387 & 0.14 & 110.22 & no & & & & \\
\hline & Pnpla5 & NM_029427 & 0.15 & 12.24 & no & & & & \\
\hline & $\mathrm{H} 2-\mathrm{Aa}$ & NM_010378 & 0.15 & 72.93 & no & & & & \\
\hline & Pdcd1Ig2 & NM_021396 & 0.15 & 8.61 & no & & & & \\
\hline & Pla2g4a & NM_008869 & 0.15 & 21.56 & no & & & & \\
\hline & Serpinb9 & NM_009256 & 0.15 & 7.67 & no & & & & \\
\hline & Bst1 & NM_009763 & 0.15 & 24.20 & no & & & & \\
\hline & Obfc2a & NM_028696 & 0.15 & 4.30 & yes & 0.91 & 0.97 & 67.70 & 66.70 \\
\hline
\end{tabular}

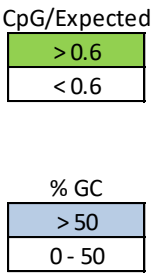




\begin{tabular}{|c|c|c|c|c|c|c|c|c|c|}
\hline \multirow[b]{2}{*}{ Class } & \multirow[b]{2}{*}{ Gene } & \multirow[b]{2}{*}{ Reference Sequence } & \multirow{2}{*}{$\begin{array}{l}\text { Effect } T \text {. gondii } \\
\qquad(\mathrm{x} \text {-fold })\end{array}$} & \multirow{2}{*}{$\begin{array}{c}\text { IFN- } p>\text { Ctr } \\
(x-\text { fold })\end{array}$} & \multirow[b]{2}{*}{ CpG-island } & \multicolumn{2}{|c|}{ CpG/Expected } & \multicolumn{2}{|c|}{$\% \mathrm{GC}$} \\
\hline & & & & & & $-200 /+1$ & $+1 /+200$ & $-200 /+1$ & $+1 /+200$ \\
\hline \multirow{67}{*}{ B } & Glipr2 & NM_027450 & 0.70 & 4.41 & yes & 0.65 & 0.69 & 70.60 & 68.20 \\
\hline & II18bp & NM_010531 & 0.70 & 18.47 & no & & & & \\
\hline & Hoxb5 & NM_008268 & 0.70 & 4.59 & no & & & & \\
\hline & Abtb2 & NM_178890 & 0.70 & 4.63 & yes & 0.80 & 1.03 & 61.20 & 63.20 \\
\hline & Ap1s3 & NM_183027 & 0.70 & 4.17 & yes & & 0.64 & & 66.20 \\
\hline & D14Ertd668e & NM_199015 & 0.70 & 9.80 & no & & & & \\
\hline & Fam82a2 & NM_001033136 & 0.71 & 4.58 & yes & 1.07 & 0.74 & 64.20 & 69.20 \\
\hline & Usp12 & NM_011669 & 0.72 & 5.10 & yes & 0.86 & 1.02 & 79.10 & 84.10 \\
\hline & Cst7 & NM_009977 & 0.73 & 15.09 & no & & & & \\
\hline & Aif1 & NM_019467 & 0.73 & 9.44 & no & & & & \\
\hline & Lair1 & NM_001113474 & 0.74 & 9.50 & no & & & & \\
\hline & $\mathrm{H} 28$ & NM_031367 & 0.74 & 4.38 & yes & & & & \\
\hline & Tapbp & NM_001025313 & 0.74 & 7.89 & yes & 0.61 & & 53.30 & \\
\hline & Chst4 & NM_011998 & 0.75 & 4.09 & no & & & & \\
\hline & Olfr703 & NM_146596 & 0.75 & 4.38 & no & & & & \\
\hline & Cd74 & NM_001042605 & 0.75 & 11.26 & no & & & & \\
\hline & Gtpbp2 & NM_019581 & 0.75 & 6.75 & yes & 0.77 & 0.86 & 58.20 & 74.10 \\
\hline & SIc19a3 & NM_030556 & 0.76 & 4.32 & yes & & & & \\
\hline & Gls & NM_001081081 & 0.77 & 7.93 & yes & 0.70 & 0.99 & 63.20 & 74.10 \\
\hline & Ass1 & NM_007494 & 0.77 & 8.17 & yes & 0.67 & & 79.10 & \\
\hline & Psmb10 & NM_013640 & 0.78 & 4.94 & no & & & & \\
\hline & Fbxo36 & NM_025386 & 0.79 & 5.10 & yes & & 0.63 & & 61.70 \\
\hline & Zc3h12d & NM_172785 & 0.80 & 4.49 & no & & & & \\
\hline & II17c & NM_145834 & 0.81 & 4.03 & no & & & & \\
\hline & Tmsb10 & NM_001039392 & 0.81 & 6.09 & yes & 0.92 & 0.72 & 65.20 & 66.70 \\
\hline & Parp9 & NM_030253 & 0.81 & 5.54 & yes & & 0.71 & & 60.20 \\
\hline & Mthfd2 & NM_008638 & 0.82 & 4.53 & yes & & 1.01 & & 70.10 \\
\hline & Wdyhv1 & NM_029734 & 0.84 & 4.26 & yes & 0.70 & 1.05 & 70.10 & 67.70 \\
\hline & C130026I21Rik & NM_001037909 & 0.84 & 4.21 & no & & & & \\
\hline & Psme1 & NM_011189 & 0.84 & 4.41 & yes & 0.66 & & 69.70 & \\
\hline & 2310046K01Rik & NM_027172 & 0.85 & 4.30 & yes & 0.80 & & 61.20 & \\
\hline & Padi6 & NM_153106 & 0.88 & 7.00 & no & & & & \\
\hline & 9030625A04Rik & NM_172488 & 0.88 & 7.25 & yes & 0.94 & 1.02 & 79.60 & 76.10 \\
\hline & II18bp & NM_010531 & 0.89 & 12.30 & no & & & & \\
\hline & Slc2a6 & NM_172659 & 0.90 & 4.11 & yes & 0.83 & 0.63 & 67.70 & 61.70 \\
\hline & Gnb2l1 & NM_008143 & 0.92 & 6.00 & yes & 0.76 & 0.72 & 54.20 & 60.20 \\
\hline & Frem2 & NM_172862 & 0.94 & 4.75 & yes & & 0.65 & & 65.70 \\
\hline & Pnp1 & NM_013632 & 0.94 & 6.31 & yes & & 0.82 & & 63.20 \\
\hline & Mlkl & NM_029005 & 0.95 & 4.85 & yes & 0.93 & & 64.70 & \\
\hline & S100a14 & NM_025393 & 0.95 & 6.33 & no & & & & \\
\hline & Sla2 & NM_029983 & 0.97 & 5.36 & no & & & & \\
\hline & Sdc3 & NM_011520 & 0.97 & 4.34 & yes & 0.97 & 1.26 & 79.60 & 79.60 \\
\hline & 4932415M13Rik & NM_001037718 & 0.99 & 12.03 & no & & & & \\
\hline & Gabrb3 & NM_001038701 & 1.00 & 4.16 & yes & 0.71 & & 56.70 & \\
\hline & Tgfbi & NM_009369 & 1.01 & 4.28 & yes & 0.66 & 0.70 & 67.20 & 68.20 \\
\hline & Gjd3 & NM_178596 & 1.03 & 6.96 & yes & & 0.86 & & 63.70 \\
\hline & Inpp5b & NM_008385 & 1.04 & 5.34 & yes & 0.65 & & 55.20 & \\
\hline & Tyk2 & NM_018793 & 1.09 & 4.53 & yes & 1.10 & & 55.20 & \\
\hline & Parp11 & NM_181402 & 1.09 & 4.05 & yes & 1.06 & 0.81 & 64.70 & 70.10 \\
\hline & Casp1 & NM_009807 & 1.09 & 4.34 & no & & & & \\
\hline & P2ry14 & NM_001008497 & 1.13 & 6.79 & no & & & & \\
\hline & Phf11 & NM_172603 & 1.18 & 6.12 & no & & & & \\
\hline & Usp37 & NM_176972 & 1.20 & 4.19 & no & & & & \\
\hline & Gnb4 & NM_013531 & 1.23 & 5.36 & yes & 1.14 & 1.07 & 82.60 & 77.60 \\
\hline & Ptprz1 & NM_001081306 & 1.27 & 8.62 & yes & 0.80 & 0.89 & 75.10 & 63.70 \\
\hline & Tgs1 & NM_054089 & 1.28 & 4.42 & yes & 0.97 & 1.10 & 64.20 & 61.70 \\
\hline & Epas1 & NM_010137 & 1.28 & 4.03 & yes & 1.13 & & 52.20 & \\
\hline & Clcn7 & NM_011930 & 1.30 & 4.47 & yes & 0.75 & 0.91 & 55.70 & 62.20 \\
\hline & Trafd1 & NM_172275 & 1.31 & 4.96 & yes & 0.67 & 1.06 & 67.00 & 83.60 \\
\hline & Arid5a & NM_145996 & 1.31 & 4.60 & yes & 0.77 & 1.02 & 63.20 & 68.70 \\
\hline & Fam161a & NM_028672 & 1.35 & 4.26 & no & & & & \\
\hline & SIfn1 & NM_011407 & 1.36 & 8.19 & no & & & & \\
\hline & Gpr114 & NM_001033468 & 1.44 & 9.66 & no & & & & \\
\hline & H2-T22 & NM_010397 & 1.48 & 6.74 & no & & & & \\
\hline & Cd69 & NM_001033122 & 1.52 & 19.58 & no & & & & \\
\hline & Tpst1 & NM_001130476 & 1.57 & 4.22 & no & & & & \\
\hline & Nos2 & NM_010927 & 1.60 & 7.00 & no & & & & \\
\hline
\end{tabular}



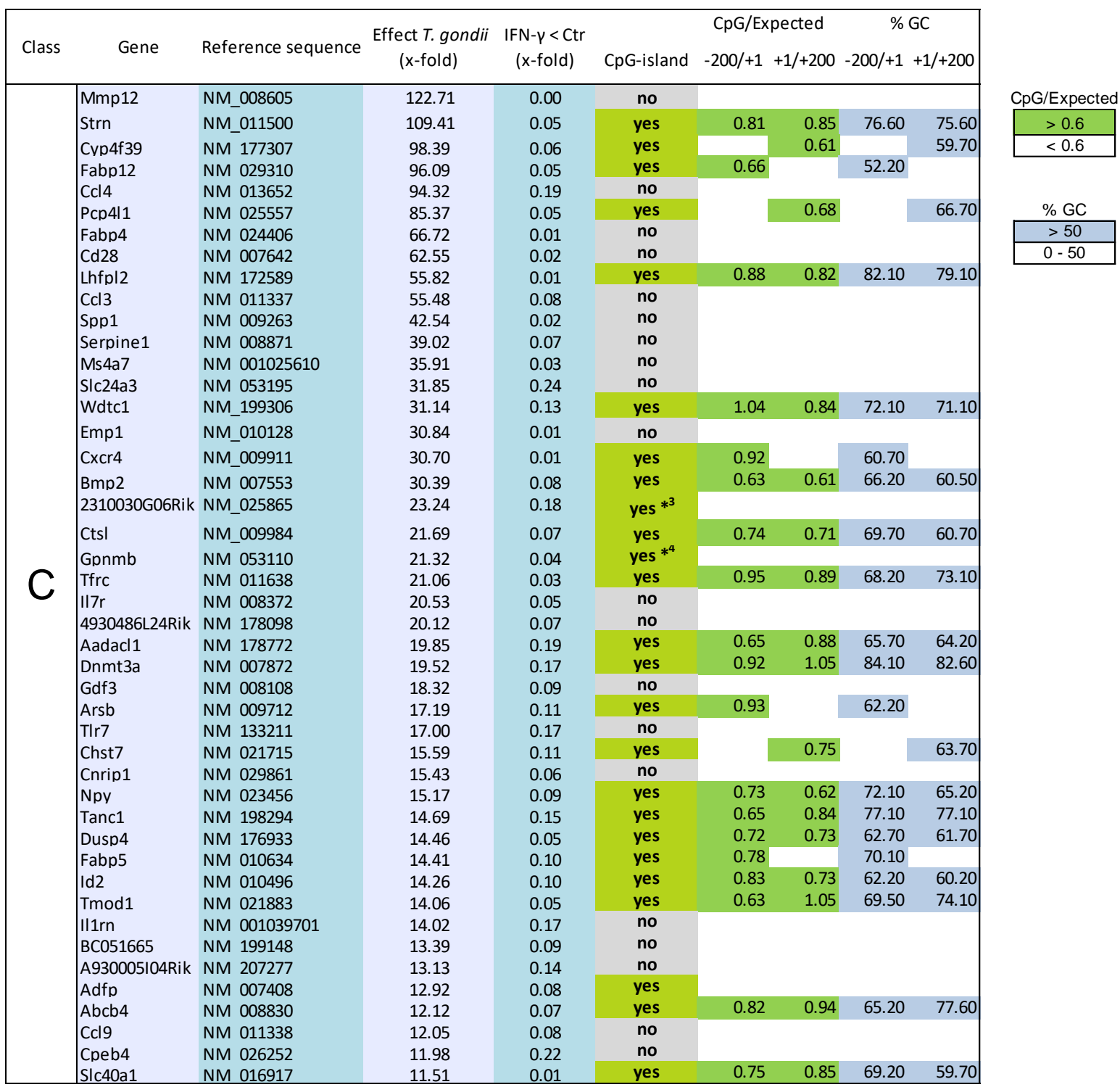


APPENDIX

\begin{tabular}{|c|c|c|c|c|c|c|c|c|c|c|}
\hline Class & Gene & Reference sequence & $\begin{array}{l}\text { Effect } T \text {. gondii } \\
\quad(\mathrm{x} \text {-fold })\end{array}$ & $\begin{array}{c}\text { IFN- }-<\text { Ctr } \\
(x-\text { fold })\end{array}$ & CpG-island & $\begin{array}{c}\text { CpG/Ex } \\
-200 /+1\end{array}$ & $\begin{array}{l}\text { pected } \\
+1 /+200\end{array}$ & $\% \mathrm{GC}$ & $\begin{array}{l}\mathrm{GC} \\
+1 /+200\end{array}$ & \multirow[b]{2}{*}{ CpG/Expected } \\
\hline & Cxcl1 & NM_008176 & 1.86 & 0.11 & no & & & & & \\
\hline & Gmpr & NM_025508 & 1.81 & 0.23 & yes & & 1.02 & & 72.60 & $>0.6$ \\
\hline & Itga9 & NM 001113514 & 1.81 & 0.16 & no & & & & & $<0.6$ \\
\hline & Gabarapl1 & NM 020590 & 1.76 & 0.23 & yes & & 0.87 & & 57.20 & \\
\hline & Tom1l1 & NM 028011 & 1.74 & 0.25 & yes & 0.77 & 0.63 & 73.60 & 60.20 & \\
\hline & Aplp2 & NM 001102455 & 1.74 & 0.18 & yes & 0.98 & 0.82 & 63.70 & 69.70 & $\% \mathrm{GC}$ \\
\hline & Wbp5 & NM 011712 & 1.74 & 0.18 & yes $*^{3}$ & & & & & $>50$ \\
\hline & Zranb3 & NM 027678 & 1.73 & 0.24 & no & & & & & $0-50$ \\
\hline & Clec4n & NM 020001 & 1.70 & 0.21 & no & & & & & \\
\hline & Abca1 & NM 013454 & 1.68 & 0.11 & yes & 1.03 & 0.75 & 59.70 & 65.20 & \\
\hline & Ear1 & NM 007894 & 1.67 & 0.08 & no & & & & & \\
\hline & Gab1 & NM 021356 & 1.66 & 0.17 & yes & 0.82 & 0.66 & 71.60 & 74.10 & \\
\hline & Aqp9 & NM 022026 & 1.66 & 0.21 & no & & & & & \\
\hline & Rnf149 & NM 001033135 & 1.64 & 0.24 & yes & 0.79 & 1.07 & 71.10 & 77.10 & \\
\hline & Osbpl11 & NM_176840 & 1.64 & 0.23 & yes & 0.80 & 0.72 & 58.70 & 71.10 & \\
\hline & Gna12 & NM_010302 & 1.60 & 0.20 & yes & 0.95 & 0.99 & 65.20 & 84.10 & \\
\hline & Stmn1 & NM_019641 & 1.59 & 0.25 & yes & 0.70 & 0.72 & 65.20 & 70.60 & \\
\hline & Dab2 & NM 001008702 & 1.59 & 0.24 & no & & & & & \\
\hline & Rapgef5 & NM_175930 & 1.55 & 0.24 & no & & & & & \\
\hline & Glul & NM_008131 & 1.51 & 0.08 & yes & 0.64 & 0.71 & 64.20 & 63.20 & \\
\hline & $\mathrm{Nt5dc2}$ & NM 027289 & 1.50 & 0.22 & no & & & & & \\
\hline & Fam63a & NM 133858 & 1.48 & 0.20 & yes & & 0.66 & & 62.70 & \\
\hline & Rgs18 & NM 022881 & 1.40 & 0.24 & no & & & & & \\
\hline & 1110002B05Rik & NM 134054 & 1.40 & 0.22 & yes & 0.96 & 0.74 & 70.10 & 68.70 & \\
\hline & Trf & NM 133977 & 1.39 & 0.11 & yes $*^{6}$ & & & & & \\
\hline & Arhgap18 & NM 176837 & 1.35 & 0.21 & no & & & & & \\
\hline & Clec4b1 & NM 027218 & 1.35 & 0.19 & no & & & & & \\
\hline & Cd163 & NM 053094 & 1.35 & 0.20 & no & & & & & \\
\hline & Cd9 & NM 007657 & 1.35 & 0.18 & yes & 0.62 & 0.69 & 62.50 & 53.70 & \\
\hline & Arhgap6 & NM 009707 & 1.32 & 0.19 & yes & & 0.64 & & 62.50 & \\
\hline & Ncoa4 & NM 001033988 & 1.30 & 0.20 & yes & 0.80 & 0.80 & 54.70 & 65.20 & \\
\hline & Pde2a & NM 001008548 & 1.26 & 0.13 & no & & & & & \\
\hline & $C \times 3 c r 1$ & NM 009987 & 1.25 & 0.14 & no & & & & & \\
\hline & Trem2 & NM 031254 & 1.21 & 0.22 & no & & & & & \\
\hline & Nme4 & NM 019731 & 1.20 & 0.23 & yes & & 0.98 & & 70.10 & \\
\hline & Cav2 & NM 016900 & 1.16 & 0.22 & yes & 0.73 & 0.70 & 78.60 & 56.20 & \\
\hline & Man2a2 & NM 172903 & 1.14 & 0.22 & yes & 0.97 & 0.81 & 82.10 & 76.10 & \\
\hline & Zdhhc14 & NM 146073 & 1.14 & 0.19 & yes & 0.74 & 0.97 & 75.60 & 72.10 & \\
\hline & Itsn1 & NM 001110275 & 1.12 & 0.24 & yes & 0.88 & 1.13 & 63.70 & 74.60 & \\
\hline & Itgb5 & NM 010580 & 1.09 & 0.25 & yes & 0.84 & 1.05 & 70.60 & 81.60 & \\
\hline & Idh1 & NM 001111320 & 1.07 & 0.12 & yes & 0.72 & 0.82 & 58.70 & 51.70 & \\
\hline & Wwp1 & NM 177327 & 1.02 & 0.19 & yes & 0.95 & 1.07 & 77.60 & 77.10 & \\
\hline & Sesn1 & NM 001013370 & 0.80 & 0.25 & yes & 0.86 & 1.00 & 74.60 & 72.10 & \\
\hline & $\mathrm{Cxcl} 2$ & NM 009140 & 0.80 & 0.10 & no & & & & & \\
\hline & 9030425E11Rik & NM 133733 & 0.70 & 0.21 & yes & & 0.72 & & 62.70 & \\
\hline
\end{tabular}

* Genes, that do not contain CpG-islands in their -200 to +1 or +1 to +200 promoter regions, but for which analysis of the 200 to +200 region identified occurrence of a CpG-island. *1: CpG/Expected -200/+200 0.61,\% GC 51.8; *2: CpG/Expected 200/+200 0.61,\% GC 53.6; *3: CpG/Expected -200/+200 0.61,\% GC 58.6; *4: CpG/Expected -200/+200 0.62,\% GC 52.9; *5: CpG/Expected -200/+200 0.61,\% GC 51.9; *6: CpG/Expected -200/+200 0.61,\% GC 61.6 